Soil organic matter dynamics in Dutch production grasslands

measurement and management

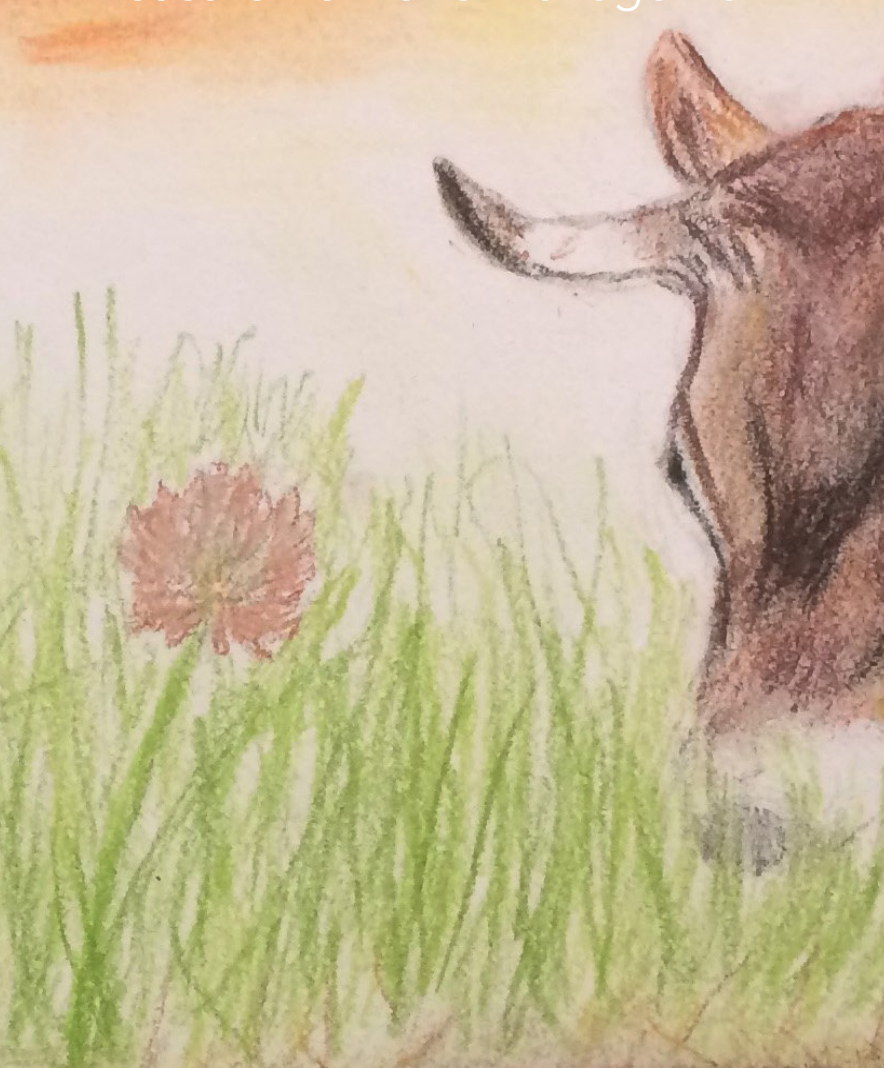

$3^{2}+x^{2}$ or os

Martine J.J. Hoogsteen
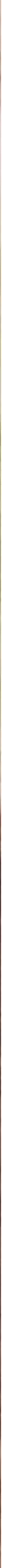



\section{Soil organic matter dynamics in Dutch production grasslands measurement and management}

Martine J.J. Hoogsteen 


\section{Thesis committee}

\section{Promotor}

Prof. Dr M.K. van Ittersum

Personal chair at Plant Production Systems Group

Wageningen University \& Research

\section{Co-promotors}

Prof. Dr A.M. Breure

Professor of Ecological Risk Assessment

Radboud University, Nijmegen

Dr E.A. Lantinga

Associate professor, Farming Systems Ecology Group

Wageningen University \& Research

\section{Other members}

Prof. Dr R.N.J. Comans, Wageningen University \& Research

Dr K. Klumpp, French National Institute for Agricultural Research (INRA), France

Dr J.P. Lesschen, Wageningen University \& Research

Dr R.L.M. Schils, Wageningen University \& Research

This research was conducted under the auspices of the C.T. de Wit Graduate School for Production Ecology \& Resource Conservation. 


\title{
Soil organic matter dynamics in Dutch production grasslands measurement and management
}

\author{
Martine J.J. Hoogsteen
}

Thesis

submitted in fulfilment of the requirements for the degree of doctor at Wageningen University

by the authority of the Rector Magnificus

Prof. Dr A.P.J. Mol,

in the presence of the Thesis Committee appointed by the Academic Board to be defended in public

on Wednesday 22 April 2020 at 11 a.m. in the Aula. 
Martine J.J. Hoogsteen

Soil organic matter dynamics in Dutch production grasslands:

measurement and management

196 pages

PhD thesis, Wageningen University, Wageningen, the Netherlands (2020) With references, with summaries in English and Dutch

ISBN: 978-94-6395-347-4

DOI: https://doi.org/10.18174/517697 
To Janie, James \& Myles for their pure love and energy To Jimi, for his everlasting support In memory of Ton, because it's finished 



\section{Table of Contents}

$\begin{array}{lll}\text { Chapter } 1 & \text { General introduction } & 9\end{array}$

Chapter 2 Estimating soil organic carbon through loss-on-ignition: 27 effects of ignition conditions and structural water loss

Chapter 3 An evaluation of the loss-on-ignition method for determining the soil organic matter content of calcareous soils

Chapter 4 Monitoring soil organic matter on grassland farms: an exploratory analysis

Chapter 5 Do species composition and harvesting regime affect root biomass and soil organic matter dynamics in temperate grassland swards?

Chapter 6 General discussion

References

Summary

Samenvatting

About the author

Acknowledgements

List of publications 191

PE\&RC Training and education statement 195

Financial support 


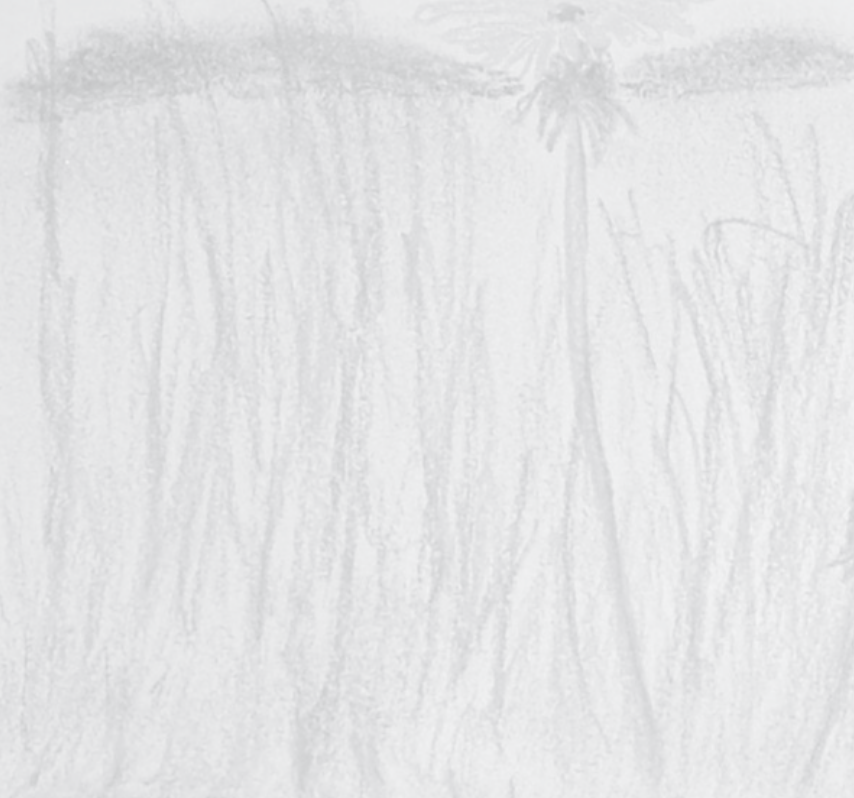

nest

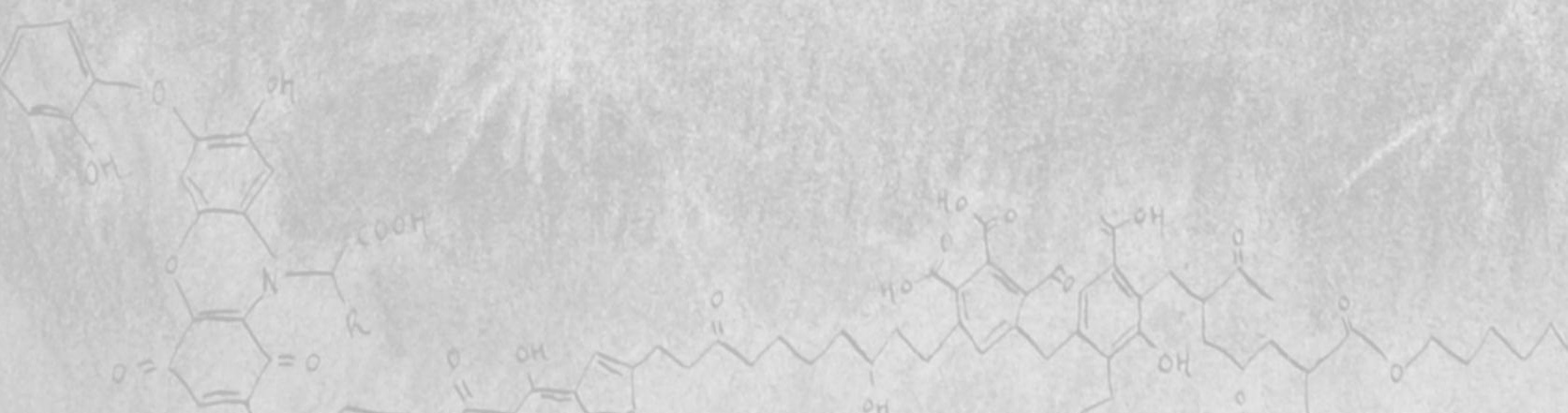




\section{Chapter 1. General introduction}

Part of the introduction (parts of section 5.1) has been published in adapted form as: FAO (2019). Measuring and modelling soil carbon stocks and stock changes in livestock production systems: Guidelines for assessment (Version 1; section 1.3). Livestock Environmental Assessment and Performance (LEAP) Partnership. Rome, Italy, FAO. 170 pp. 



\section{Soil organic matter in agricultural soils and its relevance for mitigating climate change}

Changed precipitation patterns and global warming show that climate change is associated with biodiversity loss and rising sea levels. Throughout the last decade the effects of climate change have become more prevalent affecting millions of livelihoods and increasing the pressure on ecosystems functioning (Grimm et al., 2013; Lee et al., 2017; EEA, 2019). The atmospheric concentrations of greenhouse gasses (GHGs) such as $\mathrm{CO}_{2}, \mathrm{CH}_{4}$ and $\mathrm{N}_{2} \mathrm{O}$ have increased since the industrial revolution with 40, 150 and $20 \%$, respectively (IPCC, 2013). Combustion of fossil fuel, cement production and land use activities were identified as the main sources of GHG emissions (Ciais et al., 2013). Currently, the agriculture, forestry and land use (AFOLU) sector is responsible for about $23 \%$ of the global GHG emissions (IPCC, 2019). Besides being a source of emissions, the sector has a mitigation potential through both a reduction in GHG emissions by changes in land use and removal of $\mathrm{GHGs}$ by plants. Through photosynthesis, $\mathrm{CO}_{2}$ is converted into a variety of organic compounds and sequestered in plants and soil. Elevating soil organic matter (SOM) levels through changes in land use and management may contribute to lower GHG concentrations in the atmosphere and aid in combatting climate change. Moreover, a sufficiently high level of SOM is beneficial for agricultural soils because it retains plant nutrients, enhances the soil's water holding capacity, improves soil structure and reduces the risk of erosion. Restoring or increasing SOM levels is, however, a challenging task as climate change, e.g. warmer conditions, lead to increased microbial activity and enhanced decomposition of SOM (Powlson, 2005; Kirk \& Bellamy, 2010; Taghizadeh-Toosi et al., 2014). On the other hand warmer conditions could also lead to increased net primary productivity and thus carbon inputs into the soil (e.g. through roots; positive feed-back). Today there is still no consensus about the feed-back effect and the mechanisms are to be revealed (cf. Ahrens \& Reichstein, 2017; Henry, 2019).

In the following sections soil organic matter (SOM) and soil organic carbon (SOC) are used interchangeably. The values and units of the respective studies have not been converted to a single uniform unit to avoid assumptions on conversion factors from SOM to SOC (or vice versa) or soil bulk density values to convert weight concentrations to stocks. In section 5 I will discuss the conversion from SOM to SOC.

\section{Soil organic matter trends in production grasslands of Western Europe}

During the last four decades increases as well as decreases were found in SOM contents of grassland soils of Western Europe. Mestdagh et al. (2009) 
reported that SOC stocks of Flemish production grassland soils $(0-6 \mathrm{~cm}$ soil layer) have declined by $9 \%$ between 1990 and 2000. Bellamy et al. (2005) also found a significant decrease in carbon stocks of grassland soils in England and Wales. Annual rates of decline ranged from 0.5 to $2.5 \mathrm{~g} \mathrm{SOC} \mathrm{kg}^{-1}$ (0$15 \mathrm{~cm}$ soil layer). The observed decreases in SOC contents in Great-Britain and Flanders were mainly attributed to changes in land use management. The conversion from permanent to temporary grasslands and the reduction in the application of animal manure were suggested as possible causes for this decline. A national SOC inventory on mineral soils of Denmark showed that SOC had increased between 1986 and 2009 on sandy soils, which were dominated by grasslands (Taghizadeh-Toosi et al., 2014). Furthermore, they concluded that not only topsoils, but also subsoils should be sampled in SOC

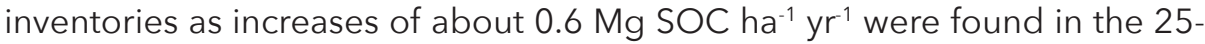
$50 \mathrm{~cm}$ soil layer. For long-term experimental grassland plots in the north and south-east of England no changes of SOC were observed for the $0-20 \mathrm{~cm}$ soil layer (Hopkins et al., 2009). Management of those grassland plots was unaltered during this period of time. Moreover, Hopkins et al. (2009) also concluded based on their study and the data of Bellamy et al., (2005), that the declines in SOC stocks of grasslands are likely to be management induced rather than due to effects of a changing climate.

Unfortunately, there is only trend data available on the SOC content of the $0-5 \mathrm{~cm}$ soil layer of Dutch grasslands soils and it is unknown, whether the SOC content has changed in deeper soil layers. In the period 1940-1960, the sampling depth was set at $5 \mathrm{~cm}$ for grassland soils on the assumption that the 5-10 cm soil layer did not contribute to phosphorus supply of the crop (van der Paauw, 1943). The condemnation of this assumption led to an increase in sampling depth to $10 \mathrm{~cm}$ for grasslands in 2003 (De Boer et al., 2003). Yet, it is risky to extrapolate conclusions on SOC trends of the $0-5 \mathrm{~cm}$, or $0-10 \mathrm{~cm}$ soil layers to deeper soil layers because of the following reasons:

(1) The largest supply of fresh organic matter occurs to this layer as compared to deeper soil layers and the majority of the organic matter compounds is relatively unstable fresh particulate organic matter (Balesdent et al., 2018).

(2) The largest SOM stocks occur in the lower soil layers $(10-100 \mathrm{~cm})$ and the carbon compounds are relatively more recalcitrant and less accessible to decomposition in deeper soil layers as compared to the topsoil (Gill et al., 1999; Angst et al., 2018).

Table 1 illustrates the latter argument: the $0-5 \mathrm{~cm}$ soil layer contains only $33 \%$ of the total SOM that is present in the $0-30 \mathrm{~cm}$ soil layer. On a farm grassland in Lunteren (Gelderse Vallei, centre of the Netherlands), the bulk density and SOM content were determined for the $0-30 \mathrm{~cm}$ soil layer in separate layers of $5 \mathrm{~cm}$ (see Chapter 4 for further specifications of the location and analytical methods). 
For the Netherlands, Reijneveld et al. (2009) concluded that the mean SOC content of grassland soils has been stable or has slightly increased since the last half century: a mean SOC content of $60 \mathrm{~g} \mathrm{~kg}^{-1}$ was found for the period 1984-2000 for the $0-5 \mathrm{~cm}$ layer of all grassland soils including peat lands (Reijneveld et al., 2009). This value was compared by Reijneveld et al. with an average SOC content of $58 \mathrm{~g} \mathrm{~kg}^{-1}$ for only mineral grassland soils in 1958 (Kortleven, 1963). Yet, it is precarious to compare an average SOC value of mineral soils with an average of mineral soils and peat lands together as peat lands are known to have much higher SOC contents than mineral soils. The SOC content of mineral soils under grassland was on average $43 \mathrm{~g} \mathrm{~kg}^{-1}$ between 1984 and 2004 (cf. Reijneveld et al., 2009), meaning that the average SOC content would have declined by $26 \%$ during the last half century (143/58). Based on the observations of Kortleven (1963) and Reijneveld et al., (2009) a decline in SOC has possibly occurred before the mid 80's (between 1984 and 2004 the SOC content in grassland soils remained more or less stable according to Reijneveld et al. (2009)). Other historical measurements support this hypothesis: Wiggers (1950) reported for grasslands in NoordBrabant (in the south of the Netherlands) an average SOM content of $63 \mathrm{~g}$ $\mathrm{kg}^{-1}$, while a value of $50 \mathrm{~g} \mathrm{~kg}^{-1}$ was found for the same region by Hanegraaf et al., (2009). Thus, there are indications that in sandy regions the SOM content has declined by about 20\% (1-50/63).

Table 1. The bulk density and soil organic matter (SOM) content of the $0-30 \mathrm{~cm}$ soil layer of a farm grassland in Lunteren, the Netherlands. All measurements were conducted in layers of $5 \mathrm{~cm}$. The fraction of SOM per layer as compared to the total SOM stock in the $0-30 \mathrm{~cm}$ soil layer is given in the last column.

\begin{tabular}{lllll}
\hline Soil layer $(\mathrm{cm})$ & $\begin{array}{l}\text { Bulk density } \\
\left(\mathrm{g} \mathrm{cm}^{-3}\right)\end{array}$ & $\begin{array}{l}\text { SOM } \\
\left(\mathrm{g} \mathrm{kg}^{-1}\right)\end{array}$ & $\begin{array}{l}\text { SOM } \\
\left(\mathrm{Mg} \mathrm{ha}^{-1}\right)\end{array}$ & $\begin{array}{l}\text { Fraction of SOM in } \\
\text { the 0-30 cm soil layer }\end{array}$ \\
\hline $0-5$ & 0.98 & 100 & 49 & 0.33 \\
$5-10$ & 1.39 & 44 & 31 & 0.20 \\
$10-15$ & 1.42 & 28 & 20 & 0.13 \\
$15-20$ & 1.43 & 26 & 19 & 0.12 \\
$20-25$ & 1.42 & 24 & 17 & 0.11 \\
$25-30$ & 1.47 & 22 & 16 & 0.11 \\
\hline
\end{tabular}

Figure 1 presents historical data on the SOC content of grassland soils in the Netherlands for the period 1940 to 2004. 


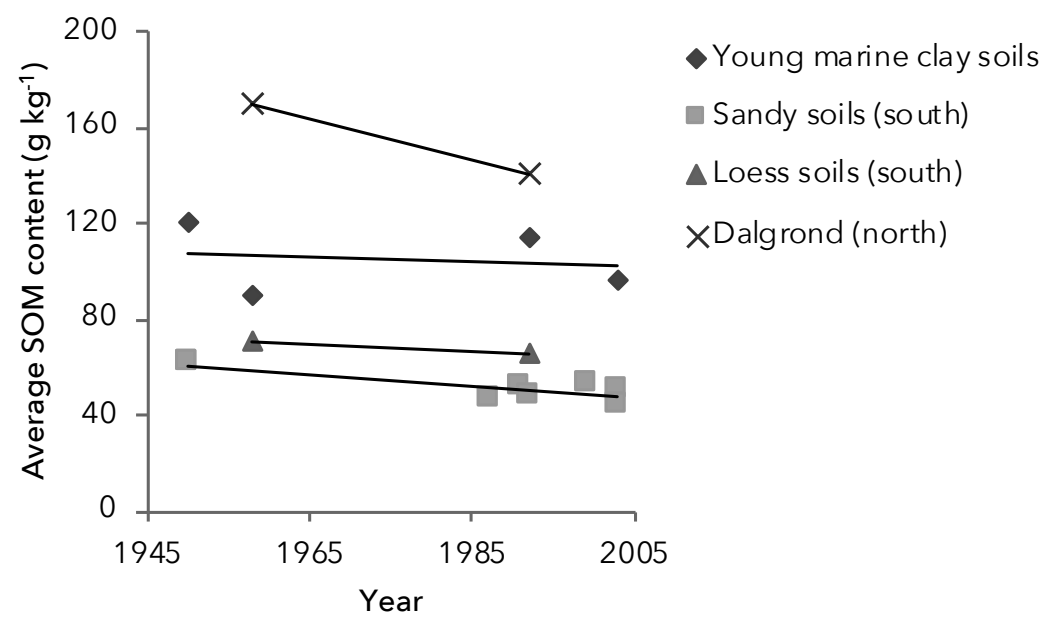

Figure 1. Soil organic matter (SOM) contents of Dutch production grassland soils for the period 1950-2003 (0-5 cm soil layer). Data was obtained from Wiggers (1950), Kortleven (1963), Hanegraaf et al. (2009), and Reijneveld et al. (2009). NB. The SOC data of Reijneveld were converted with a factor 2, to obtain SOM values (cf. Pribyl, 2010).

Figure 1 suggests that SOM stocks of grassland soils have declined during the last 60 years, which is in contradiction with Reijneveld et al., (2009) and Reijneveld (2013). As climatic factors have shown little effect on measurable changes in SOC stocks of long-term grassland field experiments in the UK under constant management (cf. Hopkins et al., 2011), it is likely that the decline in SOM in the Netherlands can be mainly attributed to changes in grassland management. Several studies showed that the increased frequency in grassland renewal, improved drainage and lowered ground water levels have been detrimental for SOM accumulation (Vellinga et al., 2004; Reijneveld et al. , 2009). Moreover, major changes took place in manure management, stocking systems and the botanical composition of grasslands.

\section{Changes in Dutch grassland management during the last half century}

\subsection{Changes in manure management}

Around the 1950s most farms were mixed farms and manure was mainly collected as solid cattle manure (SCM) and liquid manure. Production grasslands were usually fertilized with SCM in spring (on the arable part of the farm SCM was not used in spring to avoid soil compaction caused during application). During the growing season manure was applied on grasslands 
through the grazing animals and broadcasting. During the last half century, the type of manure changed from solid cattle manure with a relatively high OM content to cattle slurry with a much lower OM content (Table 2) and currently only $1 \%$ of the total ruminant manure in stables is collected as SCM (Statistics Netherlands, 2019a).

The change in type of manure was mainly caused by the alterations in animal housing. Stables changed from deep litter stables (potstallen) and tie-up cow houses (grupstallen) to cubicle stables (ligboxenstallen; Bieleman, 2010).

Remarkably, a general opinion that organic amendments had a negative effect on soil carbon stocks started to prevail in the 1950s (Kortleven, 1963). Between 1950 and the 1980s animal manure turned from a valuable resource into an unwanted product. Other reasons that led to the negativism regarding animal manure were the great increases in availability (Bieleman, 2010) and enforced application limits of livestock manure due to negative effects of large $\mathrm{N}$ losses to the environment (Wadman et al., 1987; EU Nitrates directive).

Currently, ruminant manure application rates amount to a maximum of $250 \mathrm{~kg} \mathrm{~N} \mathrm{ha}^{-1} \mathrm{yr}^{-1}$ on farms on non-sandy soils, where $80 \%$ of the acreage consists of grasslands. In Table 2 the maximum application rates of $\mathrm{N}$ and corresponding organic matter $\left(\mathrm{Mg} \mathrm{ha}^{-1} \mathrm{yr}^{-1}\right)$ are presented for cattle slurry and solid cattle manure. Throughout the last years, changes in manure policies have also put restrictions on $\mathrm{P}$ application rates.

Table 2. Maximum manure $\mathrm{N}$ - and P-application rates in the Netherlands were 250 $\mathrm{kg} \mathrm{N} \mathrm{ha-1} \mathrm{yr}^{-1}$ and $100 \mathrm{~kg} \mathrm{P}_{2} \mathrm{O}_{5} \mathrm{ha}^{-1} \mathrm{yr}^{-1}$ in 2017 . On sandy and loess soils the maximum manure-N application rate was $230 \mathrm{~kg} \mathrm{~N} \mathrm{ha}^{-1}$ (RVO, 2019a). CS = cattle slurry and SCM = solid cattle manure. Data on the OM content was taken from De Haan \& Van Geel (2019) and data on the nutrient contents was taken from the Enterprise Agency of the Netherlands (RVO, 2019b).

\begin{tabular}{|c|c|c|c|c|c|c|c|}
\hline \multirow[t]{2}{*}{$\begin{array}{l}\text { Manure } \\
\text { type }\end{array}$} & \multirow[t]{2}{*}{$\begin{array}{l}\text { OM content } \\
\left(\mathrm{kg} \mathrm{Mg}^{1}\right)\end{array}$} & \multicolumn{2}{|c|}{$\begin{array}{l}\text { Nutrient } \\
\text { content } \\
\left(\mathrm{kg} \mathrm{Mg}^{-1}\right)\end{array}$} & \multicolumn{2}{|c|}{$\begin{array}{l}\text { Manure applied } \\
\left(\mathrm{Mg} \mathrm{ha}^{-1}\right)\end{array}$} & \multicolumn{2}{|c|}{ 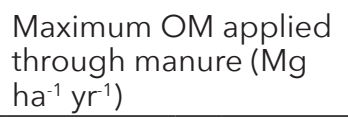 } \\
\hline & & $\mathrm{N}$ & $\mathrm{P}_{2} \mathrm{O}_{5}$ & N-limited & P-limited & $\mathrm{N}$-limited & P-limited \\
\hline CS & 64 & 4.0 & 1.5 & 63 & 67 & 4.0 & 4.2 \\
\hline $\mathrm{SCM}$ & 137 & 7.7 & 4.3 & 32 & 23 & 4.5 & 3.2 \\
\hline
\end{tabular}

Trends in cattle manure production between 1990 and 2017 in the Netherlands are shown in Figure 2. The amount of cattle slurry during the stable period has increased during the last 15 years. This is a consequence of reduced grazing and intensification (increased herd sizes) because the 
total number of dairy cattle remained more or less stable and the number of farmers declined almost exponentially (Statistics Netherlands, 2017). Between the period 1997-2015, the percentage of dairy cows that graze outside decreased from 92 to 65\% (Statistics Netherlands, 2019b). Since the last few years outside grazing has been promoted by different players in the dairy production chain and premiums are given out for grazing. The 'meadow milk label' was developed, which sets a condition of grazing for at least 120 days per year, and 6 hours per day.
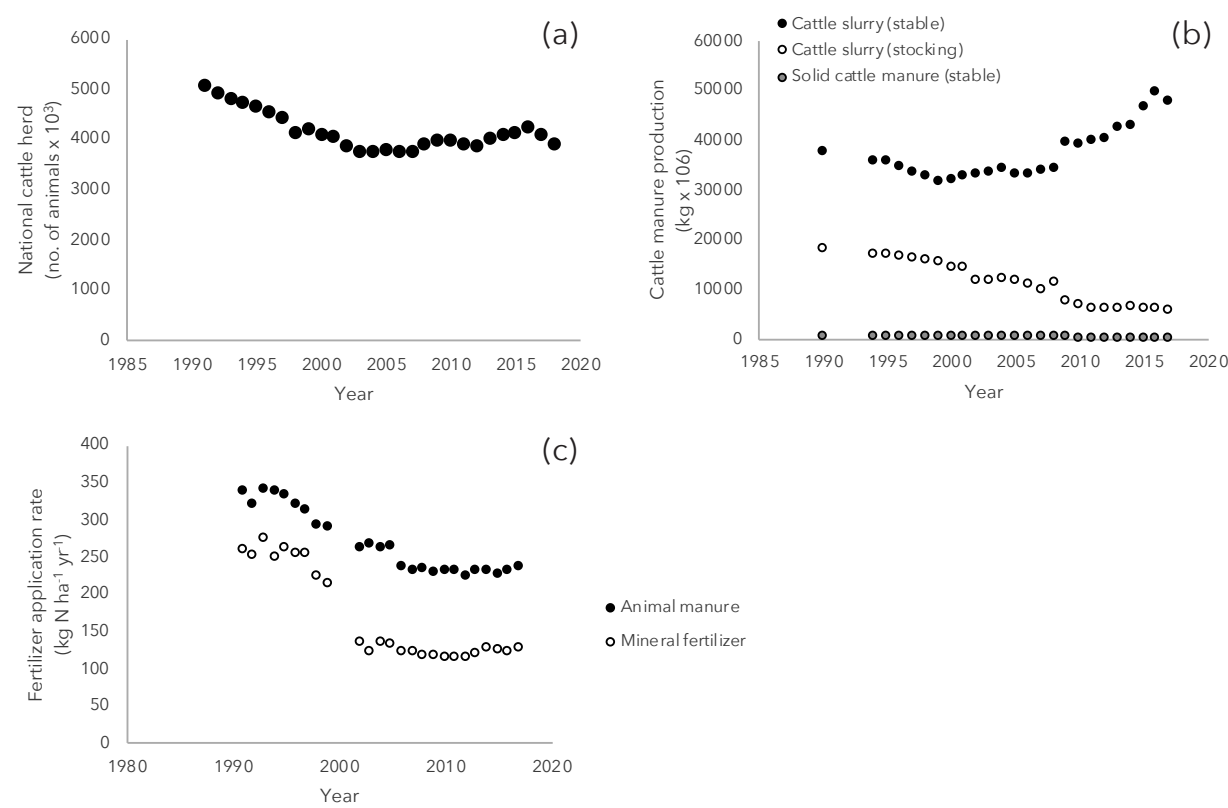

Figure 2. (a) The Dutch national cattle herd (including dairy cows, beef cattle and their young stock). (b) Trends in manure production of the national cattle herd between 1990 and 2018 in the Netherlands. Data was obtained from Statistics Netherlands (2019c, 2019a) and the numbers include dairy and beef livestock and their young stock. (c) Trends in $\mathrm{N}$ application rates of animal manure and mineral fertilizer on dairy farms for the period 1991-2017. Data was obtained from WEcR (2019a).

\subsection{Changes in stocking management}

Other factors that may have contributed to a decline in SOM stocks of production grasslands are changes in stocking systems and botanical composition. Besides animal manure, the main input sources of organic matter to grassland soils are stubbles and roots, which are influenced by the employed stocking system (Whitehead, 1990; Dormaar, 1992). Since the 1950s rotational stocking rapidly expanded at the expense of continuous 
stocking (Lantinga, 1985). Deinum (1985) found that root biomass of grazed swards was higher under continuous stocking as compared to rotational stocking: average root masses of 7.8 and $5.5 \mathrm{Mg} \mathrm{OM} \mathrm{ha}^{-1}$ were found for fields under continuous and rotational stocking, respectively $(0-10 \mathrm{~cm}$ soil layer). The greater root mass was associated with higher tiller density under continuous grazing. Moreover, Crider (1955) found that infrequent severe grass cuttings led to a standstill in root production during the growing season as carbohydrate reserves and assimilates were in first instance predominantly used to re-establish the shoot/root ratio (Crider, 1955; Figure 3). Because decaying root biomass and root exudates are the largest input sources of organic matter to the soil (Jones \& Donnelly, 2004; $40 \%$ of the net assimilated $C$ is designated below ground, cf. Jones et al., 2009), the adoption of the rotational grazing system at the expense of the continuous stocking system may have contributed to a decrease in SOM stocks of Dutch production grasslands.

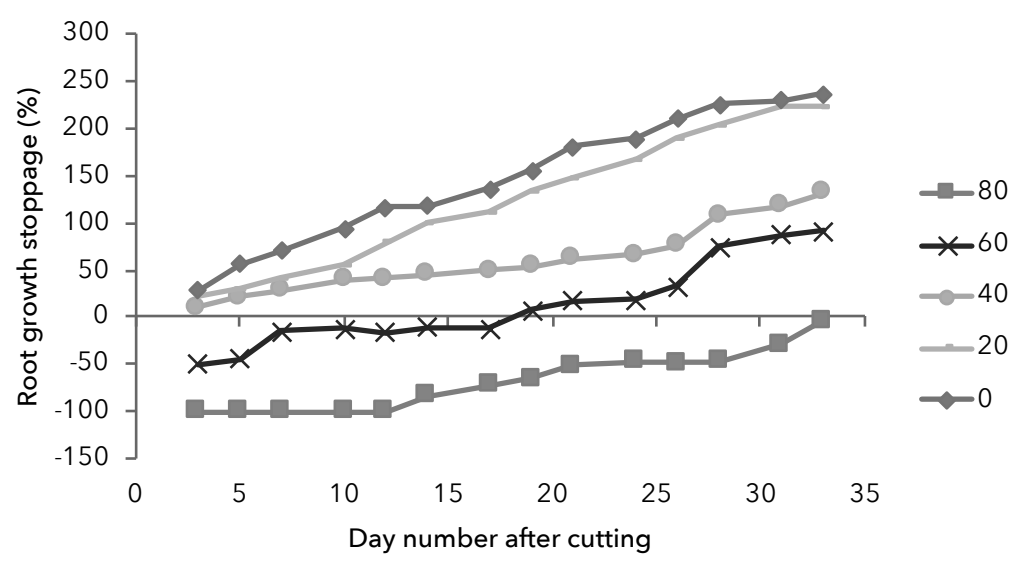

Figure 3. The effect of top reduction on root growth over time. Top reduction (ranging from 0 to $80 \%$ ) is expressed as a percentage of biomass that is removed. For instance, cutting a grass plant from $10 \mathrm{~cm}$ to $4 \mathrm{~cm}$ equals a top reduction of $60 \%$. The day number is the number of days after cutting has taken place, so day number 10 is 10 days after cutting. Root growth is expressed as a percentage and indicates for values $<0$, the percentage of roots that stopped growing. Positive values indicate the percentage of increase in active growing roots as compared to the value at the moment of clipping. Based on data from Crider (1955).

\subsection{The botanical composition of production grasslands}

Before the 1960s Dutch grasslands were characterized by the occurrence of multiple species such as perennial ryegrass (Lolium perenne L.), rough bluegrass (Poa trivialis L.), Kentucky bluegrass (Poa pratensis L.) and white clover (Trifolium repens L.), (De Vries, 1948). Throughout the last 50 years, 
grassland biodiversity has declined tremendously as a consequence of increased $\mathrm{N}$-fertilization rates, grassland renewal and the use of seed mixtures with few species. Currently species mixtures consist of one or two species only; monocultures of perennial ryegrass dominate production grasslands nowadays (Isselstein et al., 2005; De Wit et al., 2013). Several studies have demonstrated that carbon storage in grassland soils increased with increasing plant species diversity as a consequence of enhanced root production by the exploration of deeper soil layers (Reeder et al., 2001; Fornara \& Tilman, 2008; Steinbeiss et al., 2008).

\section{Grassland management options to increase soil organic matter}

Several management measures exist that have a potential to increase SOM in production grasslands. Those include the introduction of grass species with a high belowground biomass production, and adjustment of grazing and fertilization regimes. Grass roots are one of the main sources of OM supply to the soil thus, grazing management options could target increasing root production through adopting alternative stocking systems and changing the botanical composition of grasslands. Tall fescue (Festuca arundinacea) is the most important candidate grass species for introduction into a mixture with perennial ryegrass in Dutch production grasslands: it is characterized by high above as well as belowground biomass production, suitable for both grazing and mowing, and resistant to water limitation. White clover (Trifolium repens L.) is another important candidate species that can be introduced next to perennial ryegrass and tall fescue because of its agronomic characteristics. The species is able to fix atmospheric nitrogen, making swards less dependent on mineral $\mathrm{N}$ fertilization (and consequently leading to reduced GHG emissions associated with the production of mineral fertilizers).

Alternative stocking regimes that have a potential to increase SOM include continuous stocking and lenient strip stocking. Both stocking systems show relatively little temporal variation in leaf area index so that sward $\mathrm{CO}_{2}$ uptake is rather constant throughout the year (Lantinga, 1985). Consequently, root biomass production is expected to be greater than under the more commonly used rotational stocking system where the cattle are forced to graze the sward down to a height of about $7 \mathrm{~cm}$ and then moved to a new paddock after two to four days. In the latter system root growth can be interrupted for several weeks (section 3.2). 


\section{Humus, soil organic matter or soil organic carbon?}

\subsection{Definitions and nomenclature}

Soil organic matter (SOM) encompasses all organic components in the soil and is divided in a dead and living part. The living part constitutes of plant roots and soil organisms and the dead part of litter, the light fraction, water soluble organics, soil enzymes and humus (Lebbink, 1979; Stevenson, 1994). In daily life, the terms humus and soil organic matter are often used as synonyms. However, in the scientific literature there is no univocal definition of both terms: by some scientists both are regarded as the same substance (Stevenson, 1994), while others define the term humus as the part that has converted to such a degree that either its origin is chemically and visually not recognizable anymore, or solely as humic substances (Theng, 1989; Janssen, 2002). Humic substances are grouped in three fractions: humic acids, fulvic acids and humins. A nomenclature of SOM is given in Figure 4.

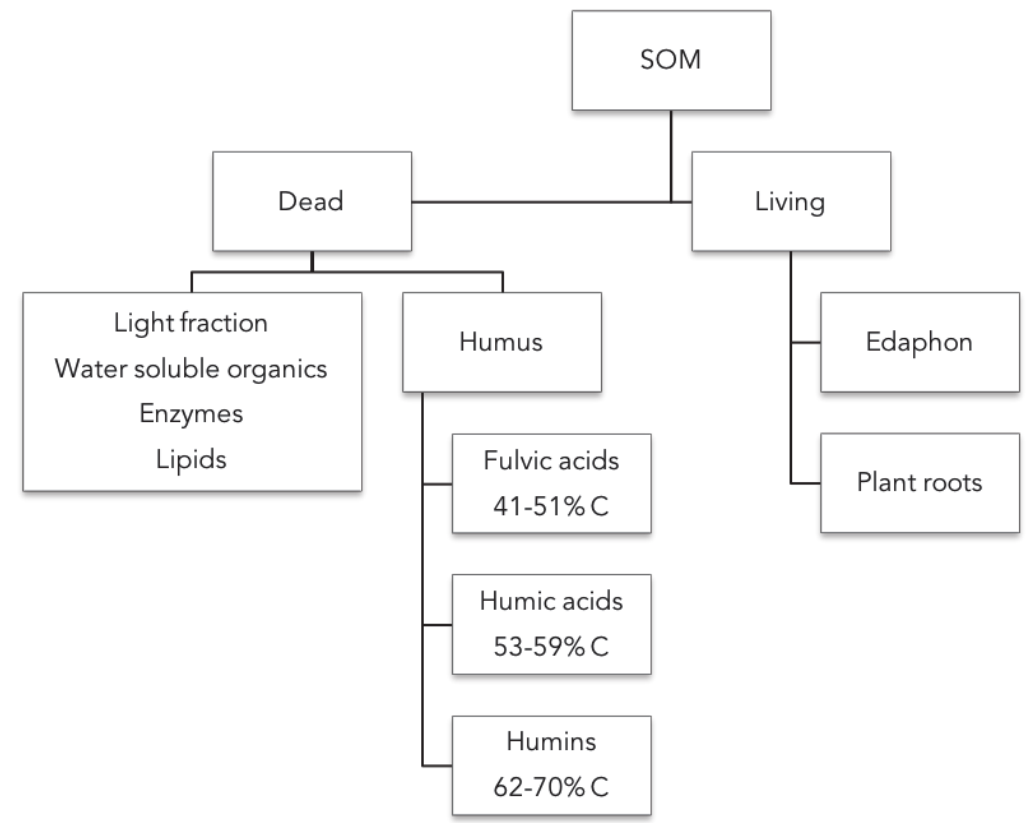

Figure 4. Nomenclature of soil organic matter after Lebbink (1979) and Stevenson (1994). The carbon content of the three groups of humic compounds was obtained from Orlov (1985) and Pribyl (2010).

Theoretically, theSOC content ofSOMrangesfrom $40 \%$ (simple carbohydrates) to $72 \%$ (the latter on the assumption that SOM consists for $80 \%$ of humins and $20 \%$ lipids with C contents of 70 and $80 \%$, respectively). Despite the wide range in carbon concentrations of the different SOM pools, a single multiplication 
factor is often used to convert SOM to SOC. The most used factor, also known as the Van Bemmelen factor, is 0.58 (Van Bemmelen, 1891). The origin of this factor dates back to the early 19th century. Sprengel (1838) and Berzelius (1839) studied the nature and chemical properties of the so called "humus acids" (SOM was named humus or humus acids in those times; Manley et al., 2007). SOM was extracted with alkali and alcohol, and chemically, individual compounds (which were in fact humic acids) were found with a carbon content of 58\%. Read \& Ridgell (1922) showed that SOM has an average percentage of 49\% SOC; however, when lower values for West-Virginian soils are excluded an average of value of $52 \%$ was obtained. Broadbent (1953) also acknowledged that a conversion factor for SOC to SOM of 1.9 (equal to $53 \%$ SOC in SOM) for surface soils is more satisfactory than 1.7 (equal to 59\%).

A detailed literature survey on the SOM to SOC conversion factor by Pribyl (2010) shows a median value of $51 \%$ based on 481 observations. For this reason, an SOM to SOC multiplication factor of around 0.50 instead of 0.58 would result in most cases in a more accurate estimate of a soil's carbon content based on SOM measurements. In this thesis, SOM and SOC refer to the same mixture of compounds (all organic materials in the soil fraction $<1.8 \mathrm{~mm}$ ) and a multiplication factor of $0.50^{*}$ is used to convert SOM to SOC (cf. Pribyl, 2010).

\subsection{Maximum capacity for soil carbon stabilization}

Organic carbon can be stabilized in soils through chemical recalcitrance, physical protection through compaction and the formation of macroaggregates, and association with silt and clay particles (Van der Linden et al., 1987; Six et al., 2002). Four carbon pools can be distinguished based on their stabilization mechanisms: silt and clay associated C (SCC), microaggregate protected C, biochemically protected C and non-protected C. Especially the silt and clay associated $C$ pool plays a key role in long-term $C$ stabilization because of its longer turn-over time as compared to the other pools (Balabane \& Plante, 2004).

The C stabilization potential of soils is often modelled through first order kinetics implying that SOC equilibrium levels increase gradually with increased C inputs (e.g. through the Roth-C model, Coleman \& Jenkinson, 2014). Throughout the last decades, the validity of those models has been contested because some long-term experimental trials showed that SOC levels did not always respond to long-term increased $C$ inputs. This led to the development of a theory on $\mathrm{C}$ saturation assuming a maximum SOC content (Six et al., 2002). According to this theory, the potential of a soil to sequester carbon is to a large extent determined by both the soil texture and its initial carbon content. Furthermore, the theory postulates that no increase in SOC equilibrium level will occur with increased $\mathrm{C}$ input levels after attaining $\mathrm{C}$

* Unless both are determined separately in the laboratory and a multiplication factor can be derived from both analyses. 
saturation (West \& Six, 2007). Several long-term experiments have shown that equilibrium SOC levels did not increase linearly with increased C application rates, indicating that soils can become carbon saturated (Gulde et al., 2008; Stewart et al., 2009; Feng et al., 2014). However, most datasets supporting this theory consist of only four treatments with increasing $C$ application rates (see Feng et al., 2014 for an overview). Both linear and asymptotic regressions are used to fit the relationship between $C$ input levels and the silt and clay associated SOC. It is concluded that if an asymptotic regression results in a better fit than a linear one, $C$ saturation occurs (see for instance West \& Six, 2007; Gulde et al., 2008).Yet, it is questionable, whether such a theory can be proven based on just four data points (four treatments): many equations will result in good fits based on four data points and equations that are selected on merely statistical criteria do not necessarily describe processes that are physically taking place in the soil. Furthermore, Feng et al. (2014) tested the $\mathrm{C}$ saturation theory with data of long-term agricultural experiments and found that the silt and clay fraction did not show saturation. Because of little quantitative underpinning, the $C$ saturation theory is today still a topic of scientific debate and its existence is questioned (Smith, 2017).

\section{Methodological limitations of monitoring SOM dynamics}

\subsection{Uncertainties in estimating SOM stocks}

Long term studies are generally necessary to assess the effects of changes in grassland management on SOM dynamics because of large uncertainties and small changes in SOM stocks over time. Uncertainties are difficult to quantify and the overall process from soil sampling to estimating the SOM content is often not considered prior to conducting experiments: the process is usually ad hoc based or budget constrained (Smith, 2004; De Gruijter et al., 2006). However, careful planning is necessary to harmonize data collection (i.e. type of information to gather in the field) and data processing (appropriate statistical method to analyse the data). De Gruijter et al. (2006) provide a detailed list on basic design criteria for survey (baseline scenario) and monitoring of natural resources, which includes balancing the source of variation. When sampling mixtures of non-identical particles, as is the case when estimating SOM, different stages (or steps) of the sampling process and accompanying sources of variation can be identified.

The total variance consists of the intrinsic or fundamental variance (environmental variability), the sampling variance and the analytical variance (see section 6.2). The intrinsic variance cannot be altered and is a given property of a certain area but through optimization of sampling schemes the sampling variance can be effectively reduced (see for instance Pitard, 1993; De Gruijter et al., 2006). The sampling strategy is of large influence on the sampling variance and can be evaluated ex ante. For this the minimum 
detectable difference can be used: a statistical approach to determine the minimum sample size or smallest significant difference in SOM that can be detected between two monitoring moments (Zar, 1996).

\subsection{Variation in analytical procedures for measuring carbon in soils}

Uncertainty in the analytical variance in determining SOM stocks arises from multiple interactions between variables and is associated with the employed analysis procedures: in order to quantify SOM stocks, the SOM concentration, bulk density and sampling depth need to be known. For instance, a strong relationship exists between SOM concentration and the bulk density of a soil sample (Adams, 1973).

Precise and accurate measurement procedures are of crucial importance for drawing conclusions on monitoring SOM dynamics. Precision refers to the closeness of agreement between SOM values obtained under certain specified sampling conditions and accuracy refers to the closeness of a measurement to the true SOM value (ISO, 1994; Figure 5).

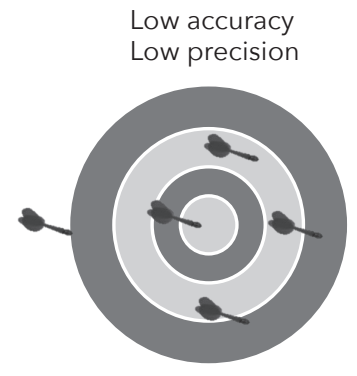

Low accuracy

High precision

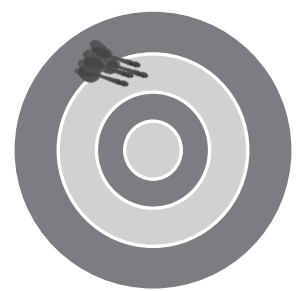

High accuracy

High precision

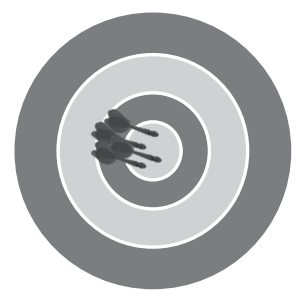

High accuracy

Low precision

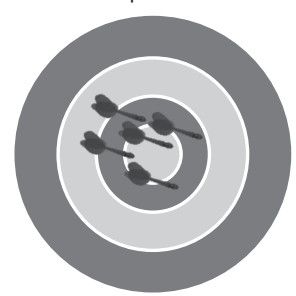

Figure 5. Illustration of the difference between precision and accuracy (based on Markert, 1996).

There is a large variation in the precision and accuracy of analytical procedures which is briefly discussed below. Worldwide, a large number of analytical procedures is employed to measure the carbon content of soils. Those methods can be divided into three categories: procedures for total 
carbon, organic carbon and organic matter analysis. With total $\mathrm{C}$ analysis, the sum of the organic and inorganic $C$ content is measured through combustion and both fractions cannot be determined separately. For this reason, samples containing carbonates are usually pre-treated with acid to remove the inorganic $\mathrm{C}$ a priori or two analyses are needed. In the latter case, the total $\mathrm{C}$ content and inorganic $C$ content are determined on separate samples. Total $\mathrm{C}$ analysis through dry combustion is regarded as a reference method and often preferred over other TOC or SOC analysis procedures because of its precision and rapidness. Homogeneous and very finely ground soil samples are required to achieve reproducible results. However, prescribed sample masses are small (e.g. $0.5 \mathrm{~g}$ in case of the High-Temperature Induction Furnace Method) and drawing a homogeneous subsample from a bulk soil sample is fairly impossible (i.e. bulk samples are in the order of a few hundred grams). Another major drawback of the method is the expensive equipment. Organic $\mathrm{C}$ analysis procedures involve oxidation of SOC through treatment of a soil sample with a mixture of $\mathrm{K}_{2} \mathrm{Cr}_{2} \mathrm{O}_{7}$ and a digestion reagent such as sulphuric acid. Advantages of the method are its rapidness, simplicity and the fact that no special equipment is needed. A disadvantage is the use of the highly polluting and carcinogenic potassium dichromate. Furthermore, $\mathrm{Fe}$ and $\mathrm{MnO}_{2}$ can interfere in the oxidation process leading to positive and negative errors, respectively (Nelson \& Sommers, 1996). SOC recovery rates varying from 35 to $144 \%$ have been reported in the literature (Richardson \& Bigler, 1982; Willet \& Beech, 1987).

The most commonly used analysis methods for quantifying SOM are losson-ignition (LOI) and wet-oxidation (WO; gravimetrical procedures and chemical oxidation are distinguished). These methods remove organic matter either by heat application alone (LOI) or by heating combined with chemical destruction (WO) using a reagent such as hydrogen peroxide (gravimetrical) or potassium dichromate (chemical). A major limitation of chemical destruction during WO is the risk of incomplete oxidation, which implies that a correction factor is needed. This correction factor varies from soil to soil (e.g. Nelson \& Sommers, 1982; De Vos et al., 2007) and depends largely on the reaction conditions, sample weight and type of reagent used (Mikutta et al., 2005). The LOI procedure also has a number of confounding factors. When soil samples containing clay are exposed to temperatures above 300 ${ }^{\circ} \mathrm{C}$, the structural water which is part of the clay mineral escapes leading to an additional mass loss and thus, an overestimation of the SOM content (Grim, 1953; Nutting, 1943; Pansu \& Gautheyrou, 2006). This also holds for soil carbonates $\left(\mathrm{CaCO}_{3}\right.$ and $\left.\mathrm{CaMg}\left(\mathrm{CO}_{3}\right)_{2}\right)$, which decompose at temperatures above $600{ }^{\circ} \mathrm{C}$ (Kasozi et al., 2009). Ball (1964) recommended an ignition temperature of $375^{\circ} \mathrm{C}$ instead of $800{ }^{\circ} \mathrm{C}$ because at higher temperatures more structural water loss occurs. However, employing a temperature of 375 ${ }^{\circ} \mathrm{C}$ leads to incomplete combustion of OM (Schnitzer et al., 1959; Turner \& Schnitzer 1962). Notwithstanding its confounding factors, the LOI method 
has a number of advantages over TOC and SOC analysis procedures. Sample masses are larger (up to $20 \mathrm{~g}$; Lowther et al., 1990) leading to increased accuracy, and neither expensive equipment, nor hazardous chemicals are needed.

Throughout the last two decades the use of the near infra-red spectroscopy (NIRS) methodology for analysing SOC has increased rapidly (especially from 2010 onwards). The NIRS method is an indirect method and the SOC content of the soil is predicted based on calibration curves. To establish calibration curves classical methods for SOC analysis are necessary. During the orientation phase in 2009 of the project underlying this thesis, the NIRS method was not widely used for SOC analysis. Furthermore, the method was not affordable at the time. For these reasons, the NIRS method falls beyond the scope of this thesis.

\section{Objectives of the thesis}

Policy makers, advisors and farmers increasingly ask for management strategies to sequester carbon and to provide indicators for soil monitoring (e.g. National Soil Top Meeting of the Netherlands, Rotterdam, 2019). This is challenging because of high levels of spatial heterogeneity in the soil, relatively small management induced changes in soil organic matter as compared to the SOM stock and a cacophony of monitoring advices and protocols, describing to use different methods, sampling designs and soil layers. Moreover, choices made in terms of indicators for monitoring and the associated methods are usually ad hoc, out of convention or budget constrained.

The overall aim of this thesis is to elucidate the effects of methodological choices on quantifying management induced changes of SOM levels over time for grassland soils, and to assess the effect of different grassland management options on SOM dynamics in the Netherlands. With respect to the first part of the aim, the focus is on the effect of methodological choices in the laboratory, field and farm, and address sampling depth and frequency. As to the second part of the aim, a field experiment was conducted to investigate the effect of grassland management options on SOM dynamics over time.

The specific objectives of this thesis are to:

Compare the analytical errors of SOM and SOC measurements through loss-on-ignition (LOI) and wet-chemical oxidation (Chapter 2).

Increase the accuracy of the LOI method by (i) deriving guidelines for ignition conditions, and (ii) developing temperature specific clay- and carbonate content multiplication factors to correct for losses of structural water and decomposition of carbonates (Chapters 2 and 3 ).

- Gain quantitative insight into the effects of: $a$. different approaches 
to derive data on stocks of SOM from measurements of the mass concentration of SOM, and the effects of $b$. the sampling depth; $c$. the sampling level of the data (field or farm), and $d$. sampling frequency and seasonality on the quality of the reported data through intensive on-farm monitoring (Chapter 4).

- Assess the effects of different simulated stocking systems (varying frequencies of biomass removal through mowing at different cutting heights) and of the introduction of tall fescue (Festuca arundinacea) and white clover (Trifolium repens L.) next to perennial ryegrass (Lolium perenne L.) on SOM dynamics and root biomass on a loamy and a sandy soil (Chapter 5).

\section{Thesis outline}

This thesis consists of six chapters. In Chapters 2 and 3, new guidelines for ignition conditions are presented based on a series of laboratory experiments and the accuracy of the LOI method is compared with a commonly employed rapid dichromate oxidation procedure. Chapter 4 presents a framework for setting up an on-farm soil carbon monitoring scheme for grasslands. In Chapter 5, a field experiment was used to assess the effect of botanical composition and simulated stocking systems (rotational, continuous and lenient strip stocking) on SOM dynamics of grasslands. The last chapter (Chapter 6) integrates the results of all research chapters and discusses the implications for monitoring SOM dynamics within the context of uncertainties in SOM assessment. This is followed by a reflection on grassland management options to increase soil carbon levels. Finally, I reflect upon the results of the thesis within the context of national climate policies of the Netherlands. 


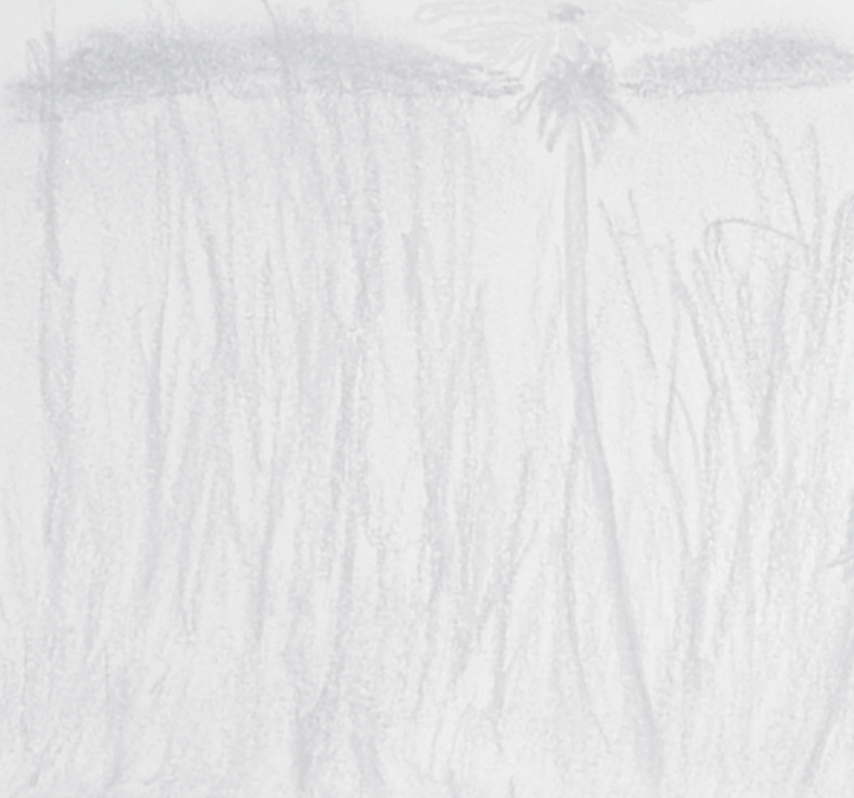

nest

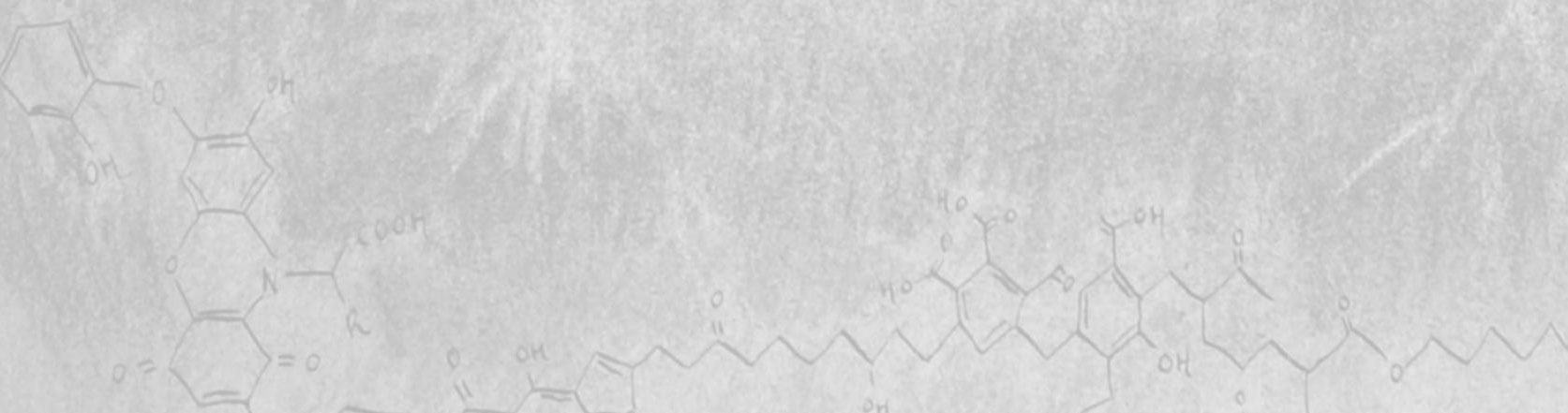




\section{Chapter 2. Estimating soil organic carbon through loss-on-ignition: effects of ignition conditions and structural water loss}

Published as: Hoogsteen, M.J.J., Lantinga, E.A., Bakker, E.J., Groot, J.C.J. \& Tittonell, P.A. 2015. Estimating soil organic carbon through loss on ignition: effects of ignition conditions and structural water loss. European Journal of Soil Science, 66, 320-328. 


\section{Summary}

Loss-on-ignition ( $\mathrm{LOI}$ ) is one of the most widely used methods for measuring organic matter content in soils but does not have a universal standard protocol. A large number of factors may influence its accuracy, such as furnace type, sample mass, duration and temperature of ignition and clay content of samples. We conducted a series of experiments to quantify these effects, which enabled us to derive (i) guidelines for ignition conditions (sample mass, duration and temperature), (ii) temperature-specific soil organic matter (SOM) to soil organic carbon (SOC) conversion factors and (iii) clay contentdependent correction factors for structural water loss (SWL). Bulk samples of a sandy soil ( $4 \%$ clay) and a silt loam soil ( $25 \%$ clay) were used to evaluate the effects of ignition conditions. Samples with a range of clay contents (0 $50 \%$ ) were used to quantify conversion and correction factors. Two furnaces, one without and one with pre-heated air, did not show significant differences in terms of within-batch LOI variability. In both furnaces less combustion occurred close to the door, which necessitated tray turning at half-time as this reduced the standard deviation per batch significantly. Variation in mass loss declined exponentially with sample mass (range, $0.15-20 \mathrm{~g}$ ). The LOI increased with duration at lower temperatures $\left(\leq 550{ }^{\circ} \mathrm{C}\right)$ for the sandy soil. At greater temperatures $\left(600\right.$ and $650^{\circ} \mathrm{C}$ ), no effect of duration was found. For the silt loam soil, LOI values increased with duration for each temperature, which was attributed to SWL. The SOM to SOC conversion factor decreased strongly with temperature at an ignition duration of 3 hours from 0.70 (350 $\left.{ }^{\circ} \mathrm{C}\right)$ to $0.57\left(500{ }^{\circ} \mathrm{C}\right)$ and stabilized around 0.55 between 550 and $650{ }^{\circ} \mathrm{C}$, indicating that at temperatures $\geq 550^{\circ} \mathrm{C}$ all SOM had been removed. The clay correction factor for SWL increased from 0.01 to 0.09 as the temperature of ignition increased from 350 to $650^{\circ} \mathrm{C}$. To minimize within-batch LOI variation we recommend a standard ignition duration of 3 hours, tray turning at halftime, a sample mass $\geq 20 \mathrm{~g}$ and temperatures equal to or greater than $550^{\circ} \mathrm{C}$. To avoid over-estimates of SOM through structural water loss, the presented SWL correction procedure should always be applied. 


\section{Introduction}

Precise quantification of soil organic matter (SOM) stocks is necessary to study organic matter dynamics over a period of time. Worldwide, the two most commonly used methods for quantifying SOM are loss-on-ignition (LOI) and wet-oxidation (WO). These methods remove organic matter either by heat application alone (LOI) or by heating combined with chemical destruction (WO) using a reagent such as hydrogen peroxide, sodium hypochlorite or disodium peroxodisulphate. After removal, the gravimetric mass loss is measured to estimate the organic matter content of the soil. A major limitation of chemical destruction during WO is the risk of incomplete oxidation, which implies that a correction factor is needed. This correction factor varies from soil to soil and depends largely on the reaction conditions, sample size and type of reagent used (see Mikutta et al., 2005). Despite the fact that a large number of oxidation protocols exist, none reaches a removal efficiency that is constant across soil types or a removal efficiency of $100 \%$ (Mikutta et al., 2005). Hence, a soil-specific multiplication factor is needed for each sample to correct for incomplete oxidation.

The type of reagent used does not influence the accuracy of the LOI method, as only physical destruction takes place. Therefore, this method might be more precise for estimating SOM. However, the LOI method has no standard protocol and involves three potentially confounding factors: incomplete combustion of SOM at low temperatures (Ball, 1964), the removal of structural water from clay minerals (Sun et al., 2009) and the decomposition of soil carbonates at large temperatures (Kasozi et al., 2009). Estimates of SOM are inaccurate when soil samples containing clay are combusted and no correction factors are applied. Inaccuracies arise because of the removal of $\mathrm{H}_{2} \mathrm{O}$-groups from sesquioxides and clay elements, and dissipation of $\mathrm{H}_{2} \mathrm{O}$ from decomposable carbonates and hydrated salts (Ball, 1964; Schulte \& Hopkins, 1996; De Vos et al., 2005). Dehydration of clay minerals involves the dissipation of unbound water, interlayer water and finally the loss of hydroxyl (or lattice $\mathrm{OH}$ ) water held by clay minerals (Grim, 1953). The latter process is also known as dehydroxylation.

As the observed mass loss from a soil sample involves combusted SOM and any loss of water that was present in it, several authors (including De Vos et al., 2005) have proposed clay correction factors to account for water losses. Houba et al. (1997) estimated a clay correction factor for LOI empirically for a large number of Dutch soils to be $7 \%$ of the fraction smaller than $2 \mu \mathrm{m}$ (sievepipette method) for water bound to clay minerals at an ignition period of 3 hours at $550{ }^{\circ} \mathrm{C}$. As dehydration and dehydroxylation are both temperature and time dependent (Grim, 1953), the clay correction factor proposed by Houba et al. (1997) can be only applied under the same ignition conditions. 
The third confounding factor that affects the accuracy of SOM estimations is the presence of carbonates (such as $\left.\mathrm{CaCO}_{3^{\prime}} \mathrm{CaMg}\left(\mathrm{CO}_{3}\right)_{2}\right)$, which decompose at ignition temperatures above $600{ }^{\circ} \mathrm{C}$ (decarbonatation; Kasozi et al., 2009). There is little consistency in the literature as to which combination of ignition temperature and duration should be employed to determine SOM contents accurately. A wide variation exists in terms of both ignition temperature (300 - $850{ }^{\circ} \mathrm{C}$ : Ball, 1964; Abella \& Zimmer, 2007) and ignition duration (2 - 28 hours: Ranney, 1969; Konen et al., 2002). Ball (1964) observed that an ignition temperature of $375^{\circ} \mathrm{C}$ for 16 hours gives more accurate SOM estimations than ignition at $850{ }^{\circ} \mathrm{C}$ for 0.5 hour, because at greater temperatures more structural water loss occurs. There is, however, a large risk of incomplete combustion at $375^{\circ} \mathrm{C}$.

Furthermore, there appears to be considerable variation in sample mass $(0.2-20 \mathrm{~g})$ and the type of ignition furnace employed (Lowther et al., 1990; Grewal et al., 1991). Wang et al. (2011) recommended a sample mass less than $5 \mathrm{~g}$ and preferably between 2 and $4 \mathrm{~g}$. We question whether such a small amount of soil will yield an accurate and precise estimate of the SOM content, because it is widely reported that variance decreases with increasing sample mass (Geelhoed \& Glass, 2004). Moreover, large within-batch variation can be expected for furnaces that do not use pre-heated air, which are commonly used for SOM analysis. To obtain a more equal heat distribution within the muffle, furnaces with pre-heated air are recommended (Fisher Scientific; M. Evers, personal communication). We analysed to what extent variation between pseudo-replicates can be attributed to furnace type and to a nonhomogeneous distribution of SOM in the sample. We also investigated if we could observe a near-door effect: heat losses close to the door will lead to reduced combustion of SOM in the crucibles there. This was expected from previous experiences (Chemical Biological Soil Laboratory (CBLB), Wageningen, the Netherlands: A. van Leeuwen, personal communication) and might be overcome by turning the tray with crucibles through $180^{\circ}$ halfway through the combustion. As the LOI method is widely used to analyse organic matter in soils, there is a clear need to refine the procedures and to develop a worldwide standard. The objectives of this study were to (i) give an overview of analytical procedures that are used worldwide, including furnace type, sample mass, and ignition temperature and duration, (ii) compare mass loss patterns of both a sandy and a silt loam soil for two different furnace types that are commonly used for LOI analysis, (iii) determine the effects of sample mass on variation in mass loss measurements for both soils, (iv) investigate if the door effect is reduced by tray turning at half time, $(v)$ determine the effects of ignition duration and temperature on mean mass loss and (vi) quantify structural water loss from clay elements and conversion factors to estimate SOC from SOM for soils with a wide range of clay contents ignited at different temperatures. 


\section{Materials and methods}

\subsection{Literature review}

A literature review was conducted by using the Scopus abstract database. In addition, the Wageningen University Library (www.library.wur.nl) and Google Scholar were consulted. We made an inventory of reported types of furnaces, sample masses and ignition conditions (temperature and duration) used for LOI determination. Publications that referred to other sources for specifications regarding using the LOI method were excluded.

\subsection{Soil samples}

Soil sample set 1 - We collected bulk samples from a podzol (sand) profile and a fluvisol (silt loam) profile. The sites were located in Wageningen (Bornse weilanden, sand; de Hoeveslagen, silt loam; Buringh, 1951). These fields were chosen because there was a large contrast in soil texture. The clay contents (volume fraction $\leq 2 \mu \mathrm{m}$ ) were $4 \%$ (sandy soil) and $25 \%$ (silt loam soil) as derived from measured optical laser diffractometry values (LD; see below).

Soil sample set 2 - Bulk soil samples were collected in arable and grassland fields in different parts of the Netherlands with known particle size distribution to obtain a wide range of clay contents. The carbonate content was not known in advance. In total, 24 fields were sampled with a clay content (mass fraction $\leq 2 \mu \mathrm{m}$ ) ranging from 1 to $50 \%$. The clay content was measured with the sieve-pipette method (SP). Because the LD method and SP method measure different soil particle diameters resulting in different textural fractions, LD values had to be converted to SP values (Vandecasteele \& De Vos, 2001; see Supplementary material Box S1). Clay types varied among samples; 12 samples contained marine clay and 12 samples contained fluvial clay. In Dutch marine clay soils, the clay minerals present are mainly illite and smectite (about $30-50 \%)$. Kaolite and chlorite represent about $10-15 \%$ of the clay fraction. In fluvial clay, vermiculite also occurs and the smectite fraction in younger deposits (post-Roman) is much smaller than in older ones (Breeuwsma, 1987). Furthermore, the free iron oxide content of the smectite-illite minerals in the clay fraction $<0.04 \mu \mathrm{m}$ of marine clay soils is $1-3 \%$ greater than the clay fraction in fluvial clay soils. Quartz sand was used in this study as a control without clay.

\subsection{Sampling procedure}

The bulk samples of soil sample set 1 were obtained from a grassland field experiment on a sandy and a silt loam soil. The $0-30$ and $30-60 \mathrm{~cm}$ soil layers were sampled with an auger using stratified sampling. Each field was divided into 48 plots and within each plot four random samples were taken from each of the two layers.

Soil sample set 2 was obtained from the $0-30 \mathrm{~cm}$ soil layer of 20 farmer's fields. A total of 40 soil samples were taken from each field in a zigzag 
pattern. A composite sample per field was obtained by mixing the 40 samples thoroughly in a bucket. This was stored in a plastic bag and brought to the laboratory. Soil samples were oven-dried for a period of 24 hours at a temperature of $105^{\circ} \mathrm{C}$. As previous studies have not shown a systematic effect of grinding on reproducibility of analytical results (Houba et al., 1993), the soil samples in this study were only crushed and sieved $(<1.8 \mathrm{~mm}$ ). However, Schumacher et al. (1990) reported that random sampling after sieving and grinding is the most time efficient method to obtain a homogeneous soil sample for LOI measurements. After sieving, the soil fines $(<1.8 \mathrm{~mm}$ ) were stored in plastic bags at room temperature. Subsamples were taken by spooning (after Carver, 1981), which we defined as the random insertion of a spoon into the sample and lifting the spoon vertically.

\subsection{Analytical methods, data processing and analysis}

Four experiments (1-4) were conducted to derive guidelines for furnace type and ignition conditions (sample mass, duration and temperature). Experiment 5 was set up to derive temperature-specific SOM to SOC conversion factors and clay-content-dependent correction factors for structural water loss (SWL). The experiments and corresponding objectives are presented below. The analytical methods that were used are described in the text under each experiment and summarized in Table 1. The Dutch standard procedure (NEN$5754,1992)$ is also listed in the table and was taken as a starting point.

\section{Experiment 1: Effect offurnace type on variation in LOI values(Objective 2).}

The soils from sample set 1 were used and two Carbolite furnace types (Carbolite, Hope Valley, UK) were compared: the carbolite wire furnace (CWF; no pre-heated air) and the analytical ashing furnace (AAF; pre-heated air). A completely randomized design was chosen with oven type and soil type as factors. This resulted in four treatments: CWF-sand, AAF-sand, CWFsilt loam and AAF-silt loam. The experiment was executed in duplicate (eight batches in total). Each batch consisted of 32 crucibles (CWF: eight rows $x$ four columns) or 21 crucibles (AAF: seven rows $\times$ three columns). To test for differences in spread of the LOI values between oven types, we calculated standard deviations as follows: (i) within row (60 values); (ii) within column (28 values); and (iii) within batch (eight values). Analyses of variance were done with soil and oven as fixed factors with interactions and batch as a random factor for cases (i) and (ii). Assumptions of normality were assessed. We also analysed the 212 observations as coming from a split-plot design with oven, soil and their interaction as fixed factors (for the main plot = batch), batch as a random factor, and row and column within oven as fixed factors (for the subplot $=$ crucible). To get appropriate tests for row and column effects within oven, row $\times$ batch and column $\times$ batch were included as well. The ignition conditions were: $550^{\circ} \mathrm{C}, 3$ hours and a dry soil sample mass of $5 \mathrm{~g}$. 


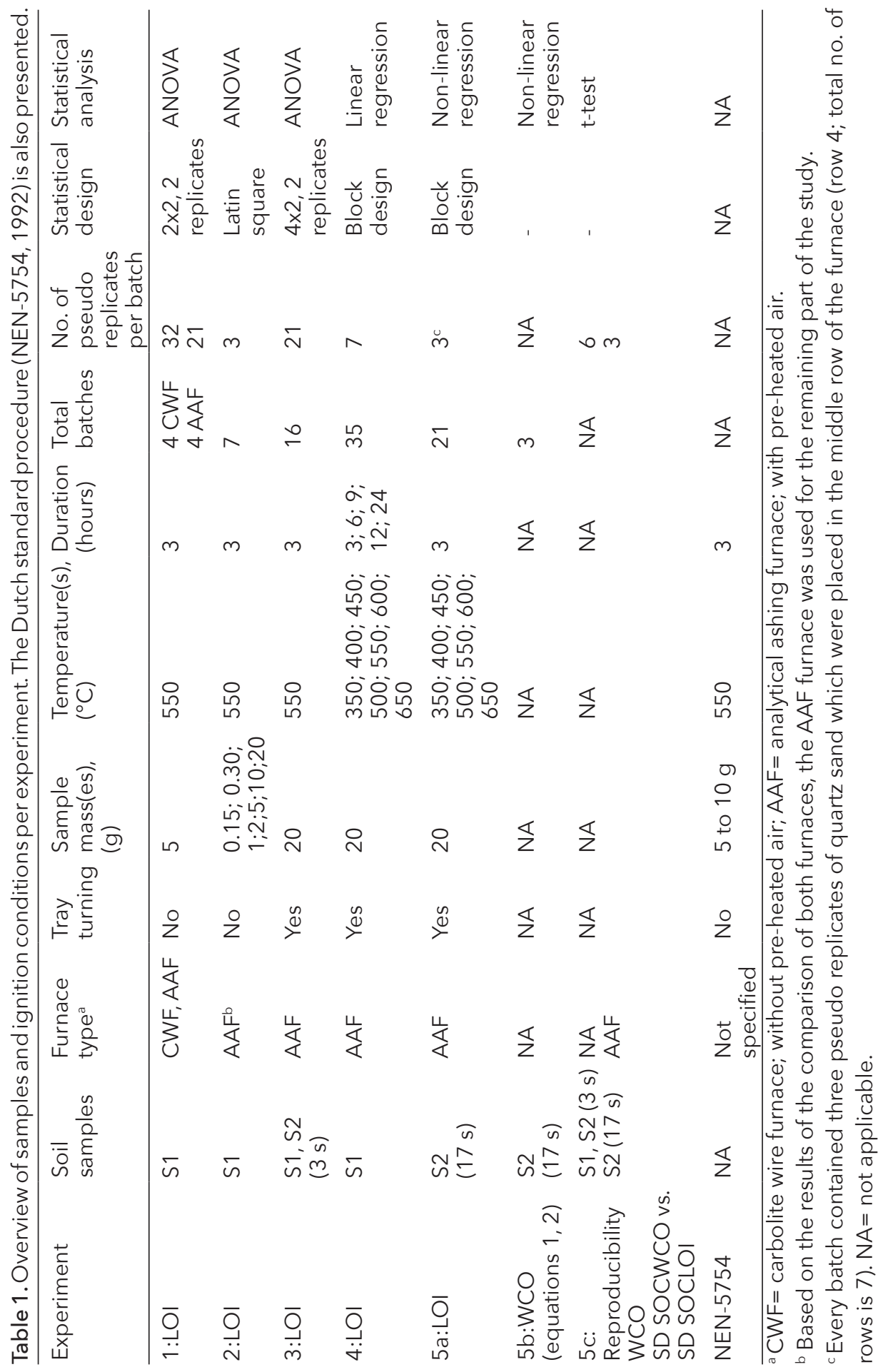


Experiment 2: Effect of sample mass on reproducibility of $L O I$ values (Objective 3).

Soil samples from sample set 1 were used. Seven different masses were chosen to assess the effect of sample mass on reproducibility of LOI values. A Latin square design was used (seven batches with seven different masses per batch) such that each sample mass occurred in triplicate in each row (see Supplementary material, Figure S2 for the layout). The chosen masses increased more or less exponentially and ranged from 0.15 to $20 \mathrm{~g}$ (see Table 1 for details). The experiment was conducted with the AAF furnace. Analysis of variance was conducted (LSD or Dunnett's T3 in the case of unequal variances, $P<0.05)$. In line with the Latin square design, batch and row number were included as block factors. The standard deviation of the $\mathrm{LOI}$ values of each row was taken as a response variable. Homogeneity of variances was assessed.

Experiment 3: Effect of tray turning on the door effect (Objective 4). In line with the results of experiment 1 (significantly reduced LOI values close to the furnace door for the silt loam sample of sample set 1) we tested whether tray turning halfway through reduced the LOI standard deviation in a batch. If turned, the tray was taken out after 1.5 hours, turned $180^{\circ}$ and put back in the furnace. We used four bulk soil samples: the silt loam sample of set 1 and three samples of set 2. Samples of set 2 were selected on the basis of the clay content, because the door effect was only observed for the loamy soil sample of set 1 in Experiment 1. The clay percentages of the selected soil samples of set 2 were 20, 31 and 40\%. Sample masses per crucible were 20 g. Every bulk sample was analysed four times (four batches each containing 21 crucibles). Two out of four batches were turned. This resulted in a total of 16 batches (see Table 1 for an overview). The ignition conditions were $550^{\circ} \mathrm{C}$ and 3 hours and the AAF furnace was used. Analysis of variance was conducted with turning and clay percentage as factors and LOI standard deviation per batch as dependent variable. For the turning/non-turning contrast, we used a onesided test as we expected the LOI standard deviation to decline with turning.

\section{Experiment 4: Effect of temperature and duration (Objective 5).}

To assess the effect of temperature and duration on ignition losses, soil samples from sample set 1 were used. The aim was to minimize duration by determining at which temperature LOI values became stable over time. Seven different temperatures that were often reported for LOI analysis were chosen (see Supplementary material, Table S2). The temperatures ranged from 350 to $650{ }^{\circ} \mathrm{C}$. Temperatures greater than $650{ }^{\circ} \mathrm{C}$ could not be used because the crucibles melted. Five ignition times were chosen and varied from 3 to 24 hours. This resulted in 35 different temperature-time combinations. Each batch consisted of 14 crucibles (seven pseudo-replicates per soil type), which were placed in two columns (one column sand, one column loam). Regression analysis was used to test the effect of duration for each temperature. For all 
batches, the tray was turned halfway through and the sample mass was $20 \mathrm{~g}$. The AAF furnace was used.

Experiment 5: Effect oftemperature on water loss from clay (Objective 6). Before conducting Experiment 5, all bulk samples (set 1 and set 2) were tested for carbonate content with the methods described in Supplementary material. Samples from carbonatic soils (eight in total: the silt loam from set 1 and seven samples from set 2) were excluded from the experiment. The remaining 17 samples consisted of eight samples containing fluvial clay and nine samples containing marine clay. The range in clay contents did not change and still extended from 0 to $50 \%$. Four replicates of quartz sand were used as control without clay. The ignition duration was 3 hours and temperatures ranged from 350 to $650{ }^{\circ} \mathrm{C}$. Six samples were placed in one batch (three pseudo-replicates per sample). The middle row (row 4) was filled with three pseudo-replicates of quartz sand (see Supplementary material, Figure S2 for the positioning of the samples in the furnace). The average LOI value was determined for each temperature. The following model was fitted to quantify structural water loss from clay elements:

$\mathrm{SOC}=\mathrm{a}_{\mathrm{T}} \times\left(\mathrm{LOI}_{\mathrm{T}}-\mathrm{b}_{\mathrm{T}} \times \mathrm{C}\right)$,

(Equation 1)

where SOC (\%) is the soil organic carbon content obtained by wet chemical oxidation (WCO, see below), LOI is mass loss of SOM (\%), C is the soil clay content (\%), $a_{T}$ is the carbon content of SOM $\left(\mathrm{kg} \mathrm{kg}^{-1}\right), b_{T}$ is the clay correction factor for structural water loss $\left(\mathrm{kg} \mathrm{kg}^{-1}\right)$ and the suffix $T$ refers to the ignition temperature. The parameters $a_{T}$ and $b_{T}$ were fitted with nonlinear regression using SPSS (19 th edition). The minimum value of $a_{T}$ and the maximum value of $b_{T}$ were estimated as a function of ignition temperature. For $a_{T^{\prime}}$ an exponential equation was fitted:

$a_{\mathrm{T}}=\alpha+\beta y^{\top}$

(Equation 2)

For $b_{T}$ we used a logistic equation following general dehydration curves of clay minerals as presented by Grim (1953):

$b_{T}=\delta+\frac{\varepsilon}{1+e^{-k(T-\lambda)}}$

(Equation 3)

Genstat (15 $5^{\text {th }}$ edition SP1) was used to fit Equations (2) and (3) to the data. Soil OC values were determined after WCO by sulphochromic acid as described by Houba et al. (1997). This method results in complete oxidation and therefore no correction factor is needed (Walinga et al., 1992). We used glucose $\left(\mathrm{C}_{6} \mathrm{H}_{12} \mathrm{O}_{6}\right)$ as a standard substance and conducted the spectrophotometric measurements at a wavelength of $585 \mathrm{~nm}$. Seven stock solutions with a C-content that increased from 0 to $20 \mathrm{mg}$ per $5 \mathrm{ml}$ were used to derive a calibration curve. We adjusted the calculation procedure because 
the prescribed equation includes a double correction factor for the blank. We also suspected chemical deviations from Beer's law for the association of chromate in acid solutions (Supplementary material, Box S3). All samples from sample set 2 were analysed in triplicate. These replicates were fitted separately with Equation (1) and the average $a_{T}$ and $b_{T}$ values together with their standard deviations were calculated. Furthermore, we compared standard deviations of measurements obtained by the WCO procedure and the LOI method. The same LOI dataset was used as for determining the clay correction factor ( 17 non-carbonatic soil samples ignited at $550{ }^{\circ} \mathrm{C}$ for 3 hours). The standard deviation (SD) of each sample was calculated from three pseudo-replicates. The data were analysed using a paired t-test.

\section{Results}

\subsection{Literature review (Objective 1)}

The literature search resulted in 40 publications from the period 1960 - 2011 in which the LOI method was used for assessing organic matter in sediments, compost and soils (Supplementary material, Table S2). Many studies were characterized by a lack of information about details of the applied LOI method, and the reported analytical conditions were very diverse. In $65 \%$ of the studies, the type of furnace was not reported. In the remaining $35 \%$ of the studies, eight different makes of furnaces were reported. Sample mass was reported in only $62 \%$ of the studies and varied between 0.2 and $20 \mathrm{~g}$ (Christensen \& Malmros, 1982; Wright et al., 2008) with an average of $5.5 \mathrm{~g}$. Heating time varied from 30 minutes to 32 hours and ignition temperature ranged from 350 to $1000^{\circ} \mathrm{C}$. No significant correlations were found between year of publication and sample mass, ignition duration and temperature.

\subsection{Effect of furnace type on LOI (Objective 2, Experiment 1)}

The average mass loss of the sandy sample in the CWF furnace was $2.98 \%$ (SD $=0.06$ ) for the two batches (Table 2). We found nearly the same values for the AAF furnace: $2.95 \%(S D=0.06$ ). For the silt loam soil we found large absolute differences between furnaces: the average LOI value was $4.29 \%$ for the CWF $(S D=0.09)$ and $4.09 \%(S D=0.09)$ for the AAF (see Supplementary material, Table S3 for the output of the analysis of variance). Large LOI ranges within batch were observed for both furnaces. The maximum difference was $0.22 \%$ for the sandy soil and $0.42 \%$ for the silt loam soil. No consistent gradient in $\mathrm{LOI}$ values with distance from the furnace door was found for the sandy soil, whereas for the silt loam soil sample ignition losses were smallest close to the door in both furnaces (Table 2). This door effect seemed less pronounced for the AAF than for the CWF furnace: differences in average LOI values between the middle row and the front row were smaller for the AAF as compared with the CWF furnace. 
Table 2. Effect of furnace type (CWF; without pre heated air and AAF; with pre heated air) on average loss-on-ignition ( $\mathrm{LOI}$ ) values per row for a sandy and loamy bulk soil sample. Ignition conditions were $550^{\circ} \mathrm{C}$ and three hours. A sample weight of $5 \mathrm{~g}$ was used. A row runs from the left to the right side of the furnace (see the image next to the table for crucible positions within the AAF furnace). Standard errors (SE) for the means per row are based on the pooled within-row standard deviations ( $n=8$ for $\mathrm{CWF}, \mathrm{n}=7$ for $\mathrm{AAF}$ ).

\begin{tabular}{|c|c|c|c|c|c|c|c|c|}
\hline \multicolumn{3}{|c|}{ Sand } & \multicolumn{2}{|c|}{ Loam } & \multicolumn{4}{|c|}{ Column no. } \\
\hline $\begin{array}{l}\text { Row } \\
\text { no. }\end{array}$ & $\begin{array}{c}C W F \\
S E=0.019\end{array}$ & $\begin{array}{c}\text { AAF } \\
\text { SE }=0.023\end{array}$ & $\begin{array}{c}C W F \\
S E=0.027\end{array}$ & $\begin{array}{c}A A F \\
S E=0.034\end{array}$ & $\begin{array}{l}\text { Row } \\
\text { no. }\end{array}$ & 1 & 2 & 3 \\
\hline 1 & 2.96 & 2.95 & 4.15 & 4.00 & 7 & 19 & 20 & 21 \\
\hline 2 & 2.98 & 2.97 & 4.22 & 4.06 & 6 & 16 & 17 & 18 \\
\hline 3 & 2.99 & 2.99 & 4.31 & 4.11 & 5 & 13 & 14 & 15 \\
\hline 4 & 3.02 & 2.91 & 4.29 & 4.11 & 4 & 10 & 11 & 12 \\
\hline 5 & 2.98 & 2.93 & 4.37 & 4.12 & 3 & 7 & 8 & 9 \\
\hline 6 & 3.01 & 2.97 & 4.36 & 4.15 & 2 & 4 & 5 & 6 \\
\hline 7 & 2.95 & 2.93 & 4.29 & 4.06 & 1 & 1 & 2 & 3 \\
\hline 8 & 2.97 & n.a. & 4.26 & n.a. & \multicolumn{4}{|c|}{ Furnace door } \\
\hline
\end{tabular}

The effect of furnace type on variation was assessed for both soil types in three analyses (standard deviation per row, column and batch). All three tests showed no significant differences in spread of LOI values between furnaces, so pre-heated air did not improve analytical precision (see Supplementary material, Table S4 for the output of the analysis of variance). Because the door effect was less pronounced for the AAF furnace, we decided to conduct the subsequent experiments only with the AAF model.

\subsection{Effect of sample weight on LOI (Objective 3, Experiment 2)}

The effects of the factors batch number and row number were not significantfor the sandy or the silt loam bulk soil. The variation in standard deviations was not equal across masses and decreased with increasing sample mass. The natural logarithm was taken to stabilize variation of the response variable (sample mass). The natural logarithm was also taken of each mass and plotted against the natural logarithm of standard deviation (Supplementary material, Figure S3). For the sandy soil, a significantly smaller standard deviation $(P=0.047)$ was observed for sample masses of $20 \mathrm{~g}$ than for masses of $5 \mathrm{~g}$ (standard protocol; NEN-5754). For the silt loam soil, we also found that standard deviations decreased with increasing sample mass. Standard deviations of sample masses of $20 \mathrm{~g}$ were slightly smaller than those for masses of $5 \mathrm{~g}$, but this was not significant $(P=0.116)$. Furthermore, we observed for both soil samples that mean LOI values increased with sample mass (Figure 1). 


\subsection{Effect of tray turning on LOI (Objective 4, Experiment 3)}

In Experiment 3, we established the effect of turning the tray on the possible decrease in standard deviation per batch. For the sandy soil of sample set 1 , no significant effect of tray turning was found. Standard deviations per batch $\left(\mathrm{SD}_{b}\right)$ were 0.04 without turning and 0.03 with turning. For the silt loam soil (set 1), tray turning had a significant effect on the $\mathrm{SD}_{b}$ : a decline from 0.10 (without turning) to 0.06 (with turning) was observed. The effect of tray turning for three bulk samples of set 2 is presented in Figure 2. Analysis of variance showed that the effects of clay percentage $(P=0.366)$ and the interaction of clay percentage and turning $(P=0.890)$ were not significant. Because the explained variation of the model $\left(R^{2}\right.$ adjusted $\left.=0.04\right)$ was very small, an ANOVA was conducted with only turning as treatment factor and clay percentage as block factor. This improved the explained variation $\left(R^{2}{ }_{\text {adjusted }}=0.16\right)$. The effect of turning was significant (one-sided $P=0.03$ ).

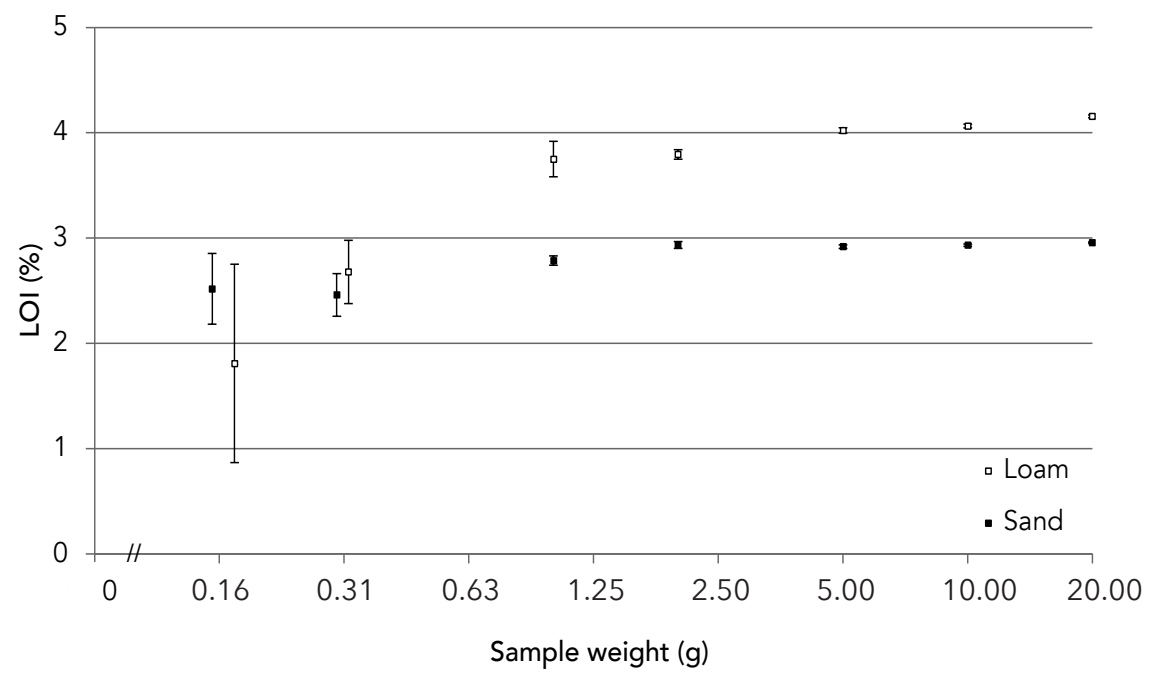

Figure 1. Effect of sample weight on average loss-on-ignition (LOI) values for a sandy and loamy bulk soil sample. Ignition conditions were $550^{\circ} \mathrm{C}$ for three hours. The AAF furnace was used. All sample weights were analysed in septuplicate. Standard errors of the mean (SEM) are presented. Sample weights are presented on a log scale. To avoid visual overlap in SEM values, for the loamy soil sample $0.02 \mathrm{~g}$ was added to the sample weights of 0.15 and $0.30 \mathrm{~g}$. 


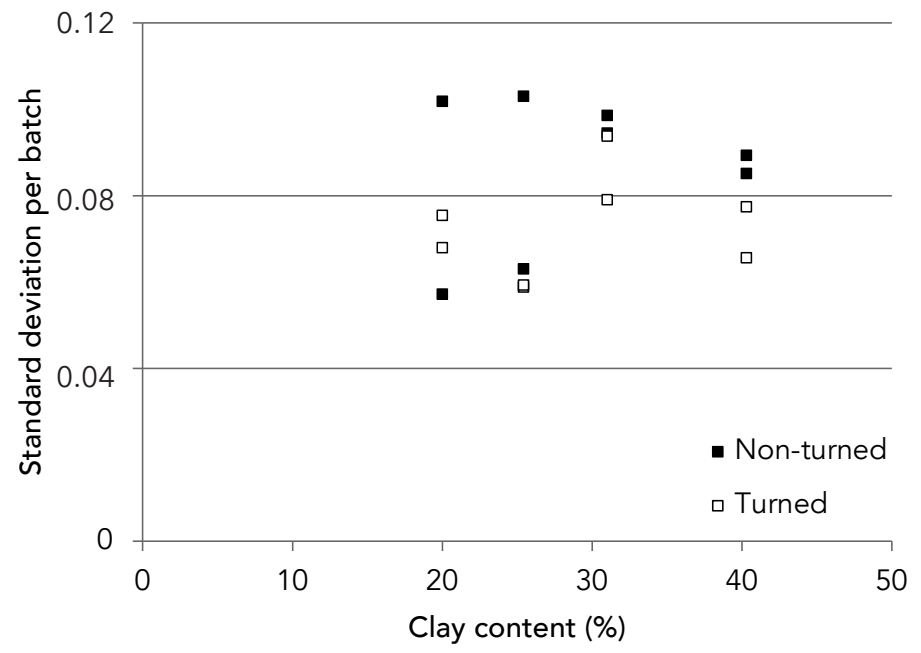

Figure 2. The effect of turning the tray after 1.5 hours on standard deviations per batch for different soil types. Four soils were used with clay contents that ranged from 20 to $40 \%$. Ignition conditions were $550^{\circ} \mathrm{C}$ for three hours. The sample weight was 20 $\mathrm{g}$ and the AAF furnace was used.

\subsection{Combined effect of ignition temperature and duration on LOI (Objective 5, Experiment 4)}

The results of the sandy and silt loam bulk sample are treated separately below.

Sandy soil (sample set 1)

In Experiment 4, mass loss increased significantly with ignition duration (3-24 hours) at temperatures between 350 and $550{ }^{\circ} \mathrm{C}$ (Figure 3a). At 600 and 650 ${ }^{\circ} \mathrm{C}$, no clear effects of ignition duration on LOI values were observed.

Silt loam soil (sample set 1)

Over the whole range of temperatures, average LOI values increased with ignition time (Figure 3b). Mass loss was least at a temperature of $350^{\circ} \mathrm{C}$ for 3 hours $(\mathrm{LOI}=2.22 \%, \mathrm{SD}=0.02)$ and nearly tripled at $650{ }^{\circ} \mathrm{C}$ for 24 hours $(\mathrm{LOI}=6.60 \%, \mathrm{SD}=0.13)$. This indicates that structural water loss from clay elements is a process that takes place at greater temperatures $\left(>550^{\circ} \mathrm{C}\right)$ and continued at increasing duration of ignition. 
(a)

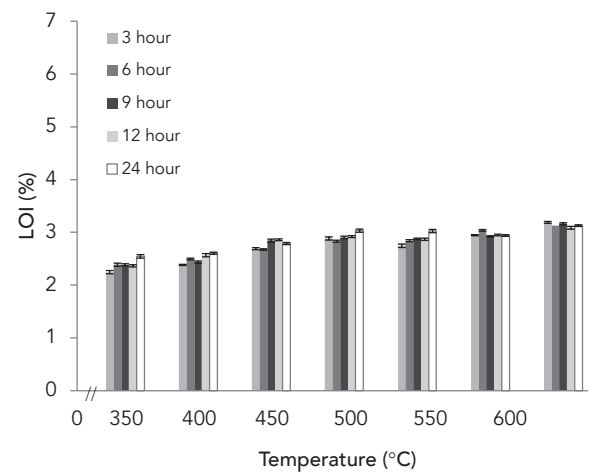

(b)

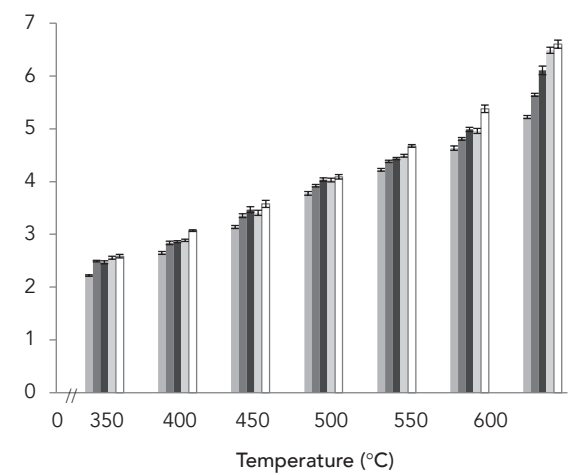

Figure 3. Effect of ignition temperature and duration on loss-on-ignition values of a sandy ( $4 \%$ clay; a) and silt loam soil sample $(25 \%$ clay; b). The sample weight was 20 $g$ and the AAF furnace was used.

\subsection{Effect of temperature on structural water-loss from clay minerals (Objective 6, Experiment 5)}

Values of coefficients $a_{T}$ and $b_{T}$ at increasing ignition temperatures are presented in Figure 4 (Experiment 5). The value of coefficient $a_{T}$, the fraction of soil organic matter that is carbon, declined with increasing temperature up to $500^{\circ} \mathrm{C}$, and stabilized at greater temperatures. The minimum value of $a_{T}$ was $0.55 \mathrm{~kg} \mathrm{~kg}^{-1}$. The value of $b_{T}$ increased in a sigmoidal fashion with $a$ maximum value for $b_{T}$ of $0.09 \mathrm{~kg} \mathrm{~kg}^{-1}$.

(a)

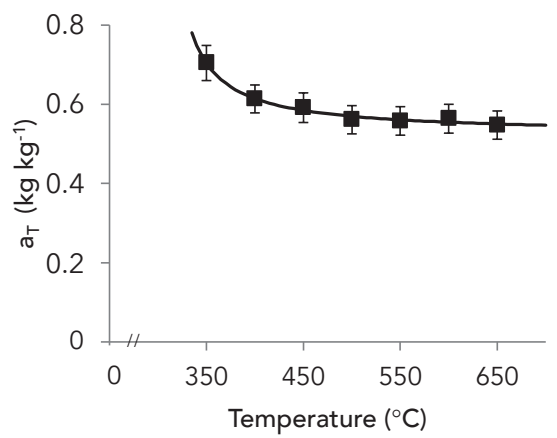

(b)

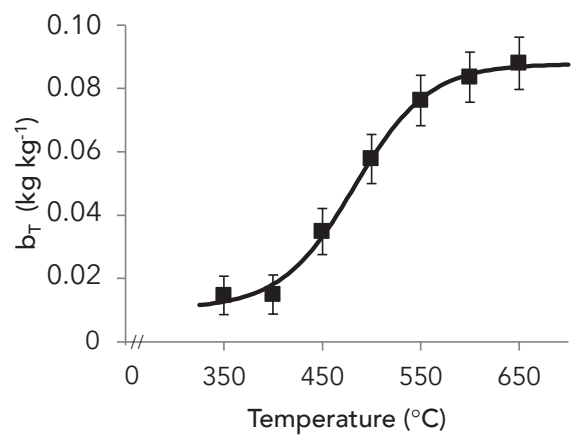

Figure 4. Relationship between furnace temperature and SOM to SOC conversion factor $a_{T}(a)$ and clay correction factor $b_{T}(b)$. Values of curvature parameters are presented in Supplementary material Table S5. The ignition duration was three hours. The sample weight was $20 \mathrm{~g}$ (SOM; loss-on-ignition). The AAF furnace was used and the tray was turned at halfway through the combustion. 


\subsection{Reproducibility of measured soil organic carbon by using wet chemical oxidation}

Standard deviations of SOC as determined by both LOI and WCO are presented in Figure 5. To compare SDs of both methods, LOI values were converted to $\mathrm{SOC}$ by multiplication with a factor 0.55 (horizontal asymptote in Figure $4 a$ ). The $\mathrm{SD}_{\text {wco }}$ value was significantly larger than that of $\mathrm{SD}_{\mathrm{LO}}$ $(P=0.0002)$.

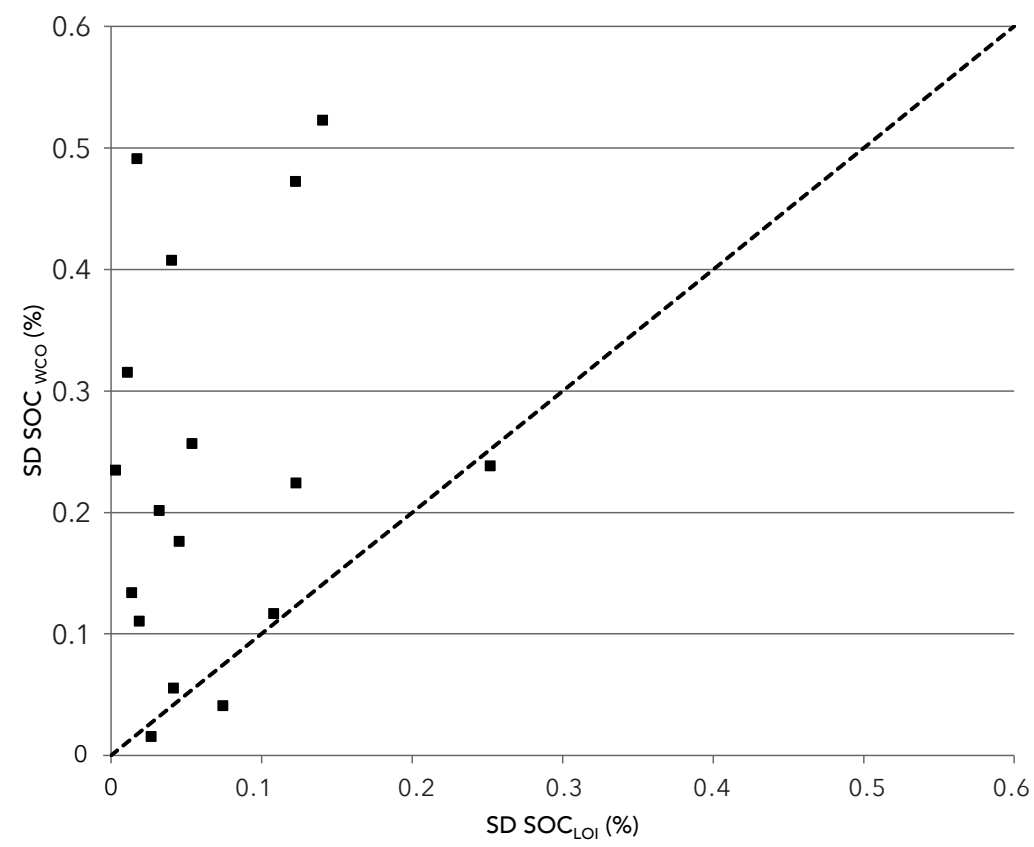

Figure 5. Relationship between standard deviation (SD) of the loss-on-ignition method (LOI) and wet-chemical oxidation method (WCO). LOI values were converted to SOC using a factor of 0.55. A 1:1 line is plotted. Seventeen different soil samples were used with a clay content that ranged from 1-50\%. All samples were analysed in triplicate. The LOI was conducted in the AAF furnace at $550^{\circ} \mathrm{C}$ for three hours, a sample weight of $20 \mathrm{~g}$ was used and the tray was turned halfway through the ignition period. The WCO method requires that a sample weight of $0.3 \mathrm{~g}$ is used.

\section{Discussion}

The observed effects of furnace type, sample mass, tray turning, ignition temperature and duration on LOI measurements (mean and standard deviation) call for standardization of procedures and materials to arrive at accurate and comparable estimates of organic carbon content of soils. We found that furnace type did not affect variation in LOI values and that within- 
batch variation can be reduced by turning the tray halfway through the ignition, in all probability counteracting heat losses close to the door (Table 2 and Figure 2). Furthermore, we showed that the precision of $\mathrm{LOI}$ measurements increased with sample masses up to $20 \mathrm{~g}$ (Figure 1 and Supplementary material, Figure S3). At temperatures greater than $550{ }^{\circ} \mathrm{C}$, no effect of heating time on LOI values was observed for the sandy bulk soil sample, while for the silt loam soil ignition losses continued to increase with time. We showed that the conversion factor from SOM (estimated through LOI) to SOC decreased at an ignition duration of 3 hours from 0.70 at $350{ }^{\circ} \mathrm{C}$ to $0.55 \mathrm{~kg} \mathrm{~kg}^{-1}$ at $650{ }^{\circ} \mathrm{C}$ (Figure 4a). Finally, we showed that the multiple linear regression approach was successful in deriving temperature-dependent clay-correction factors (Figure 4b).

Our review of the literature regarding the LOI method employed by different authors (Supplementary material, Table S2) showed a wide diversity of procedures and/or incomplete methodological information. We observed an LOI gradient in both of the furnaces used for the silt loam soil, with ignition values being least close to the furnace door. This was more pronounced for the CWF furnace than for the AAF furnace (larger differences in average $\mathrm{LOI}$ values between the front row and the centre row; Table 2). Although all samples were well mixed in our experiments, we found that standard deviations declined with increasing sample mass in a logarithmic fashion for sample masses up to $20 \mathrm{~g}$. This is in line with the literature about a large range of materials including ores and living tissues, all demonstrating that the variance of replicate measurements decreases with increasing sample mass (Ingamells, 1974; Kratochvil, 1981; Geelhoed \& Glass, 2004).

The WCO procedure uses sample masses between 300 and $500 \mathrm{mg}$ and therefore we suspected that the WCO procedure suffers from large inaccuracies. One could consider refining the WCO method by increasing the sample mass. It is, however, impossible to increase sample masses to much larger values because of the molarity of the chromate solution and incomplete oxidation. Increasing the molarity of the solution is only possible to about 1.5 times the current concentration (a further increase in molarity results in incomplete dissolution of $\left.\mathrm{K}_{2} \mathrm{Cr}_{2} \mathrm{O}_{7}\right)$. The SD values of $\mathrm{WCO}$ were significantly larger than the SD values of LOI (Figure 5). Therefore, we conclude that the LOI method (using a sample mass of $20 \mathrm{~g}$ ) is able to generate results with a much larger degree of precision than the commonly used wet chemical oxidation procedure for determining SOC.

Furthermore, we observed that mean LOI values increased with sample mass. This cannot be attributed to the effect of sample position as each mass occurred once in each row (following the Latin square design). Therefore, this is most likely the result of differences in thermal conductivity between soil and air: relatively more SOM particles in small sample masses $(<1 \mathrm{~g})$ were not surrounded by soil but by air, as in larger samples (see Supplementary 
material, Figure S4 for an image). It is known that the thermal conductivity of air is about 10 times smaller than the conductivity of quartz sand. This is probably why smaller LOI values were found for masses in the order of $1 \mathrm{~g}$ than for masses of $5 \mathrm{~g}$ and larger. To minimize the effect of heat losses close to the furnace door on within-batch variation of LOI, the effect of tray-turning halfway through was assessed. Because standard deviations per batch were significantly smaller for turned batches than for non-turned batches we recommend that the tray should always be turned. For the sandy sample, heating time increased ignition losses at temperatures $\leq 550{ }^{\circ} \mathrm{C}$ (Figure $3 a$ ). At 600 and $650^{\circ} \mathrm{C}$, no effect of heating time was observed (thus all SOM was removed). For the silt loam soil, ignition losses increased with duration for all temperatures, which is in accordance with Grim (1953). As structural water loss is a time- and temperature-dependent process, correction factors had to be calculated. We did this for temperatures ranging from 350 to $650{ }^{\circ} \mathrm{C}$ and a duration of 3 hours (no consistent effect of heating time was observed for the sandy soil at temperatures $\geq 600{ }^{\circ} \mathrm{C}$ ). The value of coefficient $\mathrm{a}_{\mathrm{T}}$, the conversion factor of $\mathrm{SOM}$ to $\mathrm{SOC}$, declined strongly with increasing temperatures up to $500{ }^{\circ} \mathrm{C}$, and stabilized between $550{ }^{\circ} \mathrm{C}\left(\mathrm{a}_{\mathrm{T}}=0.56\right)$ and $650^{\circ} \mathrm{C}\left(a_{T}=0.55\right)$. This shows that at temperatures $\geq 550^{\circ} \mathrm{C}$ all organic matter is removed, which is in line with Schnitzer et al. (1959) and Turner \& Schnitzer (1962), who have shown with thermobalances that further mass losses of $\mathrm{SOM}$ in mineral soils and pure organic matter samples, respectively, do not occur at temperatures $\geq 550^{\circ} \mathrm{C}$.

Structural water loss from clay increased in a sigmoidal fashion (Figure 4b). This is in accordance with dehydration curves and differential thermal curves, as demonstrated by Grim (1953) and Pansu \& Gautheyrou (2006). At $550{ }^{\circ} \mathrm{C}$, we obtained a value of about 0.075, which is slightly larger than the empirical value of 0.07 given by Houba et al. (1997). Although factors that are used for correction of structural water loss are not universal, Grim (1953) demonstrated that for nearly all clay types, SWL increases in a sigmoidal fashion with temperature, except for allophane and sepiolite. This indicates that an LOI method that circumvents the need for clay correction as suggested by Ball (1964) is needed.

Davies (1974) showed that a temperature between 375 and $450{ }^{\circ} \mathrm{C}$ does not lead to loss of hydroxyl water. This is, however, not in accordance with our results (structural water loss at $400^{\circ} \mathrm{C}$ ) and with those of a large number of authors who showed that dehydration occurs at temperatures in excess of $300{ }^{\circ} \mathrm{C}$ (Nutting, 1943; Pansu \& Gautheyrou, 2006). Moreover, smaller ignition temperatures result in incomplete oxidation of SOM. Therefore, we recommend that a clay correction factor for analysing SOM by the LOI method should be used. 


\section{Conclusions}

The results of our experiments to test the effects of ignition conditions (furnace type, sample mass, temperature and duration) on loss-on-ignition measurements using samples of sandy to clay soils from a temperate climate led us to conclude the following:

- No differences in precision between furnaces were found: the furnace without pre-heated air attained the same degree of precision as the furnace with pre-heated air so both furnace types can be used for the LOI method.

- Turning the tray at half-time reduces the standard deviation and overcomes the effects on LOI heat losses close to the furnace door.

A sample mass of at least $20 \mathrm{~g}$ should be used to minimize variation in LOI measurements.

To attain complete oxidation an ignition temperature of at least $550{ }^{\circ} \mathrm{C}$ is needed.

- A clay correction factor should always be used, to avoid over-estimating the SOM content by correcting for structural water loss.

Further research should investigate the introduction of correction factors for $\mathrm{CaCO}_{3}$ and free iron as those components contribute to an additional mass loss at temperatures $\geq 550^{\circ} \mathrm{C}$. 


\section{Supplementary material}

\section{Box S1 Particle size of samples from sample set 1}

The clay contents (volume fraction $\leq 2 \mu \mathrm{m}$ ) of the samples of sample set 1 were $2 \%$ (sandy soil) and 10\% (silt loam soil) as determined by optical laser diffractometry (LD). The samples of sample set 2 were determined using the sieve-pipette method (SP). The LD method and the SP method measure, however, different soil particle diameters because both methods are based on different assumptions and principles: SP is based on sedimentation rates, while LD is based on light scattering (Konert \& Vandenberghe, 1997). For this reason, the samples of set 1 needed to be converted. Vandecasteele \& De Vos (2001) reported that the largest similarity between both methods was found between the volume fraction $\leq 6 \mu \mathrm{m}$ as determined by LP and the $\leq 2$ $\mu \mathrm{m}$ mass fraction as measured by SP. A relationship between both methods is presented below. In the samples of set 1, the fractions $\leq 6 \mu \mathrm{m}$ were $5 \%$ (sand) and $26 \%$ (silt loam). Those values were converted with the equation as presented in Figure S1 which resulted in the following clay contents: $4 \%$ (sand) and 25\% (silt loam).

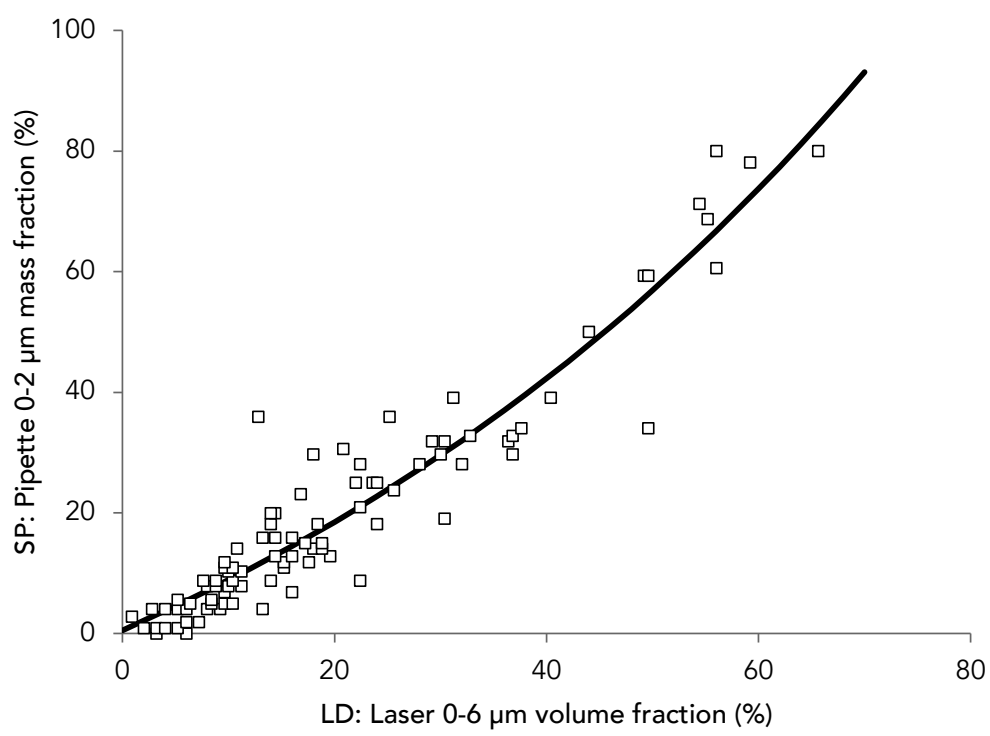

Figure S1. Relationship between the $0-6 \mu \mathrm{m}$ volume fraction of the laser diffractionation method (LD) and the 0-2 $\mu$ m mass fraction of the sieve pipette method (SP). The figure has been derived from Vandecasteele \& De Vos (2001) and axes were reversed. 


\section{Box S2 Evaluation of samples for carbonate content}

The carbonate content of samples was determined using two methods, whereas the samples containing carbonates were excluded for determining the effect of temperature on water loss from clay minerals (Experiment 5). The carbonate content was assessed visually (method 1; Breeuwsma, 1987) and gravimetrically (method 2; Loeppert \& Suarez, 1996 combined with Houba et al., 1997).

Method 1 Seven $\mathrm{ml} 4 \mathrm{M} \mathrm{HCl}$ was added to air-dry soil (sample weight between 2.4 and $2.6 \mathrm{~g})$ in a polypropylene vial. A number $(0,1$ or 2$)$ was given according to the degree of effervescence. Vials that showed a weight loss greater than the weight loss of quartz sand (per cent) and showed effervescence (1 or 2) were eliminated.

Method $2 \mathrm{~A}$ large number of protocols exist for measuring carbonates in soils. We followed the procedure of Loeppert \& Suarez (1996) and adjusted the molarity and amount of hydrochloric acid added to each sample and prepared a solution of $4 \mathrm{M} \mathrm{HCl}$ (Houba et al., 1997). Between 2.4 and $2.6 \mathrm{~g}$ of air dry soil was put into the vial. Weight losses of $\mathrm{CaCO}_{3}(>99 \%)$ and $\mathrm{MgCO}_{3}$ were also measured ( $1 \mathrm{~g}$ air dry). Quartz sand was used as control. Seven $\mathrm{ml} 4 \mathrm{M} \mathrm{HCl}$, was transferred into the vial. The total weight within the vial was calculated by summing up the soil weight (g) and the added $\mathrm{HCl}(\mathrm{g})$. Samples were swirled automatically on an orbital shaker (Gerhardt Laboshake, LS 5, Königswinter, Germany) for 45 minutes at a speed of 95 rotations per minute. The total carbonate content was expressed in $\mathrm{CaCO}_{3}$ equivalents and calculated as follows:

$\mathrm{CaCO}_{3}(\%)=\frac{100-\frac{\left(v_{d a}-v_{e}\right)}{\left(v_{d}-v_{e}\right)} * 100}{0.44}$,

where, $\mathrm{V}_{\mathrm{ad}}=$ the vial weight after destruction, $\mathrm{V}_{\mathrm{e}}=$ the empty vial weight, $\mathrm{V}_{\mathrm{bd}}=$ the vial weight before destruction, and 0.44 is the $\mathrm{CO}_{2}$ content of $\mathrm{CaCO}_{3}$. No corrections were applied for effects of acids (decarboxylation of the organic matter fraction (Loeppert \& Suarez, 1996) or dissolving of clay minerals (Grim, 1953)).

\section{Box S3 Chemical deviations from Beer's law for the association of chromate in acid solutions}

Walinga et al., (1992) argued that the absorbance of $\mathrm{Cr}^{3+}$ at a wavelength of $590 \mathrm{~nm}$ is adherent to Beer's law. However, chemical deviations from Beer's law have been reported for the association of chromate in acid solutions (non-linearity of absorbance of $\mathrm{Cr}^{3+}$ related to its concentration (Ewing, 1969; Abdel-Latif, 2013)). We assume that the concentration $\mathrm{Cr}^{3+}$ increases with extinction in an asymptotic fashion. The standard protocol (Houba et al., 1997) uses five stock solutions with glucose with a carbon content ranging

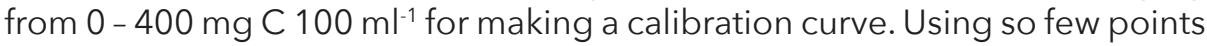


will, however, not reveal the existence of a non-linear curve. We fitted both equations (linear and asymptotic) using seventeen stock solutions ranging

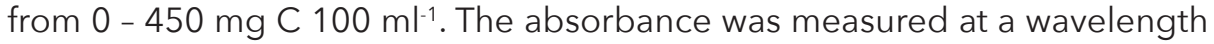
of $585 \mathrm{~nm}$. In both equations, $C$ is the amount of carbon $(\mathrm{mg})$ present in 100 $\mathrm{ml}$ of the solution and $E$ is the measured extinction value.

Linear: $C=a+b E$.

Asymptotic: $=a+b x d^{E}$.

Details of the calibration curves are given in Table S1.

Table S1. Curvature values for the linear and asymptotic calibration curve. SE values are given in brackets. NA = not applicable.

\begin{tabular}{lll}
\hline Parameter & Linear & Asymptotic \\
\hline a & $-20.98(1.59)$ & $-1953(270)$ \\
$\mathrm{b}$ & $714.06(5.74)$ & $1937(269)$ \\
$\mathrm{d}$ & $\mathrm{NA}$ & $1.396(0.059)$ \\
& & \\
$R^{2}$ & 0.999 & 1.000 \\
Estimated SE of observations & 4.46 & 1.97 \\
F-value & 15459 & 39465 \\
\hline
\end{tabular}

(a)

\begin{tabular}{lllllllll}
\hline & Batch & 1 & 2 & 3 & 4 & 5 & 6 & 7 \\
\hline 1 & & & & & & & \\
2 & 6 & 3 & 7 & 1 & 6 & 2 & 5 \\
3 & 2 & 4 & 6 & 5 & 3 & 1 & 7 \\
4 & 3 & 7 & 1 & 4 & 2 & 5 & 6 \\
5 & 7 & 1 & 5 & 2 & 4 & 6 & 3 \\
6 & 5 & 6 & 3 & 7 & 1 & 4 & 2 \\
7 & 1 & 5 & 2 & 6 & 7 & 3 & 4 \\
\hline
\end{tabular}

(b)

\begin{tabular}{lll}
\hline 1 & 1 & 1 \\
\hline 5 & 5 & 5 \\
\hline 7 & 7 & 7 \\
\hline 3 & 3 & 3 \\
\hline 2 & 2 & 2 \\
\hline 6 & 6 & 6 \\
\hline 4 & 4 & 4 \\
\hline \multicolumn{3}{c}{ Door } \\
\hline
\end{tabular}

(c)

\begin{tabular}{ccc} 
D & $E$ & $F$ \\
\hline$D$ & $E$ & $F$ \\
\hline$D$ & $E$ & $F$ \\
\hline Q & Q & Q \\
\hline A & $B$ & $C$ \\
\hline$A$ & $B$ & $C$ \\
\hline$A$ & $B$ & $C$ \\
\hline \multicolumn{3}{c}{ Door } \\
\hline
\end{tabular}

Figure S2. Design of Experiment 2 (a) and sample positions within the furnace of Experiment 2 (b) and Experiment 5 (c). Experiment 2: The Latin square design that was used for the loamy soil is presented. Numbers 1-7 resemble seven different sample weights that were analysed in triplicate. The example of batch 1 is given in (b). Experiment 5: Letters A to $F$ represent six different samples that are analysed in triplicate. $\mathrm{Q}$ is quartz sand. The position of the furnace door is indicated. 
(a)

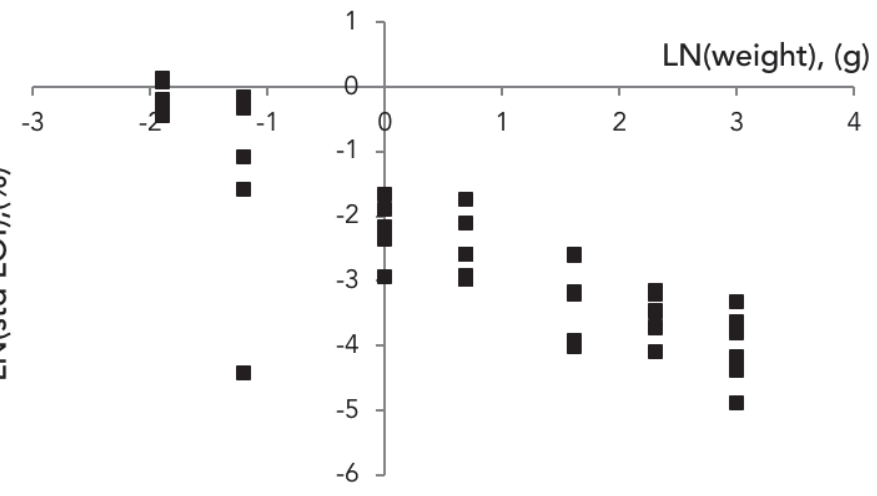

(b)

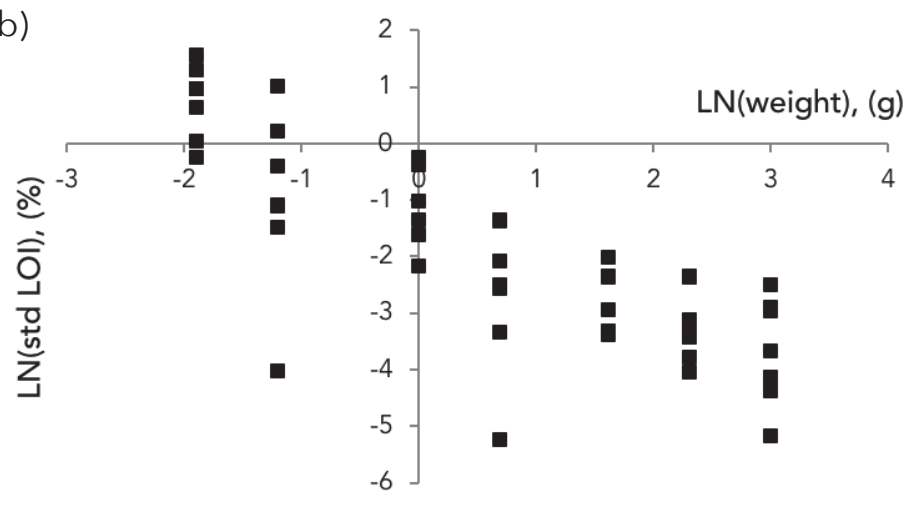

Figure S3. The effect of sample weight on standard deviations of loss-on-ignition (LOI) values for a sandy (a) and loamy (b) bulk sample. Sample weights ranged from 0.15 to $20 \mathrm{~g}$. Standard deviations were based on ignition values of three pseudo-replicates.

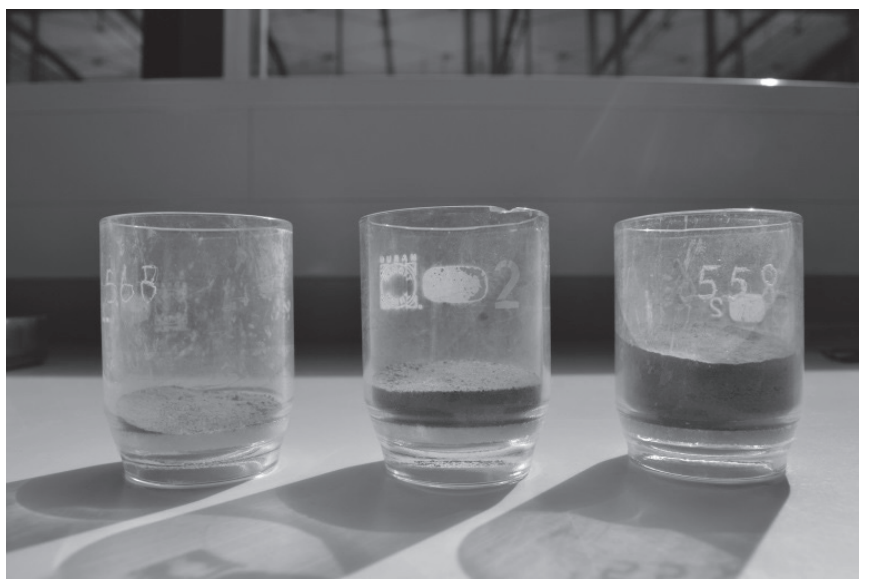

Figure S4. Crucibles filled with different amounts of soil. Sample weights from the left to the right are $1 \mathrm{~g}, 5 \mathrm{~g}$ and $20 \mathrm{~g}$. 
Table S2. Summary of the results of literature search on ignition conditions for analysing organic matter using the loss-on-ignition method. NR = not reported.

\begin{tabular}{|c|c|c|c|c|c|}
\hline Material & $\begin{array}{l}\text { Sample } \\
\text { weight } \\
\text { (g) }\end{array}$ & Furnace type & $\begin{array}{l}\text { Temperature } \\
\left({ }^{\circ} \mathrm{C}\right)\end{array}$ & $\begin{array}{l}\text { Heating } \\
\text { time } \\
\text { (hour) }\end{array}$ & Reference \\
\hline \multirow[t]{24}{*}{ Soil } & 0.2 & NR & 550 & 4 & Wright et al., 2008 \\
\hline & 0.5 & NR & 550,450 & 5 & Grewal et al., 1991 \\
\hline & 1 & NR & 800 & 4 & Sleutel et al., 2007 \\
\hline & 2 & NR & 550,1000 & $\begin{array}{l}0.4 \text { and } \\
1\end{array}$ & $\begin{array}{l}\text { Galle \& Runnels, } \\
1960\end{array}$ \\
\hline & 2 & Lindburg Model B2 & 550,1000 & 0.4 and 1 & Waugh \& Hill, 1960 \\
\hline & 3 & Nabertherm L9-C6 & 550 & 3 & De Vos et al., 2005 \\
\hline & 5 & $\begin{array}{l}\text { Thermolyne model } \\
\text { F-A1730 muffle } \\
\text { furnace }\end{array}$ & $300-600$ & $2-6$ & $\begin{array}{l}\text { Abella and Zimmer, } \\
2007\end{array}$ \\
\hline & 5 & NR & 500 & 4 & Szava-Kovats, 2009 \\
\hline & 5 & NR & 375 & 16 & $\begin{array}{l}\text { Bhatti \& Bauer, } \\
\text { 2002/ Kalra \& } \\
\text { Maynard, } 1991\end{array}$ \\
\hline & 5 & NR & 450,550 & 24 & Kasozi et al., 2009 \\
\hline & 8 & $\begin{array}{l}\text { Model } 550 \\
\text { Isotemp Series }\end{array}$ & 360 & 2 & Konen et al., 2002 \\
\hline & 15 & $\begin{array}{l}\text { Townson and } \\
\text { Mercer, Model M8- } \\
1200\end{array}$ & $150-900$ & 6 & Donkin, 1991 \\
\hline & 20 & NR & 450 & 16 & Lowther et al., 1990 \\
\hline & $5-10$ & NR & 450 & 4 & Brix, 2008 \\
\hline & $\begin{array}{l}0.88- \\
7.25\end{array}$ & $\begin{array}{l}\text { Thermolyne } \\
\text { FA } 1740\end{array}$ & 360 & 2 & Schulte et al., 1991 \\
\hline & $2-20$ & Heraus & 550 & 4 & $\begin{array}{l}\text { Christensen \& } \\
\text { Malmros, } 1982\end{array}$ \\
\hline & $5-10$ & NR & 550 & 3 & Houba et al., 1997 \\
\hline & NR & NR & 375,850 & & Ball, 1964 \\
\hline & NR & NR & 450 & 8 & Rawlins et al., 2008 \\
\hline & NR & NR & 550 & 3 & $\begin{array}{l}\text { Howard \& Howard, } \\
1990\end{array}$ \\
\hline & NR & NR & 430 & 24 & Davies, 1974 \\
\hline & NR & Exation $1200-30 \mathrm{~L}$ & $300-550$ & 2 & Salehi et al., 2011 \\
\hline & NR & NR & 450 & 8 & Craft et al., 1988 \\
\hline & NR & NR & 400 & 8 & $\begin{array}{l}\text { Ben-Dor \& Banin, } \\
1989\end{array}$ \\
\hline
\end{tabular}




\begin{tabular}{|c|c|c|c|c|c|}
\hline Material & $\begin{array}{l}\text { Sample } \\
\text { weight } \\
\text { (g) }\end{array}$ & Furnace type & $\begin{array}{l}\text { Temperature } \\
\left({ }^{\circ} \mathrm{C}\right)\end{array}$ & $\begin{array}{l}\text { Heating } \\
\text { time } \\
\text { (hour) }\end{array}$ & Reference \\
\hline \multirow{4}{*}{$\begin{array}{l}\text { Marine } \\
\text { deposits }\end{array}$} & NR & NR & 600 & 6 & Goldin, 1987 \\
\hline & NR & $N R$ & $350-440$ & $\begin{array}{l}\text { over } \\
\text { night }\end{array}$ & Schumacher, 1990 \\
\hline & NR & $\begin{array}{l}\text { Thermolyne muffle } \\
\text { furnace, Model } \\
\text { F-11730 }\end{array}$ & $350-600$ & 16 & Konare, 2010 \\
\hline & NR & $N R$ & 550 & NR & $\begin{array}{l}\text { Westman et al., } \\
2006\end{array}$ \\
\hline \multirow[t]{6}{*}{ Sediment } & 5 & Vulcan A-550 & $350-550$ & $16-32$ & $\begin{array}{l}\text { Frangipane et al., } \\
2009\end{array}$ \\
\hline & $1-5$ & $\begin{array}{l}\text { Isotemp } 750 \\
\text { Fisher Scientific }\end{array}$ & $500-1000$ & $1-20$ & Wang et al., 2011 \\
\hline & $2-10$ & $\begin{array}{l}\text { Thermolyne model } \\
62700\end{array}$ & $300-800$ & $1-10$ & Luczak et al., 1997 \\
\hline & $\begin{array}{l}0.4- \\
3.9\end{array}$ & $\begin{array}{l}\text { Nabertherm }{ }^{\circledR} \\
\text { Controller C6 }\end{array}$ & 530,550 & $\begin{array}{l}2-5,0.5- \\
64\end{array}$ & Heiri et al., 2001 \\
\hline & NR & $N R$ & 450 & 1 & $\begin{array}{l}\text { Barillé-Boyer et al., } \\
2003\end{array}$ \\
\hline & NR & NR & 450 & 16 & Sutherland, 1998 \\
\hline $\begin{array}{l}\text { Sedimen- } \\
\text { tary rocks }\end{array}$ & NR & NR & 550,1000 & 2 & Dean, 1974 \\
\hline $\begin{array}{l}\text { Clay } \\
\text { minerals } \\
\text { and carbo- } \\
\text { nates }\end{array}$ & NR & NR & 550 & 4 & Sun et al., 2009 \\
\hline $\begin{array}{l}\text { Compost, } \\
\text { biosolid, } \\
\text { mulch }\end{array}$ & 5 to 10 & $\begin{array}{l}\text { Isotemp } \\
\text { Programmable } \\
\text { Forced-Draft- } \\
\text { Furnace (Fisher } \\
\text { Scientific) }\end{array}$ & $150-700$ & $2-32$ & $\begin{array}{l}\text { Zhang \& Stoffella, } \\
2005\end{array}$ \\
\hline $\begin{array}{l}\text { Digested } \\
\text { mud }\end{array}$ & 2 & NR & $100-800$ & $1-8$ & $\begin{array}{l}\text { Mook \& Hoskin, } \\
1982\end{array}$ \\
\hline
\end{tabular}


Table S3. Results of the analysis of variance on the 212 loss-on-ignition observations. The oven types were CWF and AAF. The soil types of Set 1 were used. Four batches (twice sand and twice clay) were analysed per oven type. Each batch consisted of 32 crucibles ( 8 rows $\times 4$ columns, CWF) or 21 crucibles ( 7 rows $\times 3$ columns, AAF). The sample weight was $5 \mathrm{~g}$ and the ignition conditions were three hours at $550{ }^{\circ} \mathrm{C}$. Batch was used as random factor. $P$ and F-values (F) are presented.

\begin{tabular}{lllll}
\hline Source & df1 & df2 & $P$ & $F$ \\
\hline Oven & 1 & 4.21 & 0.001 & 62.1 \\
Soil & 1 & 4.18 & 0.000 & 7234 \\
oven x soil & 1 & 4.21 & 0.004 & 32.5 \\
batch (oven x soil) & 4 & 23.65 & 0.346 & 1.18 \\
row (oven) & 13 & 39 & 0.005 & 2.87 \\
column (oven) & 5 & 15 & 0.024 & 3.63 \\
batch x row (oven x soil) & 39 & 132 & 0.003 & 1.95 \\
batch x column (oven x soil) & 15 & 132 & 0.174 & 1.37 \\
\hline
\end{tabular}

Table S4. Results of the analysis of variance to test for differences in variation between the oven types CWF and AAF. The effect of furnace type on variation was assessed for the soil types of Set 1 in three analyses (standard deviation per row, column and batch). Four batches (twice sand and twice clay) were analysed per oven type. Each batch consisted of 32 crucibles ( 8 rows $x 4$ columns, CWF) or 21 crucibles ( 7 rows $x$ 3 columns, AAF). All F-tests had 1 and 4.0 degrees of freedom. $P$ and $F$-values (F) are presented.

\begin{tabular}{lllllll}
\hline Standard deviations per & oven & \multicolumn{3}{l}{ soil } & \multicolumn{3}{c}{ oven x soil } \\
\hline \multirow{3}{*}{ Row } & $P$ & $F$ & $P$ & $F$ & $P$ & $F$ \\
Column & 0.53 & 0.48 & 0.07 & 5.98 & 0.85 & 0.04 \\
Batch & 0.70 & 0.17 & 0.04 & 8.81 & 0.62 & 0.28 \\
\hline
\end{tabular}

Table S5. Curvature values of Equations (2) and (3).

Standard errors are given in brackets.

\begin{tabular}{ll}
\hline$a_{T}$ & $b_{T}$ \\
\hline$\alpha: 0.553(0.013)$ & $\delta: 0.011(0.005)$ \\
$\beta: 47(100)$ & $\varepsilon: 0.077(0.008)$ \\
$Y: 0.984(0.006)$ & $\kappa: 0.027(0.006)$ \\
& $\lambda: 482.85(9.21)$ \\
$R^{2}: 0.69$ & $R^{2}: 0.95$ \\
$F: 23.58$ & $F: 123$ \\
\hline
\end{tabular}




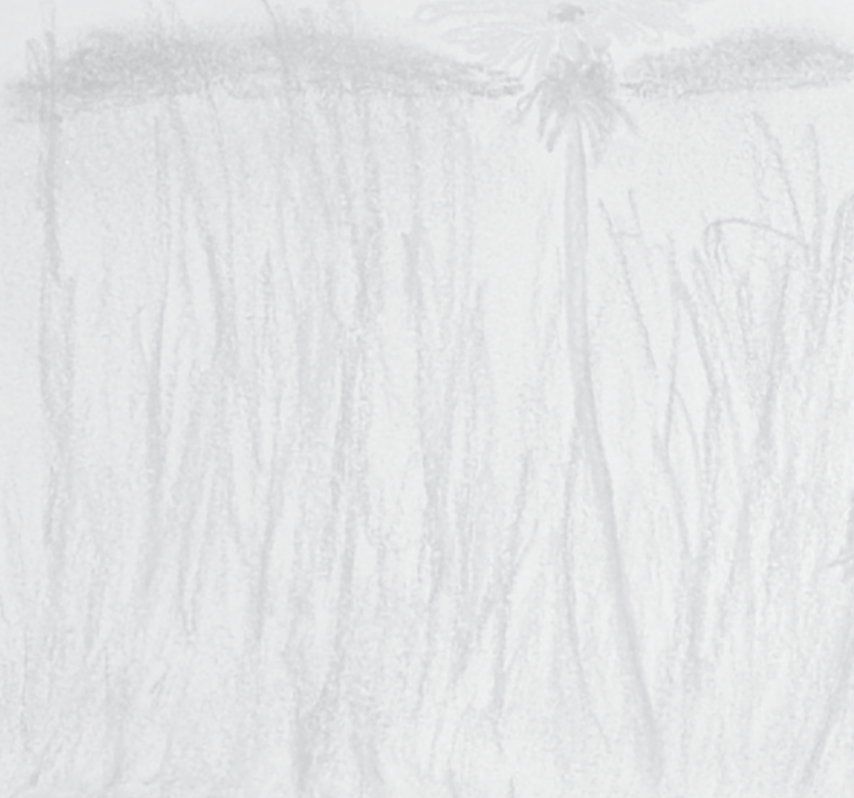

nest

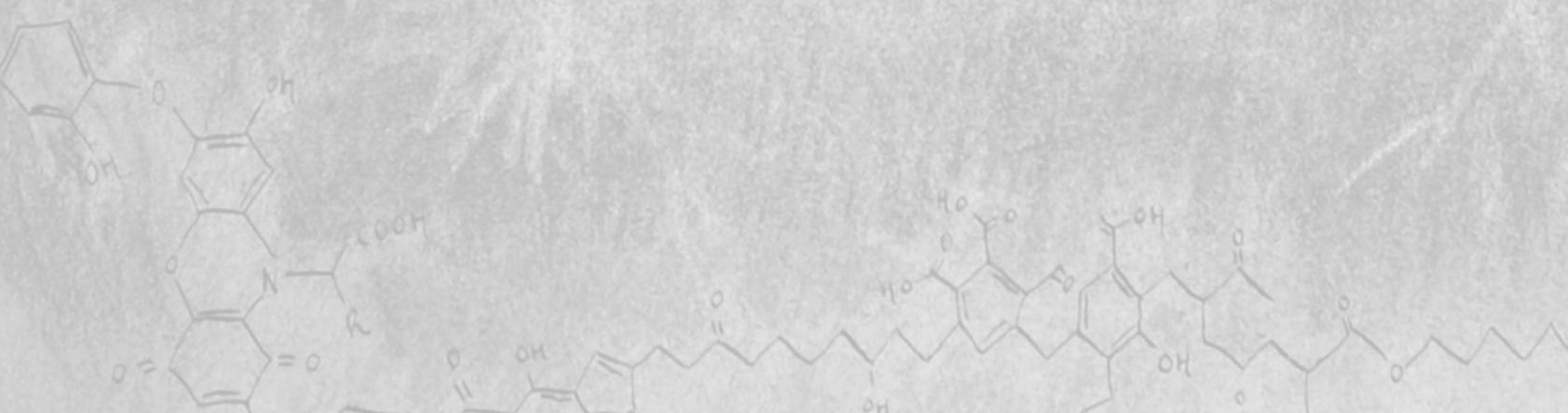




\section{Chapter 3. An evaluation of the loss-on-ignition method for determining the soil organic matter content of calcareous soils}

Published as: Hoogsteen, M. J. J., Lantinga, E. A., Bakker, E. J., \& Tittonell, P. A. (2018). An evaluation of the loss-on-ignition method for determining the soil organic matter content of calcareous soils. Communications in soil science and plant analysis, 49 (13), 1541-1552. 


\section{Summary}

The loss-on-ignition (LOI) method is widely employed for measuring the organic matter (OM) content of soil samples. There is a risk of carbonate losses when calcareous soil samples are analysed through LOI, but this has never been investigated in detail. Moreover, a worldwide standard protocol for determining the carbonate content of soils is not available. The aims of this study were (i) to evaluate two commonly employed carbonate analysis procedures using calcareous and non-calcareous soil samples: the gravimetric method with (GMF) and without (GM) the addition of the antioxidant $\mathrm{FeCl}_{2}$ and the acetic acid dissolution procedure (AAD); (ii) to evaluate the effect of ignition temperature on losses of pure calcite, calcite-quartz and calcareous soil samples. We found that the average apparent carbonate content of the non-calcareous soils was greatest for the GMF method followed by the AAD procedure. The GM method showed smallest apparent carbonate contents. For the calcite-quartz sand mixture, ignition losses started at $600{ }^{\circ} \mathrm{C}$ and increased with temperature in a sigmoidal way. LOI values stabilized at 750 ${ }^{\circ} \mathrm{C}$ when $80 \%$ of the $\mathrm{CO}_{2}$ was released. We recommend the $\mathrm{GM}$ procedure for carbonate analysis because the apparent carbonate contents of the noncalcareous soil samples were smallest. Furthermore, we recommend an LOI temperature of $550{ }^{\circ} \mathrm{C}$ because at this ignition temperature $99.98 \%$ of the total calcite fraction remains in the soil samples. 


\section{Introduction}

The loss-on-ignition method ( $\mathrm{LOI}$ ) is widely used for estimating organic matter in soils and lake sediments. The weight losses observed at temperatures above $400{ }^{\circ} \mathrm{C}$ can be mostly ascribed to the destruction of soil organic matter (SOM) and structural water losses from clay minerals (Hoogsteen et al., 2015). Currently this method cannot be recommended for analysing SOM in calcareous soils, as necessary ignition temperatures should be equal or higher than $550{ }^{\circ} \mathrm{C}$ to assure complete oxidation of SOM. However, the temperature at which carbonates start to decompose is between 500 and $600{ }^{\circ} \mathrm{C}$ (Kasselouri et al., 1995; Kasozi et al., 2009). This will result in overestimations of the actual SOM because the measured weight losses are then partly due to the decomposition of carbonates. Multiplication factors for the LOI method to correct for weight losses of carbonates do not exist. Samples containing calcite are usually pre-treated with an $\mathrm{HCl}$-solution so that most of the calcareous material is removed prior to SOM analysis (Konen et al., 2002). A drawback of this method is that dolomite $\left(\mathrm{CaMg}\left(\mathrm{CO}_{3}\right)_{2}\right)$ has an incomplete reaction with acid, hence not all carbonates are removed. Furthermore, other components such as clay minerals and SOM can be dissolved in addition to carbonates, leading to errors in SOM determination (Dean, 1974).

If the carbonate content is known, corrections can be made for the amount of $\mathrm{CO}_{2}$ that was released during ignition. Kasozi et al., (2009) showed using thermogravimetry that $\mathrm{CO}_{2}$ losses are strongly temperature dependent and complete decomposition is attained at temperatures in excess of $800{ }^{\circ} \mathrm{C}$ for a pure calcite $\left(\mathrm{CaCO}_{3}\right)$ sample. Previously we found that ignition losses significantly increased with increasing soil sample weight (cf. Hoogsteen et al., 2015). We questioned if the same holds for losses of carbonates: sample weights used for thermogravimetric analysis are in the order of 10 $\mathrm{mg}$. As sample weights used for LOI measurements are about 1000 times larger, ignition losses of carbonates might be much higher from soil samples analysed through this method.

Calcite is the dominant carbonate type that occurs in Dutch soils. Other carbonates include dolomite $\left(\mathrm{CaMg}\left(\mathrm{CO}_{3}\right)_{2}\right)$ and in minor quantities magnesite $\left(\mathrm{MgCO}_{3}\right)$, siderite $\left(\mathrm{FeCO}_{3}\right)$ and aragonite $\left(\mathrm{CaCO}_{3}\right.$, a polymorph of calcite). The crystal system of aragonite is orthorhombic and aragonite is the main component of shells (Van der Marel, 1950; Breeuwsma \& Drijver-De Haas, 1987). Aragonite changes to calcite at temperatures between 380 and $470{ }^{\circ} \mathrm{C}$ (Yoshioka \& Kitano, 1985). Siderite occurs mostly in peat soils and stream valleys (De Bakker, 1987) and dolomite in ancient sedimentary rocks of marine origin (Winterswijk, located in the Eastern part of the Netherlands). 
Dolomite is also found in the river clay soils of the river Rhine but there it is only $6 \%$ of the total carbonate fraction (Van der Marel, 1950), whereas $94 \%$ of the carbonate fraction is calcite or aragonite.

We also showed in Hoogsteen et al. (2015) that multiple linear regression was successful in deriving temperature dependent clay correction factors for a diverse range of mineral soils, and proposed the following equation:

$\mathrm{SOC}=a_{\mathrm{T}} \times\left(\mathrm{LOI}_{\mathrm{T}}-b_{\mathrm{T}} \times \mathrm{C}\right)$,

Where, $\mathrm{a}_{\mathrm{T}}$ is the SOC content of SOM $\left(\mathrm{kg} \mathrm{kg}^{-1}\right), \mathrm{b}_{\mathrm{T}}$ is the clay correction factor for structural water loss $\left(\mathrm{kg} \mathrm{kg}^{-1}\right), \mathrm{C}$ is the clay content (\%) and the suffix $\mathrm{T}$ is the ignition temperature. Here, we aim to expand this equation with a calcite correction factor $\left(c_{T}\right)$ to correct for the mass loss of $\mathrm{CO}_{2}$, for which the concentration of carbonates in the soil sample should be known a priori. A wide range of protocols exists for determining carbonates in soils based on acid dissolution (NB: this should not be confused with the addition of acids to remove carbonates prior to conducting the $\mathrm{LOI}$ analysis as described above).

Gravimetric and $\mathrm{pH}$ methods are commonly used to determine the carbonate content of soil samples. Gravimetric carbonate analysis procedures attain weight loss through acid addition whether or not with ferrous compounds such as $\mathrm{FeCl}_{2}$ (Allison \& Moodie, 1965) or $\mathrm{FeSO}_{4}$ (Rabenhorst, 1988) which are added as antioxidants. The measured weight loss is $\mathrm{CO}_{2}$ and expressed as calcite equivalents by using a multiplication factor of $1 / 0.44\left(\mathrm{CO}_{2}\right.$ is $44 \%$ of the mass of $\mathrm{CaCO}_{3}$ ). Antioxidants are thought to protect the organic matter fraction from decomposition caused by the added acid. However, evidence of this was not presented in previous studies (Nelson, 1982; Loeppert \& Suarez, 1996). The acetic acid dissolution method is a procedure based on the reaction between acetic acid and $\mathrm{CaCO}_{3}$. Only a $\mathrm{pH}$ meter is needed and the $\mathrm{pH}$ is a proxy for the carbonate content. A calibration curve is made with pure calcite to convert measured $\mathrm{pH}$ values to carbonate contents. We chose to compare both methods, gravimetric and $\mathrm{pH}$, because of their simplicity.

Sources of error for both methods are the dissolution of components other than $\mathrm{CaCO}_{3}$ such as SOM and/ or clay minerals (Loeppert et al., 1984; Loeppert \& Suarez, 1996). Moreover, the acetic acid dissolution method suffers from inaccuracies due to the consumption of protons by the soil exchange complex. This results in an increase in $\mathrm{pH}$ and thus overestimations of the carbonate content.

The objectives of this study were to (i) compare the gravimetric method $(\mathrm{HCl}$ with and without the addition of $\mathrm{FeCl}_{2}$ and acetic acid dissolution method for estimating the carbonate content of soil samples and assess if there was an effect of the addition of $\mathrm{FeCl}_{2}$ on the protection of $\mathrm{SOM}$; (ii) assess 
the effect of sample weight on ignition losses of pure calcite samples; (iii) quantify the decomposition losses of calcite mixed with quartz sand for temperatures ranging from $350{ }^{\circ} \mathrm{C}$ to $800{ }^{\circ} \mathrm{C}$; (iv) develop temperature specific multiplication factors for mineral calcareous soils to correct for decomposition of carbonates when analysing SOM through LOI.

We hypothesize that (i) overestimations of carbonate content are largest for the gravimetric method without the addition of $\mathrm{FeCl}_{2}$ because the acid is stronger (4 $\mathrm{M}$ hydrochloric vs. $0.4 \mathrm{M}$ acetic acid). The addition of $\mathrm{FeCl}_{2}$ to $\mathrm{HCl}$ will result in lower apparent carbonate values because $\mathrm{FeCl}_{2}$ acts as an antioxidant (as suggested by Nelson, (1982); Objective 1); (ii) ignition losses of pure calcite increase with sample weight in an exponential way (Objective 2); (iii) a sigmoidal relation exists between temperature and decomposition losses of carbonates between 350 and $800{ }^{\circ} \mathrm{C}$ for the LOI method. Carbonatation is completed at $800{ }^{\circ} \mathrm{C}$ (as shown by Kasozi et al. (2009) using thermogravity; Objective 3).

\section{Materials and methods}

\subsection{Site description and sampling procedure}

For this study the same 24 bulk soil samples were used as previously described by Hoogsteen et al., (2015). The samples were collected from soils (0-30 cm layer) across the Netherlands under grassland or arable farming. The clay content as determined by the sieve-pipette method was known prior to the study and ranged from 1-50\%. Seven out of 24 samples were classified previously as calcareous. One calcareous sample was removed because the reported clay content was erroneous (clay contents were determined before the start of the study). Thus, we remained with 23 samples of which six samples contained carbonates (see Table 1 for specifications of the samples that were used for each experiment). The clay content of the calcareous soil samples ranged from 19 to $37 \%$. Half of the soils samples contained fluvial clay, the other half contained marine clay. In addition, the soil of a grassland experiment in Wageningen (the Netherlands) was sampled. The clay content was $25 \%$ and the soil contained small amounts of carbonates originating from river shells. So the total number of calcareous soil samples used in this study was seven (six from agricultural fields and one from a field experiment). Quartz sand was used as a control, containing no organic matter and no carbonates. In this study we decided to include also the 17 non-calcareous samples because we wanted to quantify the side-effects of clay and SOM for the carbonate analyses procedures. Below we describe the experiments that we conducted and the samples that were used corresponding to each objective. An overview of all experiments is presented in Table 1. 
Table 1. Overview of the setup of each experiment and corresponding objectives. LOI = loss-on-ignition. $\mathrm{WCO}=$ wet chemical oxidation. $\mathrm{NA}=$ not applicable.

\begin{tabular}{|c|c|c|c|c|}
\hline Experiment & $\begin{array}{l}\text { No. and type } \\
\text { of samples }\end{array}$ & $\begin{array}{l}\text { Analytical } \\
\text { methods }\end{array}$ & $\begin{array}{l}\text { No. of } \\
\text { replicates }\end{array}$ & $\begin{array}{l}\text { Statistical } \\
\text { methods and } \\
\text { type of function }\end{array}$ \\
\hline $\begin{array}{l}\text { 1.Carbonate } \\
\text { analysis } \\
\text { procedures }\end{array}$ & $\begin{array}{l}17 \text { Non- } \\
\text { carbonatic and } \\
7 \text { carbonatic } \\
\text { bulk soil } \\
\text { samples }\end{array}$ & $\begin{array}{l}\text { Gravimetric: } \\
\mathrm{HCl}, \mathrm{HCl}+ \\
\mathrm{FeCl}_{2} \\
\text { Acetic acid } \\
\text { dissolution }\end{array}$ & 1 (NA) & $\begin{array}{l}\text { Regression } \\
\text { analysis, linear } \\
\text { and logarithmic } \\
\text { equations }\end{array}$ \\
\hline $\begin{array}{l}\text { 2. Effect of } \\
\text { sample weight } \\
\text { on weight } \\
\text { losses of pure } \\
\text { calcite }\end{array}$ & Calcite & $\begin{array}{l}\text { LOI, } 3 \text { hours, } \\
650{ }^{\circ} \mathrm{C} \text {. Sample } \\
\text { weights (g): } 0.1 \text {; } \\
0.2 ; 0.3 ; 0.5 ; \\
0.75 ; 1\end{array}$ & $3(2)$ & $\begin{array}{l}\text { Regression } \\
\text { analysis, power } \\
\text { function }\end{array}$ \\
\hline $\begin{array}{l}\text { 3. Effect of } \\
\text { temperature on } \\
\text { weight losses } \\
\text { of calcite-quartz } \\
\text { sand mixtures }\end{array}$ & $\begin{array}{l}\text { Calcite, quartz } \\
\text { sand } \\
\text { (ratio } 1: 11.5 \text { ) }\end{array}$ & $\begin{array}{l}\text { LOI, } 3 \text { hours, } \\
\text { temperatures in } \\
{ }^{\circ} \mathrm{C}:, 550,600 \text {, } \\
650,700,750, \\
800\end{array}$ & $\begin{array}{l}1(21(550-650 \\
\left.{ }^{\circ} \mathrm{C}\right) \text { and } 13(700- \\
\left.\left.800^{\circ} \mathrm{C}\right)\right)^{1}\end{array}$ & $\begin{array}{l}\text { Regression } \\
\text { analysis, } \\
\text { Gompertzian } \\
\text { function }\end{array}$ \\
\hline \multirow[t]{2}{*}{$\begin{array}{l}\text { 4. Temperature } \\
\text { specific calcite } \\
\text { factors }\end{array}$} & $\begin{array}{l}7 \text { carbonatic } \\
\text { soil samples, } \\
\text { quartz sand }\end{array}$ & $\begin{array}{l}\text { LOI, } 3 \text { hours, } \\
\text { temperatures } \\
\text { in }{ }^{\circ} \mathrm{C}: 350,400 \text {, } \\
450,500,550, \\
600,650 . \\
\text { Sample } \\
\text { weight }=20 \mathrm{~g} .\end{array}$ & $3(3)$ & $\begin{array}{l}\text { Regression } \\
\text { analysis, multiple } \\
\text { linear regression, } \\
\text { exponential and } \\
\text { logistic equations }\end{array}$ \\
\hline & & WCO & $3(3)$ & NA \\
\hline
\end{tabular}

1 The number of pseudo replicates is given in between brackets per replicate. Each replicate was placed in a different batch.

Experiment 1 A comparison of the gravimetric method and acetic acid dissolution procedure for assessing carbonates in soils (Objective 1) We followed two procedures of Loeppert \& Suarez (1996) which were (i) the carbonate analysis method using hydrochloric acid with and without the addition of $\mathrm{FeCl}_{2}$, and (ii) the acetic acid dissolution method. The molarity and amount of the added $\mathrm{HCl}$ solution was adjusted from $3 \mathrm{M}$ to $4 \mathrm{M}$ based on the standardized protocols of Wageningen UR (Houba et al., (1997). For each method we used all 24 bulk soils, we took 3 subsamples and the sample weights varied between 2.4 and $2.6 \mathrm{~g}$. Quartz sand was used as a control. Each sample was put into a polypropylene vial with a pierced top to assure that escape of $\mathrm{CO}_{2}$ would be possible.

We prepared three solutions: 
Method 1a: $4 \mathrm{M} \mathrm{HCl}, 7 \mathrm{ml}$ per vial

Method $1 \mathrm{~b}: 4 \mathrm{M} \mathrm{HCl}$ and $\mathrm{FeCl}_{2}(3 \%), 7 \mathrm{ml}$ per vial

Method2: $0.4 \mathrm{M} \mathrm{CH}_{3} \mathrm{COOH}, 25 \mathrm{ml}$ per vial

We abbreviate the gravimetric method with $\mathrm{FeCl}_{2}$ to $\mathrm{GMF}$ and without $\mathrm{FeCl}_{2}$ to GM. The acetic acid dissolution procedure is abbreviated as AAD. The total weight within the vial was recorded by summing up the soil weight and the added acid. Although $\mathrm{CO}_{2}$ started to escape from the carbonatic soil samples as soon as the acid was added, this proved to be the most accurate way of recording the weight. This was also reported by Ashworth (1997). Weighing the acid before in a beaker resulted in inaccuracies as some acid remained in the beaker after transfer to the vial. All samples were swirled on an orbital shaker (Gerhardt Laboshake LS 5, Königswinter, Germany) for 45 minutes (Methods $1 \mathrm{a}$ and $1 \mathrm{~b}$ ) and 16 hours (Method 2) at a speed of 95 rotations per minute. The total carbonate content was expressed as $\mathrm{CaCO}_{3}$ equivalents. For the AAD method a standard curve was prepared with calcite (see Loeppert \& Suarez (1996) for details). All samples were corrected with the weight losses of the quartz sand samples. The losses of quartz sand are volatilization losses of the added acids because quartz sand does neither contain clay nor SOM.

Samples were measured singularly and regression analysis was conducted to compare the analysis procedures. Furthermore, we used the data on SOM and clay contents of the 17 non-calcareous soils (Hoogsteen et al., 2015) to determine if there was a correlation between SOM, clay content and apparent weight losses from carbonates which were in fact caused by interactions of $\mathrm{H}^{+}$with clay and SOM. To quantify the effect of the soil exchange complex we subtracted the carbonate values as determined with GM from the carbonate values as determined by the AAD procedure. The GM procedure does not suffer from inaccuracies arising through the consumption of protons because the $\mathrm{pH}$ is not used as a proxy for the carbonate content: interactions can occur between protons and clay/ SOM but this will not lead to higher losses of $\mathrm{CO}_{2}$ for the GM and GMF procedures as in case of the AAD procedure (see Carroll \& Starkey (1971) for the effects of hydrochloric and acetic acid on dissolution of clay minerals). Data was analysed with regression using Table Curve 2D and Table Curve 3D, two curve fitting software packages.

Experiment 2 The effect of sample weight on pure calcite losses (Objective 2)

The effect of sample weight was assessed on weight loss of pure calcite with the LOI method. The AAF furnace was used. Six different sample weights were used: $0.1 \mathrm{~g}, 0.2 \mathrm{~g}, 0.3,0.5 \mathrm{~g}, 0.75 \mathrm{~g}$ and $1.0 \mathrm{~g}$. These weights were chosen because they are commonly found in Dutch agricultural soils, resembling carbonate contents ranging from 1 to $5 \%$ in samples with a weight of $20 \mathrm{~g}$ (or from 2 to $8 \%$ in case sample weights of $12.5 \mathrm{~g}$ were used as in Experiment 3). All sample weights were analysed in triplicate (three batches) with two 
pseudo replicates per batch. Crucibles were placed in two rows from the left to the right of the furnace (see the supplementary material, Table S2, for the placement of the crucibles). The ignition duration was three hours and the temperature was set at $650^{\circ} \mathrm{C}$. After 1.5 hours the tray was turned $180^{\circ}$ and put back in the furnace.

Experiment 3 The effect of temperature on weight loss of calcite samples mixed with quartz sand (Objective 3)

Quartz sand was mixed with pure calcite (Sigma, C6763) to resemble natural soil samples. Quartz sand was chosen because it does neither contain SOM nor carbonates and only re-arranges structurally when exposed to temperatures between 400 and $800^{\circ} \mathrm{C}$ (Wahl et al., 1961). The following ratio was used: $1 \mathrm{~g}$ calcite: $11.5 \mathrm{~g}$ quartz sand, so each sample had a carbonate content of $8 \%$. Several authors reported that the average carbonate content of Dutch agricultural calcareous soils is around this value: the carbonate content of a number of Dutch sea and river clay soils averaged in the 1950's 8\% (Van der Marel, 1950). More recent data could only be obtained from Flevoland (calcareous young sea clay soils in the centre of the Netherlands). The median of the carbonate content was 7\% in 2011 (Reijneveld, 2013).

Both quartz sand and calcite were mixed in a glass beaker (volume $=1000$ $\mathrm{ml}$ ) and the mixture was stirred manually for five minutes to obtain an even spread of calcite throughout the sample. Each crucible was filled with 12.5 $\mathrm{g}$ of the mixture. We used $12.5 \mathrm{~g}$ instead of $20 \mathrm{~g}$ as recommended in the previous study because it was not possible to mix larger volumes of soil in the glass beaker. The effect of temperature on ignition loss was assessed for temperatures ranging from $550{ }^{\circ} \mathrm{C}$ to $800{ }^{\circ} \mathrm{C}$. At $800{ }^{\circ} \mathrm{C}$ the process of carbonatation is completed (Kasozi et al., 2009). Therefore this temperature was chosen as the highest temperature. For the temperatures $550-650{ }^{\circ} \mathrm{C}$, glass crucibles were used. Per batch 21 crucibles were filled. These crucibles melted at temperatures higher than $650^{\circ} \mathrm{C}$. Therefore, porcelain crucibles were used for the treatments between $700{ }^{\circ} \mathrm{C}$ and $800^{\circ} \mathrm{C}$. The porcelain crucibles had a larger diameter as compared to the glass ones and therefore only 13 crucibles fitted in the furnace. The weight loss was recorded and expressed as a percentage. We conducted regression analysis to quantify the effect of temperature on calcite losses. A Gompertzian curve was used to express $\mathrm{CaCO}_{3}$ losses as a function of furnace temperature.

$$
\mathrm{CaCO}_{3}=\alpha+\beta e^{-e^{-\gamma(T-\delta)}}
$$

Where $\mathrm{CaCO}_{3}$ is the fraction of weight loss from the $\mathrm{CaCO}_{3}$ concentration present in the sample and $T$ is the furnace temperature in ${ }^{\circ} \mathrm{C}$. The term $\alpha$ refers to the maximum weight loss. $\mathrm{CaCO}_{3}$ decomposes to $\mathrm{CaO}$ and $\mathrm{CO}_{2}$ where $\mathrm{CO}_{2}$ comprises $44 \%$ of the weight of a $\mathrm{CaCO}_{3}$ molecule. Thus, in case complete decomposition is attained, only $\mathrm{CaO}$ remains in the sample, 
which is $56 \%$ of the weight of the total $\mathrm{CaCO}_{3}$ mass. Each sample contained $1 \mathrm{~g}$ pure calcite, so $0.44 \mathrm{~g}$ per $12.5 \mathrm{~g}$ is the maximum attainable amount of weight loss. This is $0.44 / 12.5 * 100=3.52 \%$. $\beta$ and $y$ are both curvature parameters, representing the asymptotes following from the optimization. $\delta$ is the temperature value for the point of inflexion.

We also compared the weight loss of the $650{ }^{\circ} \mathrm{C}$ treatment with the results obtained in Experiment 2 (sample weight $=1 \mathrm{~g}$ ) to test if there was an effect of quartz sand on absolute weight loss of calcite. A t-test was conducted.

Experiment 4 Development of temperature specific calcite multiplication factors for the LOI method (Objective 4)

The seven calcareous bulk soil samples were used (see the section 'site description and sampling procedure' above). All samples were analysed with loss-on-ignition and an adapted version of the wet-chemical oxidation procedure with a sulfochromic acid (see Box S3 of the supplementary material of Hoogsteen et al. (2015)). The sample weight for LOI was $20 \mathrm{~g}$ and the temperatures ranged from 350 to $650^{\circ} \mathrm{C}$. We decided to assess the range $350-500^{\circ} \mathrm{C}$, despite the fact that decomposition of calcite does not occur at this temperature range. We wanted to evaluate if the clay correction factors in the previous study would have the same value as the clay correction factors following from the multiple linear regression with the calcareous soil samples alone. We did not chose higher temperatures than $650{ }^{\circ} \mathrm{C}$ because only 13 porcelain crucibles would fit in one batch at temperatures in excess of $650^{\circ} \mathrm{C}$. This would interfere with the design of the experiment. The ignition duration was three hours and the tray was turned halfway through the ignition period. Each sample was analysed thrice. Temperature specific calcite multiplication factors were derived using the following equation:

SOC $=a_{T} \times\left(\right.$ LOI- $\left.b_{T} \times C-c_{T} \times D\right)$

In equation $2, a_{T}$ is the conversion factor from SOM to SOC and $\mathrm{b}_{\mathrm{T}}$ and $\mathrm{c}_{\mathrm{T}}$ are the clay and $\mathrm{CaCO}_{3}$ multiplication factors, respectively. All are expressed in $\mathrm{kg} \mathrm{kg}^{-1}$. C is the clay content (\%) and D is the carbonate content (\%). The parameter values which followed from the optimization for $a_{T}$ and $b_{T}$ were compared with the values that were obtained in the previous part of the study. The clay contents were determined with the sieve-pipette method and the $\mathrm{CaCO}_{3}$ content was determined with the gravimetric method using $\mathrm{HCl}$ as a solvent. This carbonate analysis procedure was chosen because the consumption of protons by the soil exchange complexwould not interfere with the $\mathrm{CaCO}_{3}$ measurements. A strong correlation between 'apparent' carbonate content (the measured carbonate content of non-calcareous samples) and clay content was observed as a result of Experiment 1 (Figure 1). Moreover, Carroll \& Starkey (1971) reported that the only small quantities of silica were removed by the addition of $40-50 \mathrm{ml}, 6 \mathrm{M} \mathrm{HCl}$ to a range of clay minerals. 


\section{Results}

Experiment 1 Carbonate analysis procedures (Objective 1)

All samples (calcareous and non-calcareous soils) were used in this experiment. $\mathrm{CaCO}_{3}$ values were highest for the gravimetric method with the addition of $\mathrm{FeCl}_{2}$ (GMF; 2.04\%, SEM=0.32) and lowest for the gravimetric method without $\mathrm{FeCl}_{2}(0.63 \%, \mathrm{SEM}=0.23) . \mathrm{CaCO}_{3}$ values as determined with the acetic acid dissolution method (AAD) were on average 1.04\% (SEM=0.32). In Table 2 average values are shown for the calcareous and non-calcareous soils separately. Although the non-calcareous soils did not contain carbonates, the measured $\mathrm{CaCO}_{3}$ contents are much higher for the GMF method as compared to the other methods $(1.40 \%$ as compared to $0.11 \%(G M)$ and $0.71 \%(A A D))$.

Table 2. Measured carbonate values of calcareous and non-calcareous soils analysed by the gravimetric method and the acetic acid dissolution procedure. The clay content ranged from $19-37 \%$ for the calcareous soils $(n=7)$ and from $1-50 \%$ for the non-calcareous soils $(n=17)$. Standard errors of the mean are given between brackets. The following abbreviations are used $\mathrm{GM}=$ gravimetric method using $\mathrm{HCl}, \mathrm{GMF}=$ gravimetric method using $\mathrm{HCl}$ with the addition of $\mathrm{FeCl}_{2} \cdot \mathrm{AAD}=$ acetic acid dissolution procedure. All values are expressed as $\mathrm{g} \mathrm{CaCO}_{3}$ per $100 \mathrm{~g}$ dry soil.

\begin{tabular}{llll}
\hline & GM & GMF & AAD \\
\hline Non-calcareous soils & $0.11(0.02)$ & $1.40(0.09)$ & $0.71(0.07)$ \\
Calcareous soils & $1.88(0.57)$ & $3.60(0.93)$ & $3.10(0.90)$ \\
\hline
\end{tabular}

Additionally, the effects of clay and SOM content were assessed on weight losses of the 17 non-calcareous soil samples. In the following paragraphs, "the apparent $\mathrm{CaCO}_{3}$ content" is the measured weight loss expressed in $\mathrm{CaCO}_{3}$ equivalents, which is caused by the decomposition of other components than $\mathrm{CaCO}_{3}$ (clay and SOM and/ or consumption of protons by the soil exchange complex). No significant correlations were observed between the apparent $\mathrm{CaCO}_{3}$ content as determined by GM and GMF with clay content (not shown). The same holds for both methods for the relation between the apparent $\mathrm{CaCO}_{3}$ content and SOM.

A strong positive correlation was observed between the apparent $\mathrm{CaCO}_{3}$ content as determined by the AAD method and the clay content (Figure 1). For this method we also assessed the relationship between apparent $\mathrm{CaCO}_{3^{\prime}}$ SOM and clay content and found a significant model. All details concerning the equation are given in the supplementary material, Box S1 and Table S1. 
Experiment 2 The effect of sample weight on ignition losses of pure calcite

Ignition losses of pure calcite samples decreased with increasing sample weight in an exponential way (Figure 2). A sample weight of $0.1 \mathrm{~g}$ resulted in a weight loss of $18 \%(S E M=2.2)$, while losses of samples of $1 \mathrm{~g}$ were on average $4.4 \%($ SEM $=0.4)$.

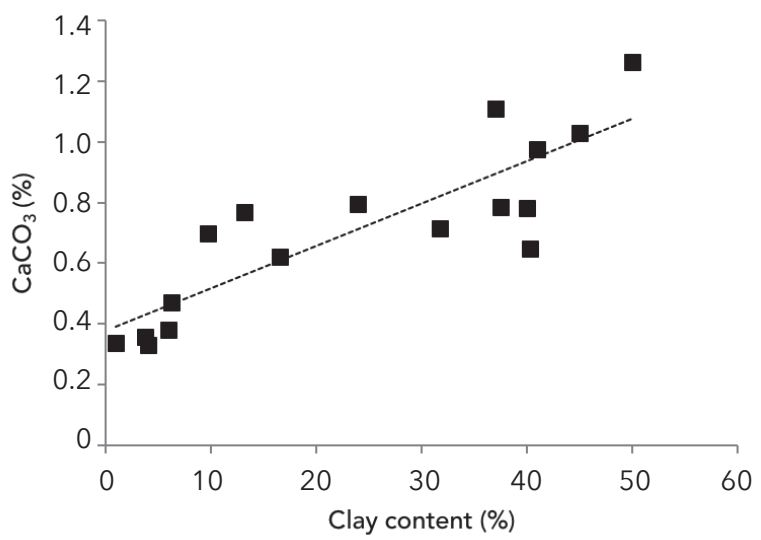

Figure 1. The effect of clay content on the apparent $\mathrm{CaCO}_{3}$ content of 17 non-calcareous samples. The apparent carbonate content (the measured weight loss expressed in $\mathrm{CaCO}_{3}$ equivalents) was determined with the acetic acid dissolution method.

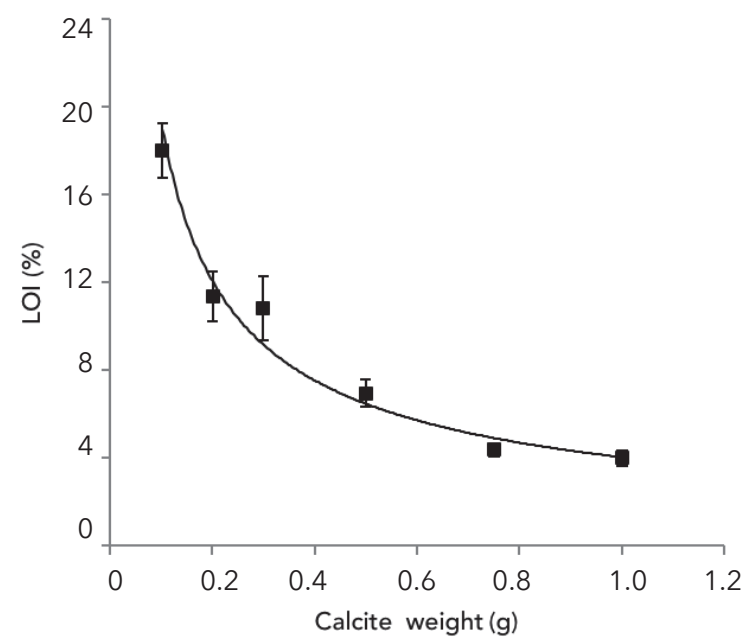

Figure2. Relationshipbetween sampleweightof purecalcitesamplesandignitionlosses. The ignition temperature was setat $650^{\circ} \mathrm{C}$ and the duration was three hours. The tray was turned halfway through. All sample weights were analyzed in triplicate (three batches) with two pseudo replicates per batch. Standard errors of the mean (SEM) are given. 
Absolute losses of pure calcite samples $(1 \mathrm{~g})$ were significantly lower $(P=0.004)$ as compared to losses of the calcite quartz sand mixture $(1 \mathrm{~g}$ calcite: $11.5 \mathrm{~g}$ sand). The pure calcite samples lost on average $0.05 \mathrm{~g}(\mathrm{SEM}=0.002)$ while calcite mixed with quartz sand lost on average $0.06 \mathrm{~g}(\mathrm{SEM}=0.002)$.

Experiment 3 The effect of temperature on weight loss of calcite samples mixed with quartz sand

LOI-values increased in a sigmoidal way with temperature (Figure 3 ). The Gompertzian equation fitted to this relationship yielded an $R^{2}$-value of 0.99 . Its curvature parameters and standard errors are presented in Table 3 . The sample contained $8 \%$ calcite and a maximum of $44 \%$ of the calcite mass could be lost during ignition as $\mathrm{CO}_{2}$ (44\% of the weight of $\mathrm{CaCO}_{3}$ comprises $\mathrm{CO}_{2}$ ). Hence, the maximum attainable LOl-value for the calcite-quartz sand samples of $12.5 \mathrm{~g}$ was $0.08 \times 0.44 \times 100=3.52 \%$. The upper horizontal asymptote (parameter $\alpha$ ) had a value of $2.80 \%$, so complete decomposition was not attained. Only $80 \%$ of the calcite was decomposed $(2.80 / 3.52=0.8)$ in a period of three hours at an ignition temperature of $800{ }^{\circ} \mathrm{C}$.

Table 3. Curvature values of Equation $1\left(\mathrm{CaCO}_{3}=\alpha+\beta e^{-e^{-\gamma(T-\delta)}}\right)$. Standard errors are given in brackets. $\mathrm{CaCO}_{3}$ is expressed as a percentage ( $100 \mathrm{~g}^{-1}$ dry calcite) and T is the temperature in ${ }^{\circ} \mathrm{C} . R^{2}=0.99, \mathrm{~F}=5644$. The standard error of observations was estimated to be 0.09 .

\begin{tabular}{ll}
\hline Parameter & Value \\
\hline$\alpha$ & $2.80(0.02)$ \\
$\beta$ & $-2.77(0.03)$ \\
$\gamma$ & $-0.03(0.00)$ \\
$\delta$ & $707(0.95)$ \\
\hline
\end{tabular}

Experiment 4 Temperature specific multiplication factors of calcite losses for the LOI method

Temperature specific multiplication factors of $a_{T}$ and $b_{T}$ are shown in Figure 4. The parameters of the fitted equations are presented in the Table 4. $a_{T}$ decreased in an exponential way from 0.60 at $350{ }^{\circ} \mathrm{C}$ to 0.50 at $450{ }^{\circ} \mathrm{C}$. From $450{ }^{\circ} \mathrm{C}$ onwards, $\mathrm{a}_{\mathrm{T}}$ remained stable. The on-set temperature of structural water losses from clay elements was $400^{\circ} \mathrm{C}$ and $\mathrm{b}_{\mathrm{T}}$ increased in a sigmoidal way from $0.01\left(400^{\circ} \mathrm{C}\right)$ to $0.09\left(650^{\circ} \mathrm{C}\right)$. Parameter $\mathrm{C}_{\mathrm{T}}$ was constrained $\left(\mathrm{c}_{\mathrm{T}} \geq 0\right)$ because the unconstrained multiple linear regressions yielded negative values for $\mathrm{c}_{\mathrm{T}}$ (all temperatures) leading to an apparent increase in ignition values. $\mathrm{C}_{\mathrm{T}}$ had a value of 0.00 between $350{ }^{\circ} \mathrm{C}$ and $600^{\circ} \mathrm{C}$ and at $650{ }^{\circ} \mathrm{C}, \mathrm{C}_{\mathrm{T}}$ was 0.04 (SEM=0.03). Because decomposition of $\mathrm{CaCO}_{3}$ was only visible at $650{ }^{\circ} \mathrm{C}$, the effect of temperature on $\mathrm{C}_{\mathrm{T}}$ is not shown. 


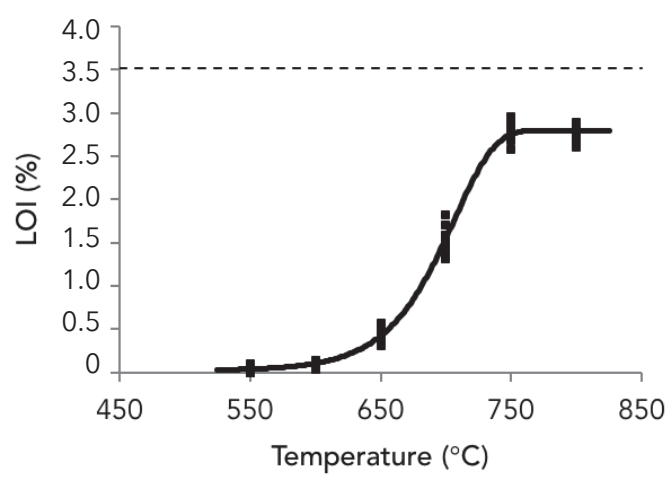

Figure 3. The effect of ignition temperature on weight loss of the quartz sand-calcite mixture. LOI=loss-on-ignition. The carbonate content was $8 \%$ and the sample weight was $12.5 \mathrm{~g}$. The duration was three hours and the tray was turned halfway through the ignition period. The maximum attainable weight loss is indicated with a dashed line and has a value of $3.52 \%$ which is $44 \%$ of the $\mathrm{CaCO}_{3}$ content (i.e. $\mathrm{CO}_{2}=44 \%$ of the mass of $\left.\mathrm{CaCO}_{3} ; 8 \% \times 0.44=3.52 \%\right)$.

Table 4. Curvature values of equations fitted with data from Figure 5. The fitted equations were for $a_{\mathrm{T}:} a_{\mathrm{T}}=\alpha+\beta \psi^{\top}$ and for $b_{\mathrm{T}}: \mathrm{bT}=\delta+\frac{\varepsilon}{1+\mathrm{e}^{-k(T-\lambda)}}$. For $\mathrm{c}_{\mathrm{T}}$ no equation was fitted because only at a temperature of $650^{\circ} \mathrm{C}, \mathrm{C}_{\mathrm{T}}$ had a value above zero. Parameter values of the equations for $a_{T}$ and $b_{T}$ that were found in the previous study (Hoogsteen et al., 2015) for a range of non-calcareous Dutch soils are also reported. Standard errors are given in brackets.

\begin{tabular}{llllll}
\hline $\begin{array}{l}\text { Parameter } \\
a_{T} \text { (non- } \\
\text { calcareous } \\
\text { samples) }\end{array}$ & $\begin{array}{l}a_{T} \text { (calcareous Parameter } \\
\text { samples) }\end{array}$ & $\begin{array}{l}b_{T} \text { (non- } \\
\text { calcareous } \\
\text { samples) }\end{array}$ & $\begin{array}{l}b_{T} \text { (calcareous } \\
\text { samples) }\end{array}$ \\
\hline$\alpha$ & $0.553(0.013)$ & $0.493(0.010)$ & $\delta$ & $0.011(0.005)$ & $-0.006(0.009)$ \\
$\beta$ & $47(100)$ & $72(182)$ & $\varepsilon$ & $0.077(0.008)$ & $0.110(0.020)$ \\
$\gamma$ & $0.984(0.006)$ & $0.982(0.007)$ & $k$ & $0.027(0.006)$ & $0.018(0.006)$ \\
& & & $\lambda$ & $483(9)$ & $520(15)$ \\
$R^{2}$ & 0.69 & 0.67 & $R^{2}$ & 0.95 & 0.94 \\
F-value & 23.58 & 22.17 & F-value & 123 & 103.17 \\
\hline
\end{tabular}


(a)
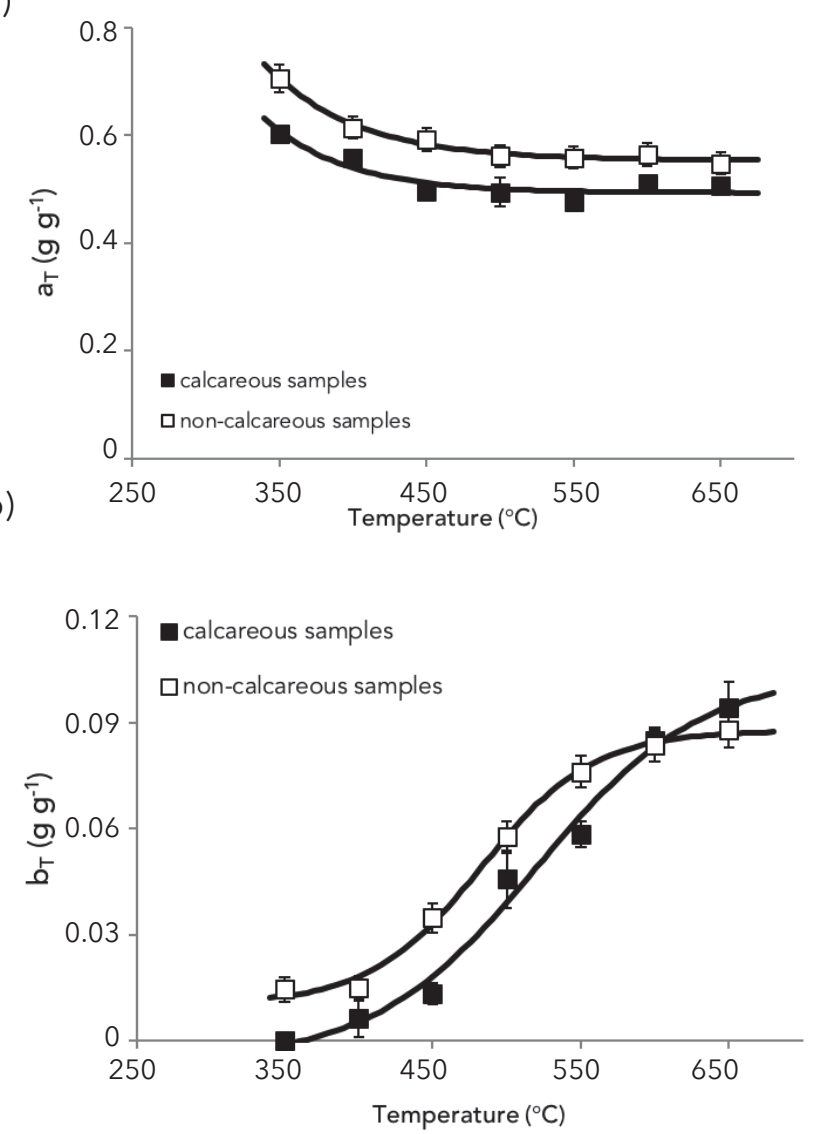

Figure 4. Relationship between the ignition temperature and the SOM to SOC conversion factor $a_{T}(a)$ and clay correction factor $b_{T}(b)$ for six calcareous soil samples. The ignition duration was three hours and the sample weight was $20 \mathrm{~g}$ (loss-on-ignition, LOI) and $300 \mathrm{mg}$ (wet chemical oxidation). The tray was turned halfway through. The multiplication factors $\left(a_{T}\right.$ and $\left.b_{T}\right)$ that were obtained for the 17 non-calcareous soils are also presented (see Hoogsteen et al., 2015).

\section{Discussion}

We hypothesized that overestimations of carbonate content would be largest for the gravimetric method without the addition of $\mathrm{FeCl}_{2}$ because the acid treatment is stronger. Moreover, we hypothesized that the addition of $\mathrm{FeCl}_{2}$ to $\mathrm{HCl}$ would result in lower apparent carbonate values because $\mathrm{FeCl}_{2}$ would act as an antioxidant (Nelson, 1982). The results of this study show that there was no effect of spiking $\mathrm{HCl}$ with $\mathrm{FeCl}_{2}$ for $\mathrm{SOM}$ protection because average apparent carbonate values of the non-calcareous soils were highest for 
the gravimetric method where $\mathrm{FeCl}_{2}$ was added to $\mathrm{HCl}$ (GMF) and lowest for the gravimetric method without the addition of $\mathrm{FeCl}_{2}(\mathrm{GM})$, (Table 2). Apparent carbonate contents of those samples as determined by the acetic acid dissolution (AAD) procedure took an intermediate position. A strong relation between clay content and apparent $\mathrm{CaCO}_{3}$ content was observed for the AAD method (Supplementary material, Box S1 and Figure S1). Thus, we conclude that the AAD procedure can be employed for soils that are low in carbonates because corrections can be made for the proton consumption by the soil exchange complex. Loeppert et al. (1984) investigated the effect of mixtures of both clay minerals and carbonates, and SOM and carbonates in various concentrations on measured carbonate contents. They observed that absolute errors in measured $\mathrm{CaCO}_{3}$ values decreased with increasing $\mathrm{SOM} /$ carbonate ratios (SOM/Carbonate $\times 1.46=$ measurement error, $\left.R^{2}=0.84\right)$. This was also observed for clay minerals: the higher the ratio clay/ carbonate, the lower the measurement error in $\mathrm{CaCO}_{3}$ (Clay/Carbonate $x 0.11=$ error, $\left.R^{2}=0.99\right)$. We found the same for the non-calcareous soils (Supplementary material, Box S1 and Table S1): the effect of SOM on the carbonate measurement error was greater than the effect of clay. This is because the binding capacity of humus molecules is much larger than that of clay (Drake \& Motto, 1982; Supplementary material, Box S1). However, we do not recommend using the AAD procedure because the SOM, clay and carbonate contents (as determined by for instance the $\mathrm{HCl}$ method) need to be all known to be able to quantify the measurement error.

We cannot explain the large differences in measured carbonate contents between GM and GMF. The measurements were conducted at the same momentso differences cannot be ascribed to changes in ambient temperature. Furthermore, sample weights were in the same range (all between 1.8 and 2.0 g) as well as weight losses of the quartz sand-acid mixtures ( $G M=0.0065 \mathrm{~g}$; $G M F=0.006 \mathrm{~g}$ ). Due to the high apparent carbonate values that we obtained with GMF we do not recommend to spike the solution.

Carbonate contents of samples as determined by the AAD method were larger as compared to GM. A possible explanation is that the reaction time was much longer for AAD (16 hours for AAD as compared to 45 minutes for GM). Furthermore, the amount of acid added was greater ( $25 \mathrm{ml}$ as compared to $10 \mathrm{ml}$ ) resulting in a better solution of the soil sample.

We expected that ignition losses of calcite would increase with sample weight in an exponential way as observed for the sandy and loamy bulk soil samples in a previous study (Hoogsteen et al., 2015). The opposite was found: ignition losses were highest (28\%) for the smallest sample weight $(0.1 \mathrm{~g})$ and decreased to $4.4 \%$ (1 g). Standard deviations decreased with increasing sample weight, thus larger sample weights led to less variability. Decomposition of calcite increased with temperature in a sigmoidal way which has also been reported 
by Kasselouri et al. (1995), Singh \& Singh (2007), and Kasozi et al. (2009) and started at $600{ }^{\circ} \mathrm{C}$. The lower asymptote had an LOI-value of $0.02 \%$, so $0.02 / 3.52=0.007 \%$ of the $\mathrm{CO}_{2}$ fraction was lost. Dry $\mathrm{CaCO}_{3}$ contains $0.2 \%$ bonded water at temperatures above $105^{\circ} \mathrm{C}$ (Risnes et al., 2005). The calcitequartz sand mixture contained thus $0.002 \times 8 \%=0.016 \%$ bonded water. This is close to the value of the lower asymptote $(0.02 \%)$.

Ignition losses stabilized to $2.8 \%$ at $750{ }^{\circ} \mathrm{C}$ which was $80 \%$ of the total $\mathrm{CO}_{2}$ fraction. This is in contradiction with Kasozi et al. (2009) who observed complete decarbonatation at this temperature using thermogravity. Sample weights used for thermographic analyses are however much smaller (9 to $15 \mathrm{mg}$ ) as compared to sample weights of $\mathrm{LOI}(1000 \mathrm{mg} \mathrm{CaCO}$ per 12.5 g sample). Chattaraj et al. (1973) observed with differential thermal analysis that the starting temperature for decomposition of $\mathrm{CaCO}_{3}$ was $700{ }^{\circ} \mathrm{C}$ using sample weights of $800 \mathrm{mg}$. The process of decarbonatation was completed at $975^{\circ} \mathrm{C}$. Because ignition losses of pure $\mathrm{CaCO}_{3}$ decreased with increasing sample weight, we suggest that the temperature at which decarbonatation is completed (range: $800-975^{\circ} \mathrm{C}$ ) depends on the sample weight used.

We were able to derive temperature dependent multiplication factors through multiple linear regression (cf. Figure 4). The parameter $\mathrm{a}_{\mathrm{T}}$, the carbon content of $\mathrm{SOM}$, stabilized from $450^{\circ} \mathrm{C}$ onwards and attained an equilibrium level of $0.49 \mathrm{~kg} \mathrm{~kg}^{-1}$ (horizontal asymptote). This was lower than the value obtained for the non-calcareous soil samples $\left(0.55 \mathrm{~kg} \mathrm{~kg}^{-1}\right)$ and can be explained by differences in the chemical composition of organic matter. The calcareous samples used in this study might have been richer in fulvic acids (41-51\% C) while the non-calcareous soils contained predominantly humic acids (53$58 \%$ C), as suggested earlier (e.g., Kononova, 1966; Orlov, 1985; Stevenson, 1994). Parameter $b_{T}$ increased in a sigmoidal fashion with temperature. The shape of the curve differed slightly from the curve that was previously found for non-calcareous soils. This may be attributed to differences in the chemical composition of the clay minerals. The vermiculite content of the clay fraction in Dutch soils containing marine clay is lower $(2.5 \%)$ than in soils that contain fluvial clay (15\%). Furthermore, the smectite fraction of the clay fraction is about three times larger for marine clay (35\%) as compared to fluvial clay (12.5\%; Breeuwsma, 1987). The onset and completion temperatures of hydroxyl losses from clayey elements vary among clay types: vermiculite shows a more a gradual loss of $\mathrm{OH}$ up to a temperature of $850{ }^{\circ} \mathrm{C}$ while smectite shows a rapid increase in $\mathrm{OH}$ losses at $500{ }^{\circ} \mathrm{C}(\mathrm{Grim}, 1953)$. Losses of smectite are completed at $800{ }^{\circ} \mathrm{C}$. The number of samples that contained fluvial clay was much higher in this study (5 out of 7 ) as compared to the set of non-calcareous samples that was used in the previous study (7 out of 17 samples contained fluvial clay, Hoogsteen et al., 2015). This explains why the values of factor $b_{T}$ were higher at $T \geq 600{ }^{\circ} \mathrm{C}$ for the calcareous samples: the vermiculite fraction is higher and the smectite fraction is lower (not such 
rapid losses of $\mathrm{OH}$ at $500{ }^{\circ} \mathrm{C}$ as compared to the non-calcareous soils that had a much larger smectite content). No effect of temperature was observed on the $\mathrm{CaCO}_{3}$ multiplication factor $\mathrm{C}_{\mathrm{T}}$ up to $600{ }^{\circ} \mathrm{C}$. At $650{ }^{\circ} \mathrm{C}, \mathrm{C}_{\mathrm{T}}$ had a value of 0.04 ( $\mathrm{SE}=0.03$ ) so $4 \%$ of the carbonate was lost. This is close to the value that was measured at $650{ }^{\circ} \mathrm{C}$ for the quartz sand-calcite mixture: $5.6 \%$ of the total carbonate content was lost (cf. Figure $3 ; 0.45 \%$ weight loss divided by $\left.8 \% \mathrm{CaCO}_{3}\right)$.

Although carbonate multiplication factors can be used to accurately determine the OM content through $\mathrm{LOI}$ we recommend to keep $\mathrm{CaCO}_{3}$ losses to a minimum and to use an ignition temperature of $550{ }^{\circ} \mathrm{C}$. In this way all $\mathrm{SOM}$ is decomposed while overestimations through carbonates are minimal. Samples with for instance a $\mathrm{CaCO}_{3}$ content of $8 \%$ would lose only $0.02 \%$ of their weight through the loss of the water fraction of dry $\mathrm{CaCO}_{3}$ (Figure 3). Because of these marginal losses we also recommend using sample weights preferably above $20 \mathrm{~g}$ to minimize variation in the determination of SOM content of calcareous soils through loss-on-ignition.

\section{Conclusions}

The comparison of pre-treatment methods and ignition temperatures for determining SOM content of calcareous soils through loss on ignition led us to the following conclusions:

- The gravimetric method without the addition of $\mathrm{FeCl}_{2}$ showed the smallest overestimations of the $\mathrm{CaCO}_{3}$ content (apparent $\mathrm{CaCO}_{3}$ content of non-calcareous soils) and is therefore recommended.

- An ignition temperature of $550{ }^{\circ} \mathrm{C}$ should be employed to analyse the SOM content of calcareous soils through LOI because at this temperature 99.98\% of the calcite fraction remains in the sample.

Future research should contemplate the effect of ignition conditions on magnesite $\left(\mathrm{MgCO}_{3}\right)$ losses. When soil samples contain considerable amounts of $\mathrm{MgCO}_{3}$, the SOM content will be overestimated because magnesite decomposes at temperatures below $550^{\circ} \mathrm{C}$. 


\section{Supplementary material}

Box S1. The effects of soil organic matter and clay on measured carbonate values for non-carbonatic samples

When conducting the acetic acid dissolution procedure to the determine the carbonate content of a soil sample, large overestimations can occur due to the absorption of protons by clay and soil organic matter (SOM). The magnitude of this error is dependent on the ratios $\mathrm{CaCO}_{3}$ : clay and/or $\mathrm{CaCO}_{3}$ : SOM. However, measurement errors decline with increasing $\mathrm{CaCO}_{3}$ contents. Loeppert et al., (1984) reported for blends of $\mathrm{CaCO}_{3}$ and clay overestimations varying from $0 \%$ (200 $\mathrm{mg} \mathrm{CaCO}, 100 \mathrm{mg}$ clay) to $50 \%$ (20 mg CaCO${ }_{3}, 1600$ $\mathrm{mg}$ clay). The same was observed for mixtures of $\mathrm{CaCO}_{3}$ and SOM: $200 \mathrm{mg}$ $\mathrm{CaCO}_{3}$ mixed with $20 \mathrm{mg} \mathrm{SOM}$ yielded no overestimation of the carbonate content (0\%), whereas $20 \mathrm{mg} \mathrm{CaCO}$ mixed with $160 \mathrm{mg} \mathrm{SOM}$ resulted in an overestimation of $50 \%$. Because measurement errors increase both with larger SOM and clay contents, these effects are cumulative. Nevertheless, the effect of SOM is much larger than that of clay: $1600 \mathrm{mg}$ clay vs. $160 \mathrm{mg}$ SOM lead to the same overestimation of the $\mathrm{CaCO}_{3}$ content. However, the SOM content is in many soils much lower than the clay content. To quantify those effects in greater detail, we determined the apparent carbonate content of 17 non-carbonatic soil samples as follows:

$A C C=\alpha+\beta \times C+\gamma \times D(1)$

Where ACC is the apparent carbonate content $(\mathrm{mg}), \mathrm{C}$ is the clay content $(\mathrm{mg})$ and $\mathrm{D}$ is the SOM content $(\mathrm{mg})$. The values of the parameters are shown in Table S1.

Table S1. Values of the parameters from Equation 1 ( $A A C=\alpha+\beta \times C+\gamma \times D$ ), where $A A C=$ the apparent carbonate content $(\mathrm{mg}), C=$ the clay content $(\mathrm{mg})$ and $D=$ the SOM content (mg). Standard errors are given between brackets.

\begin{tabular}{ll}
\hline Parameter & Value \\
\hline$\alpha$ & $4.358(1.754)$ \\
$\beta$ & $0.012(0.002)$ \\
$\gamma$ & $0.026(0.001)$ \\
$R^{2}$ adjusted & 0.73 \\
F-value & 24.98 \\
\hline
\end{tabular}


Table S2. Placement of crucibles within the furnace (Experiment 2). The letters A-F resemble different sample weights. Each weight occurred twice in each batch. The letter ' $x$ ' indicates that no crucible was placed at the position. The location of the furnace door is also indicated. Halfway through the ignition period the tray was turned $180^{\circ}$ and put back into the furnace.

\begin{tabular}{ccc}
\hline$x$ & $x$ & $x$ \\
\hline$D$ & $E$ & $F$ \\
\hline$A$ & $B$ & $C$ \\
\hline$x$ & $x$ & $x$ \\
\hline$D$ & $E$ & $F$ \\
\hline$A$ & $B$ & $C$ \\
\hline$x$ & $x$ & $x$ \\
\hline \multicolumn{3}{c}{ Door } \\
\hline
\end{tabular}




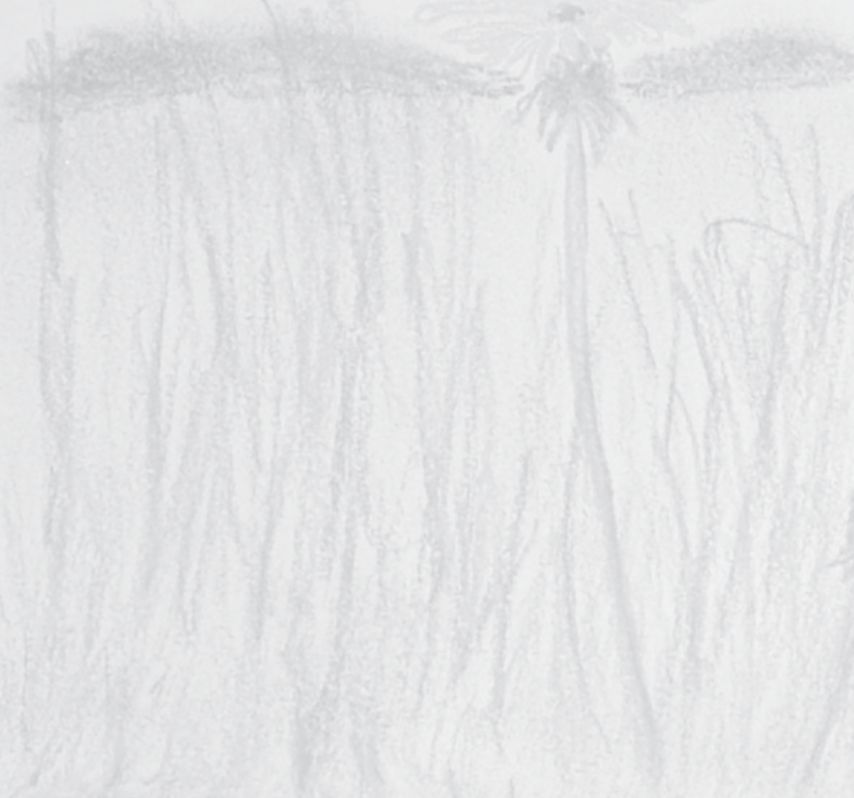

nest

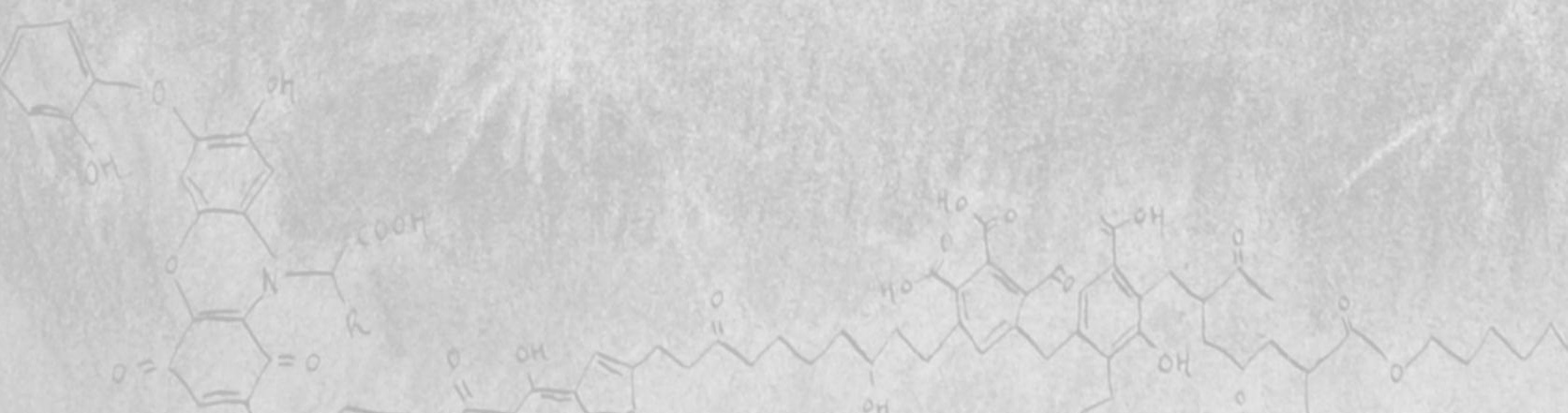




\section{Chapter 4. Monitoring soil organic matter on grassland farms: an exploratory analysis}

Hoogsteen, M.J.J., Breure, A.M. \& van Ittersum, M.K. To be submitted. Monitoring soil organic matter on grassland farms: an exploratory analysis. 


\section{Summary}

To meet the goals of the Climate Agreement, policy makers consider incentivizing soil carbon sequestration by carbon credits to offset greenhouse gas emissions from agriculture, industry and other sectors. Therefore, the interest in monitoring soil organic matter dynamics is growing rapidly, yet factors affecting the precision of the monitoring results are rarely quantified. We used the rhetorical scheme "The seven circumstances" to structure the methodological aspects of setting up an SOM monitoring program. Through intensive observations during four years on two grass-based dairy farms in the Netherlands we explored the effects of multiple methodological choices and gained quantitative insights into the circumstances: How (conversion of SOM weight concentrations to SOM stocks), Where (soil depth; the integration level of the data (field or farm)), and When (seasonality) for measurements of SOM stocks and the development thereof in time. We found that all three circumstances affect conclusions on SOM stocks or SOM dynamics strongly. Considerable variation exists in pedotransfer curves relating soil bulk density and SOM weight concentration. Therefore, preferably a site specific pedotransfer curve should be used when comparing SOM stocks based on SOM weight concentrations across sites. Large differences in trends of SOM stock changes over time were found between fields and sampling depths. We conclude that a sampling depth in grassland soils up to $60 \mathrm{~cm}$ may be relevant to capture the dynamics in deeper layers. Furthermore, for quantitative underpinning of carbon payment schemes, the whole farm should be monitored rather than a few fields as trends between fields are highly variable. 


\section{Introduction}

The public interest in soils is growing rapidly: a recent parliamentary letter of the government of the Netherlands states that maintaining soil quality is eminent to find solutions for multiple challenges society is facing such as climate change and water pollution (Government of the Netherlands, 2019a). Today, no national policy framework or agreement exists on soils. Although it is acknowledged that maintaining soil quality levels is an important condition for complying with the UN Climate agreement, the EU Water Framework Directive and the EU Nitrates directive, the ambitions in the national soil policy document are rather vague and not yet quantified. With the recent adoption of the 'no-debit rule' to compensate for emissions associated with land use by equivalent amounts of $\mathrm{CO}_{2}$ removal, the Netherlands must improve land use management strategies to increase $\mathrm{CO}_{2}$ absorption in agricultural and forest soils, because today the LULUCF ${ }^{1}$ sector is still a net source of greenhouse gas emissions. In 2017, the net emissions from this category were $5.6 \mathrm{Tg} \mathrm{CO}$ equivalents in the Netherlands (RIVM, 2019a). This should be reduced to zero emissions according to the 'no-debit rule'. The National Climate agreement of the Netherlands states that an additional amount of $0.5 \mathrm{Tg}$ of $\mathrm{CO}_{2}$ equivalents should be sequestered in agricultural lands (Government of the Netherlands, 2019b).

Policy makers ask scientists, advisors and farmers explicitly to operationalize goals of sustainable soil management and to deliver indicators for monitoring soil quality (Government of the Netherlands, 2019a). Especially, monitoring of soil organic matter (SOM) is of interest as this is a crucial factor to comply with the 'no-debit' rule. Regional governments are even considering incentivizing farmers for carbon sequestration (e.g. the province of Friesland in the North of the Netherlands) proposes to pay farmers $€ 30$ per ton $\mathrm{CO}_{2}$ that is sequestered.) This is challenging as SOM stocks (commonly expressed in $\mathrm{Mg}$ (tonnes) of SOM ha-1) are characterized by high levels of spatial heterogeneity and management induced changes in SOM are relatively small as compared to the SOM stock (Goidts et al., 2009; Fornara et al., 2020). Another complicating factor is that the requirements for setting up such a soil monitoring program are equivocal. A cacophony of monitoring advices is available prescribing to use different indicators, analytical methods, sampling designs and to sample different soil layers all depending on the scale and time period in which monitoring should take place (e.g. De Gruijter, 2006; Goidts et al., 2009; Hoogsteen et al., 2015).

\subsection{Current SOM measurements and results in the Netherlands}

In the Netherlands, soil quality and agricultural production levels are generally high (Reijneveld, 2013). Recently, concerns were raised about declining soil quality and specifically, the quantity of soil organic matter (SOM): farmers

$1 \quad$ LULUCF $=$ land-use, land-use change and forestry 
fear that SOM levels are declining as a consequence of increased stringency in the application rates of animal manure to their fields (PBL, 2019). Trends at national level show that the SOM content of grasslands remained stable (Figure 1). For arable land the SOM content tend to increase (n.s.) and under fields of silage maize no changes in SOM content have been observed (Figure 1). However, information on SOM in grasslands is only available for the topsoil $(0-10 \mathrm{~cm})$.

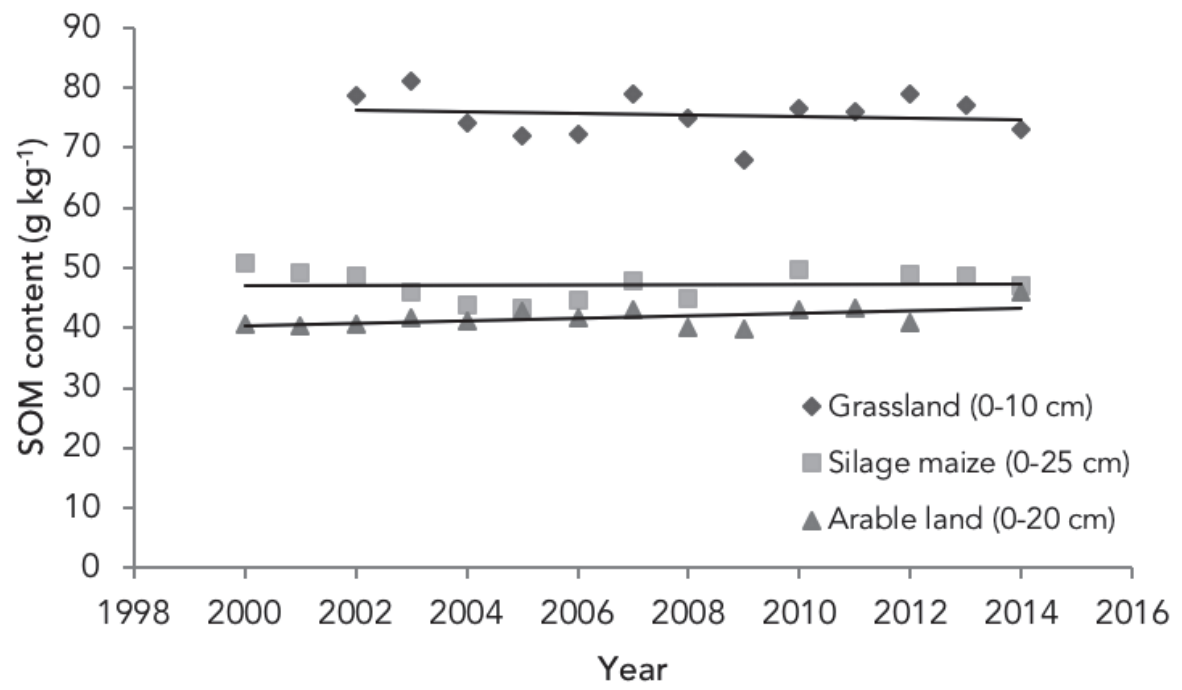

Figure 1. Trends in soil organic matter (SOM) content for different land-use categories in the Netherlands (PBL, 2019).

\subsection{Rhethorical scheme for soil monitoring}

A number of factors need to be considered prior to setting up a monitoring system. This can be done in a structured way through the application of the rhethorical scheme "The seven circumstances" (after the Greek rhetoric Hermagoras of Temnos, as described by Robertson, 1946). Seven questions are central to this scheme: 1.Who, 2. What, 3. Where, 4. When, 5. How, 6. Why, 7. By what means. In the context of soil monitoring for SOM, the main objective is to quantify accurately the stocks of SOM and the development thereof in time. In Figure 2, we provided a number of answers for all 'Circumstances'. In the present study "Who" are the information requestors, the policy makers and farmers. The answer to the "What" question is: information on the stocks of soil organic matter and their trends. The aspects 6 and 7 are beyond the scope of this paper. The aim of this paper is to gain quantitative insights into the circumstances "How", "Where" and "When" for measurements of soil organic matter stocks in grasslands and the development of SOM stocks in 
time, in order to answer the questions of the requestors. Through intensive soil monitoring on two dairy farms we explore the effects of different approaches to derive data on stocks of SOM from measurements of the mass concentration of SOM (How), the effect of the sampling depth, the integration level of the data (field or farm), (Where), and the effects of seasonality (When) on the quality of the reported data.

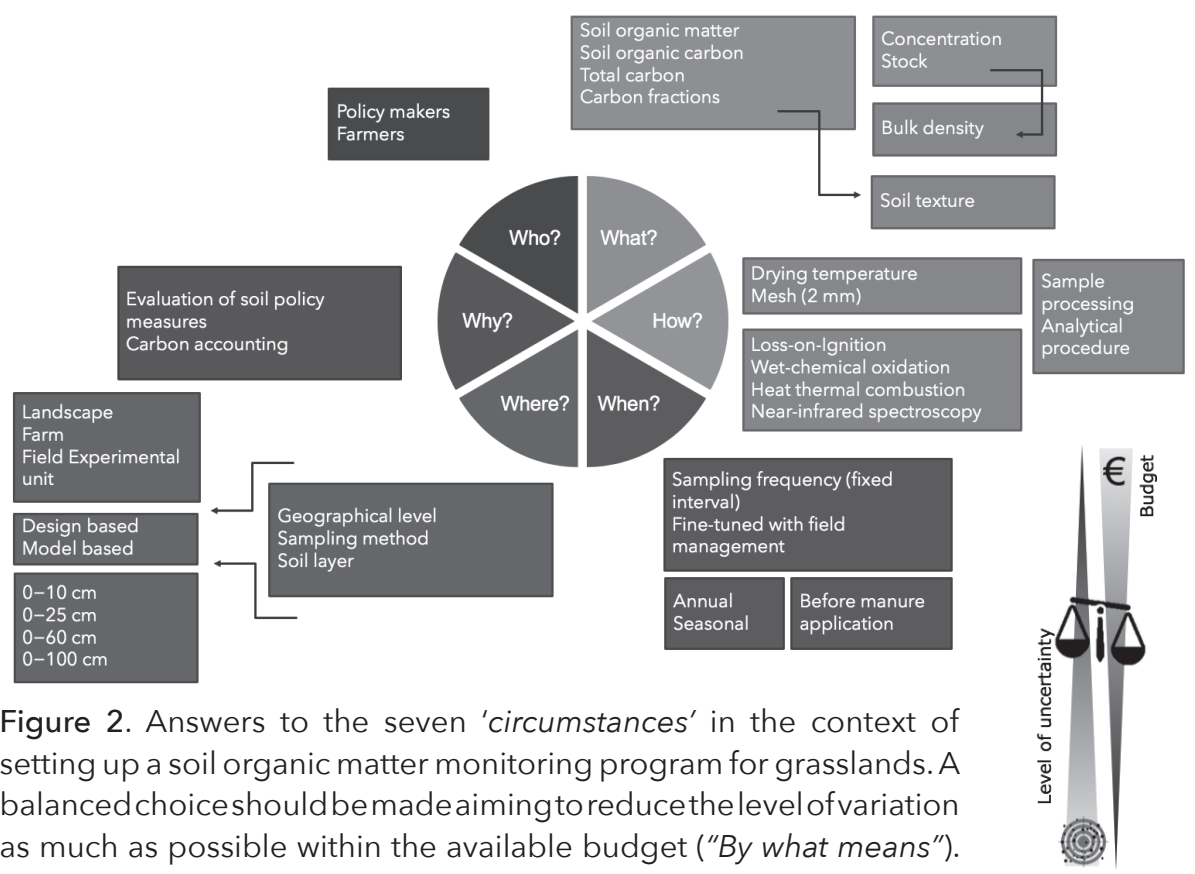

\section{Materials and methods}

\subsection{Farm characteristics and grassland management}

The farms were located in "De Gelderse Vallei" which is a sub-region in the center of the Netherlands (province of Gelderland). From March 2010 to January 2014, 14 grassland fields were monitored on two farms (7 fields per farm). The farms are located on sandy soils in "Het Binnenveld" (Farm A, 51 ${ }^{\circ}$ 99' 72.79" N; 5 62' 18.84" E) and Lunteren (Farm B, 52 $08^{\prime} 95.46^{\prime \prime} \mathrm{N} ; 5^{\circ} 59^{\prime}$ $\left.07.35^{\prime \prime} \mathrm{E}\right)$ and are about $10 \mathrm{~km}$ away from each other. The silt and clay content (fraction $\leq 20 \mu \mathrm{m}$ ) of the 14 fields ranged from 41 to $132 \mathrm{~g} \mathrm{~kg}^{-1}$. The SOM content of all farm grasslands was monitored during the four years with a three monthly sampling interval. Samples were collected in the first month of each season (spring, summer, autumn and winter). We monitored SOM dynamics in three different layers: the $0-10 \mathrm{~cm}, 10-30 \mathrm{~cm}$ and $30-60 \mathrm{~cm}$ soil layers were sampled separately. 


\section{Farm A - De Hooilanden}

The field size varied from 1.2 to 4.0 ha. A map of the farm and the sampled fields is shown in Figure 3. Historically the farmlands were referred to as hay lands (in Dutch: De Hooilanden) because the soil was too wet for other agricultural purposes (Oosting, 1936). In the $14^{\text {th }}$ century, the area consisted of peat swamps that disappeared after the peat harvesting in the middle ages (Municipality of Veenendaal, 2019). A sandy cover soil remained. In the $18^{\text {th }}$ century, the area was mainly used for livestock production. In the fields monitored in this study, some peat fragments were observed only in the subsoil layer on the North West side of the farm (field 5). The subsoil of the other fields was sandy. Farm A has been under organic management since 2003 and employed the 'Pure graze' stocking system, a lenient strip stocking system. This lenient strip stocking system uses movable fences and cows are put to graze in long standing biomass. Every three hours the stocking area is enlarged by moving the fence except for the night when the fence is moved after a period of six hours. The 'Pure graze' system aims at minimizing the use of concentrates and synchronizes grass demand with supply by spring calving. The annual dry matter yield of the grasslands was estimated to be $6 \mathrm{Mg}$ DM ha-1. The cattle diet consisted of mainly forage (grass/clover) and was supplemented with maize and triticale. All cattle were housed in a cubicle stable and cattle slurry was the main manure type produced on the farm. Some solid farmyard manure was also produced during the calving period because at that time the calving cows were housed in a deep litter stable. In 2012 solid cattle manure was applied once to fields 6 and 7 at a rate equivalent to $7 \mathrm{~m}^{3}$ $\mathrm{ha}^{-1} \mathrm{yr}^{-1}$. Every year in early spring (March) all fields were fertilized with cattle slurry (CS; $\left.25 \mathrm{~m}^{3} \mathrm{ha}^{-1}\right)$ and an additional application of CS followed in July and August $\left(15 \mathrm{~m}^{3} \mathrm{ha}^{-1}\right)$. The stocking management was identical across the fields as the herd was quickly rotated over the farm. Every field was grazed seven times during the growing season. The total number of grazing days was about 240 days per year, in the period April - November. The fields close to the homestead were used mainly for night grazing (fields 1-3), while the fields further away (4-7) were used for day grazing. In 2010, fields 1-6 have had been under grass for at least 20 years and field 7 since 2003. The main grassland species on the farm were perennial ryegrass (Lolium perenne L.), orchard grass (Dactylis glomerata L.), white clover (Trifolium repens L.) and red clover (Trifolium pratense L.). 


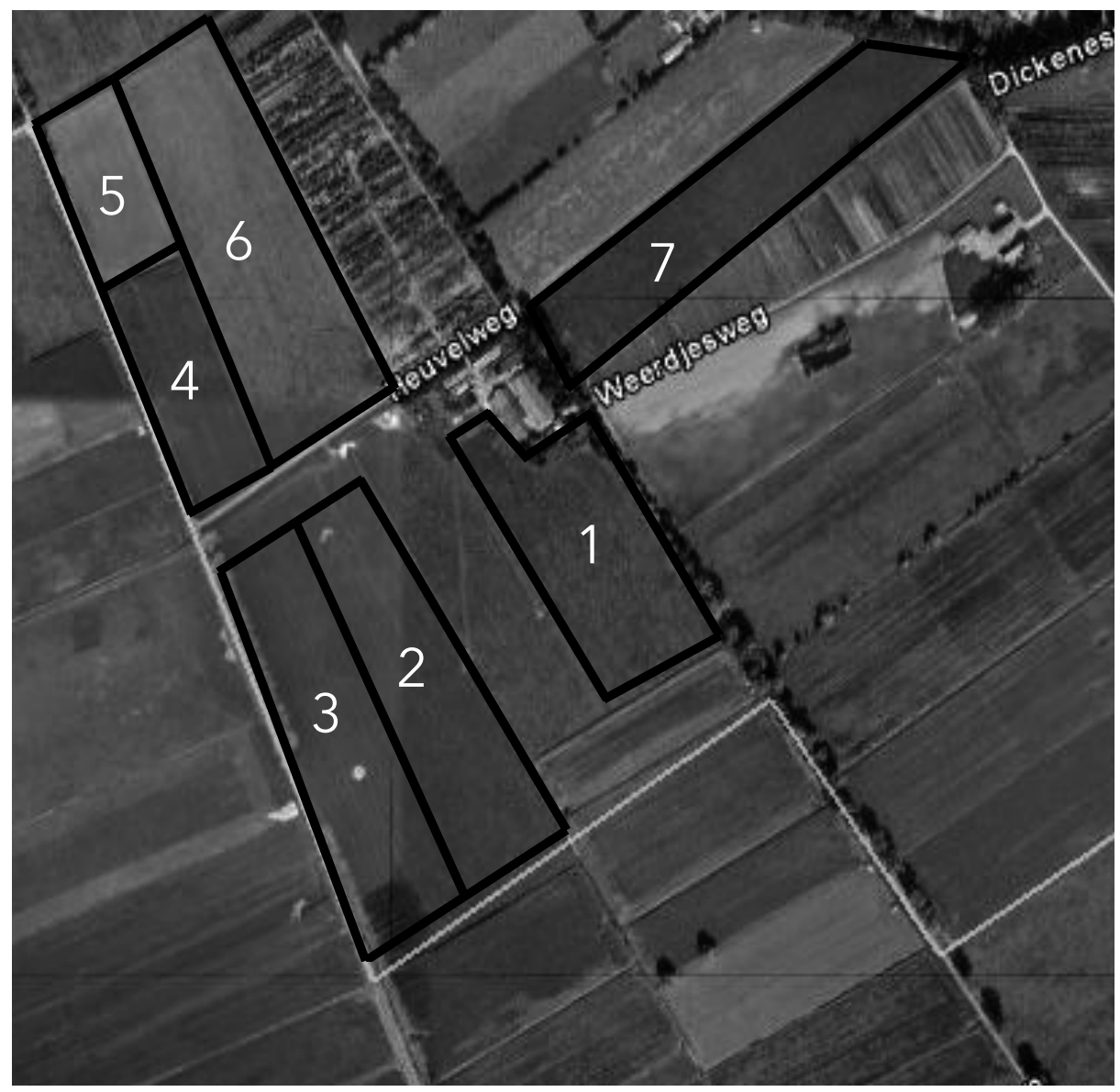

Figure 3. Location of the sampled fields (Field 1-7) of Farm A, "De Hooilanden" in Bennekom, the Netherlands. See the text for details. General details about the farm management are presented in Table 1. Characteristics at field level are provided in Table 2.

\section{Farm B - De Groote Voort}

De Groote Voort has been managed by the family Van der Voort for over four centuries and is under organic management since 1992. The farmer employs the modern continuous stocking systems and the grazing season lasts from April to the beginning of November. In this system, cattle are quickly rotated over the parcels and graze a few hours on each field every day. The field size varied from 2.4 to 4.3 ha. In February and August all fields were fertilized with respectively, 12.5 and $2.5 \mathrm{~m}^{3}$ solid cattle manure per hectare. In March $10 \mathrm{~m}^{3}$ of cattle slurry per ha was applied to all fields. The diet of the cows consisted of fresh forage and triticale, supplemented with a mixture of herbs, dried fruits, nuts, and minerals. Figure 4 shows the location of the sampled fields. 
In 2010, fields 1-5 have had been under permanent grassland for a period of 23 to 25 years. Before that time, the fields were in grass/maize rotation. The botanical composition consisted of perennial ryegrass (Lolium perenne L.), white clover (Trifolium repens L.), and dandelion (Taraxacum officinale). Cuckooflower (Cardamine pratensis L.) and common daisy (Bellis perennis L.). Creeping thistle (Cirsium arvense) also occurred on the grasslands.

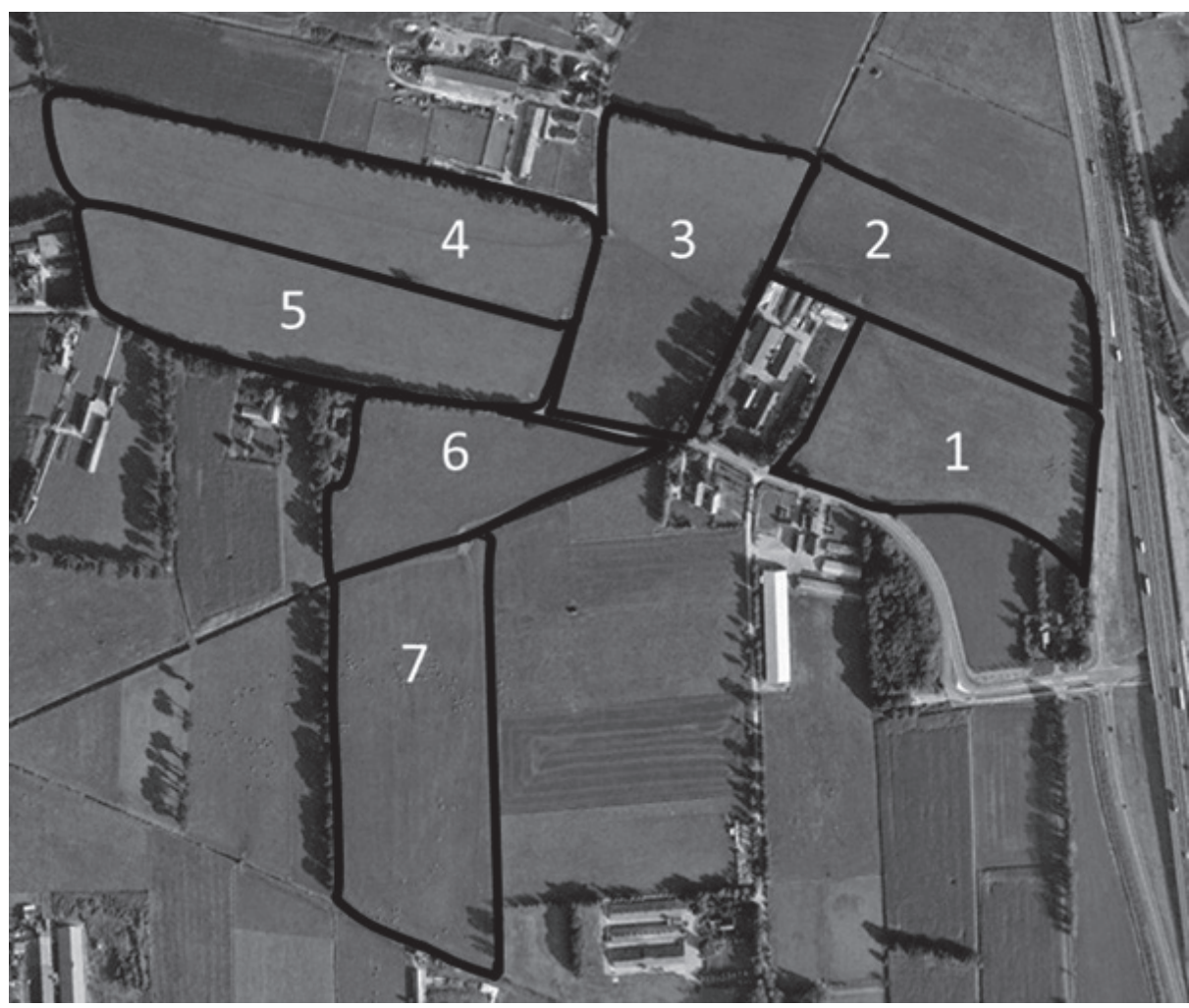

Figure 4. Location of the sampled fields (Field 1-7) of Farm B, "De Groote Voort" in Lunteren, the Netherlands. See the text for details. General details about the farm management are presented in Table 1. Characteristics at field level are provided in Table 2.

About forty years ago, a horse riding school was established on the front side of field 6 . The back of the field was an orchard. After the closure of the riding school, the productivity of the field was extremely low and the area was used as storage area. In 2010 the field had been under grass for about 25 years and the botanical composition consisted of perennial ryegrass and white clover as the dominant plant species. The backside of the field was characterized by a variety of herbs and orchard grass (Dactylis glomerata L.). 
Field 7 was the most productive field about 40 years ago according to the farmer. Despite the great productivity, extension workers recommended the field to be deeply ploughed (ploughing down to a depth of $60 \mathrm{~cm}$ ) in the 1980's for unknown reasons. After ploughing, grass was grown in rotation with maize. About 12 years ago, the field was renovated and a mixture of perennial ryegrass and white clover was sown.

The total number of grazing days was about 200 days per year in the period April-November. Weather data was obtained from a local weather station of Wageningen University \& Research centre which was about $1 \mathrm{~km}$ away from Farm A and $15 \mathrm{~km}$ away from Farm B. Between 2004 and 2014, the average yearly temperature was $10.4^{\circ} \mathrm{C}$ and the annual precipitation sum was $859 \mathrm{~mm}$.

Table 1. Characteristics of the soil and grassland management of two farms on sandy soils in "de Gelderse Vallei", the Netherlands, at the start of the monitoring period (Spring 2010). The silt + clay content (SC) is expressed in $\mathrm{g} \mathrm{kg}^{-1}$ soil. The SOM content is given in $\mathrm{Mg} \mathrm{ha}^{-1}$. Standard errors of the mean are given between brackets. $\mathrm{CS}=$ cattle slurry, $\mathrm{SCM}=$ solid cattle manure. The amounts of applied manure are expressed in $\mathrm{Mg}$ $\mathrm{OM} \mathrm{ha-1} \mathrm{yr}^{-1}$.

\begin{tabular}{|c|c|c|c|c|}
\hline & Farm A & & Farm B & \\
\hline No. of fields sampled & 7 & & 7 & \\
\hline Soil layer & $\begin{array}{l}\mathrm{SC} \\
\left(\mathrm{g} \mathrm{kg}^{-1}\right)\end{array}$ & $\begin{array}{l}\text { SOM } \\
\left(\mathrm{Mg} \mathrm{ha}^{-1}\right)\end{array}$ & $\begin{array}{l}\mathrm{SC} \\
\left(\mathrm{g} \mathrm{kg}^{-1}\right)\end{array}$ & $\begin{array}{l}\text { SOM } \\
\left(\mathrm{Mg} \mathrm{ha}^{-1}\right)\end{array}$ \\
\hline $\begin{array}{r}0-10 \mathrm{~cm} \\
10-30 \mathrm{~cm} \\
30-60 \mathrm{~cm}\end{array}$ & $\begin{array}{l}97(7) \\
98(8) \\
88(7)\end{array}$ & $\begin{array}{l}65(3) \\
108(6) \\
126(11)\end{array}$ & $\begin{array}{l}59(3) \\
57(3) \\
52(2)\end{array}$ & $\begin{array}{l}60(3) \\
74(4) \\
64(7)\end{array}$ \\
\hline Livestock type & Whitehead & & Jersey & \\
\hline Herd size (no. of dairy cows) & 74 & & 85 & \\
\hline Grassland area of the farm (ha) & 30 & & 32 & \\
\hline Stocking system & Lenient strip & & Continuous & \\
\hline $\begin{array}{l}\text { Average age of the grassland } \\
\text { (years) }\end{array}$ & 18 & & 25 & \\
\hline \multirow{4}{*}{$\begin{array}{l}\text { Type and amount of applied } \\
\text { manure from dairy cows (Mg } \\
\left.\text { OM ha-1 } \mathrm{yr}^{-1}\right)^{\mathrm{b}}\end{array}$} & \multicolumn{2}{|l|}{ CS: 2.9} & \multicolumn{2}{|l|}{ CS: 0.7} \\
\hline & \multicolumn{2}{|l|}{ SCM: 0 or $1^{\mathrm{a}}$} & \multicolumn{2}{|l|}{ SCM: 2.1} \\
\hline & \multicolumn{2}{|l|}{$\begin{array}{l}\text { During } \\
\text { grazing: } 1.7\end{array}$} & \multicolumn{2}{|l|}{$\begin{array}{l}\text { During } \\
\text { grazing: } 1.6\end{array}$} \\
\hline & \multicolumn{2}{|l|}{$\begin{array}{l}\text { Total: } 4.6 \text { or } \\
5.5\end{array}$} & \multicolumn{2}{|l|}{ Total: 4.4} \\
\hline
\end{tabular}

a SCM was applied every year to two out of seven fields, thus each field received manure once every four years. The amount was $1 \mathrm{Mg} \mathrm{OM} \mathrm{ha-1}^{-1}$ which is equal to $0.25 \mathrm{Mg}$ $\mathrm{OM} \mathrm{ha-1} \mathrm{yr}^{-1}$ (1 Mg OM ha-1 per 4 years). The application of SCM rotated over the fields. b See the Supplementary material, Box S1 for details on the calculation. 
Table 2. Characteristics of each field. The size, silt+clay content and age of the grassland is given. Other relevant details concerning the (former) management of the fields are also provided. N.A. is not applicable: in those cases no other details were worthwhile mentioning.

Silt + clay content

(fraction $<20 \mu \mathrm{m}$ )

\begin{tabular}{ccc}
\hline Farm Field Field $0-10 \mathrm{~cm}$ & $10-30 \mathrm{~cm} \quad 30-60 \mathrm{~cm}$ & $\begin{array}{l}\text { Age of the Other details } \\
\text { srassland } \\
\text { (ha) }\end{array}$ \\
& $\begin{array}{l}\text { in } 2010 \\
\text { (years) }\end{array}$ \\
\hline
\end{tabular}

\begin{tabular}{|c|c|c|c|c|c|c|c|}
\hline \multirow[t]{4}{*}{$A$} & 1 & 3.0 & 11.8 & 12.7 & 9.9 & $>20$ & Day + Night grazing \\
\hline & 2 & 4.0 & 8.2 & 8.4 & 7.6 & $>20$ & Day + Night grazing \\
\hline & 3 & 4.0 & 9.8 & 9.5 & 10.0 & $>20$ & Day + Night grazing \\
\hline & 4 & 1.6 & 10.4 & 10.0 & 6.6 & $>20$ & $\begin{array}{l}\text { Day grazing } \\
\text { Some peat } \\
\text { fragments in subsoil }\end{array}$ \\
\hline & 5 & 1.2 & 10.4 & 10.6 & 10.5 & $>20$ & Day grazing \\
\hline & 6 & 4.6 & 7.5 & 7.4 & 6.5 & $>20$ & $\begin{array}{l}\text { Day grazing } \\
\text { SCM application in } \\
2012\end{array}$ \\
\hline & 7 & 3.6 & 6.9 & 7.2 & 7.8 & 7 & $\begin{array}{l}\text { Day grazing } \\
\text { SCM application in } \\
2012 \\
\text { Also used as } \\
\text { stocking area for } \\
\text { young stock }\end{array}$ \\
\hline B & 1 & 3.4 & 4.1 & 4.1 & 3.9 & $23-25$ & N.A. \\
\hline & 2 & 3.1 & 6.2 & 5.9 & 5.4 & $23-25$ & N.A. \\
\hline & 3 & 4.1 & 5.9 & 5.7 & 4.9 & $23-25$ & N.A. \\
\hline & 4 & 4.3 & 6.3 & 6.1 & 5.5 & $23-25$ & N.A. \\
\hline & 5 & 4.0 & 6.4 & 6.1 & 5.5 & $23-25$ & N.A. \\
\hline & 6 & 2.4 & 5.9 & 5.4 & 4.7 & 25 & $\begin{array}{l}\text { Land-use } 30 \text { years } \\
\text { ago: horse riding } \\
\text { school and orchard }\end{array}$ \\
\hline & 7 & 4.8 & 5.0 & 5.1 & 4.6 & 12 & $\begin{array}{l}\text { Deep-ploughing } \\
\text { event in the 1980's }\end{array}$ \\
\hline
\end{tabular}




\subsection{Sample collection and analytical procedures "How"}

Sampling took place four times per year for a period of four years (Spring 2010 - Winter 2014; the average sampling interval was 89 days). All fields were sampled systematically in a zigzag pattern and 40 subsamples per field were collected to obtain three composite samples, i.e. one per soil layer: 0-10 cm, 10-30 cm, 30-60 cm. Samples were stored in plastic bags and dried overnight at $105^{\circ} \mathrm{C}$. After drying, samples were crushed and sieved at $1.8 \mathrm{~mm}$. The soil organic matter (SOM) content was determined by losson-ignition ( $\mathrm{LOI} ; 550^{\circ} \mathrm{C}$ with an ignition period of three hours and a sample weight of $20 \mathrm{~g}$ (see Hoogsteen et al., (2015) for details on the method). The $\mathrm{LOI}$ method was chosen because of the smaller variation among pseudoreplicates as compared to SOC analysis procedures (Hoogsteen et al., 2015). The near-infrared method analysis was not a common practice at the start of the monitoring period in spring 2010 and was therefore not chosen for SOM analysis. Corrections were made for structural water losses by subtracting $0.075 x$ the clay fraction from the LOI measurements (Hoogsteen et al., 2015). The soil texture of all samples was determined through laser diffractometry (Beckman Coulter LS Particle size analyser, Woerden, the Netherlands).

Samples for the soil bulk density (BD) measurements of the $0-30 \mathrm{~cm}$ soil layer were taken in July 2013 ( $n=6$ per field) for each layer of $5 \mathrm{~cm}$. In total 252 samples were collected per farm ( 6 layers $\times 6$ sampling locations per field $x 7$ fields). A soil pit was dug and cylindrical cores were pressed into the soil profile (ISO, 1998). The soil was carefully pressed out of the cores, collected in a paper bag and dried overnight at $105^{\circ} \mathrm{C}$. The SOM content was determined in every BD sample (through LOI, see above) to derive for both farms a relationship between bulk density and SOM. The bulk density in the $30-60 \mathrm{~cm}$ soil layer was not determined.

\subsection{Data processing and statistical analyses}

"What to report?" - How to derive SOM stocks from SOM weight concentrations

Carbon credits are commonly expressed in tonnes of $\mathrm{CO}_{2}$ equivalents. When laboratory measurements for soil organic matter (SOM) are conducted a mass concentration is reported in $\mathrm{g} \mathrm{SOM} \mathrm{kg}^{-1}$ soil. Using the soil bulk density $\left(\mathrm{kg} \mathrm{m}^{-3}\right)$, these concentrations can be converted to volume concentrations ( $\mathrm{kg}$ $\mathrm{SOM} \mathrm{m}{ }^{-3}$ ) or SOM stocks ( $\mathrm{kg} \mathrm{SOM} \mathrm{ha}^{-1}$ ). BD measurements are labor intensive and for this reason generic pedotransfer functions or even fixed values are used (e.g. BD is only measured at the start or end of an experiment). It is to be expected that the effect of different BD functions on SOM stock changes on the same field in time will be smaller than on the absolute amounts of SOM stocks, but the size of both effects is unclear. Therefore, we examined the effect of different pedotransfer functions describing the relationship between the BD and SOM weight concentrations. 
Per farm three models depicted as curves were derived from the data:

(a) A curve including all data points from the farm.

(b) A curve representing the lower limit of all BD/SOM data points.

(c) A curve representing the upper limit of all BD/SOM data points.

Six pedotransfer functions (three per farm) were derived for the relationship between $\mathrm{BD}$ and the SOM weight concentration:

$\mathrm{BD}=\alpha \cdot e^{-\beta \cdot S O M}$

Eq 1.

Where:

$\mathrm{BD}=$ soil bulk density in $\mathrm{g} \mathrm{cm}^{-3}$

$\mathrm{SOM}=$ the soil organic matter concentration in $\mathrm{g} \mathrm{SOM} \mathrm{kg}^{-1}$ soil

$\alpha\left(\mathrm{g} \mathrm{cm}^{-3}\right)$ and $\beta\left(\mathrm{kg} \mathrm{g}^{-1}\right)$ are the regression coefficients.

For the average curves all data points are included to derive the equations. For the upper and lower limit curve, data points were divided in 'bins' of equal distances (of increasing SOM content, i.e. Bin 1: 0-10 $\mathrm{g} \mathrm{SOM} \mathrm{kg}^{-1}$ soil; Bin 2: 10-20 g SOM kg-1 soil etc.; Cade \& Noon, 2003). Of each bin the highest and lowest BD values were taken. Next, the six pedotransfer functions were applied to the SOM weight concentrations measured on the two farms and their fields. The estimated BD value and the SOM weight concentration were used to calculate the SOM stock:

$\operatorname{SOM}$ stock $\left(\mathrm{Mg} \mathrm{ha}^{-1}\right)=$

soil layer $(\mathrm{cm}) \cdot 10^{8}\left(\mathrm{~cm}^{2} \mathrm{ha}^{-1}\right) \cdot a \cdot e^{-\beta \cdot \operatorname{SOM}}\left(\mathrm{g} \mathrm{cm}^{-3}\right) \cdot 10^{-9}\left(\mathrm{Mg} \mathrm{g}^{-1}\right) \cdot \mathrm{SOM}\left(\mathrm{g} \mathrm{kg}^{-1}\right) \cdot$ $10^{-3}\left(\mathrm{~kg} \mathrm{~g}^{-1}\right)$

Eq. 2.

The three curves (i.e. All data points, BDmin and BDmax) were applied to the $\mathrm{SOM}$ weight concentrations at $\mathrm{t}=0$ and for each farm-soil layer combination. Analysis of variance was conducted with SOM stock as the dependent variable and BD curve as factor (i.e. All data points, BDmin and BDmax), (LSD or Dunnett's T3 in the case of unequal variances, $P<0.05$ ). The statistical analysis for assessing SOM stock change over time is presented below (see section "Where?" - Analysis at farm and field level for different soil layers). SPSS $\left(24^{\text {th }}\right.$ edition $)$ was used to perform the statistical analyses.

Pedotransfer curves from the literature

The Google Scholar abstract database (in English) and Google search engine (in Dutch) were used to find reported relationships between BD and SOM. The search terms were: soil bulk density, relationship and soil organic matter. In Dutch the same search terms were used (i.e. bodemdichtheid = soil bulk density; relatie = relationship; bodem organische stof = soil organic matter). The criterion for inclusion was the presentation of individual data points on both BD and SOM weight concentration. This resulted in three studies in 
English and three studies in Dutch. Data was taken from the tables or from the graphs using WebPlotDigitizer (Automeris, 2019). An overview of the curves obtained from the literature, for the two farms of the current study and the ranges in $\mathrm{BD}$ and $\mathrm{SOM}$ is presented in Table 3. Furthermore, the equation used by Eurofins Agro, (one of the largest soil laboratories in the Netherlands), to convert SOM weight concentrations to SOM stocks in sandy cover soils, is also given in this table. Note, Farms A and B are located on sandy cover soils.

Table 3. Overview of the equations obtained for the two farms and from the literature for the relationship between the soil bulk density (BD) and the soil organic matter weight concentration (SOM). n.r. = not reported.

\begin{tabular}{|c|c|c|c|c|c|}
\hline Study & $\begin{array}{l}\text { Region and land- } \\
\text { use }\end{array}$ & $\mathrm{n}$ & $\begin{array}{l}\text { Range } \\
\text { in } \mathrm{BD}(\mathrm{g} \\
\left.\mathrm{cm}^{-3}\right)\end{array}$ & $\begin{array}{l}\text { Range } \\
\text { in SOM } \\
\left(\mathrm{g} \mathrm{kg}^{-1}\right)\end{array}$ & Equation \\
\hline $\begin{array}{l}\text { This study, } \\
\text { Farm A }\end{array}$ & NL - grassland & 252 & $1.75-0.61$ & $0-244$ & $B D=\alpha \cdot e^{-\beta \cdot S O M}$ \\
\hline $\begin{array}{l}\text { This study, } \\
\text { Farm B }\end{array}$ & $\mathrm{NL}$ - grassland & 252 & $1.66-0.70$ & $0-153$ & $B D=\alpha \cdot e^{-\beta \cdot S O M}$ \\
\hline $\begin{array}{l}\text { Adams, } \\
(1973)\end{array}$ & Podzolic soils & n.r. & $1.64-0.24$ & $0-1000$ & $B D=\frac{1000}{\left(\frac{S O m}{\alpha}\right)+\left(\frac{1000-S O M}{\beta}\right)}$ \\
\hline $\begin{array}{l}\text { Hossain et } \\
\text { al., (2015) }\end{array}$ & $\begin{array}{l}\text { Canada, Arctic } \\
\text { region, forest soils } \\
\text { and wetland }\end{array}$ & 111 & $1.69-0.06$ & $0-892$ & $B D=\alpha+\beta \cdot e^{-\beta \cdot S O M}$ \\
\hline $\begin{array}{l}\text { Perie \& } \\
\text { Ouimet, } \\
(2008)\end{array}$ & $\begin{array}{l}\text { Canada, Boreal } \\
\text { forest soils }\end{array}$ & 125 & $1.92-0.37$ & $2-248$ & $\begin{array}{l}B D=\alpha+\beta \cdot S O M-y \\
* \ln S O M-\varepsilon *(\ln S O M)^{2}\end{array}$ \\
\hline $\begin{array}{l}\text { De Haan \& } \\
\text { van Geel } \\
(2019)\end{array}$ & NL - Unknown & 20 & $1.47-0.86$ & $10-200$ & $B D=\frac{1}{a \cdot S O M+\beta}$ \\
\hline $\begin{array}{l}\text { Zwart et al., } \\
\text { (2013) }\end{array}$ & $\mathrm{NL}$ - Arable soils & 20 & $1.45-0.20$ & $28-950$ & $B D=\alpha \cdot \ln S O M+\beta$ \\
\hline $\begin{array}{l}\text { Van Eekeren } \\
\text { et al., (2018) }\end{array}$ & NL - Unknown & 4 & $1.42-1.17$ & $20-79$ & Not mentioned. \\
\hline $\begin{array}{l}\text { Eurofins } \\
\text { Agro }\end{array}$ & $\begin{array}{l}\mathrm{NL} \text { - sandy cover } \\
\text { soils }\end{array}$ & n.r. & $1.53-0.78$ & $0-250$ & $B D=\frac{1}{a \cdot S O M+\beta}$ \\
\hline
\end{tabular}


"Where?" - Analysis at farm and field level for different soil layers In total 672 samples were collected (two farms $\mathrm{x}$ seven fields $\mathrm{x}$ three soil layers $x 16$ sampling dates). SOM weight concentrations were converted to SOM stocks using Equation 2 (farm specific curves, including all data points per farm). The SOM stocks from the $0-30 \mathrm{~cm}$ and $0-60 \mathrm{~cm}$ soil layers were obtained by summing up the stocks of the $0-10 \mathrm{~cm}$ and $10-30 \mathrm{~cm}$ soil layers, and all sampled layers, respectively. SOM stocks $\left(\mathrm{Mg} \mathrm{ha}^{-1}\right)$ were plotted against time. Values that were outside 1.5 times the interquartile range were considered as outliers (Tukey, 1977). Eleven out of 672 observations were removed as outliers (five measurements from Farm A and six from Farm B). Normality was assessed with the Shapiro Wilk test (data not presented).

Statistical analysis was conducted at farm level and at field level. SOM stock levels at the farm scale were obtained by multiplying the SOM stock of each field with the field size divided by the total sampled area (see Table 2 for the field sizes). Trends in the stock of SOM over time were estimated for each farm-soil layer combination using ordinary linear regression (soil layers: $0-10 \mathrm{~cm}, 10-30 \mathrm{~cm}, 30-60 \mathrm{~cm}, 0-30 \mathrm{~cm}, 0-60 \mathrm{~cm}$ ), in 2 farms $\times 5$ soil layers $=10$ analyses. The SOM stock was the dependent variable and time was the independent variable. At field level the same analyses were conducted (2 farms $\times 5$ soil layers $\times 7$ fields per farm $=70$ analyses).

\section{"When?" - Sampling frequency}

The effect of sampling frequency on the estimated changes in stocks of SOM over time was assessed for a sampling frequency of four times per year, twice per year (spring and autumn; winter and summer) and once per year (spring, summer, autumn, winter). Ordinary linear regression was conducted using SOM stock as the dependent variable and time as the independent variable. Analyses were conducted for each farm-soil layer combination.

\section{Results}

\section{1 "What to report?" - How to derive SOM stocks from SOM weight concentrations}

Very strong relationships were found between the bulk density and soil organic matter weight concentrations (Figure 5). Most variance was explained for the dataset with the maximum BD/SOM ratio's (BDmax) of Farm A (cf. $R^{2}=0.99$; Figure $5 a$ ). Figure $5 c$ demonstrates that the curves of Farms $A$ and $B$ are within the range of other curves found in the literature.

SOM weight concentrations at the start of the monitoring period ( $t=0$, spring 2010) were converted to SOM stocks with the farm specific pedotransfer functions (cf. Figures $5 \mathrm{a}$ and $5 \mathrm{~b}$ ). The BDmin curve resulted in the lowest calculated SOM stocks and the BDmax curve in the highest SOM stocks 
(Figure 6). The SOM stocks calculated with the BDmin curve were on average $16 \%$ less than the SOM stocks based on the curve using all data points. SOM stocks based on the BDmax curve were on average 12\% larger than the SOM stocks based on all data points (Supplementary material, Figure S1). Significant differences were found between SOM stocks calculated based on different pedotransfer curves derived from the monitoring activities described in this paper and derived from the literature (Supplementary material, Table S3). However, note that the different pedotransfer functions do hardly affect the trends in SOM stocks which will be presented in the rest of this section (Supplementary material, Figure S2).
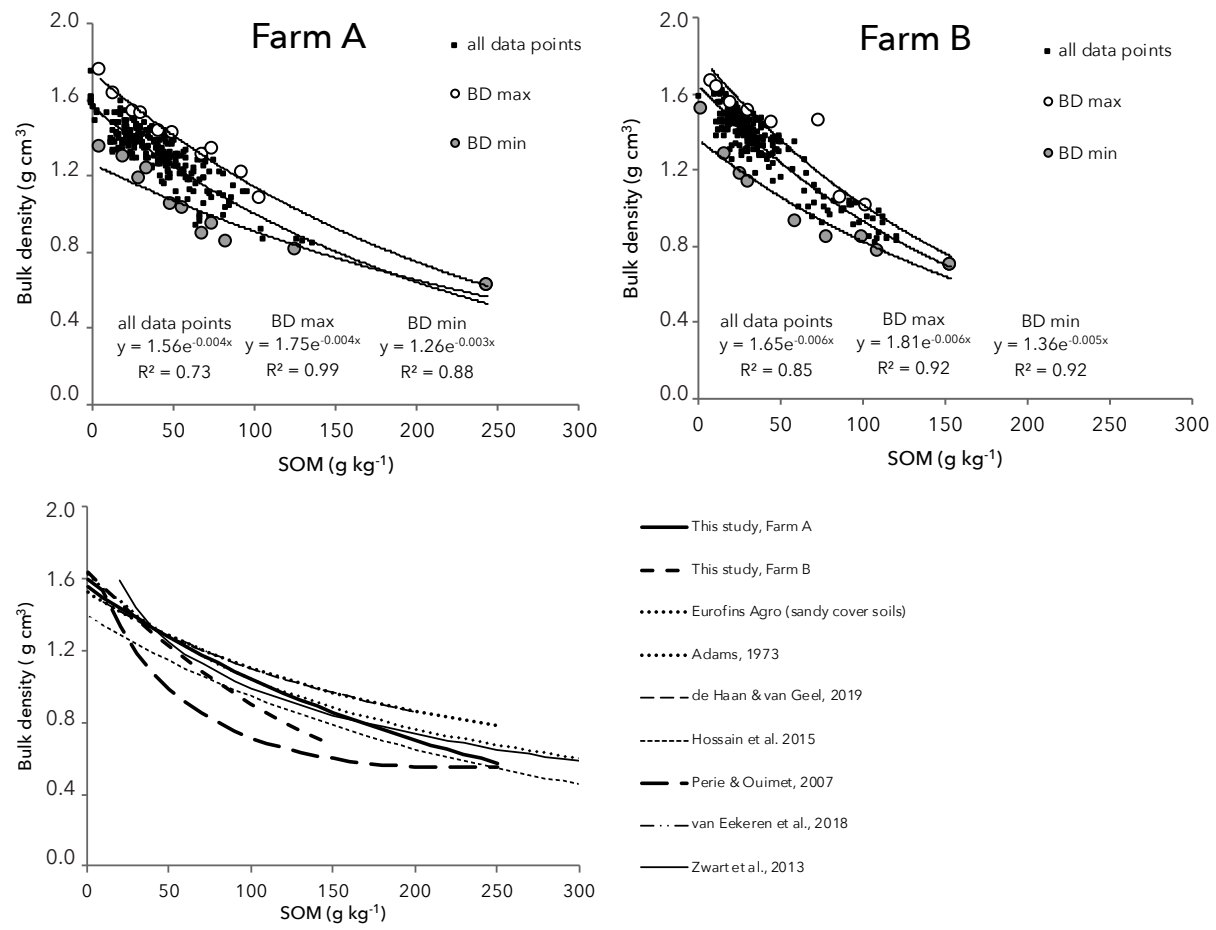

Figure 5. Relationship between soil bulk density and soil organic matter (SOM) weight concentration for Farm A [a], Farm B [b] and a number of equations obtained from the literature [c]. In [a], [b]: the upper and lower curve (BDmax and BDmin, respectively) were derived from a subset of the data points (see Materials and methods). Details of the curves are provided in the supplementary material, Table S2. In [c] the curves of both farms based on all data points are given. 

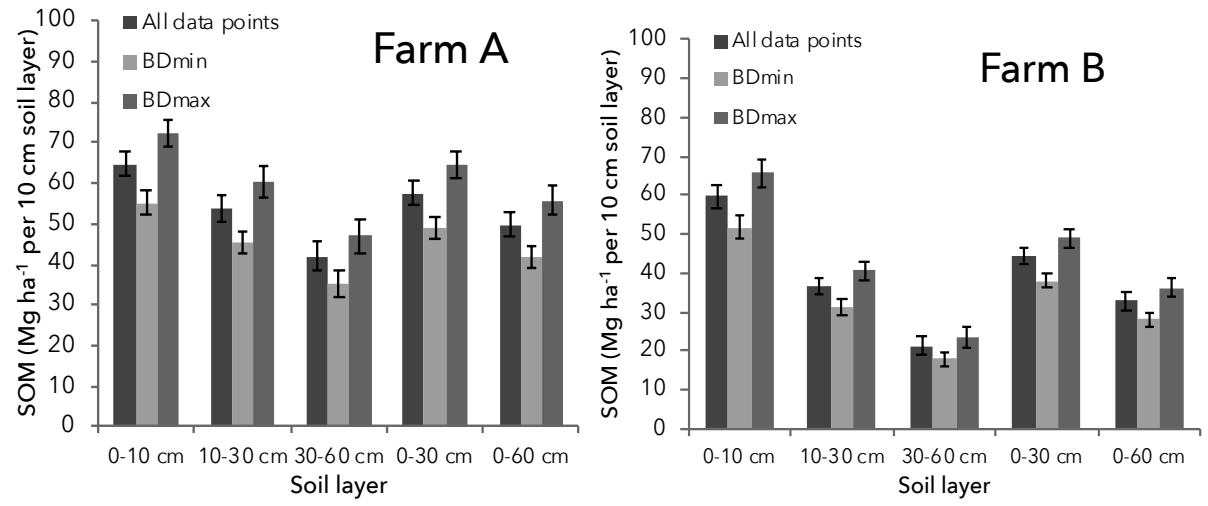

Figure 6. Effect of different BD-SOM curves on the calculation of SOM concentrations to stocks for different soil layers at $\mathrm{t}=0$. Standard errors of the mean are presented. See Figure $5 a$ and 5b, and Table S2 for more details about the curves. The two upper graphs show cumulative total stocks for the three soil layers, and the two lower graphs show the stocks expressed per $10 \mathrm{~cm}$ soil layer.

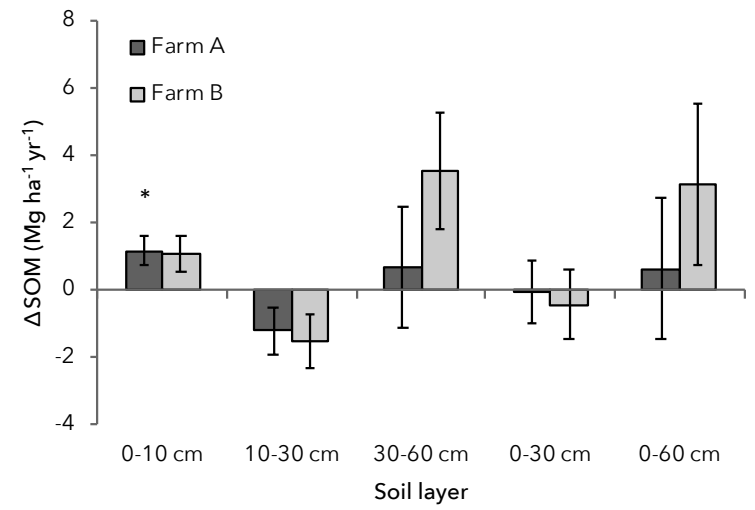

Figure 7. Changes in soil organic matter (SOM) stocks over time for Farm A and Farm $B$ per soil layer using a sampling frequency of four times per year. Standard errors are given. * indicates significance for slope values different from zero at $P<0.05$.

\section{2 "Where?" - Analysis at farm and field level for different soil layers} Farm level - In the 0-10 cm soil layer SOM increased with on average 1.2 and $1.1 \mathrm{Mg} \mathrm{ha}^{-1} \mathrm{yr}^{-1}$ on Farm A and Farm B, respectively (Figure 7). In the $10-30 \mathrm{~cm}$ soil layer SOM tended to decline on both farms with $-1.2 \mathrm{Mg} \mathrm{ha}^{-1} \mathrm{yr}^{-1}$ (Farm $A$, $P=0.12$ ) and $-1.5 \mathrm{Mg} \mathrm{ha}^{-1} \mathrm{yr}^{-1}$ (Farm $\mathrm{B}, P=0.07$ ). In the $30-60 \mathrm{~cm}$ soil layer no change in SOM was observed on Farm $A\left(0.7 \mathrm{Mg} \mathrm{ha}^{-1} \mathrm{yr}^{-1}, P=0.71\right)$. On Farm B SOM tended to increase with $3.6 \mathrm{Mg} \mathrm{ha}^{-1} \mathrm{yr}^{-1}(P=0.06)$. Large differences between farms were observed when considering changes in the whole 
sampled profile: the SOM stock in the $0-60 \mathrm{~cm}$ soil layer of Farm A remained stable $\left(0.65 \mathrm{Mg} \mathrm{ha}^{-1} \mathrm{yr}^{-1}, P=0.77\right)$ and on Farm B the SOM stock tended (nonsignificantly) to increase (3.1 Mg ha-1 $\left.\mathrm{yr}^{-1}, P=0.21\right)$.

Field level - Large differences in SOM dynamics were found between fields, especially when considering the whole sampled soil profile (Figure 8). In all fields of both farms, SOM tended to increase in the $0-10 \mathrm{~cm}$ soil layer, however, this was in most cases not significant. Greatest SOM accumulation rates in the $0-10 \mathrm{~cm}$ soil layer were found in field number 5 of Farm A (4.6 Mg SOM ha-1 $\left.\mathrm{yr}^{-1} ; P=0.02\right)$ and Field 1 of Farm B (2.3 Mg ha-1 $\left.\mathrm{yr}^{-1} ; P=0.00\right)$. In the $10-30 \mathrm{~cm}$ soil layer, two significant changes of SOM were found on Farm A (Fields 6 and 7). SOM tended to decrease in nearly all fields of Farm B (in Fields 3 and 6 significantly). In the $30-60 \mathrm{~cm}$ soil layer, no significant changes in SOM were found for Farm A. For Farm B, three out of seven fields showed a significant increase in SOM over time (Field numbers 1, 5 and 7).
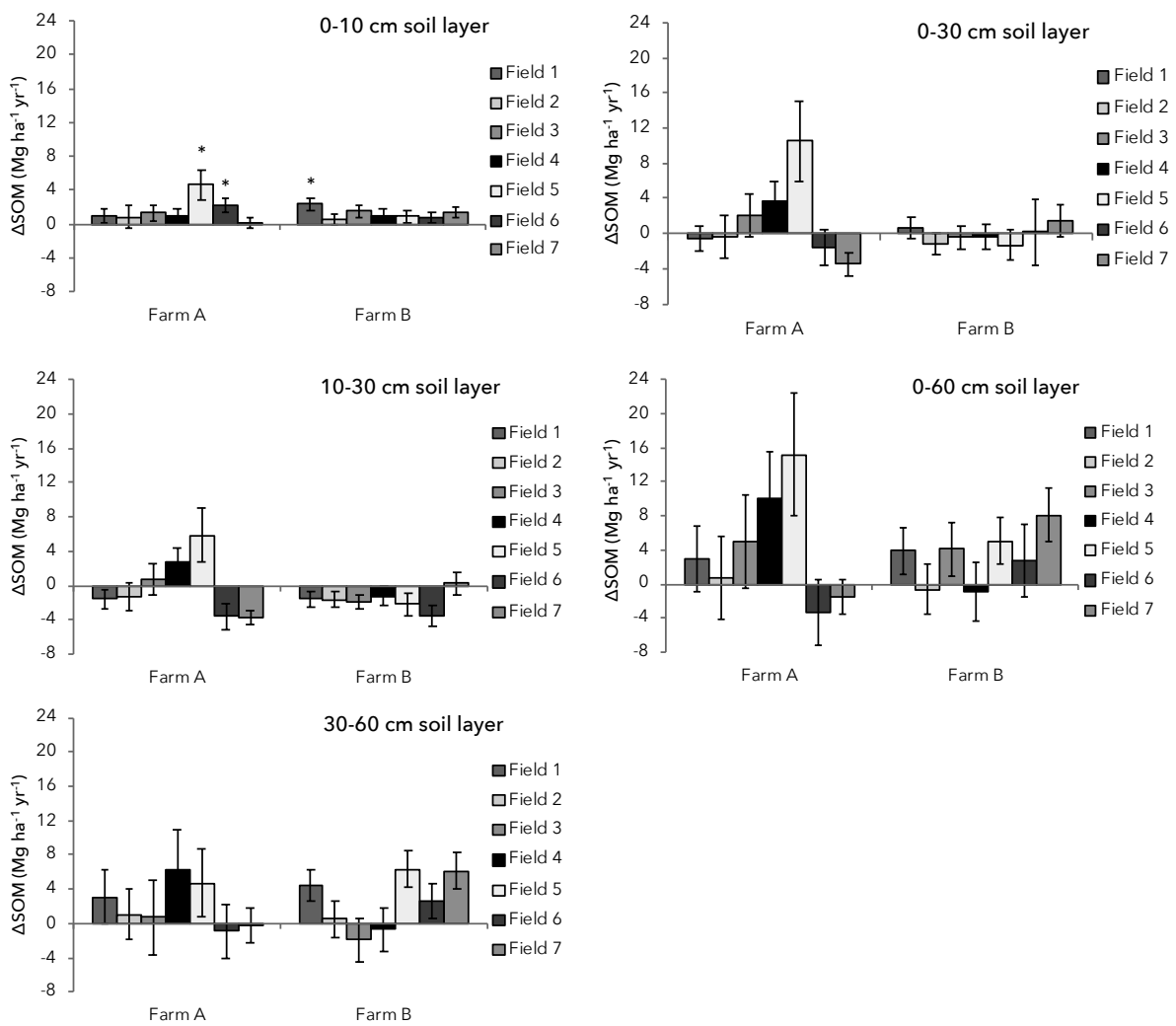

Figure 8. Changes in soil organic matter (SOM) stocks over time for Farm A and Farm $B$ per soil layer per field. Standard errors are given. * indicates significance for slope values different from zero at $P<0.05$. Note the difference in scales with Figure 7. 


\section{3 "When?" - Sampling frequency}

A sampling frequency of twice per year (spring and autumn; winter and summer) showed trends that were similar to a sampling frequency of four times per year (Figures 7 and 9). Yet, $P$-values were higher than the $P$-values obtained with a sampling frequency of four times per year. None of the trends at farm level with a sampling frequency of twice per year showed a significant change of SOM stocks over time (Figure 9).
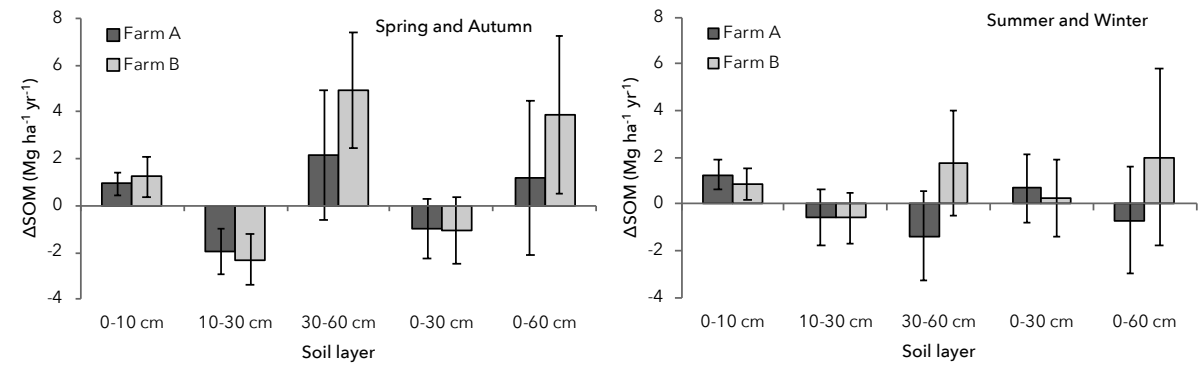

Figure 9. Changes in soil organic matter (SOM) stocks over time for Farm A and Farm $B$ per soil layer for a sampling frequency of two times per year. Standard errors are given. * indicates significance for slope values different from zero at $P<0.05$.
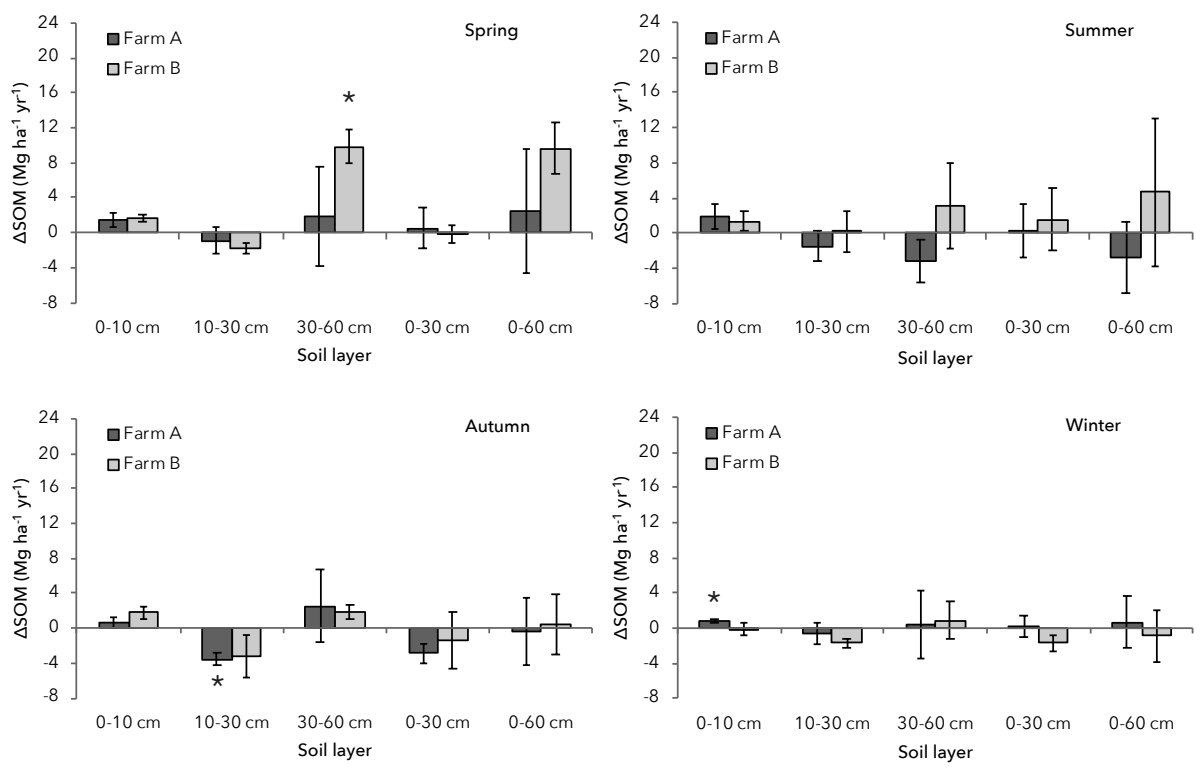

Figure 10. Changes in soil organic matter (SOM) stocks over time for Farm $A$ and Farm B per soil layer for a sampling frequency of once per year. Standard errors are given. * indicates significance for slope values different from zero at $P<0.05$. Note the difference in scales with Figure 9. 
A sampling frequency of once per year (spring, summer, autumn or winter) showed no seasonal effect on SOM stock changes in the $0-10 \mathrm{~cm}$ soil layer at both farms (Figure 10). In most cases SOM tended to increase or remained stable. In the 10-30 cm soil layer at Farm A, SOM remained stable in spring, summer and winter measurements. With autumn measurements a significant decrease in SOM was found. At Farm B, SOM tended to decline in the 10-30 $\mathrm{cm}$ soil layer, except for the summer measurements when SOM remained stable. In the 30-60 cm soil layer no changes in SOM were observed at Farm A for the different seasons. At Farm B, SOM increased significantly with spring measurements (30-60 cm soil layer; Figure 10a). This was the case for all fields (Supplementary material, Figure S3). Overall, smallest changes in SOM over time were observed in winter measurements for all soil layers at both farms (Figure 10d).

\section{Discussion}

We aimed to provide quantitative insights into the circumstances "How", "Where" and "When" for measurements of soil organic matter stocks in grasslands and the development thereof in time through intensive monitoring of two dairy farms in the Netherlands. We found that all three circumstances affected conclusions on SOM stocks or SOM dynamics strongly. In the following sections we discuss the findings of this study for each circumstance separately.

\section{1 "What to report?" - How to derive SOM stocks from SOM weight concentrations?}

The SOM weight concentration is of large influence on the BD as a consequence of large differences in specific weight between organic matter and the mineral fraction (Adams, 1973). Therefore, it is to be expected that significant differences are found between SOM stocks when different pedotransfer curves are used to convert SOM concentrations to SOM stocks. Comparison of different pedotransfer functions showed that the curves derived in this study were similar to the curves found in the scientific literature and some practical manuals (Figure 5c). Yet, a significant effect of pedotransfer curve was found on the calculation of SOM stocks (Supplementary material, Figure S1).

In this study we assumed that the SOM weight concentration is the only variable influencing the soil bulk density. All other components in the soil such as the soil texture are presumed to be constant across different soil layers (NB. Table 2 shows little variation in soil texture levels between soil layers). It is not expected that the shape of the BD curve (BD against the SOM weight concentration) depends strongly on the soil texture, as the specific gravity of sand is very similar to clay (sand: 2.7; clay: 2.6; Cabalar \& Hasan, 
2013). However, stoniness could be a major issue, leading to overestimations of SOM stocks (Poeplau et al., 2017). The method we used to convert SOM weight concentrations to SOM stocks is therefore only suitable for areas with unconsolidated soils without rock fragments, like most of the sedimentary soils in the Netherlands. For soils high in rock fragments, the current approach is only recommended when rock fragments are removed prior to determination of the soil mass (Poeplau et al., 2017). Note that in case rock fragments are not removed, BD values will be much higher thus leading to overestimations of SOM stocks (voids that are filled with rocks are in reality filled with SOM free material, and not with soil).

Although the type of BD curve (All data points, BDmin, BDmax) hardly influences conclusions on SOM stock changes over time, we argue that it is most accurate to use a pedotransfer curve based on site specific measurements rather than a (generic) curve from the literature, especially when SOM stocks are to be compared across different sites.

\section{2 "Where?" - Analysis at farm and field level for different soil layers} Large differences in SOM dynamics were found between farms, fields and depths (Figures 7 and 8). In the $0-10 \mathrm{~cm}$ soil layer SOM increased on both farms (significantly at Farm A) and in the $10-30 \mathrm{~cm}$ soil layer, SOM tended to decline on both farms. This is in line with both Don et al. (2009) and Hoogsteen et al. (2020) who showed that SOM contents declined in the $10-20 \mathrm{~cm}$ and 10-30 cm soil layer after the conversion from arable land to grasslands. It is, however, remarkable that even after a grassland period of around 25 years, SOM stocks were still declining in this layer $(0-30 \mathrm{~cm}$ soil layer, cf. Figures 7 and 8). The increases in SOM in the $0-10 \mathrm{~cm}$ soil layer were fully compensated by decreases in the 10-30 cm soil layer, resulting in no net change for the 0-30 $\mathrm{cm}$ soil layer. Evidently, our results underpin that sampling depth is of crucial importance when monitoring SOM dynamics to draw conclusions on the sequestration potential of grassland soils (cf. Taghizadeh-Toosi et al., 2014). Our grasslands did not sequester carbon as such, which is in contradiction with the 'rules of thumb' of Dutch farm advisors (e.g. Klein Swormink et al., 2019). Large differences in SOM stock changes were found between farms for the 30-60 cm soil layer. On Farm A, no net change was observed and on Farm B, SOM tended to increase with $3.6 \mathrm{Mg} \mathrm{ha}^{-1} \mathrm{yr}^{-1}$ (Figure 7).

\section{3 "When?" - Sampling frequency}

The analysis at season level (sampling once per year) revealed that a significant increase in SOM stocks was only found when sampling in spring (Farm B and 30-60 cm); all fields of Farm B showed a consistent, significant increase of SOM in the 30-60 cm soil layer (Figure S3). The sampled farms show large differences between seasons which we could not explain, and which need further investigation. Based on a four year intensive monitoring period it is not possible to disentangle the effects of sampling frequency and 
seasonal variation in SOM trends. A higher measurement frequency does not lead to finding a larger number of significant trends (Table S4). More insight is needed in the spatial variation of SOM in combination with detailed carbon balances at field level to determine a suitable sampling interval for assessing significant changes of SOM over time. For pragmatic reasons we recommend to sample once per year in winter because then we expect SOM inputs to interfere least with accuracy in SOM measurements (i.e. no soil compaction and trampling because stocking does not take place in winter and no manure input occurs (Figure 10d)).

\subsection{Differences between farms and fields}

Possible explanations for the differences in SOM stock changes between farms are differences in manure and stocking management. Farm A employed a lenient strip stocking system which is characterised by putting cows to graze in long standing biomass (about $20 \mathrm{~cm}$ ). Some commercial farm enterprises claim multiple benefits of this system, including an increased level of soil carbon sequestration as compared to other stocking systems (Farmers practice network: "Organic: climate neutral!", 2019). Although the grazing area of the cows is enlarged every three hours, the high livestock density (especially at the start of each day when the grazing area was smallest), results in large losses of herbage yield due to trampling and consequently extra $C$ inputs into the soil. Annual net dry matter herbage yields were estimated to be roughly $6 \mathrm{Mg} \mathrm{ha}^{-1}$ which is low for Dutch production grasslands which commonly yield around $11 \mathrm{Mg} \mathrm{ha}^{-1} \mathrm{yr}^{-1}$ (WEcR, 2019b). Therefore, we presume that a large part of the produced biomass was not harvested leading to additional $C$ input into the soil. This was not reflected in higher SOM accumulation rates of Farm $A$ as compared to Farm $B$, perhaps most likely because the additional SOM input was too small to be detected against a large and heterogeneous background SOM stock. According to Janssen (1984) about $20 \%$ of the added OM as green matter is still present in the soil after 1 year. Therefore, the annual additional input remaining after one year of application was estimated to be $0.2 \times(11-6)=1 \mathrm{Mg} \mathrm{ha}^{-1} \mathrm{yr}^{-1}$, against a background stock of around $65 \mathrm{Mg} \mathrm{SOM} \mathrm{ha}^{-1}(\mathrm{SD}=8)$ in the $0-10 \mathrm{~cm}$ soil layer (note, soil sampling was not more difficult at Farm A, as the sward was much more open and the high biomass could be easily pushed to the side prior to putting the auger into the soil). The extra C flux did not occur on Farm B where grasslands were continuously stocked.

The average sward height on Farm B throughout the grazing season was about $8 \mathrm{~cm}$ and yield losses were considerably less than on Farm A: the annual net dry matter yield was estimated to be about $12 \mathrm{Mg} \mathrm{ha}^{-1}$ as confirmed by regular observations by the farmer (Personal communication with J.D. van der Voort, 2015). The difference in grass height also led to differences in clover content and consequently differences in soil life between both farms and thus decomposition rates of SOM (Rashid, 2013). 
Van Eekeren et al. (2015) have shown a negative correlation between clover content and herbage height, which we also observed on the two farms, i.e. the clover content on Farm A was much lower than on Farm B. Furthermore, Van Eekeren et al., (2010) showed that the number of earthworms increased with increasing clover content, which was confirmed by observations on the same farms: Rashid (2013) found that the total number of earthworms and enchytraeids were, respectively, five and three times greater on the grasslands of Farm B (Field B2) than of Farm A (Field A3; Farm A and Farm $B$ in this study were, respectively, Farm D and Farm B in the study of Rashid, 2013). The greater number of earthworms at Farm B as compared to Farm A possibly led to higher decomposition rates of SOM and more vertical transportation of SOM (through illuviation of for instance root exudates and mucilage; Jones \& Donnelly, 2004). Soil displacement rates from earthworms (based on mounding) between $50 \mathrm{Mg} \mathrm{ha}^{-1} \mathrm{yr}^{-1}$ were reported in the literature for non-tropical areas and bioturbation plays a key role in the carbon cycle (Wilkinson et al., 2009). The number of endogeic earthworms (which occur predominantly in the 10-15 cm soil layer; Van Eekeren, 2008) was four times larger on Farm B as compared to Farm A (304 per m² vs. 76 per m², Rashid, 2013). The difference in earthworm numbers and other biota (cf. Rashid, 2013) could be also related to the manure management. Large amounts of straw were imported at Farm B and most of the manure was applied as solid cattle manure from a deep litter stable, while cattle slurry was the main source of manure applied on the fields of Farm A. Van Eekeren (2010) assessed the effect of different fertilizer treatments on soil biota in a grassland experiment on a sandy soil in the Netherlands and found that the total number of earthworms was higher under the farm yard manure (FYM) treatment than the cattle slurry treatments. Although we do not have sufficient information to draw up carbon balances at farm level, we conclude that besides the amount of manure applied, other management characteristics such as stocking management, manure type and consequently soil biota, need to be taken into account. Deriving conclusions on grasslands as potential carbon sinks need specification of their management.

At field level the initial SOM weight concentration varied among fields, especially in the 30-60 cm soil layer (Figure S4). On Farm A, the SOM weight concentration of field 5 was about twice as high as that of the other fields (46 vs. $28 \mathrm{~g} \mathrm{SOM} \mathrm{kg}^{-1}$ soil; 60 vs. $39 \mathrm{Mg} \mathrm{ha}^{-1}, 30-60 \mathrm{~cm}$ soil layer, Figure S4) because of fragmented peat remains. Although all fields were classified as sandy soils, historical data show that peat harvesting took place in the area between the $10^{\text {th }}$ and the $17^{\text {th }}$ century and possibly field 5 was located on a former peatland. However, no detailed historical information is available at field level. On Farm B, the initial SOM weight concentration of the 30-60 $\mathrm{cm}$ layer of field 7 was much lower as compared to the other fields (8 vs. 15 g SOM kg-1 soil; 37 vs. $69 \mathrm{Mg} \mathrm{ha}^{-1}, 30-60 \mathrm{~cm}$ soil layer, Figure S4). About 35 years ago, field 7 was ploughed to a depth of $60 \mathrm{~cm}$ as, at that time, it was 
thought by farm advisors that this field was too rich in SOM for unknown reasons. This one-time ploughing event led to redistribution of SOM in the soil profile and enhanced decomposition of SOM which is still reflected in the lower SOM content in the $30-60 \mathrm{~cm}$ soil layer of this field as compared to the rest of the farm. It has been suggested in the literature that sequestration rates of SOM decrease with increases in SOM content (e.g. Gulde et al., 2008), but no consistent relationship has been observed on both farms (Figure S4). Furthermore, it is not expected that the fields we sampled, had attained a new equilibrium (steady-state) induced by field management as it takes several decades to reach a steady-state (cf. Macdonald et al., 2015; Fornara et al., 2020).

\subsection{Implications}

This study underlines that caution should be taken when setting up an SOM monitoring network to comply with environmental directives or for giving out carbon credits. Large variation exists among fields (Figure 8). Recently, programs on carbon credits have been promoted by the province of Friesland and a few fields per farm will be selected for monitoring (e.g. two fields per farm; National Soil Top Meeting on the 11 th of September, 2019, Rotterdam, the Netherlands). In Figure 11 we presented the consequences of deriving conclusions based on the two fields with the highest and lowest changes in SOM stocks over time. As stated before the sampled soil layer is of utmost important on conclusions. In case we assess the $0-60 \mathrm{~cm}$ soil layer, SOM dynamics of Farm A varied between fields from $14.6 \mathrm{Mg} \mathrm{ha}^{-1} \mathrm{yr}^{-1}$ to -4.0 $\mathrm{Mg} \mathrm{ha}^{-1} \mathrm{yr}^{-1}$. At Farm B, SOM dynamics varied from 8 to $-2.3 \mathrm{Mg} \mathrm{ha}^{-1} \mathrm{yr}^{-1}$. A target price of $30 €$ per $\mathrm{Mg} \mathrm{CO}_{2}$ was set in the province of Friesland (VVM, 2019), which is equivalent to about $0.5 \mathrm{Mg} \mathrm{SOM} \mathrm{ha}^{-1} \mathrm{yr}^{-1}$ (using a factor of two to convert SOC to SOM; Pribyl, 2010). This potentially means that Farm A could be paid an amount of about $€ 900 \mathrm{ha}^{-1} \mathrm{yr}^{-1}(14.6 \times 2 \times 30)$ or has to pay an amount of $€ 200 \mathrm{ha}^{-1} \mathrm{yr}^{-1}(-2.3 \times 2 \times 30)$. A similar situation would occur at Farm B.
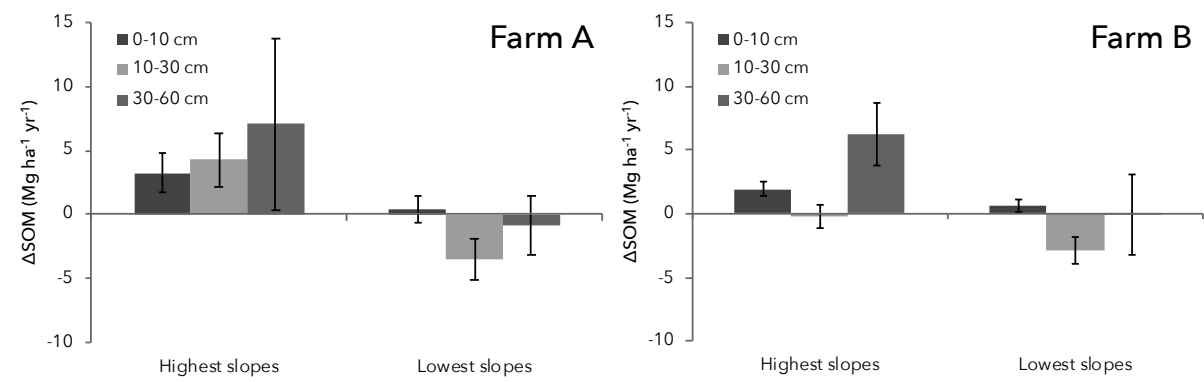

Figure 11. SOM stock changes over time for Farms A and B. Perfarm and soil layer, the fields with two highest slope values and two lowest slope values were taken. 
As the intrinsic variation of the SOM contents in the field is high, SOM trends are associated with a high level of uncertainty, even between fields under equal management. It may therefore be better for policy makers to incentivize agronomical measures that potentially contribute to SOM sequestration, rather than basing payment schemes on highly variable trends. If quantitative underpinning is wished than it is recommended to collect soil samples across the whole farm instead of two fields as trends across fields have shown to be highly variable.

\section{Conclusions}

The application of the rhetorical scheme 'Seven circumstances' in the context of on-farm soil monitoring led us to conclude that a large number of factors is of influence on the calculation of SOM stocks and stock changes and thus allocating carbon credits. We gained quantitative insights into the circumstances "How" (conversion of SOM weight concentrations to SOM stocks), "Where" (soil depth), and "When" (seasonality) and conclude that:

Considerable variation exists in pedotransfer curves relating soil bulk density and SOM weight concentration. Therefore, a site specific pedotransfer curve should be used when comparing SOM stocks based on SOM weight concentrations across sites.

- Sampling depth of grassland soils should be increased from $10 \mathrm{~cm}$ to at least $60 \mathrm{~cm}$ for quantification of SOM stocks and stock changes over time.

Large differences between SOM stock changes over time were found between fields. Yet, few trends were significantly different from zero, indicating that an intensive monitoring period of four years was too short for assessing significant changes of SOM over time. An increase in sampling frequency did not result in finding more significant trends in SOM stocks over time.

The whole farm should be sampled for quantitative underpinning of carbon payment schemes as trends between fields are highly variable.

Although it is claimed that the 'Pure graze' system sequesters significant amounts of carbon, this is not reflected in the monitoring results of Farm $A$ as no net change was observed in four years. Yet, we hypothesize that it is relevant to investigate the effect of specific management factors on SOM stock changes. 


\section{Supplementary material}

Box S1 Calculation of manure application on Farms A and B

Manure was applied to the grasslands as solid cattle manure, cattle slurry and during grazing. The total number of grazing hours of the total herd and fraction of the time that the herd was outside is provided in Table S1. The total manure production of the herd per year was based on national fixed rate values (RVO, 2019b; $24.7 \mathrm{~m}^{3} \mathrm{cow}^{-1} \mathrm{yr}^{-1}$, under the assumption that the milk yield was between $6.88 \cdot 10^{3}$ and $8.37 \cdot 10^{3}$ Liter $\left.\operatorname{cow}^{-1} \mathrm{yr}^{-1}\right)$.

Table S1. Calculation of the OM applied as manure during grazing for Farms $A$ and $B$.

\begin{tabular}{|c|c|c|}
\hline Characteristic & Farm A & Farm B \\
\hline Herd size (no. of dairy cows) & 74 & 85 \\
\hline $\begin{array}{l}\text { Manure production of dairy cows }\left(\mathrm{m}^{3} \text { cattle }\right. \\
\left.\text { slurry } \mathrm{yr}^{-1}\right)\end{array}$ & 1824 & 2095 \\
\hline Grazing hours of dairy cows (hour $\mathrm{yr}^{-1}$ ) & $25.9 \cdot 10^{4}$ & $25.5 \cdot 10^{4}$ \\
\hline Grazing hours per year (fraction) & 0.40 & 0.34 \\
\hline $\begin{array}{l}\text { Total manure applied during grazing } \\
\left(\mathrm{m}^{3} \mathrm{yr}^{-1}\right)\end{array}$ & 729 & 717 \\
\hline Farm size (ha) & 30.3 & 31.9 \\
\hline $\begin{array}{l}\text { Density of cattle slurry }\left(\mathrm{kg} \mathrm{m}^{-3}\right) \\
\text { OM content of cattle slurry }\left(\mathrm{kg} \mathrm{Mg}^{-1} \text { fresh }\right. \\
\text { product); De Haan \& van Geel, 2019). }\end{array}$ & $\begin{array}{l}1005 \\
71\end{array}$ & \\
\hline $\begin{array}{l}\text { Total manure applied per ha } \\
\left(\mathrm{Mg} \mathrm{OM} \mathrm{ha-1} \mathrm{yr}^{-1}\right)\end{array}$ & $\begin{array}{l}(729 \times 1.005 \times \\
0.071) / 30.3=1.7\end{array}$ & $\begin{array}{l}(717 \times 1.005 \times \\
0.071) / 31.9=1.6\end{array}$ \\
\hline
\end{tabular}

Table S2. Curvature parameters of the relationships between soil bulk density (BD) and soil organic matter (SOM) provided in Figure 5.

The equation reads: $B D=\alpha \cdot e^{-\beta \cdot S O M}$. Standard errors are given in parenthesis.

\begin{tabular}{llll}
\hline Farm & Function & $\alpha$ & $\beta$ \\
\hline A & All data points & $1.562(0.014)$ & $-0.004(<0.001)$ \\
& BDmin & $1.746(0.021)$ & $-0.004(<0.001)$ \\
& BDmax & $1.263(0.050)$ & $-0.003(<0.001)$ \\
B & All data points & $1.647(0.012)$ & $-0.006(<0.001)$ \\
& BDmin & $1.361(0.060)$ & $-0.005(<0.001)$ \\
& BDmax & $1.814(0.086)$ & $-0.006(<0.001)$ \\
\hline
\end{tabular}


Table S3. $P$-values from the analysis of variance comparing SOM stocks at $t=0$ for the three different pedotransfer functions (cf. Figures $5 a$ and $5 b$ ).

\begin{tabular}{cll}
\hline Soil layer & Farm A & Farm B \\
\hline $0-10 \mathrm{~cm}$ & 0.004 & 0.021 \\
$10-30 \mathrm{~cm}$ & 0.016 & 0.019 \\
$30-60 \mathrm{~cm}$ & 0.115 & 0.261 \\
$0-30 \mathrm{~cm}$ & 0.007 & 0.011 \\
$0-60 \mathrm{~cm}$ & 0.024 & 0.054 \\
\hline
\end{tabular}

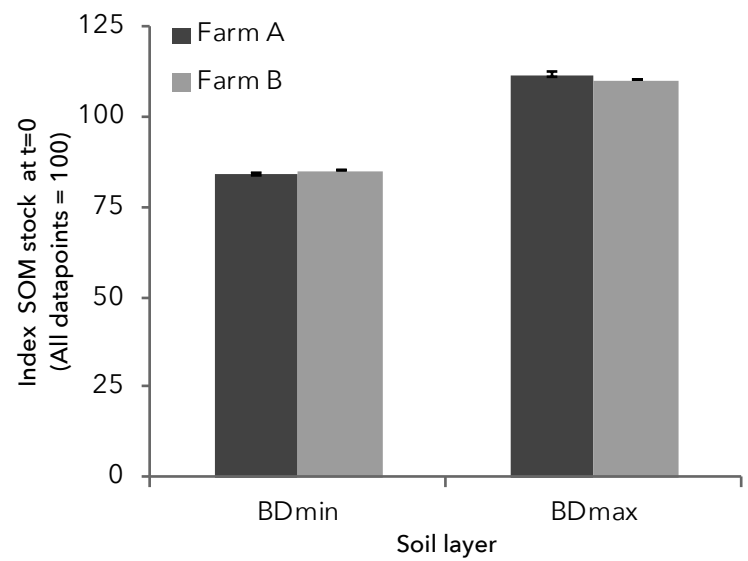

Figure S1. Index of SOM stocks at t $=0$ converted with the curves BDmin and BDmax (cf. Figures $5 \mathrm{a}$ and $5 \mathrm{~b}$ ). The SOM stocks calculated based on the curve including all data points was set at a value of 100 . The SOM stock calculated with BDmin and BDmax were divided by the SOM stock of all data points and expressed as a percentage (SOM stock, all data points $=100 \%)$. Averages of all layers are presented $(0-10 \mathrm{~cm}$, $10-30 \mathrm{~cm}, 30-60 \mathrm{~cm}, 0-30 \mathrm{~cm}, 0-60 \mathrm{~cm}$ ). Standard errors are given.
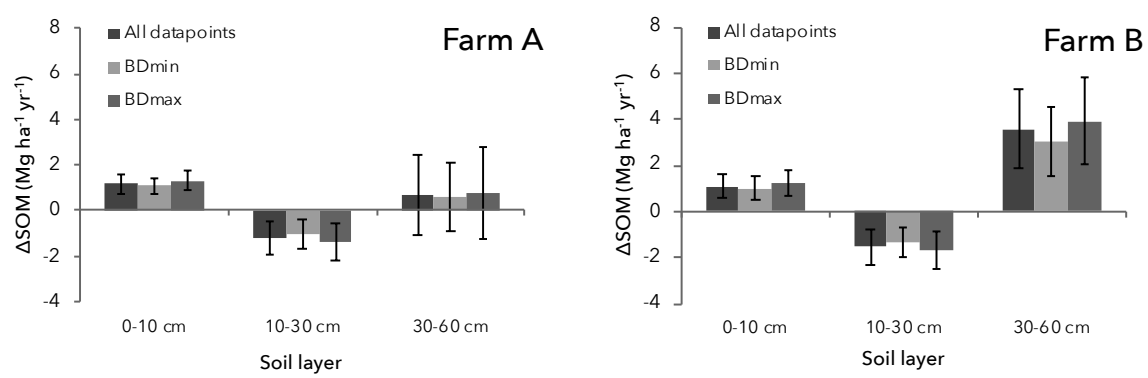

Figure S2. SOM stock changes over time calculated with different pedotransfer (BD/ SOM) curves. Standard errors are given. 


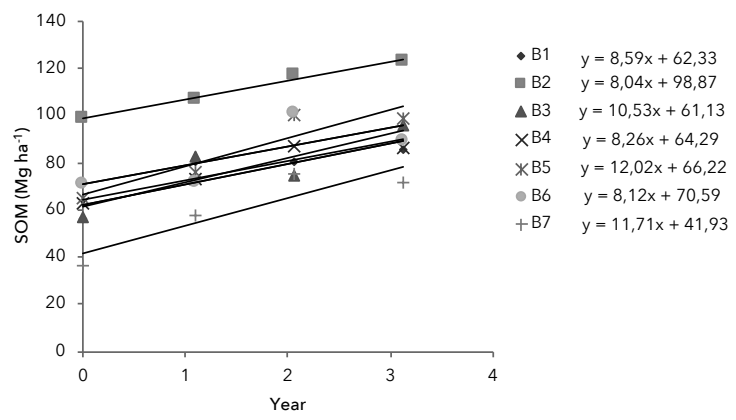

Figure S3. SOM stock changes over time for the $30-60 \mathrm{~cm}$ soil layer of all fields of Farm $B$ based on samples collected in the spring of each year. B1= field 1, B2= field 2, B3=field 3...B7=field 7 .
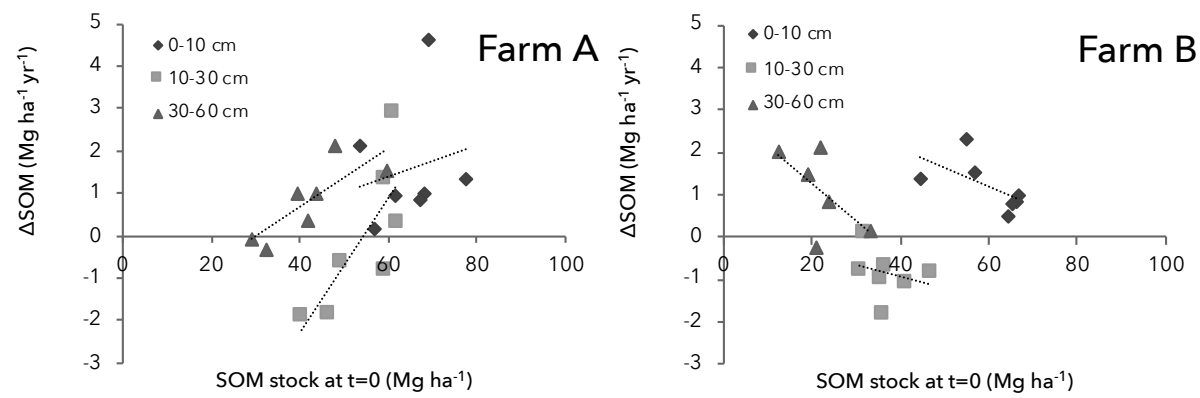

Figure S4. Relationship between changes in SOM stocks over time and SOM stock at $\mathrm{t}=0$ for three different soil layers. The SOM stocks and slopes were expressed in layers of $10 \mathrm{~cm}$ (i.e. SOM stocks and slopes values of the 10-30 cm soil layer were divided by 2 . Values of the $30-60 \mathrm{~cm}$ soil layer were divided by 3 ). Every data point is a field.

Table S4. Sampling frequency and number of significant trends.

\begin{tabular}{llll}
\hline $\begin{array}{l}\text { Sampling frequency } \\
\text { (times per year) }\end{array}$ & Number of trends per farm $\begin{array}{l}\text { Number of significant } \\
\text { trends }\end{array}$ \\
\hline & & Farm A & Farm B \\
1 & 20 & 2 & 1 \\
2 & 10 & 0 & 0 \\
$4:$ farm level & 5 & 1 & 0 \\
4: field level & 35 & 6 & 8 \\
\hline
\end{tabular}




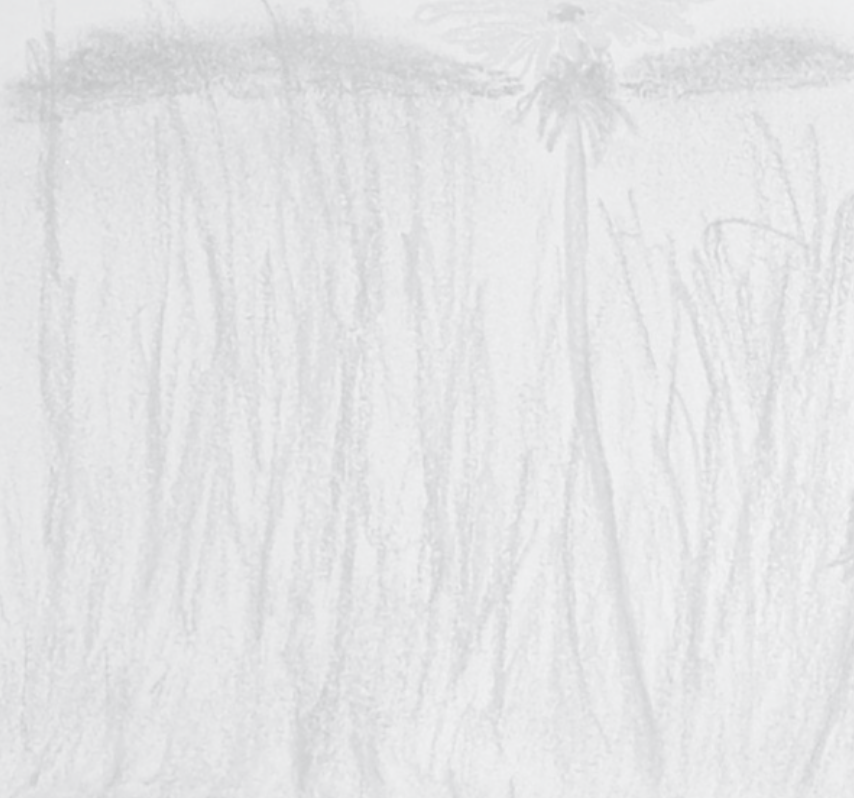

nest

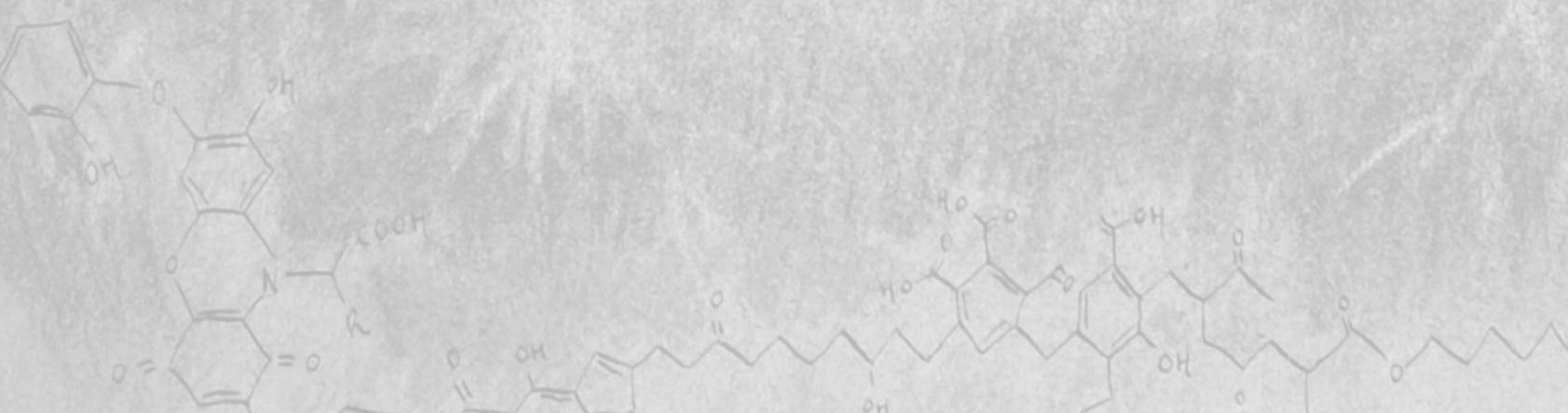


Chapter 5. Do species composition and harvesting regime affect root biomass and soil organic matter dynamics in temperate grassland swards?

Published (with minor revisions) as: Hoogsteen, M., Bakker, E.J., van Eekeren, N., Tittonell, P.A., Groot, J.C., van Ittersum, M.K., \& Lantinga, E.A. (2020). Do grazing systems and species composition affect root biomass and soil organic matter dynamics in temperate grassland swards? Sustainability, 12(3), 1260. 


\section{Summary}

Soil organic matter (SOM) dynamics of grassland soils may be affected by plant species composition and harvesting practices. We analysed the effects of simulated stocking systems (continuous (CS), rotational (RS) and lenient strip stocking (LS)) and species composition (monocultures of perennial ryegrass fertilized (LP+) and unfertilized (LP-)), tall fescue (fertilized, FA+) and a mixture of these two species with white clover (fertilized, LFT+)) on root biomass and SOM dynamics in field experiments on loamy and sandy soils in the Netherlands. Dried cattle manure was added to all fertilized treatments. We hypothesized that SOM accumulation would be highest under CS and $\mathrm{LS}$, and FA+ and LFT+ as a consequence of greater belowground biomass production. SOM was monitored for a period of two (loam and sand) and five (sand) years after conversion from arable land. We found that conclusions on management practices to increase SOM storage are strongly influenced by sampling depth and length of the grassland period. SOM increased significantly in nearly all fertilized treatments in the 0-60 cm layer. No differences between species compositions were found. However, when only the 30-60 cm soil layer was considered, significantly higher SOM increases were found under FA+ which is consistent with its greater root biomass than the other species. SOM increases tended to be higher under LS than RS. The results of this study suggest that it seems possible to comply with the 4 thousandth initiative during a period of five years with fertilized perennial ryegrass or tall fescue in monoculture. 


\section{Introduction}

Accumulation of soil organic matter (SOM) may improve soil quality by enhancing aggregate stability, soil life, crop nutrition, water infiltration and water holding capacity. A sufficiently high SOM content is therefore crucial to enhance grassland productivity. Great concern exists about the effects of climate change on SOM stocks in Western Europe (Bellamy et al., 2005; Sleutel et al., 2007; Reijneveld et al., 2009), as a warmer and wetter climate will enhance SOM decomposition. Over the last century a temperature rise of $1.6^{\circ} \mathrm{C}$ has been observed and precipitation increased by 21 per cent in the Netherlands (Royal Dutch Weather Institute (KNMI), 2012). At the same time, greater risks for prolonged drought periods are foreseen (Lenderink et al., 2011). To be able to cope with either sudden water shortages or large surpluses, it is of key importance for grassland-based dairy farmers to explore management options that maintain or increase SOM. Moreover, grasslands could function as potential carbon sinks when managed properly (Smith, 2014) and can therefore play an important role in the recently proposed 4 thousandth initiative (UNFCCC, 2016).

SOM changes depend on the amount and chemical composition of the applied materials, as well as the rates of decomposition of both the existing and added OM. The latter is predominantly influenced by climatic and edaphic factors like soil texture, soil structure and microbial activity (Stevenson, 1994). Several studies have focused on the effects of climatic factors such as temperature and precipitation and of soil texture on SOM dynamics in temperate grasslands (e.g. Hanegraaf et al., 2009; Reijneveld et al., 2009; Hopkins et al., 2009). Furthermore, the positive effects of increased organic matter inputs through for instance animal manure on SOM stocks of grasslands have received due attention (Van Eekeren et al., 2009; Maillard \& Angers, 2014; Verloop et al., 2015). However, data regarding the effects on SOM dynamics of other management factors such as stocking systems and plant species composition are still scarce.

Decaying plant roots and aboveground plant tissues are the main input sources of organic matter in soils of ungrazed natural grasslands (Whitehead, 1990; Dormaar, 1992). Several authors have reported that the fraction of carbon (C) retained in the soil from decaying roots is greater than that from decaying shoots due to the greater lignin content of root tissues and physicochemical C protection mechanisms in the soil (Janssen, 2002; Rasse et al., 2005; Schmidt et al., 2011). In managed grasslands farmers are able to influence root mass and therefore SOM dynamics through grazing management (Ennik et al., 1980; Reeder et al., 2001). In this respect, both Deinum (1985) and Lantinga (1985) have reported that throughout the grazing season the root biomass of grazed swards was larger under continuous stocking as compared to rotational stocking. This was associated 
with a higher tiller density under continuous stocking where the grass sward is defoliated very frequently. Moreover, Crider (1955) and Ennik et al. (1980) observed that infrequent grass cuttings like under rotational stocking led to a standstill in root production during the first few weeks of the regrowth period. In this case, carbohydrate reserves and assimilates will be used in first instance predominantly for the re-establishment of the shoot/root ratio. Next to continuous stocking, other systems which theoretically have potential to increase SOM through enhanced root production include also the so-called 'Pure Graze' system. The 'Pure Graze' system is a Dutch lenient strip stocking system that uses movable fences and cattle are put to graze in long standing biomass for a few hours (see the Materials \& Methods section for further details). In both continuous and lenient strip stocking systems, shorter periods or absence of root growth stoppage occur due to smaller fluctuations in leaf area index than under rotational stocking (Crider, 1955; Deinum, 1985; Lantinga, 1985).

Steinbeiss et al. (2008) investigated the effects of plant species diversity on short-term changes in SOM stocks and found that a larger diversity of grassland species mitigated carbon losses in the $20-30 \mathrm{~cm}$ soil layer. They suggested (but not measured) that increases in carbon stocks were greater in more diverse swards due to differences in root distribution and root biomass between plant species. Currently, production grasslands in Western Europe are dominated by monocultures of perennial ryegrass (Lolium perenne L.; Isselstein et al., 2005; De Wit et al., 2013) because of its suitability for grazing, high palatability for cattle and high yield potential.

Based on their agronomic characteristics, tall fescue and white clover are the most suitable companion species for grazing purposes in a highly productive mixture with perennial ryegrass in North-western Europe. Tall fescue (Festuca arundinacea Schreb.) is a species that produces a large amount of belowground biomass, performs well under both grazing and mowing and is drought resistant (Cougnon et al., 2014). Due to its ability to fix atmospheric nitrogen, white clover (Trifolium repens L.) is considered as a complementary species to perennial ryegrass and tall fescue. Its stoloniferous growth habit enables coexistence with both grass species leading to highly productive swards that are less dependent on external nitrogen $(\mathrm{N})$ inputs (Lüscher et al., 2014). Despite its relatively low root biomass compared to grasses leading to reduced carbon inputs from root material - the inclusion of white clover in this three-species mixture has three benefits: (i) the organic matter digestibility of both perennial ryegrass and white clover is higher compared to that of tall fescue, (ii) the risk of bloat is lower than in case white clover is mixed with only perennial ryegrass due to the higher content of lessdigestible cell walls in tall fescue (Carruthers \& Henderson, 1994; Baert et al., 2012), and (iii) white clover and tall fescue are more drought-resistant than perennial ryegrass (Karsten \& MacAdam, 2001; Cougnon et al., 2013). 
The objective of this study was to assess the effects of species composition and simulated cattle stocking systems, by applying different cutting frequencies and heights, on root biomass and SOM dynamics in a loamy and a sandy soil. We hypothesized that SOM accumulation rates would be highest under continuous and lenient strip stocking due to a more constant aboveground biomass production over time, no stand-still in root growth and therefore an expected higher root biomass. Furthermore, we hypothesized that the tall fescue monoculture as well as the species mixture with perennial ryegrass, tall fescue and white clover would lead to a higher belowground biomass production and thus increased SOM accumulation rates compared to perennial ryegrass in monoculture.

\section{Materials and methods}

\subsection{Experimental site, treatments and design}

The study was conducted on two sites, a sandy podzol and a silt loam fluvisol (FAO World Soil Classification) in Wageningen, the Netherlands. The sites were located on "De Bornse Weilanden" (clay content: 5\%; 51 ${ }^{\circ} 59^{\prime} 34.0^{\prime \prime} \mathrm{N}$ 5³9'19.1"E) and "De Hoeveslagen" (clay content: 26\%; 51'57'10.4"N $5^{\circ} 38^{\prime} 13.2^{\prime \prime E}$ ). The loamy site was characterized by an underground water flow to the nearby river Rhine. Before the experiment started, the sandy soil had been under arable cropping for more than 40 years and the loamy soil for about 20 years. Before that time, the loamy soil was used as a fruit orchard. The preceding crops (2005-2010) on the sandy soil were spring barley, maize, spring barley, potato and winter wheat; and on the loamy soil these were winter wheat, potato, winter wheat, sugar beet and spring wheat. The sandy soil had received regular applications of cattle slurry (about $25 \mathrm{Mg} \mathrm{ha}^{-1} \mathrm{yr}^{-1}$ ) and the loamy soil had received no animal manure during the whole arable cropping period. The main soil characteristics are presented in Table 1.

The experimental fields were sown by hand in April 2011 and measurements were conducted for a period of five (sand) and two (loam) years: one year during the establishment year (April 2011 - April 2012) of the sown swards and the subsequent complete growing seasons. A mixture of the diploid perennial ryegrass (Lolium perenne L.) cultivars Barflip, Barforma and Arsenal was sown for the treatments LP- (unfertilized) and LP+ (fertilized). The tall fescue (Festuca arundinacea Schreb.; F) cultivars Barolex and Bariane were used for the fertilized monoculture FA+. The same cultivars of both perennial ryegrass and tall fescue were used for the mixture (LFT+) with white clover (Trifolium repens L.; T) cultivars Alice and Riesling. The unfertilized LPtreatment was included in the experiment to compare the differences in SOM changes over time with the fertilized LP+ treatment. All seeding rates are listed in the supplementary material (Table S1). 
Table 1. Main soil characteristics of the study sites. Average values of 0-60 cm layer are presented for the granular composition. The $\mathrm{pH}$ of the $0-25 \mathrm{~cm}$ soil layer is given. Standard errors of the mean are given between brackets for the soil bulk density and initial soil organic matter content (SOM ${ }_{i}$ September 2011).

\begin{tabular}{lllll}
\hline & Sandy soil & \multicolumn{3}{l}{ Loamy soil } \\
\hline Sand (\%) & 89 & & 15 \\
Silt (\%) & 6 & 59 & \\
Clay (\%) & 5 & & 26 \\
$\mathrm{pH}-\mathrm{CaCl}_{2}$ & 5.1 & & 7.3 \\
Soil layer & Bulk density $\left(\mathrm{g} \mathrm{m}^{-3}\right)$ & $\mathrm{SOM}_{\mathrm{i}}\left(\mathrm{Mg} \mathrm{ha}^{-1}\right)$ & Bulk density $\left(\mathrm{g} \mathrm{cm}^{-3}\right) \mathrm{SOM}_{\mathrm{i}}\left(\mathrm{Mg} \mathrm{ha}^{-1}\right)$ \\
$0-10 \mathrm{~cm}$ & $1.31(0.05)$ & $42.6(0.4)$ & $1.30(0.04)$ & $40.0(0.4)$ \\
$10-30 \mathrm{~cm}$ & $1.50(0.01)$ & $79.7(0.7)$ & $1.46(0.01)$ & $72.5(1.5)$ \\
$30-60 \mathrm{~cm}$ & $1.60(0.01)$ & $71.7(2.8)$ & $1.43(0.01)$ & $70.4(2.7)$ \\
\hline
\end{tabular}

In the year of establishment, the LP+ and FA+ treatments were fertilized with cattle manure granules $\left(200 \mathrm{~kg} \mathrm{~N} \mathrm{ha}^{-1}\right)$. To promote tillering, calcium ammonium nitrate (CAN; $52.5 \mathrm{~kg} \mathrm{~N} \mathrm{ha}^{-1}$ ) was applied once in late summer of 2011 to all fields including the LP- treatment. In the subsequent years, the monocultures $\mathrm{LP}+$ and FA+ were fertilized with a combination of mineral fertilizer nitrogen (200 kg N per ha applied as CAN) and cattle manure granules (50 kg N ha $1)$. The species mixture containing white clover was fertilized only with the manure granules $\left(50 \mathrm{~kg} \mathrm{~N} \mathrm{ha}^{-1}\right)$. This amount of manure granules corresponds to an organic matter $(\mathrm{OM})$ input from cattle manure at a rate of ca. $2.2 \mathrm{Mg}$ $\mathrm{OM} \mathrm{ha-1}$ year ${ }^{-1}$. The $\mathrm{N}$ content of the manure was analysed and averaged $16.6 \mathrm{~g} \mathrm{~N}$ per $\mathrm{kg}$ air-dry matter. The OM content of the granules was $74 \%$. Swards under the continuous stocking system received five split applications of CAN, whereas those under rotational and lenient strip stocking systems received three split applications of CAN. The dates and amounts of fertilizer application are shown in the supplementary material, Tables S2 and S3.

Three cutting regimes reflecting three different stocking systems were superimposed: rotational (RS), continuous (CS) and lenient strip (LS) stocking. Normally in practice, cattle in rotational stocking systems are put to graze when the standing biomass above $4 \mathrm{~cm}$ stubble height is about 1.5 to $2 \mathrm{Mg}$ dry matter per ha and are shifted to a new paddock every three to five days (Visscher et al., 2011). In our experiment rotational stocking was simulated by mowing five times per year at a height of $4 \mathrm{~cm}$. Cutting took place when the sward height of the fertilized treatments was about $18 \mathrm{~cm}$ at the day of cutting. In case of commercial cattle farms continuous stocking is generally characterized by grazing management that aims to maintain a sward height of about $8 \mathrm{~cm}$ throughout the growing season. In our experiment the continuous stocking system was simulated through frequent cutting (eight to nine times 
per year) when the sward height of the fertilized plots was about $11 \mathrm{~cm}$. The cutting height was $4 \mathrm{~cm}$ resulting in the desired average sward height of 8 $\mathrm{cm}$ (average height: $(11+4) / 2=8 \mathrm{~cm}$ ). In practice the 'Pure Graze' system is characterized by cows that are put to graze in swards with a relatively large amount of standing biomass (2.5-3.0 Mg DM/ ha above $4 \mathrm{~cm}$ stubble height). Movable fences are used to enclose the grazing area of the cows and every three to six hours the grazing area is enlarged by moving the front fence, when about half of the available biomass has been defoliated down to a sward height of about $10 \mathrm{~cm}$ (Visscher et al., 2011). Generally, the rear fence is moved only once per day. Hereafter we will refer to this system as lenient strip (LS) stocking. In our experiment lenient strip stocking was simulated by mowing at a cutting height of $10 \mathrm{~cm}$. Herbage was harvested about seven times per year. Averages of the harvested herbage per treatment are given in the supplementary material (Figure S2). The sward height of the fertilized plots was around $17 \mathrm{~cm}$ at the day of cutting. An overview of the cutting heights, cutting interval and herbage heights at defoliation of the simulated stocking systems is presented in Table 2.

Table 2. Overview of the simulated stocking systems. CS=continuous stocking, $\mathrm{LS}=$ lenient strip stocking and $\mathrm{RS}=$ rotational stocking.

\begin{tabular}{llll}
\hline Stocking system & $\begin{array}{l}\text { Cutting height } \\
(\mathrm{cm})\end{array}$ & $\begin{array}{l}\text { Average cutting } \\
\text { interval in 2012-2013 } \\
\text { (days) }\end{array}$ & $\begin{array}{l}\text { Average grass height } \\
\text { at defoliation in 2013 } \\
(\mathrm{cm})\end{array}$ \\
\hline Continuous (CS) & 4 & 23 & 11 \\
Lenient strip (LS) & 10 & 32 & 17 \\
Rotational (RS) & 4 & 48 & 18 \\
\hline
\end{tabular}

The experiment was laid out on both soil types in a split-plot design with four replications (blocks) with three plots each, to which the stocking systems were randomly assigned. Species composition (LP-, LP+, FA+, LFT+) was randomly assigned to the four subplots within the main plots. Hence, each of the two experiments consisted of 12 plots ( 4 blocks $\times 3$ stocking systems) and 48 subplots ( 4 species composition treatments per plot). The gross subplot size was $2.75 \mathrm{~m} \times 10 \mathrm{~m}$. The net subplot size was $1.5 \mathrm{~m} \times 10 \mathrm{~m}$.

Precipitation data were obtained from a weather station nearby Wageningen and temperature data were obtained from the weather station at Deelen (KNMI, 2016). During the experimental period (2011-2016) the mean annual temperature was $11.0^{\circ} \mathrm{C}$ and the average annual precipitation sum amounted to $907 \mathrm{~mm}$. When dry spells occurred during the summer, fields were occasionally irrigated. This was only done when perennial ryegrass started yellowing and browning as a consequence of drought stress. Each time $20-25 \mathrm{~mm}$ of water was applied. 


\subsection{Harvesting and processing of samples}

\subsubsection{Biomass samples}

The plots were cut with a Haldrup grass harvester (Haldrup, Løgstør, Denmark). In the year of establishment (2011), three cuts were taken at a cutting height of $4 \mathrm{~cm}$. In the following years harvesting took place between May and November. A biomass subsample was taken after each cutting event and brought to the laboratory. The fresh weight was measured and samples were dried overnight at $70^{\circ} \mathrm{C}$ to determine the dry matter content.

Root samples were collected down to a depth of $60 \mathrm{~cm}$ for each subplot in July 2013 and March 2014 by using a hydraulic auger. Each field was sampled twice and the $0-10,10-30$ and $30-60 \mathrm{~cm}$ soil layers were collected separately. The 0-10 cm layer was sampled because this is the depth used in the standard procedure for sampling grassland soils in The Netherlands. The 10-30 cm layer was sampled because of differences in root distribution patterns between perennial ryegrass and tall fescue: about $80 \%$ of the root biomass of perennial ryegrass occurs in the $0-8 \mathrm{~cm}$ soil layer, while only about $65 \%$ of the roots of tall fescue can be found here (Deru et al., 2011). According to a literature review by Lorentz \& Lal (2005), about $95 \%$ of the total grass root biomass occurs in the $0-60 \mathrm{~cm}$ soil layer. Therefore, we also sampled the 30-60 cm soil layer. Samples were washed and the roots were dried at $70^{\circ} \mathrm{C}$ overnight. The dry weight was recorded.

\subsubsection{Soil samples}

Soil sampling followed the sampling depths of 0-10 cm, 10-30 cm and 30-60 $\mathrm{cm}$ for root biomass and SOM. An overview of the root and SOM sampling dates is provided in Table 3. Because the root biomass sampling took a number of days, the month is indicated in this table. The time indication for SOM is also given in the table: in the remainder of the paper 'two years' refers to the monitoring period 19-9-2011 to 27-1-2014 and 'five years' refers to the period 19-9-2011 to 20-5-2016. The initial SOM content was determined in September 2011 and the second sampling took place when the cutting regimes started (May 2012). In February 2014, the soil bulk density was determined for the $0-60 \mathrm{~cm}$ profile using cylindrical cores with a diameter of $5 \mathrm{~cm}$. On both locations, a small pit was dug in six subplots (two fields per stocking regime). Cores were pressed horizontally in the soil profile, the cylinders were removed and the moist samples were put in paper bags. Samples were dried overnight at $105{ }^{\circ} \mathrm{C}$ and their dry weight was recorded. Details on the conversion from SOM contents to stocks are given in the Supplementary material, Box S1.

Soil and manure granule samples were analysed for organic matter content by the loss-on-ignition (LOI) method. The LOI method was chosen above other SOM or SOC analysis procedures because of its relatively large sample weights. To be able to monitor SOM changes within a short experimental 
period, the analytical error had to be minimized. See Hoogsteen et al. (2015) for details on the method. The ignition conditions were $550{ }^{\circ} \mathrm{C}$ for a period of three hours. Sample weights of $20 \mathrm{~g}$ (soil) and $5 \mathrm{~g}$ (manure granules) were used. The SOM content in the 0-10 cm layer in September 2011 averaged $30.2 \mathrm{~g} \mathrm{~kg}^{-1}\left(\mathrm{SD}=2.2\right.$, sand) and $28.1 \mathrm{~g} \mathrm{~kg}^{-1}$ (SD=2.3, loam). For the 10-30 cm soil layer average SOM values were $28.0 \mathrm{~g} \mathrm{~kg}^{-1}(\mathrm{SD}=2.0$, sand) and $25.5 \mathrm{~g}$ $\mathrm{kg}^{-1}\left(\mathrm{SD}=2.0\right.$, loam). For the $30-60 \mathrm{~cm}$ soil layer, the averages were $16.0 \mathrm{~g} \mathrm{~kg}^{-1}$ $(\mathrm{SD}=4.6$, sand) and $15.7 \mathrm{~g} / \mathrm{kg}(\mathrm{SD}=4.4$, loam $)$.

Table 3. Soil organic matter (SOM) and root biomass sampling dates per soil type. $L=$ loam and $\mathrm{S}=$ sand. The time indication refers to period in which SOM dynamics were monitored.

\begin{tabular}{|c|c|c|c|}
\hline Date & $\begin{array}{l}\text { SOM } \\
\text { measurement }\end{array}$ & $\begin{array}{l}\text { Root biomass } \\
\text { measurement }\end{array}$ & Time indication \\
\hline 19-9-2011 & $L+S$ & & \\
\hline $22-5-2012$ & $L+S$ & & \\
\hline 25-9-2012 & $L+S$ & & \\
\hline 28-1-2013 & $L+S$ & & \\
\hline $27-5-2013$ & $L+S$ & & \\
\hline July 2013 & & $L+S$ & \\
\hline 23-9-2013 & $L+S$ & & \\
\hline $27-1-2014$ & $L+S$ & & 2 years (19-9-2011 until 27-1-2014) \\
\hline March 2014 & & $L+S$ & \\
\hline $21-3-2016$ & $\mathrm{~S}$ & & \\
\hline $20-5-2016$ & $\mathrm{~S}$ & & 5 years (19-9-2011 until 20-05-2016) \\
\hline
\end{tabular}

\subsection{Statistical analysis}

Data were processed with Microsoft Excel 2010 and analysed with IBM SPSS Statistics 20.0. Differences in bulk density values between the sandy and loamy soil were analysed with a t-test. Average SOM contents at the beginning of the experiment in September 2011 are presented per species composition, by combination of soil type and soil layer. The averages are based on a mixed model with species composition as fixed factor and block and plot (nested within block) as random factor (Supplementary material, Figure S1 and Table S4).

Root biomass observations were analysed per soil type and per soil layer using analysis of variance. In each of the six analyses, species composition, stocking system and their interaction were included as fixed factors, while block and 'block x stocking system' (equivalent to plot) were used as random factor. When significant interaction effects were observed, the means for 
the treatments (stocking system - species composition combinations) were compared pairwise using LSD.

The SOM trends over time were estimated in 15 analyses, per soil layer (0-10 $\mathrm{cm}, 10-30 \mathrm{~cm}, 30-60 \mathrm{~cm}, 0-30 \mathrm{~cm}, 0-60 \mathrm{~cm}$ ) and per combination of soil typemonitoring period (SM levels: loam 2 years, sand 2 years, and sand 5 years). All samples were included in the analyses.

In each analysis, we used a random coefficient model that also does justice to the split-plot design. The model was as follows: SOM is dependent variable; species composition (sps) and stocking system (ss) are fixed factors, time is a (fixed) continuous variate, with included interactions for sps-ss, time-ss and time-sps; random factors are block, plot within block, field within plot and field-time interactions. This leads to fixed slope estimates that vary with species composition and stocking system and 48 random slopes. We discuss the differences in fixed slopes between species compositions and stocking systems.

\section{Results}

\subsection{Root biomass}

For both soil types, root biomass decreased for consecutive soil layers for all species compositions (Figure 1). The root biomass of the $0-60 \mathrm{~cm}$ layer of LP- was on average $1500 \mathrm{~kg} / \mathrm{ha}$ higher on the sandy soil than on the loamy soil. For FA+ the root biomass was $1800 \mathrm{~kg} / \mathrm{ha}$ higher on the loamy soil than on the sandy soil. In the $0-10 \mathrm{~cm}$ soil layer the effect of species composition was significant for both soil types, with the highest root biomass values for $\mathrm{FA}+$, followed by LP+ (see Table 4 and supplementary material, Table S5). Root biomass of the mixture with tall fescue $(\mathrm{LFT}+)$ was similar to unfertilized perennial ryegrass plots.

In the 10-30 cm soil layer root mass of FA+ was also greater than the other species compositions and no differences in root biomass were observed between LP-, LP+ and LFT+. This was also found in the 30-60 cm soil layer of the loamy soil. Root biomass of LP-, LP+ and LFT+ was twice as large in the $30-60 \mathrm{~cm}$ soil layer of the loamy soil as compared to the sandy soil, whereas no effect of soil type was observed on root biomass of FA+ (Supplementary material, Table S5). We found no significant effects of the three simulated stocking systems on root biomass in any of the soil layers (Table 4). 


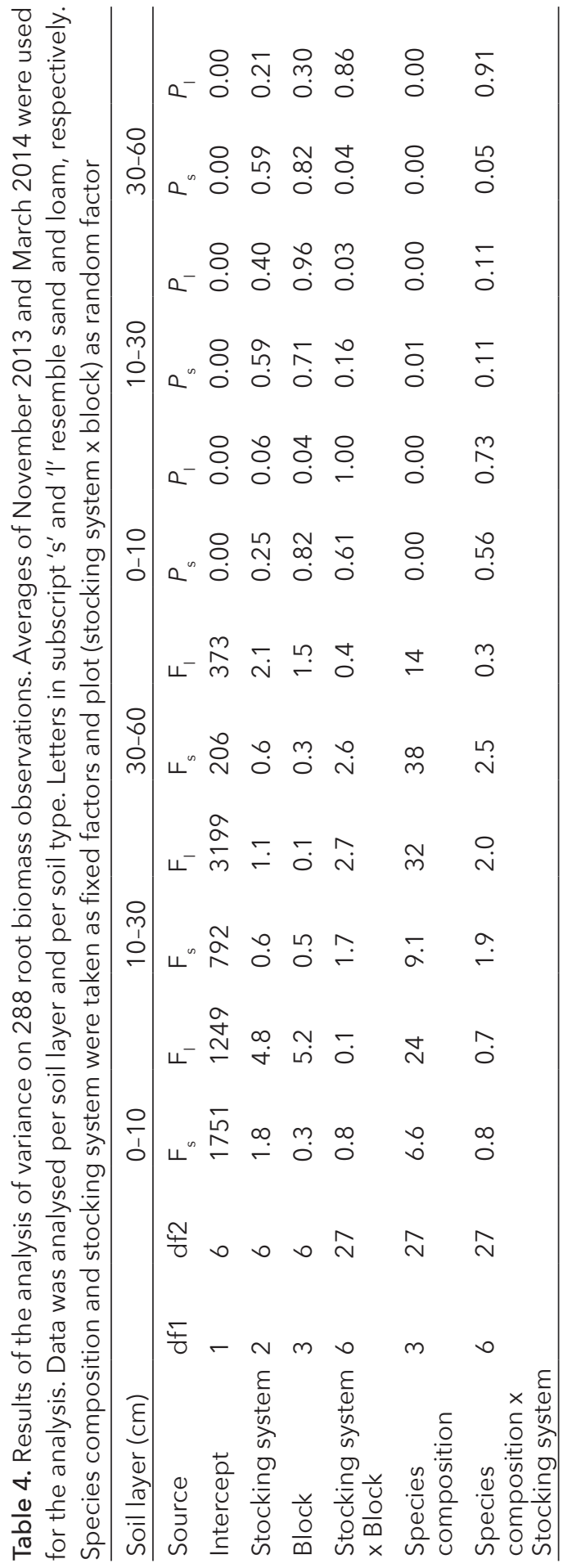




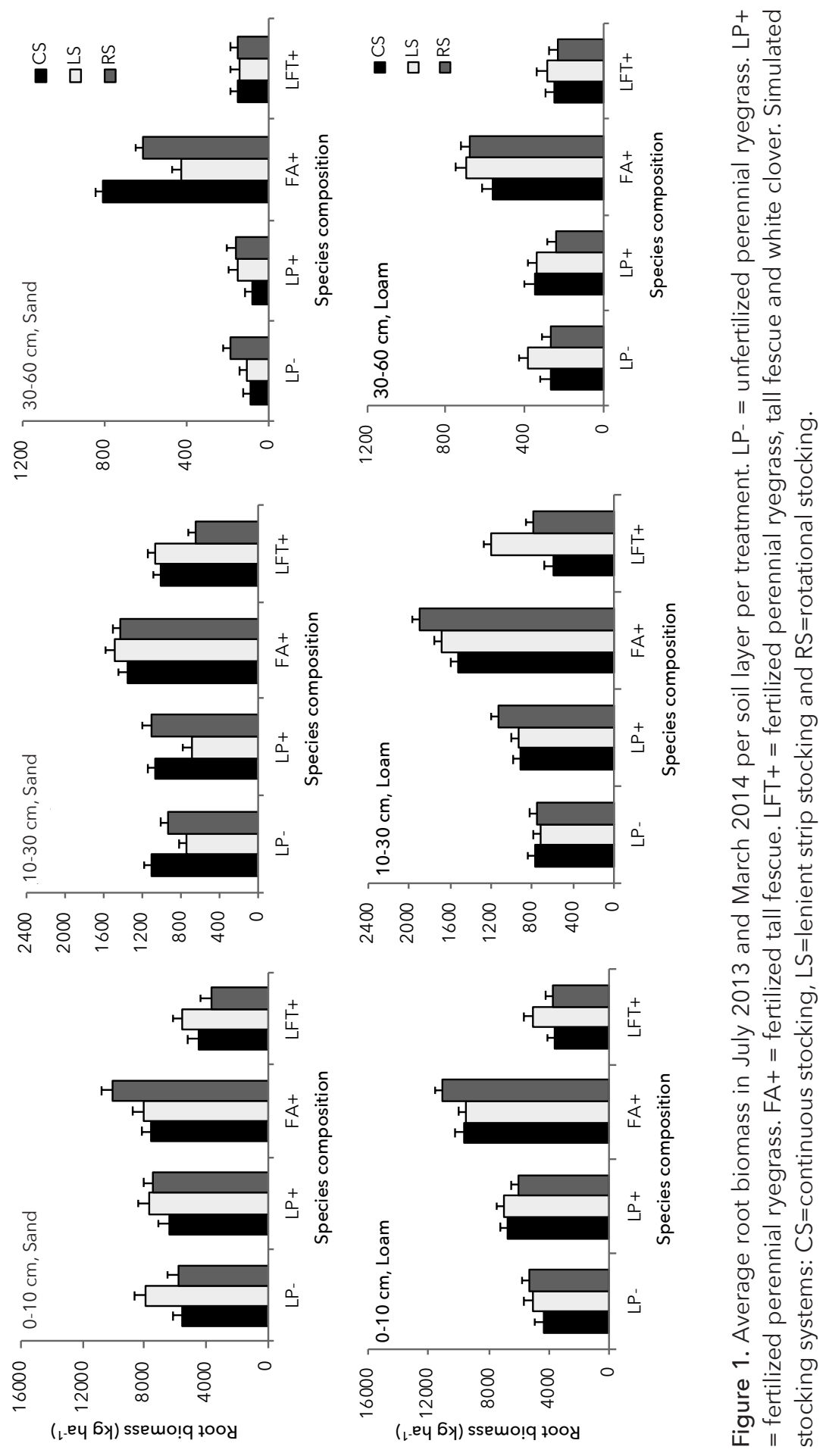




\subsection{Soil organic matter dynamics}

During the first two years of the experiment SOM increased significantly over time in the 0-10 cm soil layer in all fertilized treatments (Figure 2a, b), and the differences between the LP+, FA+ and LFT+ treatments were not significant (Supplementary material, Table S6). After two years, the average increase in SOM was 1.9 Mg ha-1 $\mathrm{yr}^{-1}$ in the sandy soil and $2.2 \mathrm{Mg} \mathrm{ha}^{-1} \mathrm{yr}^{-1}$ in the loamy soil, while for unfertilized treatments these accumulation rates were 0.6 (sand) and $0.9 \mathrm{Mg} \mathrm{ha}^{-1} \mathrm{yr}^{-1}$ (loam).

In the 10-30 cm soil layer, SOM tended to decrease (five times significantly; Figure 2d, e). In the 30-60 cm soil layer increases were observed, as well as decreases; in both cases a significant slope was found only once (Figure 2g, h). At both experimental sites, large differences in initial SOM content of the 30-60 cm soil layer were observed between subplots: in the sandy soil the SOM stocks ranged from 34 to $112 \mathrm{Mg} \mathrm{ha}^{-1}$ and in the loamy soil SOM stocks ranged from 31 to $104 \mathrm{Mg} \mathrm{ha}^{-1}$. No significant correlation was observed between initial SOM stocks and SOM rates of change (Figure S3).

Table 5. Results of the analysis of variance on soil organic matter observations. Data was analysed per soil layer and per soil type.

\begin{tabular}{|c|c|c|c|c|c|c|c|c|c|c|}
\hline \multicolumn{11}{|c|}{$0-10 \mathrm{~cm}$ soil layer } \\
\hline \multirow[b]{2}{*}{ Source } & \multirow[b]{2}{*}{$d f 1$} & \multicolumn{3}{|c|}{ Loam, 2 years } & \multicolumn{3}{|c|}{ Sand, 2 years } & \multicolumn{3}{|c|}{ Sand, 5 years } \\
\hline & & $\mathrm{df} 2$ & $\mathrm{~F}$ & $P$ & $\mathrm{df} 2$ & $\mathrm{~F}$ & $P$ & df2 & $\mathrm{F}$ & $P$ \\
\hline Intercept & 1 & 3 & 2886.1 & 0.00 & 3 & 3984.1 & 0.00 & 3 & 4174.2 & 0.00 \\
\hline Stocking system & 2 & 45 & 1.0 & 0.39 & 7 & 1.0 & 0.40 & 6 & 1.4 & 0.31 \\
\hline $\begin{array}{l}\text { Species } \\
\text { composition }\end{array}$ & 3 & 34 & 8.5 & 0.00 & 31 & 6.5 & 0.00 & 21 & 10.1 & 0.00 \\
\hline Time & 1 & 38 & 102.1 & 0.00 & 42 & 130.7 & 0.00 & 392 & 635.0 & 0.00 \\
\hline $\begin{array}{l}\text { Stocking systems } \\
\text { x Species } \\
\text { composition }\end{array}$ & 6 & 31 & 1.4 & 0.26 & 28 & 0.8 & 0.56 & 29 & 1.1 & 0.41 \\
\hline $\begin{array}{l}\text { Stocking system } \mathrm{x} \\
\text { Time }\end{array}$ & 2 & 38 & 1.1 & 0.34 & 42 & 0.8 & 0.47 & 392 & 3.5 & 0.03 \\
\hline $\begin{array}{l}\text { Species } \\
\text { composition } \times \text { Time }\end{array}$ & 3 & 38 & 3.0 & 0.04 & 42 & 7.4 & 0.00 & 392 & 6.3 & 0.00 \\
\hline
\end{tabular}

10-30 cm soil layer

Loam, 2 years Sand, 2 years Sand, 5 years

\begin{tabular}{lcccccccccc}
\hline Source & $d f 1$ & $d f 2$ & $F$ & $P$ & $d f 2$ & $F$ & $P$ & $d f 2$ & $F$ & $P$ \\
Intercept & 1 & 4 & 4428.6 & 0.00 & 3 & 3062.6 & 0.00 & 3 & 3796.1 & 0.00 \\
Stocking system & 2 & 14 & 0.1 & 0.89 & 8 & 1.8 & 0.22 & 6 & 1.9 & 0.23 \\
$\begin{array}{l}\text { Species } \\
\text { composition }\end{array}$ & 3 & 34 & 0.2 & 0.90 & 28 & 0.8 & 0.51 & 27 & 0.3 & 0.86
\end{tabular}




\begin{tabular}{|c|c|c|c|c|c|c|c|c|c|c|}
\hline Time & 1 & 346 & 8.7 & 0.00 & 28 & 19.1 & 0.00 & 379 & 3.2 & 0.07 \\
\hline $\begin{array}{l}\text { Stocking systems } \\
\times \text { Species } \\
\text { composition }\end{array}$ & 6 & 36 & 3.1 & 0.01 & 30 & 1.4 & 0.23 & 27 & 0.7 & 0.67 \\
\hline $\begin{array}{l}\text { Stocking system } \mathrm{x} \\
\text { Time }\end{array}$ & 2 & 346 & 2.3 & 0.11 & 28 & 0.1 & 0.92 & 379 & 3.0 & .05 \\
\hline $\begin{array}{l}\text { Species } \\
\text { composition } \times \text { Time }\end{array}$ & 3 & 346 & 0.2 & 0.92 & 28 & 0.4 & 0.75 & 379 & 0.1 & .95 \\
\hline \multicolumn{11}{|c|}{$30-60 \mathrm{~cm}$} \\
\hline & & \multicolumn{3}{|c|}{ Loam, 2 years } & \multicolumn{3}{|c|}{ Sand, 2 years } & \multicolumn{3}{|c|}{ Sand, 5 years } \\
\hline Source & $\mathrm{df1}$ & $\mathrm{df} 2$ & $\mathrm{~F}$ & $P$ & $\mathrm{df} 2$ & $\mathrm{~F}$ & $P$ & $\mathrm{df} 2$ & $\mathrm{~F}$ & $P$ \\
\hline Intercept & 1 & 3 & 147.3 & 0.00 & 3 & 100.3 & 0.00 & 3 & 99.5 & 0.00 \\
\hline Stocking system & 2 & 32 & 1.5 & 0.24 & 6 & 0.3 & 0.75 & 6 & 0.5 & 0.62 \\
\hline $\begin{array}{l}\text { Species } \\
\text { composition }\end{array}$ & 3 & 32 & 1.4 & 0.26 & 28 & 0.7 & 0.56 & 27 & 0.1 & 0.95 \\
\hline Time & 1 & 282 & 1.1 & 0.30 & 42 & 0.0 & 0.94 & 39 & 20.7 & 0.00 \\
\hline $\begin{array}{l}\text { Stocking systems } \\
\text { x Species } \\
\text { composition }\end{array}$ & 6 & 33 & 1.5 & 0.22 & 27 & 0.4 & 0.87 & 27 & 0.4 & 0.88 \\
\hline $\begin{array}{l}\text { Stocking system } \mathrm{x} \\
\text { Time }\end{array}$ & 2 & 282 & 1.4 & 0.26 & 42 & 0.8 & 0.47 & 39 & 0.6 & .55 \\
\hline $\begin{array}{l}\text { Species } \\
\text { composition } \times \text { Time }\end{array}$ & 3 & 282 & 1.1 & 0.33 & 42 & 3.8 & 0.02 & 39 & 3.1 & 0.04 \\
\hline \multicolumn{11}{|c|}{$0-30 \mathrm{~cm}$ soil layer } \\
\hline & & \multicolumn{3}{|c|}{ Loam, 2 years } & \multicolumn{3}{|c|}{ Sand, 2 years } & \multicolumn{3}{|c|}{ Sand, 5 years } \\
\hline Source & df1 & $\mathrm{df} 2$ & $\mathrm{~F}$ & $P$ & $\mathrm{df} 2$ & $\mathrm{~F}$ & $P$ & $d f 2$ & $\mathrm{~F}$ & $P$ \\
\hline Intercept & 1 & 3 & 3829.4 & 0.00 & 3 & 3725.9 & 0.00 & 3 & 4063.3 & 0.00 \\
\hline Stocking system & 2 & 8 & 0.2 & 0.84 & 7 & 1.5 & 0.28 & 6 & 1.7 & 0.25 \\
\hline $\begin{array}{l}\text { Species } \\
\text { composition }\end{array}$ & 3 & 25 & 1.7 & 0.20 & 28 & 2.6 & 0.07 & 25 & 2.3 & 0.10 \\
\hline Time & 1 & 285 & 16.5 & 0.00 & 470 & 2.3 & 0.13 & 377 & 116.7 & 0.00 \\
\hline $\begin{array}{l}\text { Stocking systems } \\
\text { x Species } \\
\text { composition }\end{array}$ & 6 & 28 & 1.9 & 0.11 & 29 & 1.2 & 0.35 & 27 & 0.8 & 0.57 \\
\hline $\begin{array}{l}\text { Stocking system } x \\
\text { Time }\end{array}$ & 2 & 285 & 2.5 & 0.09 & 470 & 0.1 & 0.92 & 377 & 5.0 & 0.01 \\
\hline $\begin{array}{l}\text { Species } \\
\text { composition } \times \text { Time }\end{array}$ & 3 & 285 & 0.9 & 0.47 & 470 & 1.0 & 0.41 & 377 & 1.3 & 0.27 \\
\hline
\end{tabular}


$30-60 \mathrm{~cm}$

\begin{tabular}{|c|c|c|c|c|c|c|c|c|c|c|}
\hline \multirow[b]{2}{*}{ Source } & \multirow[b]{2}{*}{$d f 1$} & \multicolumn{3}{|c|}{ Loam, 2 years } & \multicolumn{3}{|c|}{ Sand, 2 years } & \multicolumn{3}{|c|}{ Sand, 5 years } \\
\hline & & $\mathrm{df2}$ & $\mathrm{F}$ & $P$ & $\mathrm{df} 2$ & $\mathrm{~F}$ & $P$ & $\mathrm{df} 2$ & F & $P$ \\
\hline Intercept & 1 & 3 & 621.6 & 0.00 & 3 & 497.3 & 0.00 & 3 & 483.1 & 0.00 \\
\hline Stocking system & 2 & 36 & 1.0 & 0.38 & 6 & 0.6 & 0.60 & 6 & 0.8 & 0.48 \\
\hline $\begin{array}{l}\text { Species } \\
\text { composition }\end{array}$ & 3 & 33 & 1.4 & 0.27 & 26 & 0.5 & 0.69 & 26 & 0.5 & 0.71 \\
\hline Time & 1 & 317 & 1.2 & 0.27 & 301 & 0.5 & 0.50 & 40 & 63.1 & 0.00 \\
\hline $\begin{array}{l}\text { Stocking systems } \\
\text { x Species } \\
\text { composition }\end{array}$ & 6 & 38 & 2.0 & 0.09 & 28 & 0.5 & 0.80 & 27 & 0.5 & 0.81 \\
\hline $\begin{array}{l}\text { Stocking system } x \\
\text { Time }\end{array}$ & 2 & 317 & 2.1 & 0.12 & 301 & 0.5 & 0.63 & 40 & 1.6 & 0.21 \\
\hline $\begin{array}{l}\text { Species } \\
\text { composition x Time }\end{array}$ & 3 & 317 & 0.5 & 0.65 & 301 & 2.8 & 0.04 & 40 & 2.8 & 0.05 \\
\hline
\end{tabular}

In the 0-30 $\mathrm{cm}$ layer, SOM tended to increase for both soil types (once significantly, Figure $2 \mathrm{j}, \mathrm{k}$ ). In the $0-60 \mathrm{~cm}$ layer all estimated trends were not significant except for FA+ under continuous stocking on the sandy soil (Figure $2 m, n$ ).

The experimental period of five years on the sandy soil showed significant increases in SOM in all treatments in the $0-10 \mathrm{~cm}$ soil layer (Figure 2c). In the 10-30 cm soil layer, SOM did not significantly change, except for two treatments where a significant decrease was found (Figure 2f). In the 30-60 $\mathrm{cm}$ soil layer, SOM increased in most of the fertilized treatments (three times significantly; Figure $2 \mathrm{i}$ ). In the $0-30 \mathrm{~cm}$ soil layer, SOM increased significantly in all fertilized treatments except one (Figure $2 \mathrm{I}$ ). In the $0-60 \mathrm{~cm}$ soil layer all estimated trends were positive, and significant for six of the nine fertilized treatments (Figure 20).

After two years, no significant effect of stocking system was observed for any soil type-layer combination, except for the $0-30 \mathrm{~cm}$ layer of the loamy soil. SOM increases were significantly higher under lenient stocking as compared to rotational stocking $\left(\triangle \mathrm{SOM}_{\mathrm{LS}}-\Delta \mathrm{SOM}_{\mathrm{RS}}=1.61 \mathrm{Mg} \mathrm{ha}^{-1} \mathrm{yr}^{-1}, P=0.03\right.$, Fig. 2j; Supplementary material, Table S7). This was also observed on the sandy soil in the 0-30 cm layer after five years $\left(\triangle S_{S O M}-\Delta S_{L S}=0.38 \mathrm{Mg} \mathrm{ha}_{R S}^{-1} \mathrm{yr}\right.$ $1, P=0.01$, Fig. 2l; Supplementary material, Table S7). For all soil type-layer combinations SOM increases tended to be higher under LS than under RS. As root biomass was not significantly different for stocking systems, this increase in SOM might be attributed to greater organic matter inputs from decaying aboveground plant material. 

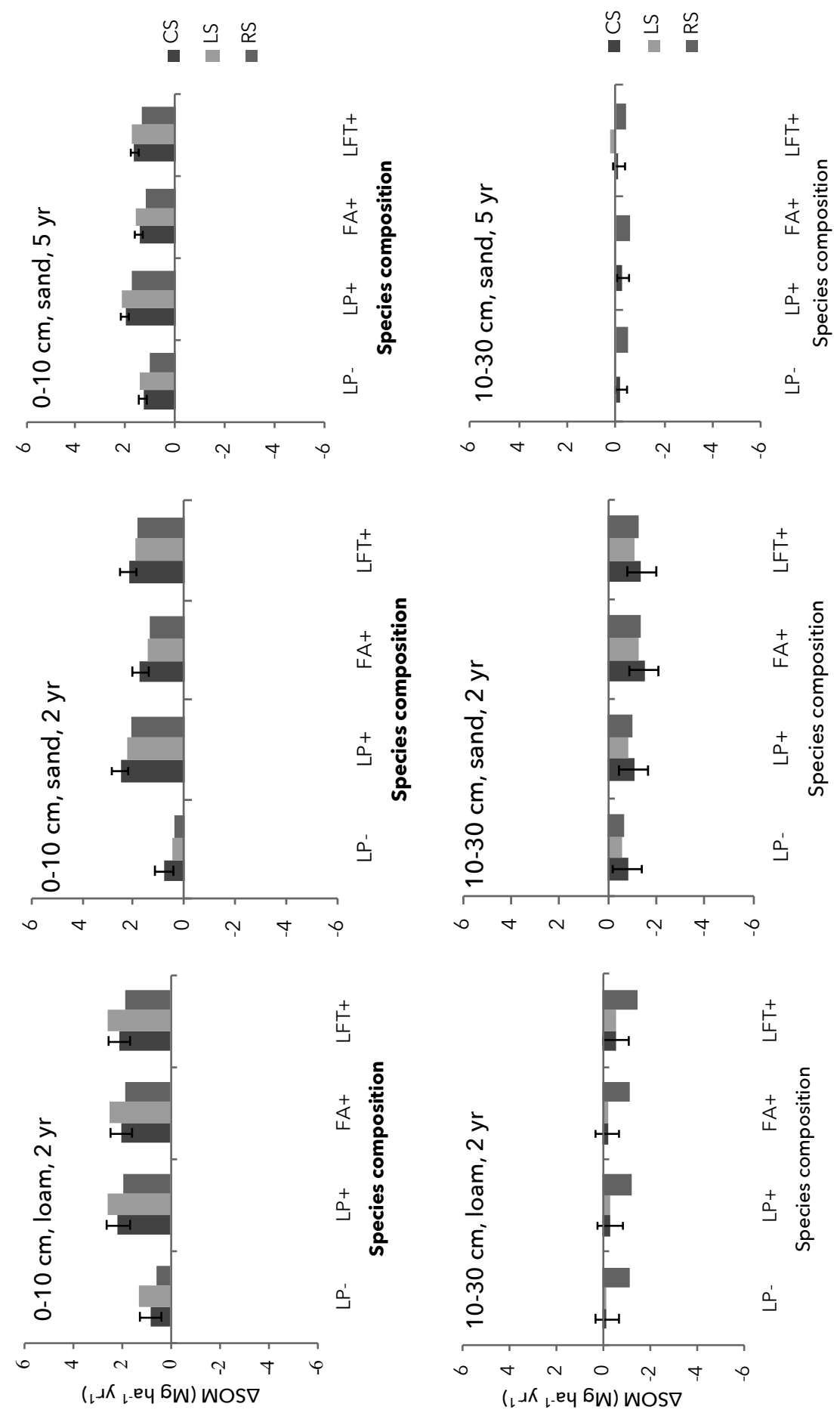

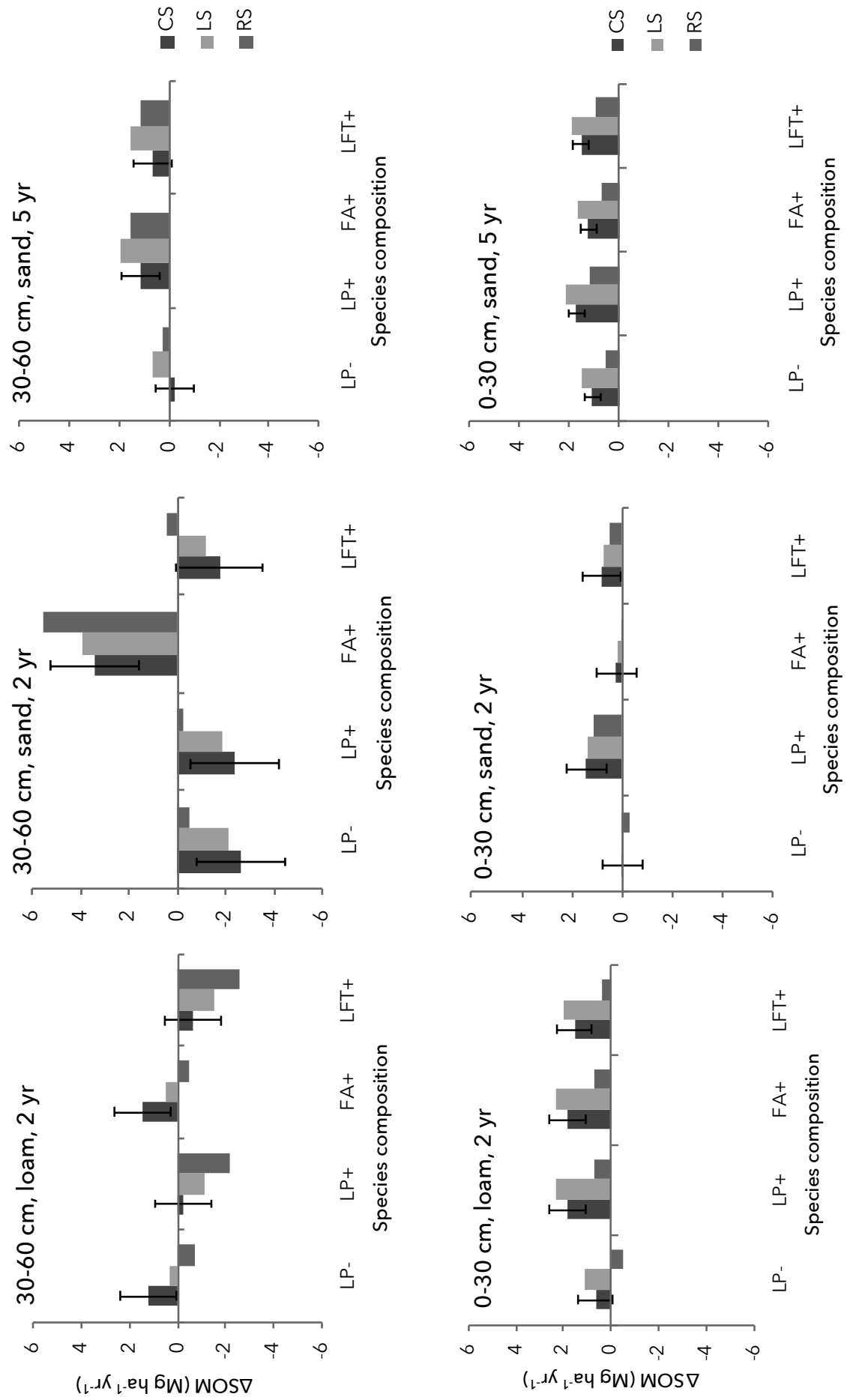

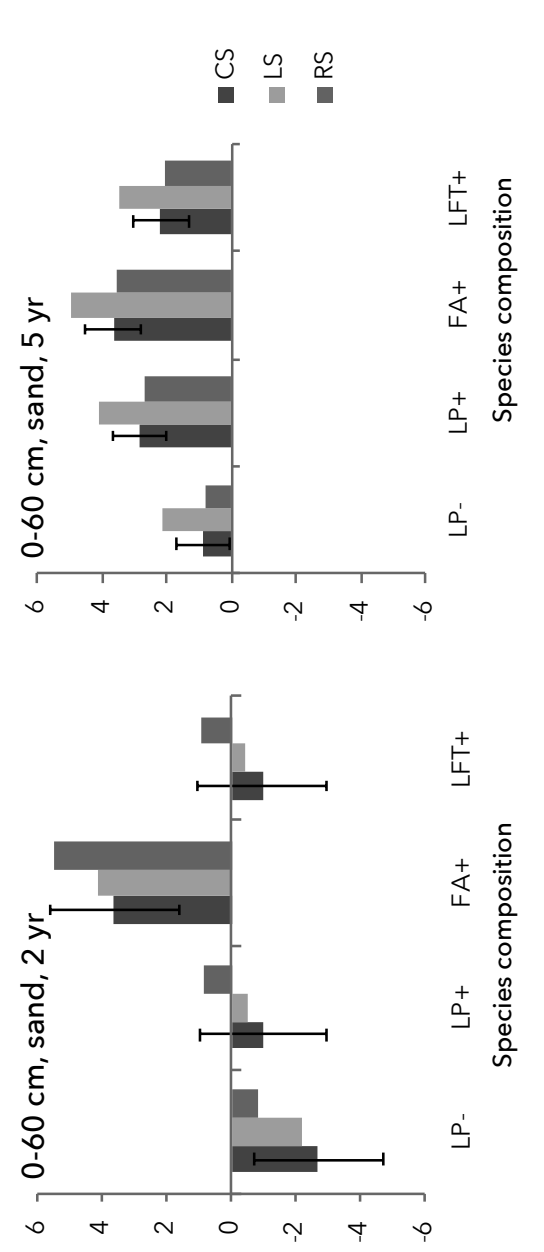

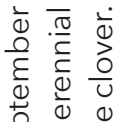

요료.

ช. $\frac{0}{3}$

을 $\frac{\text { N }}{\overline{0}} \frac{\mathrm{O}}{\mathrm{C}}$

인

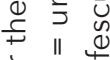

证章

䒕它勿

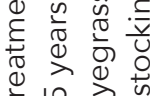

\pm 는

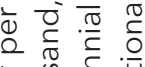

ब)

ख๐

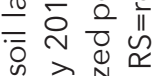

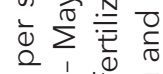

든

i。

혼

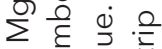

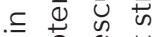

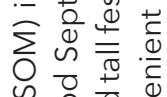

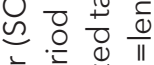

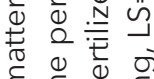

$\varepsilon \stackrel{0}{\oplus} \stackrel{0}{\leftarrow}$

늘

兵完走

ơ 品

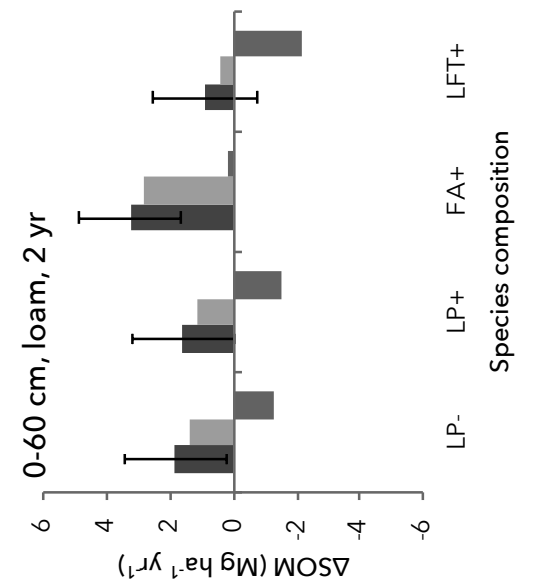

$\overline{\overline{0}} \stackrel{0}{0} \stackrel{0}{0}$

फ

() हो

ช

들

บ $\frac{0}{\pi} \frac{1}{d}$

ᄂ。

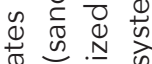

व $匚$ व

ฮ্ণ

$\stackrel{\frac{\pi}{10}}{\sqrt{2}+}$

४

궁

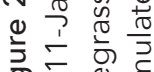

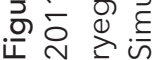


Visual observations showed that the amount of above-ground stubble was much larger under LS as compared to the other treatments $(10 \mathrm{~cm}$ vs. 4 $\mathrm{cm}$ ) resulting in a larger OM supply to the soil (data not shown). Significant differences in SOM dynamics between species compositions were found. In the $0-10 \mathrm{~cm}$ soil layers of the loamy and sandy soil, SOM rates of change were significantly lower for LP- than for all other species compositions after a two-year period. After a five-year period, SOM increases under LP+ were significantly larger than all other species compositions in the $0-10 \mathrm{~cm}$ layer of the sandy soil. After a two and five-year period, SOM increases for FA+ were significantly higher, compared to all other species compositions in the 30-60 $\mathrm{cm}$ soil layer of the sandy soil (Supplementary material, Table S8).

In the 0-30 cm soil layer, no significant differences in SOM dynamics between species compositions were found after two and five years. But, in the $0-60 \mathrm{~cm}$ soil layer, SOM increases were significantly higher under FA+ than under the other species compositions on sand. After a period of five years, on sand both $\mathrm{LP}+$ and FA + showed significantly higher SOM increases than LP-in the $0-60 \mathrm{~cm}$ soil layer. The estimated differenceswere 1.96 and $2.77 \mathrm{Mg} \mathrm{ha}^{-1} \mathrm{yr}^{-1}$, respectively.

The difference in estimated SOM trends between sand and loam, both averaged over the 12 treatments, was not significant for any of the layers (0-10 cm, 10-30 cm, 30-60 cm, 0-30 cm, 0-60 cm).

No correlation was detected between SOM rates of change and root biomass values, as shown in Figure S4 (Supplementary material), in which only the results of the $0-30 \mathrm{~cm}$ soil layer are presented due to the large variation of the initial SOM content in the 30-60 cm layer (cf. Supplementary material, Figure S3).

\section{Discussion}

\subsection{Effects of stocking systems on root biomass and SOM dynamics}

During the first two years of this field experiment on a sandy and loamy soil we found no significant effects of the three simulated stocking systems on root biomass for any of the soil layers (Table 4). In the light of these findings, we would have to reject our hypothesis that SOM accumulation rates would be highest under lenient strip stocking due to an increased root biomass production. Yet, SOM increases tended to be higher under lenient stocking than under rotational stocking which could be ascribed to greater OM inputs from aboveground biomass (Table S9).

\subsection{Effects of species composition and fertilization on root biomass and SOM dynamics}

We expected that the monoculture of and the mixtures with tall fescue (FA+, LFT+) would have a higher belowground biomass production and 
hence higher SOM accumulation rates as compared to perennial ryegrass in monoculture. However, the effect of species composition on root biomass was only significant in the FA+ treatments, which had the greatest root biomass in all soil layers (Figure 1, Table 4). This corroborates with Van Eekeren et al. (2010) and Cougnon et al. (2013) who also found a greater root biomass for monocultures of tall fescue as compared to perennial ryegrass in sandy and loamy soils. The greater root biomass observed under tall fescue than for other species compositions was reflected in higher SOM accumulation rates in the sandy soil in the $30-60 \mathrm{~cm}$ soil layer (Figures $2 \mathrm{~h}, 2 \mathrm{i}$ ). This is in agreement with Carter \& Gregorich (2010) who also found significant increases in SOM under tall fescue after a period of seven years in the $40-60 \mathrm{~cm}$ soil layer of a sandy loam soil. In that particular experiment, SOM stocks increased by about $5 \mathrm{Mg} \mathrm{ha}^{-1} \mathrm{yr}^{-1}$ in the 40-60 $\mathrm{cm}$ soil layer during the first five experimental years which is similar to our results (4.3 $\mathrm{Mg} \mathrm{SOM} \mathrm{ha-1}^{-1} \mathrm{yr}^{-1}$, Figure 2i).

In the loamy soil, we did not observe significantly larger SOM increases under $\mathrm{FA}+$ as compared to the other species compositions (Figure $2 \mathrm{~g}, \mathrm{~m}$ ). The difference in SOM accumulation rates under FA+ between sand and loam for the 30-60 cm soil layer might have been caused by the significantly lower bulk density of the loamy soil in the $30-60 \mathrm{~cm}$ soil layer compared to the sandy soil (Table 1, $P=0.000$ ). For this reason and the higher soil $\mathrm{pH}$, root dry matter decomposition could have been faster in the loamy soil, leading to less SOM accumulation as compared to the more compacted and less alkaline sandy soil (Gill et al., 1999). Due to the relatively short duration of the experiment on the loamy soil we cannot predict how SOM dynamics would evolve over time. A ley period of 3 years, which is common in The Netherlands where often a 3-year grassland phase is followed by one or two year(s) of maize, does not seem to be long enough to detect significant increases in SOM on loamy soils.

During the entire experimental period, 2.2 $\mathrm{Mg} \mathrm{OM} \mathrm{ha}^{-1}$ was applied each year with the manure granules to the fertilized treatments. Assuming that the root and stubble turnover rates were similar for unfertilized and fertilized perennial ryegrass (Whitehead, 1990) and are, therefore, reflected in the OM increase for LP-, a substantial part of the OM increase in the fertilized treatments could be attributed to the $\mathrm{OM}$ applied as manure granules $\left(\triangle \mathrm{SOM} \mathrm{LP+}_{+}-\triangle S O M_{\mathrm{LP}-}=\right.$ 1.3 (loam, 2 years), 1.7 (sand, 2 years) and 0.7 (sand, 5 years) $\mathrm{Mg} \mathrm{ha}^{-1} \mathrm{yr}^{-1}$ in the $0-10 \mathrm{~cm}$ soil layer).

In the 10-30 cm layer we found a decline of SOM in all treatments during the first two years. This is most likely a consequence of a reduction in $\mathrm{OM}$ input in this layer after the conversion from arable land to grassland. During the arable period, relatively large amounts of $\mathrm{OM}$ were added each year as crop residues. In the 10-30 cm layer of the grassland soils in our experiment, roots were the main source of $\mathrm{OM}$ and this input source was apparently not able to compensate the previous input of crop residues which were incorporated 
annually through ploughing. This phenomenon was also observed by Don et al. (2009) who investigated the effect of the conversion from cropland to grassland on SOC stocks. They also found that SOC increased in the $0-10 \mathrm{~cm}$ soil layer and decreased in the $10-30 \mathrm{~cm}$ soil layer.

Over a period of five years, SOM had not changed in the $10-30 \mathrm{~cm}$ soil layer (Figure 2f). Hence, after the initial decline, SOM started increasing again two years after the conversion from arable land to grassland. This implies that both sampling depth and the length of the monitoring period are of great influence on conclusions regarding the carbon storage potential of grassland soils, especially for fields under temperate grasslands.

\subsection{Temporary grasslands as potential carbon sinks?}

Our results suggest that the conversion from arable land to temporary grassland without the application of animal manure need not necessarily lead to an increased carbon stock in the soil (c.f., Johnston et al., 2009; Smith, 2014; Maillard et al., 2015). After a period of five years, SOM increased by 1.3 $\mathrm{Mg} \mathrm{ha}{ }^{-1} \mathrm{yr}^{-1}$ under the LP- treatment $(0-60 \mathrm{~cm}$ soil layer, Figure 20$)$, but this difference was not significantly different from zero. Under the LP+ treatment, SOM increased by $3.2 \mathrm{Mg} \mathrm{ha}^{-1} \mathrm{yr}^{-1}(0-60 \mathrm{~cm}$ soil layer). The difference of 1.9 $\mathrm{Mg} \mathrm{ha}^{-1} \mathrm{yr}^{-1}$ should be attributed to the greater root biomass $\left(0.8 \mathrm{Mg} \mathrm{ha}^{-1}\right.$, root mass $_{\mathrm{LP}_{-}}$- root mass $\left.\mathrm{PP}_{+}=8.3-7.5=0.8\right)$ and the input of manure granules $(2.2$ $\left.\mathrm{Mg} \mathrm{ha}^{-1} \mathrm{yr}^{-1}\right)$. In fields under FA+ the joint effect of manure application and increased root biomass could also be observed $\left(\triangle \mathrm{SOM}_{\mathrm{FA}_{+}}=4 \mathrm{Mg} \mathrm{ha}^{-1} \mathrm{yr}^{-1}\right.$; Figure 2o) when considering the whole sampled profile. This indicates that there was an extra amount of around $0.8 \mathrm{Mg} \mathrm{OM} /$ ha $\left(\Delta \mathrm{SOM}_{\mathrm{FA+}}-\Delta \mathrm{SOM}_{\mathrm{LP+}}=\right.$ 4-3.2 $=0.8 \mathrm{Mg} \mathrm{ha}^{-1} \mathrm{yr}^{-1}$ ) coming from tall fescue roots compared to the LP+ treatment. This is equal to about one third of the additional root biomass of tall fescue (root masses of LP+ and FA+ were, respectively, 8.3 and $10.6 \mathrm{Mg} \mathrm{ha}^{-1}$ for the 0-60 cm soil layer; 0.8/(10.6-8.3), Supplementary material, Table S5).

After a period of five years, large differences in SOM accumulation rates were found between the $0-30$ and $0-60 \mathrm{~cm}$ soil layer (Figure 2l, o). Largest rates of increase were observed in the $30-60 \mathrm{~cm}$ soil layer (up to $70 \%$ of the total accumulation of SOM was found in this layer; for instance for FA+, $\triangle \mathrm{SOM}_{0.30 \mathrm{~cm}}=1.2$ and $\left.\triangle \mathrm{SOM}_{0.60 \mathrm{~cm}}=4.0 \mathrm{Mg} \mathrm{ha}^{-1} \mathrm{yr}^{-1}\right)$. The divergence between distribution of root mass and SOM was also observed by Gill et al. (1999) who attributed this to differences in water availability (increased decomposition in the top soil) and root senescence, i.e. roots in deeper soil layers persisted much longer than roots in the surface. Moreover, it seems that also a process of vertical translocation of OM has occurred from the $0-30 \mathrm{~cm}$ to the 30-60 $\mathrm{cm}$ soil layer. The mechanisms behind this can however not be derived from the data gathered in this experiment and pulse labelling of plants could possibly reveal the magnitude of these processes. 
Generally, the conversion from arable land to grassland is thought to lead to soil C accumulation (Soussana et al., 2007; 2010). However, this experiment has shown that conclusions on the SOM storage capacity are strongly determined by sampling depth, length of the grassland period, species composition and management. After five years, significant increases in SOM were found for both fertilized and unfertilized treatments in the $0-10 \mathrm{~cm}$ soil layer. However, when the whole sampled profile is considered, only the fertilized treatments showed significant increases in SOM (Figure 20). The current sampling depth in The Netherlands is $10 \mathrm{~cm}$ for grassland soils. Thus, in the light of these findings we plea to increase the sampling depth of Dutch grassland soils from 10 to $30 \mathrm{~cm}$ or even better, to $60 \mathrm{~cm}$ (cf. Ward et al., 2016).

\subsection{Comparison of the experiment with on-farm grasslands}

The $0-30 \mathrm{~cm}$ layer of both soils in this experiment had an SOM content of about $2.8 \%$ at the start of the experiment which is in the range of the average SOM contents of Dutch arable land on sandy and clayey soils. Reijneveld et al., (2009) reported values of $2.6 \%$ and $3.4 \%$ for sand and clay, respectively. A limitation of the study is that we did not account for differences between stocking systems in trampling and compaction and spatial distribution of urine and faeces occurring in grazed grasslands. We can therefore only conclude as to the effects of differences between stocking systems in terms of cutting height and frequency on root biomass and SOM. Furthermore, excreta deposition of grazing animals was simulated by applying pelleted cattle manure. The manure application rate in this experiment was lower than on Dutch dairy farms who are registered for the derogation (equivalent ${ }^{\star}$ to 3.9 $\mathrm{Mg} \mathrm{OM} \mathrm{ha-1} \mathrm{yr}^{-1}$ on temporary grasslands; RIVM, 2016). For this reason, higher changes in OM can be expected in newly seeded temporary grasslands (with predominantly perennial ryegrass) on dairy farms in clayey and sandy regions of the Netherlands. Especially since on dairy farms more grazing and harvesting losses occur compared to a simulated stocking experiment.

To comply with the recently proposed 4 thousandth initiative (UNFCCC, 2016), Dutch temporary grasslands on mineral soils would have to sequester on average $0.7 \mathrm{Mg} \mathrm{SOM} \mathrm{ha}^{-1} \mathrm{yr}^{-1}$ (after Conijn \& Lesschen, 2015; the average SOC content of mineral soils in the Netherlands is $94 \mathrm{Mg} \mathrm{SOC/ha}$ in the 0-30 $\mathrm{cm}$ soil layer. Using a conversion factor of $2 \times \mathrm{SOC}=\mathrm{SOM}$, this results in 187 Mg SOM ha-1 and $\left.187 \times 0.004=0.7 \mathrm{Mg} \mathrm{SOM} \mathrm{ha}^{-1} \mathrm{yr}^{-1}\right)$. Especially the subsoil should be considered as a potential carbon sink, because this layer is usually not ploughed during the arable phase of soils that are under lay-arable rotations and $\mathrm{C}$ stocks are relatively stable.

The results of this study suggest that it seems possible to comply with the 4 thousandth initiative in a period of five years after conversion from arable land to grassland, with fertilized perennial ryegrass or tall fescue in monoculture as average SOM sequestration rates were 1.5 and $2.8 \mathrm{Mg} \mathrm{ha}^{-1} \mathrm{yr}^{-1}$ in the $30-60 \mathrm{~cm}$ 
soil layer (cf. Figure 2i). For this reason, we highly recommend monitoring the subsoil for future carbon inventories (cf.Skinner \& Dell, 2016; Ward etal., 2016).

\section{Conclusions}

The analysis of root biomass and SOM dynamics down to $60 \mathrm{~cm}$ depth in a two-year and five-year field experiment on arable land converted to grassland, testing different sward species compositions and simulated stocking systems leads to the following conclusions:

- No effects of different simulated stocking systems in terms of cutting height and frequency on root biomass were observed in both the sandy and loamy soil during the first two years of the experiment.

- Root biomass was greatest under monocultures of tall fescue which was also reflected in the largest SOM accumulation rates in the $30-60 \mathrm{~cm}$ soil layer of the sandy soil.

- SOM increases tended to be higher under lenient strip stocking than under rotational stocking most likely due to a larger in put of aboveground decaying plant material.

- No effects of species composition were found, except for tall fescue in dry sandy subsoils.

- No causal relationships could be established between root biomass and SOM rates of change in both soils $(0-30 \mathrm{~cm}$ soil layer) during the first 2 years, probably as a consequence of declining SOM stocks in the 10-30 $\mathrm{cm}$ soil layer and large variation in both root biomass and initial SOM stocks.

- Manure appeared to be crucial to increase SOM stocks. In this particular experiment with simulated stocking systems, the conversion from arable land to grassland did only lead to an increase in SOM after five years (sandy soil), in the treatments where animal manure was applied and considering the $0-60 \mathrm{~cm}$ soil profile.

- With fertilized perennial ryegrass or tall fescue in monoculture it seems possible to comply with the 4 thousandth initiative in a period of five years, but this requires that the commonly used sampling depth of $10 \mathrm{~cm}$ for grassland soils in the Netherlands should be increased to a depth of preferably $60 \mathrm{~cm}$ to monitor soil organic matter changes.

\footnotetext{
* Average $\mathrm{N}$ animal manure application rates on Dutch dairy farms registered for derogation

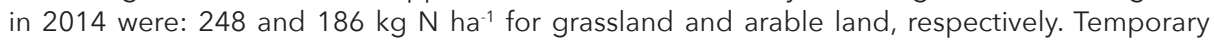
grasslands are considered as arable land and are under grassland for a period less than 5 years. National fixed rate values for cattle slurry were used to convert $\mathrm{N}$ animal manure application rates into organic matter. The median of the $\mathrm{N}$ content and $\mathrm{OM}$ content of cattle slurry were 4.1 $\mathrm{g} \mathrm{N}$ and $64 \mathrm{~g}$ OM per ton of fresh product (De Haan \& van Geel, 2019). Thus, OM-slurry application rate on temporary grassland was in 2014 on average $248 / 4.1^{\star} 64 / 10^{3}=3.9 \mathrm{Mg} \mathrm{ha}^{-1} \mathrm{yr}^{-1}$.
} 


\section{Supplementary material}
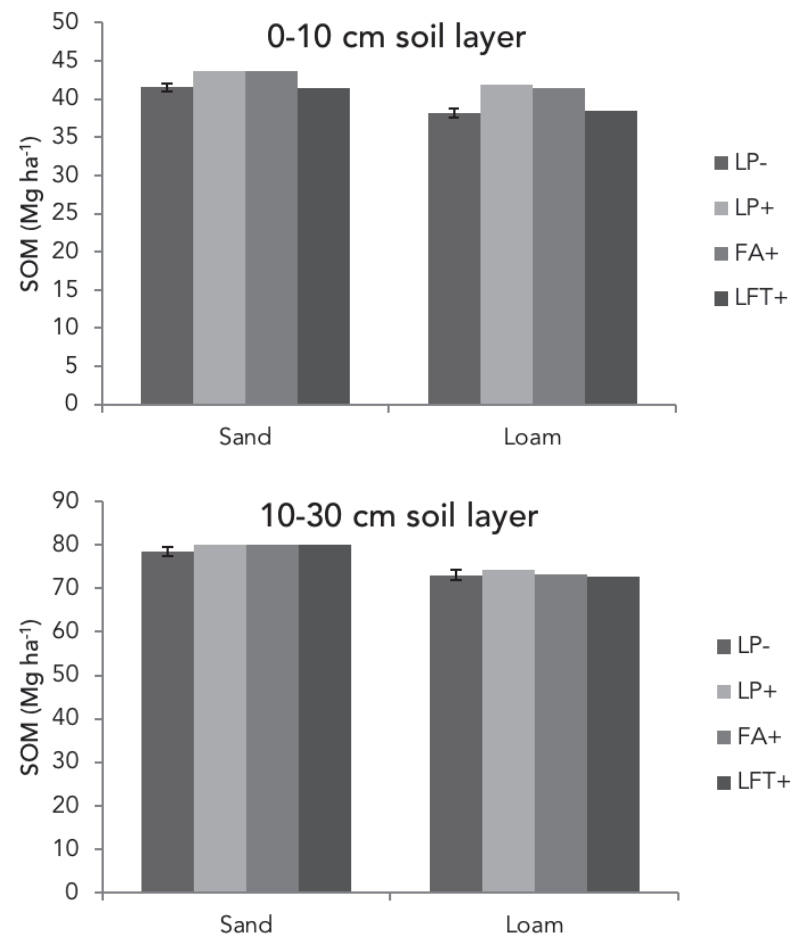

Figure S1. Initial soil organic matter (SOM) content (Mg ha $\left.{ }^{-1}\right)$ in September 2011 per species composition per soil type (sand and loam) and soil layer (0-10 cm and 10-30 $\mathrm{cm})$. LP- $=$ unfertilized perennial ryegrass. $\mathrm{LP}+=$ fertilized perennial ryegrass. FA+ $=$ fertilized tall fescue. LFT+ = fertilized perennial ryegrass, tall fescue and white clover. Analyses were conducted per soil type and per soil layer. The results of the analysis of variance are presented in Table S4. The standard errors depicted in the graph are 0.529 (sand, 0-10 cm), 0.571 (loam, 0-10 cm), 0.998 (sand, 10-30 cm) and 1.107 (loam, 10-30 cm). 

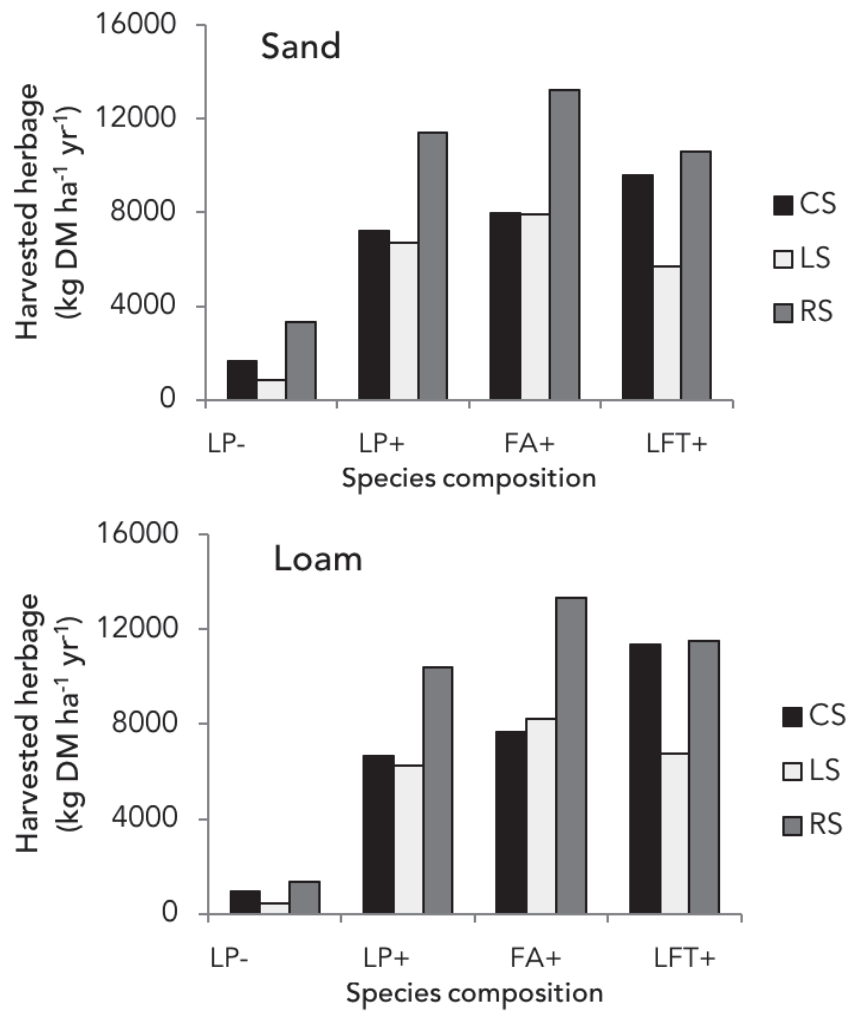

Figure S2. Harvested herbage per treatment. Average values of the year 2012 and 2013 are given. LP- $=$ unfertilized perennial ryegrass, $L P+=$ fertilized perennial ryegrass, $F A+=$ fertilized tall fescue and $L F T+=$ perennial ryegrass, tall fescue and white clover. Three stocking systems were simulated: CS=continuous stocking, $\mathrm{LS}=$ lenient stocking and $\mathrm{RS}=$ rotational stocking. 

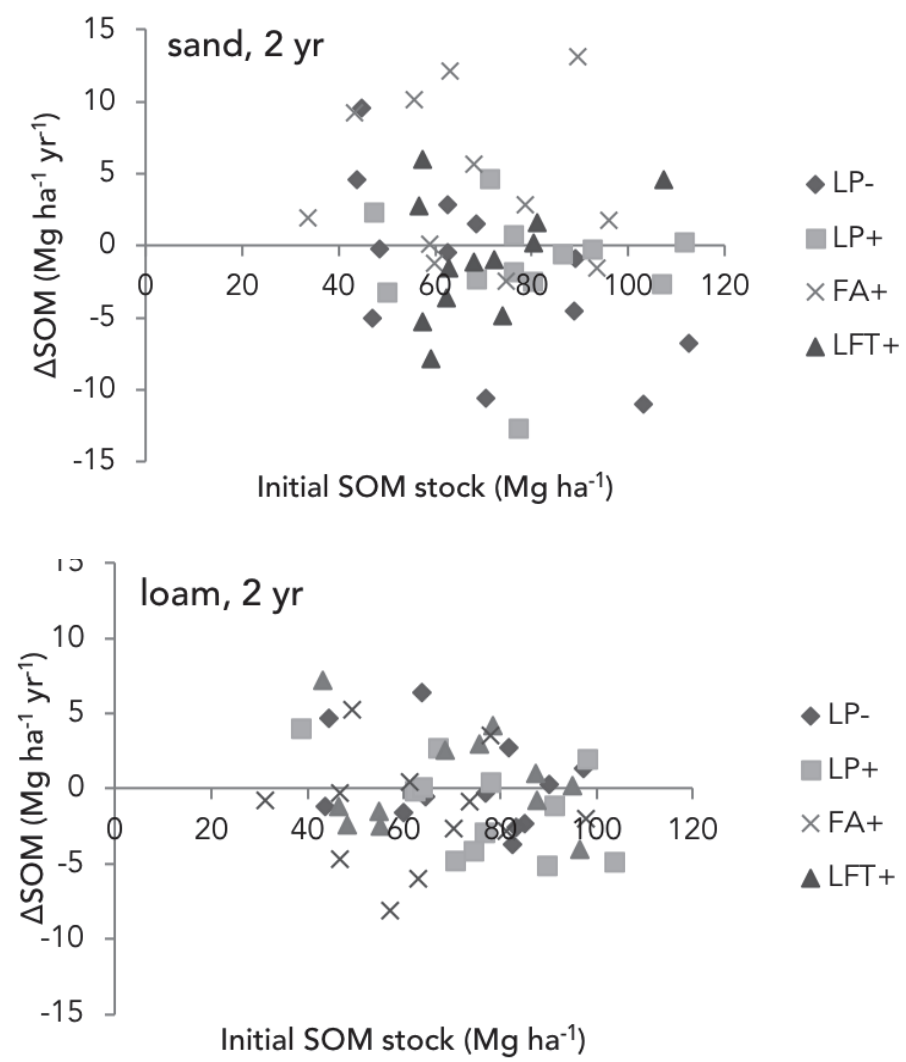

Figure S3. Relationship between initial soil organic matter (SOM) stocks and $\triangle \mathrm{SOM}$ ( $\mathrm{Mg} \mathrm{ha}^{-1} \mathrm{yr}^{-1}$ ) per species composition for the $30-60 \mathrm{~cm}$ soil layer. Because the relationship was not significant the regression lines were not plotted. LP- $=$ unfertilized perennial ryegrass. $\mathrm{LP}+=$ fertilized perennial ryegrass. $F A+=$ fertilized tall fescue. $\mathrm{LFT}+=$ fertilized perennial ryegrass, tall fescue and white clover. 


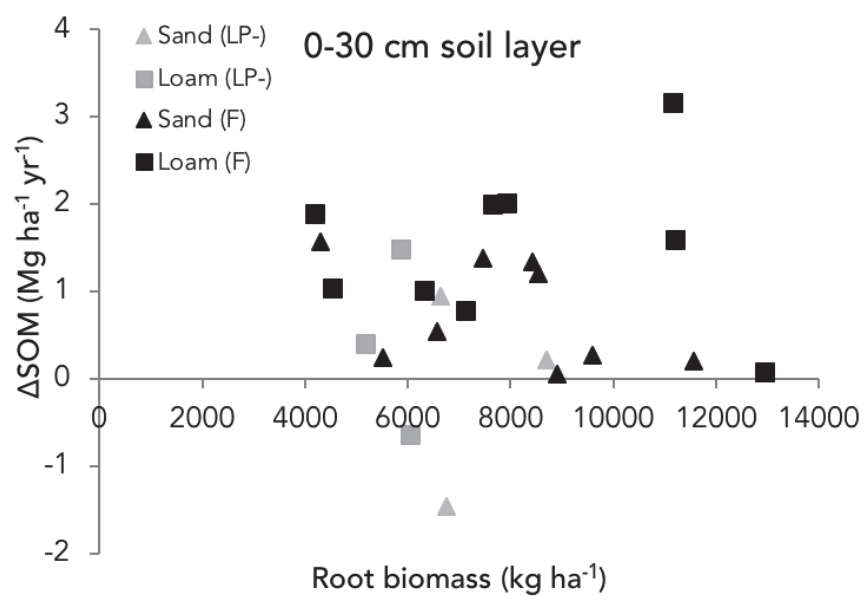

Figure S4. Relationship between root biomass and rates of change of soil organic matter (SOM) per soil type for the $0-30 \mathrm{~cm}$ soil layer. F=all fertilized treatments (monocultures of perennial ryegrass and tall fescue and the mixture of the two grass species with white clover). LP-=unfertilized perennial ryegrass.

Table S1. Seeding rates of plant species per treatment. LP- = unfertilized perennial ryegrass, $\mathrm{LP}+=$ fertilized perennial ryegrass, $\mathrm{FA}+=$ fertilized tall fescue and $\mathrm{LFT}+=$ fertilized perennial ryegrass, tall fescue and white clover. T=white clover.

\begin{tabular}{lll}
\hline Treatment & Cultivar & Seeding rate $\left(\mathrm{kg} \mathrm{ha}^{-1}\right)$ \\
\hline LP- and LP+ & Barflip & 8.33 \\
& Barforma & 8.33 \\
& Arsenal & 8.33 \\
FA+ & Barolex & 10 \\
& Bariane & 40 \\
LFT+ & LP: see treatments LP-, LP+ 10 \\
& FA: see treatment FA+ & 20 \\
& T: Alice & 1.5 \\
& T: Riesling & 1.5 \\
\hline
\end{tabular}


Table S2. Dates of fertilizer application during the first two experimental years. Stocking methods were not applicable in 2011. The abbreviations CS, LS and RS refer to continuous, lenient strip and rotational simulated stocking, respectively. LP- = unfertilized perennial ryegrass, $\mathrm{LP}+=$ fertilized perennial ryegrass, $\mathrm{FA}+=$ fertilized tall fescue and $\mathrm{LFT}+=$ fertilized perennial ryegrass, tall fescue and white clover. 'All' refers to all treatments: LP-, LP+, FA+ and LFT+. N-CAN = nitrogen applied as calcium ammonium nitrate.

\begin{tabular}{|c|c|c|c|}
\hline Dates 2011 & Species composition & Fertilizer type & Amount $\left(\mathrm{kg} \mathrm{ha}^{-1}\right)$ \\
\hline $\begin{array}{l}07-06 \\
07-06\end{array}$ & $\begin{array}{l}\mathrm{LP}+, \mathrm{FA}+ \\
\mathrm{LFT}+\end{array}$ & $\begin{array}{l}\text { N-Manure granules } \\
\text { N-Manure granules }\end{array}$ & $\begin{array}{l}120 \\
50\end{array}$ \\
\hline $15-08$ & $\mathrm{LP}+, \mathrm{FA}+$ & N-Manure granules & 80 \\
\hline $16-08$ & All & $\mathrm{N}-\mathrm{CAN}$ & 52.5 \\
\hline Dates 2012 & Species composition & Fertilizer type & Amount (kg ha-1) \\
\hline $13-04$ & $\mathrm{LP}+, \mathrm{FA}+, \mathrm{LFT}+$ & N-Manure granules & 50 \\
\hline $29-03$ & $\mathrm{LP}+, \mathrm{FA}+$ & N-CAN & 80 \\
\hline $25-06$ & $\mathrm{LP}+, \mathrm{FA}+$ & N-CAN & $30(\mathrm{CS}) ; 60(\mathrm{LS}, \mathrm{RS})$ \\
\hline $16-07$ & $\mathrm{LP}+, \mathrm{FA}+$ & N-CAN & 30 \\
\hline $01-08$ & $\mathrm{LP}+, \mathrm{FA}+$ & N-CAN & 30 (CS); 60 (LS, RS) \\
\hline $13-08$ & $\mathrm{LP}+, \mathrm{FA}+$ & N-CAN & 30 \\
\hline $27-8$ & All & $\mathrm{K}_{2} \mathrm{O}$ & 100 \\
\hline Dates 2013 & Species composition & Fertilizer type & Amount $\left(\mathrm{kg} \mathrm{ha}^{-1}\right)$ \\
\hline $02-04$ & $\mathrm{LP}+, \mathrm{FA}+, \mathrm{LFT}+$ & N-Manure granules & 50 \\
\hline $05-04$ & $\mathrm{LP}+, \mathrm{FA}+$ & N-CAN & 80 \\
\hline $26-04$ & All & $\mathrm{K}_{2} \mathrm{O}$ & 80 \\
\hline $22-05$ & All & $\mathrm{P}_{2} \mathrm{O}_{5}$ & 50 \\
\hline $22-05$ & All & Trace elements ${ }^{\star}$ & \\
\hline $28-05$ & $\mathrm{LP}+, \mathrm{FA}+$ & N-CAN & 30 (CS); 60 (LS, RS) \\
\hline $26-06$ & $\mathrm{LP}+, \mathrm{FA}+$ & N-CAN & 30 \\
\hline $30-07$ & $\mathrm{LP}+, \mathrm{FA}+$ & N-CAN & 30 (CS); 60 (LS, RS) \\
\hline $21-08$ & $\mathrm{LP}+, \mathrm{FA}+$ & N-CAN & 30 \\
\hline
\end{tabular}

*The composition and application rate of trace elements is presented in Table S3. 
Table S3. Annual application rates of micronutrients from 2013 to 2016.

\begin{tabular}{ll}
\hline Element & Application rate $\left(\mathrm{kg} \mathrm{ha}^{-1} \mathrm{yr}^{-1}\right)$ \\
\hline $\mathrm{MgO}$ & 13.0 \\
$\mathrm{~B}$ & 0.2 \\
$\mathrm{Cu}$ & 0.9 \\
$\mathrm{Fe}$ & 13.0 \\
$\mathrm{Mn}$ & 2.2 \\
$\mathrm{Mo}$ & 0.03 \\
$\mathrm{Zn}$ & 0.9 \\
$\mathrm{SO}_{3}$ & 33.0 \\
\hline
\end{tabular}

Table S4. Results of the analysis of variance on 288 SOM (soil organic matter) observations. Samples were taken in September 2011. Data were analysed per soil layer and per soil type (sand and loam). Species composition and block were taken as fixed factor and plot within block as random factor. $F$ and $P$ values are presented. $\mathrm{df}=$ degrees of freedom.

\begin{tabular}{|c|c|c|c|c|c|c|c|}
\hline \multirow[t]{2}{*}{ Soil layer } & \multirow[t]{2}{*}{ Soil type } & \multicolumn{2}{|c|}{ Species composition } & \multicolumn{2}{|l|}{ Block } & \multicolumn{2}{|c|}{ Plot within block } \\
\hline & & $\mathrm{F}$ & $P$ & $\mathrm{~F}$ & $P$ & $\mathrm{~F}$ & $P$ \\
\hline \multirow[t]{2}{*}{$0-10 \mathrm{~cm}$} & Sand & 5.74 & 0.00 & 0.42 & 0.74 & 5.94 & 0.00 \\
\hline & Loam & 11.374 & 0.00 & 4.23 & 0.05 & 1.53 & 0.19 \\
\hline \multirow[t]{2}{*}{$10-30 \mathrm{~cm}$} & Sand & 0.67 & 0.58 & 1.29 & 0.34 & 5.51 & 0.00 \\
\hline & Loam & 0.34 & 0.80 & 2.87 & 0.10 & 3.17 & 0.01 \\
\hline \multirow[t]{4}{*}{$30-60 \mathrm{~cm}$} & Sand & 2.08 & 0.12 & 1.91 & 0.21 & 6.78 & 0.00 \\
\hline & Loam & 1.77 & 0.17 & 7.25 & 0.01 & 1.26 & 0.30 \\
\hline & & df1 & $d f 2$ & $d f 1$ & $d f 2$ & $d f 1$ & $\mathrm{df} 2$ \\
\hline & Sand, Loam & 3 & 33 & 3 & 8 & 8 & 33 \\
\hline
\end{tabular}

Table S5. Average root biomass (kg dry matter/ha) in July 2013 and March 2014 per soil layer per treatment. LP- = unfertilized perennial ryegrass. LP+ = fertilized perennial ryegrass. FA+ $=$ fertilized tall fescue. $L F T+=$ fertilized perennial ryegrass, tall fescue and white clover. Standard errors of the mean are presented between brackets.

\begin{tabular}{lllllll}
\hline & \multicolumn{2}{c}{$0-10 \mathrm{~cm}$} & \multicolumn{2}{c}{$10-30 \mathrm{~cm}$} & \multicolumn{2}{c}{$30-60 \mathrm{~cm}$} \\
Mixture & Sand & Loam & Sand & Loam & Sand & Loam \\
\hline LP- & $6451(655)$ & $4939(540)$ & $920(83)$ & $748(75)$ & $123(39)$ & $305(49)$ \\
LP+ & $7183(655)$ & $6579(540)$ & $952(83)$ & $988(75)$ & $130(39)$ & $309(49)$ \\
FA+ & $8596(655)$ & 10067 & $1426(83)$ & $1698(75)$ & $616(39)$ & $648(49$ \\
& $(540)$ & & & & \\
LFT+ & $4565(655)$ & $4153(540)$ & $902(83)$ & $865(75)$ & $147(39)$ & $255(49)$ \\
\hline
\end{tabular}


Table S6. Estimates and $P$-values for differences between species compositions between SOM rates of change in $\mathrm{Mg} \mathrm{ha}^{-1} \mathrm{yr}^{-1}$ after a period of 2 years, by soil layer and by soil type. Values for the sandy soil are printed in bold; values for the loamy soil are printed in italics. LP-=unfertilized perennial ryegrass, LP+=fertilized perennial ryegrass, $F A+=$ fertilized tall fescue and $L F T+=$ fertilized perennial ryegrass, tall fescue and white clover. A negative difference such as between LP- and LP+ $(0-10 \mathrm{~cm}$ soil layer; -1.71) means that the annual SOM rate of change of LP- was $1.71 \mathrm{Mg} \mathrm{ha}^{-1}$ lower than the rate of $\mathrm{LP}+\left(\mathrm{LP}-=0.55 \mathrm{Mg} \mathrm{SOM} \mathrm{ha}^{-1} \mathrm{yr}^{-1} ; \mathrm{LP}+=2.26 \mathrm{Mg} \mathrm{SOM} \mathrm{ha}^{-1} \mathrm{yr}^{-1}\right.$; $0.55-2.26=-1.71)$. For values of the sandy soil comparisons between treatments are horizontally presented. For the loamy soil comparisons are vertically presented (for

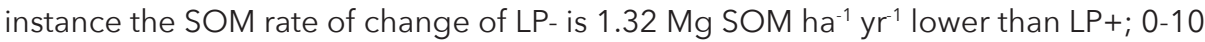
$\mathrm{cm}$ layer).

\begin{tabular}{|c|c|c|c|c|}
\hline \multicolumn{5}{|c|}{$0-10 \mathrm{~cm}$ soil layer } \\
\hline $\begin{array}{l}\text { Species } \\
\text { composition }\end{array}$ & LP- & $\mathrm{LP}+$ & $\mathrm{FA}+$ & LFT+ \\
\hline LP- & $x$ & $-1.71(0.00)$ & $0.94(0.00)$ & $-1.40(0.02)$ \\
\hline $\mathrm{LP}+$ & $-1.32(0.00)$ & $x$ & $0.78(0.43)$ & $0.31(0.05)$ \\
\hline $\mathrm{FA}+$ & $-1.22(0.01)$ & $0.10(0.92)$ & $x$ & $0.46(0.24)$ \\
\hline $\mathrm{LFT}+$ & $-1.27(0.01)$ & $0.05(0.84)$ & $0.05(0.13)$ & $x$ \\
\hline \multicolumn{5}{|c|}{$10-30 \mathrm{~cm}$ soil layer } \\
\hline LP- & $x$ & $0.28(0.66)$ & $0.69(0.37)$ & $0.58(0.28)$ \\
\hline $\mathrm{LP}+$ & $0.14(0.81)$ & $x$ & $0.41(0.65)$ & $0.30(0.53)$ \\
\hline $\mathrm{FA}+$ & $0.02(0.53)$ & $-0.12(0.85)$ & $x$ & $0.12(0.86)$ \\
\hline$\underline{\mathrm{LFT}+}$ & $0.37(0.97)$ & $0.23(0.70)$ & $-0.35(0.56)$ & $x$ \\
\hline \multicolumn{5}{|c|}{$30-60 \mathrm{~cm}$ soil layer } \\
\hline LP- & $x$ & $-0.25(0.90)$ & $-6.05(0.00)$ & $-0.90(0.66)$ \\
\hline LP+ & $1.41(0.30)$ & $x$ & $-5.80(0.00)$ & $0.64(0.75)$ \\
\hline $\mathrm{FA}+$ & $0.22(0.87)$ & $-1.63(0.23)$ & $x$ & $5.16(0.01)$ \\
\hline$\underline{\mathrm{LFT}+}$ & $-1.83(0.18)$ & $0.42(0.76)$ & $-2.05(0.13)$ & $x$ \\
\hline
\end{tabular}

Table S7. Estimates and $P$-values for differences between stocking systems in SOM rates of change in $\mathrm{Mg} \mathrm{ha}^{-1} \mathrm{yr}^{-1}$ in the loamy (italics) and sandy soil (bold) for the $0-30 \mathrm{~cm}$ soil layer after a period of two and five years, respectively. CS=continuous stocking, $\mathrm{LS}=$ lenient strip stocking, $\mathrm{RS}=$ rotational stocking. The results of the two year period of the sandy soil are not presented because none of the values were significant.

\begin{tabular}{llll}
\hline Stocking system & CS & LS & RS \\
\hline CS & $x$ & $-0.42(0.17)$ & $0.55(0.07))$ \\
LS & $-0.45(0.54)$ & $x$ & $0.97(0.00)$ \\
RS & $-1.16(0.12)$ & $-1.61(0.03)()$ & $x$ \\
\hline
\end{tabular}


Table S8. Estimates for differences between species compositions in SOM rates of change in $\mathrm{Mg} \mathrm{ha}^{-1} \mathrm{yr}^{-1}$ in the sandy soils after a period of five years. $P$-values are given in parentheses. $\mathrm{LP}-=$ unfertilized perennial ryegrass, $\mathrm{LP}+=$ fertilized perennial ryegrass, $F A+=$ fertilized tall fescue and $L F T+=$ fertilized perennial ryegrass, tall fescue and white clover. A negative difference such as between LP- and LP+ $(0-10 \mathrm{~cm}$ soil layer; -0.71$)$ means that the annual SOM rate of change of LP- was $0.71 \mathrm{Mg} \mathrm{ha}^{-1}$ lower than the rate of $L P+\left(L P-=1.23 \mathrm{Mg} \mathrm{SOM} \mathrm{ha}^{-1} \mathrm{yr}^{-1} ; \mathrm{LP}+=1.94 \mathrm{Mg} \mathrm{SOM} \mathrm{ha}^{-1} \mathrm{yr}^{-1} ; 1.23-1.94=-0.71\right)$.

\begin{tabular}{llllll}
\hline $\begin{array}{l}\text { Species } \\
\text { compositions }\end{array}$ & $0-10 \mathrm{~cm}$ & $10-30 \mathrm{~cm}$ & $30-60 \mathrm{~cm}$ & $0-30 \mathrm{~cm}$ & $0-60 \mathrm{~cm}$ \\
\hline LP- vs. LP+ & $-0.71(0.00)$ & $0.07(0.81)$ & $-1.33(0.13)$ & $-0.65(0.07)$ & $-1.96(0.05)$ \\
LP- vs. FA+ & $-0.15(0.38)$ & $-0.01(0.97)$ & $-2.63(0.00)$ & $-0.17(0.64)$ & $-2.77(0.01)$ \\
LP- vs. LFT+ & $-0.34(0.05)$ & $-0.10(0.73)$ & $-0.91(0.31)$ & $-0.44(0.22)$ & $-1.32(0.18)$ \\
LP+ vs. FA+ & $0.56(0.00)$ & $-0.08(0.78)$ & $-1.30(0.14)$ & $0.48(0.18)$ & $-0.82(0.40)$ \\
LP+ vs. LFT+ & $0.37(0.03)$ & $-0.16(0.56)$ & $0.43(0.63)$ & $0.21(0.56)$ & $0.64(0.51)$ \\
FA+ vs. LFT+ & $-0.18(0.28)$ & $-0.08(0.76)$ & $1.72(0.05)$ & $-0.27(0.45)$ & $1.45(0.13)$ \\
\hline
\end{tabular}

Table S9. Average rates of change of soil organic matter (SOM) in $\mathrm{Mg} \mathrm{ha}^{-1} \mathrm{yr}^{-1}$ per soil layer per simulated stocking system for the period September 2011 - January 2014 (sand and loam, 2 years) and the period September 2011 - May 2016 (sand, 5 years). Simulated stocking systems: CS=continuous stocking, LS=lenient strip stocking and $\mathrm{RS}=$ rotational stocking.

\begin{tabular}{|c|c|c|c|c|c|}
\hline \multirow[b]{2}{*}{ Soil type } & \multirow[b]{2}{*}{ Period (yr) } & \multirow[b]{2}{*}{ Layer $(\mathrm{cm})$} & \multicolumn{3}{|c|}{$\Delta \mathrm{SOM}\left(\mathrm{Mg} \mathrm{ha}^{-1} \mathrm{yr}^{-1}\right)$} \\
\hline & & & CS & LS & RS \\
\hline \multirow[t]{5}{*}{ Loam } & 2 & $0-10$ & 1.8 & 2.2 & 1.6 \\
\hline & & $10-30$ & -0.3 & -0.3 & -1.3 \\
\hline & & $30-60$ & 0.4 & -0.5 & -1.5 \\
\hline & & $0-30$ & 1.5 & 1.9 & 0.3 \\
\hline & & $0-60$ & 1.9 & 1.5 & -1.2 \\
\hline \multirow[t]{5}{*}{ Sand } & 2 & $0-10$ & 1.8 & 1.5 & 1.4 \\
\hline & & $10-30$ & -1.2 & -0.9 & -1.1 \\
\hline & & $30-60$ & -0.8 & -0.3 & 1.3 \\
\hline & & $0-30$ & 0.6 & 0.6 & 0.3 \\
\hline & & $0-60$ & -0.2 & 0.3 & 1.6 \\
\hline \multirow[t]{5}{*}{ Sand } & 5 & $0-10$ & 1.6 & 1.7 & 1.3 \\
\hline & & $10-30$ & -0.2 & 0.1 & -0.5 \\
\hline & & $30-60$ & 1.0 & 1.8 & 1.4 \\
\hline & & $0-30$ & 1.4 & 1.8 & 1.0 \\
\hline & & $0-60$ & 2.4 & 3.7 & 2.6 \\
\hline
\end{tabular}


Box S1 Soil bulk density measurements and the conversion from SOM concentrations to stocks

Soil bulk density (BD) measurements were needed to convert SOM concentrations to SOM stocks. BD measurements were taken in the experimental fields using the core method at the end of the 'two year period' (see Materials \& Methods). All collected samples for SOM could not be accompanied by BD measurements as no surface would remain at the end of the experiment. For this reason, BD values had to be estimated for all individual SOM measurements that were used to derive SOM trends. A strong relationship exists between the SOM content and soil bulk density value of a sample. SOM increases with decreasing BD because the true density of organic matter is much lower as compared to mineral particles (Adams, 1973). A dataset that contained both $L O I$ and $B D$ values was used to derive a relationship between $\mathrm{LOI}$ and $\mathrm{BD}$ (Figure S5). The equation was used to estimate BD values of the experimental fields based on SOM contents. Next, SOM contents were converted to SOM stocks with the estimated BD values.

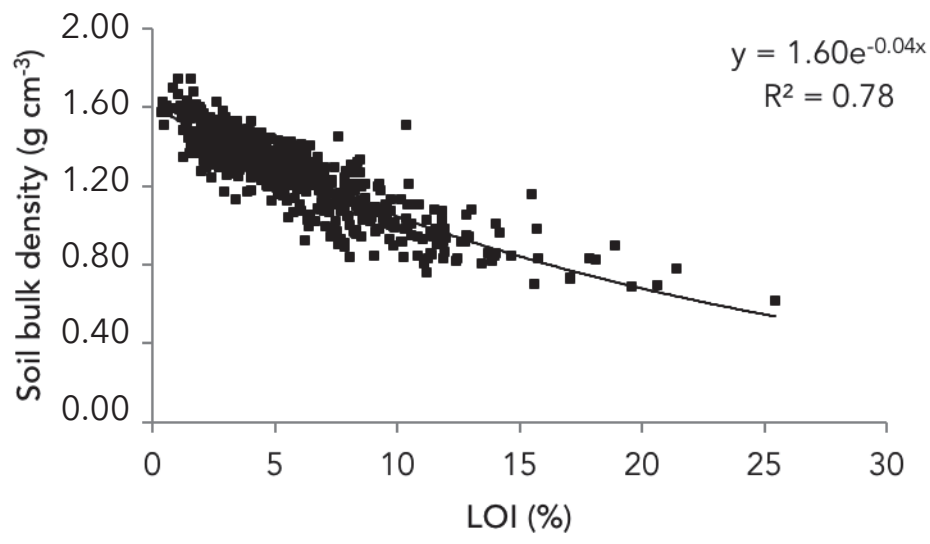

Figure S5. Relationship between soil bulk density and loss-on-ignition values $(n=684)$. Data was obtained from the $0-30 \mathrm{~cm}$ soil layer of 19 grasslands in the neighborhood of Wageningen, the Netherlands. 



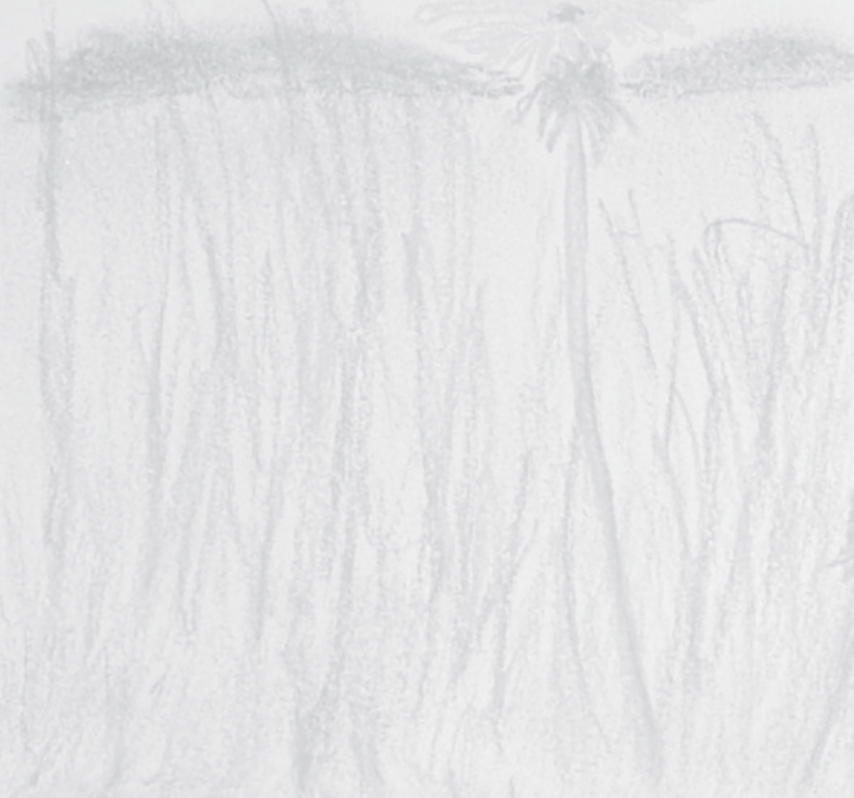

nest

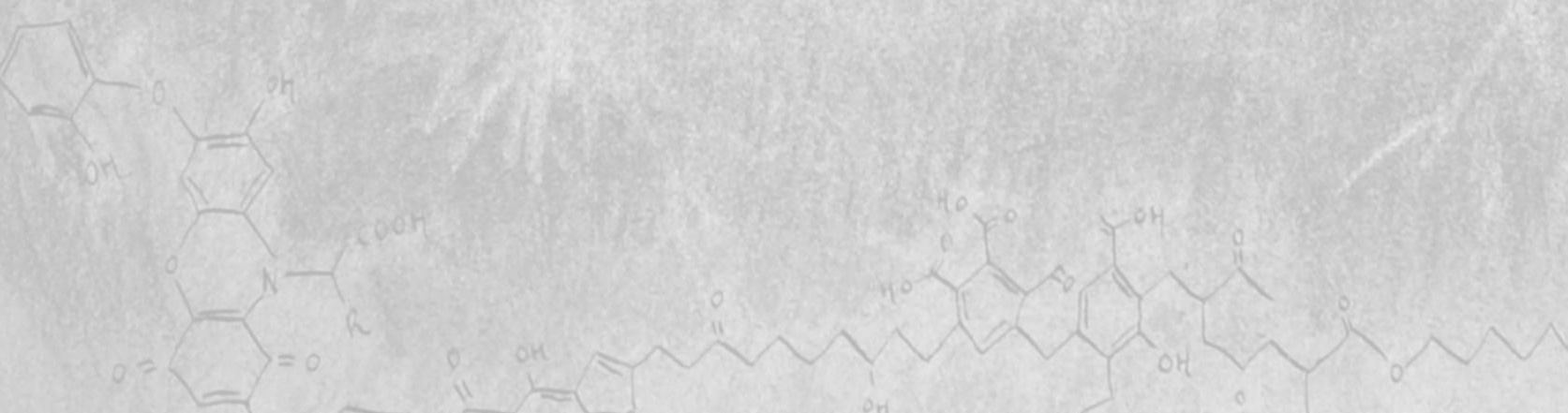




\section{Chapter 6. General discussion}

Parts of the general discussion (paragraphs of section 4.1) have been published in adapted form as the author's contribution (Personal contribution - Box 2, page 44) to: FAO (2019). Measuring and modelling soil carbon stocks and stock changes in livestock production systems: Guidelines for assessment. Livestock Environmental Assessment and Performance (LEAP) Partnership. Rome, Italy, FAO. 170 pp. 



\section{Introduction}

Effects of climate change are becoming more severe and put a threat to society and agricultural productivity in the European Union (EEA, 2019). The public interest in soils is growing rapidly to safeguard the production of sufficient food for a growing population, and due to the potential of soil carbon (C) sequestration to offset emissions of greenhouse gases. Policy makers ask scientists, advisors and farmers explicitly to quantify $C$ sequestration in order to give out carbon certificates. Yet, there is no consensus in the scientific community on methodological aspects of on-farm carbon monitoring. A wide range of analytical methods and sampling designs exists and different soil layers are sampled leading to incomparable results in terms of $C$ sequestration levels across sites.

The overall aim of this thesis was to elucidate effects of methodological choices on quantifying management induced changes of soil organic matter (SOM) levels over time for grassland soils, and to assess the effect of different grassland management options on SOM dynamics. Through conducting a number of laboratory experiments guidelines were produced that allow for a reduction in the variation in the results of measurements caused by analytical procedures for determining SOM weight concentrations (Chapters 2 and 3). On-farm measurements gave insight into the effects of a number of methodological choices on the quantification of SOM stocks and the development thereof in time (Chapter 4). In Chapter 5, a field experiment shed light on several grassland management options for dairy farmers to sequester $\mathrm{C}$. In this chapter, the implications of the main findings of the thesis are discussed and brought into a policy context.

In Chapter 4 the rhetorical scheme "The seven circumstances" was used to structure the methodological aspects of setting up an SOM monitoring program. In this general discussion, I discuss the findings of this thesis along the questions that are central to this rhetorical scheme: 1.Who, 2. What, 3. Where, 4. When, 5. How, 6. Why, 7. By what means. Point 1, "Who" is not investigated in the thesis. Policy makers, environmental managers and farmers are interested in the layout and findings resulting from a monitoring system. First, the "What" question is addressed and the relevance of refining laboratory procedures is highlighted (section 2). This isfollowed by a discussion on the effects of sampling depth and length of the monitoring period on conclusions on SOM dynamics ("Where" and "When"; section 3). Next, a critical reflection is given on the conversion of SOM weight concentrations to SOM stocks and the experimental design of Chapter 5 ("How" and "By what means"; section 4). Hereafter, trade-offs and synergies of different grassland management options were identified ("Why"; section 5). Finally, recommendations are derived to feed into the establishment of a nationally harmonized sampling strategy for carbon monitoring, as an advice to "Who". 


\section{2. "What" - The relevance of refining laboratory procedures}

In general, long-term studies are necessary to assess the effects of changes in grassland management on SOM dynamics because of the high spatial variation in SOM concentration (Kravchenko \& Robertson, 2011; Fornara et al., 2020). The time period over which significant trends are detectable depends on the spatial variation, experimental design (e.g. number of replicates), size of the changes in time and the analytical procedures employed. Therefore, precise and accurate measurement methods are of crucial importance for drawing conclusions on monitoring SOM dynamics in grasslands. The SOM content can be analysed as SOC directly through, for instance, dichromate oxidation techniques, or indirectly as part of the total $\mathrm{C}$ content of soil or as weight losses through combustion. Only two analytical procedures exist *for determining SOM: loss-on-ignition (LOI) and wet oxidation (WO). In this thesis the focus was on LOI because there is a risk of incomplete oxidation when analysing SOM through WO.

Therefore, a factor needs to be applied to compare the data obtained through WO with LOI derived data. Mikutta et al. (2005) have shown that this correction factor depends largely on the reaction conditions, sample size and type of reagent. The LOI procedure also has a number of confounding factors: e.g. Nelson \& Sommers (1996) argued that the LOI method overestimates the SOM content because of the removal of inorganic constituents such as the dissipation of $\mathrm{H}_{2} \mathrm{O}$ from clay minerals and inorganic $\mathrm{C}$ losses. However, this thesis shows that structural water losses (SWL) from clay elements can be corrected for by applying the temperature specific multiplication factors provided in Chapter 2 of this thesis. It was shown, that a clay correction factor of 0.075 times the clay content is needed, when applying an ignition temperature of $550^{\circ} \mathrm{C}$ for a duration of three hours. This is slightly higher than the empirically derived factor of Houba et al., (1997, i.e. 0.07 times the clay content). This factor cannot be applied to allophane and sepiolite, due to their different SWL curves (Grim, 1953). However, circumventing the use of a clay correction factor through a temperature reduction is not recommended. Reducing the ignition temperature to, for instance, $300{ }^{\circ} \mathrm{C}$ would result in incomplete oxidation of SOM and consequently to an underestimation of the SOM content.

In Chapter 3 guidelines were derived for analysing the SOM content of calcareous soils through LOI. It is shown that in mixtures of calcite and quartz ignition losses appear at $600^{\circ} \mathrm{C}$ and increase with temperature in a sigmoidal way. Temperature specific calcite correction factors were derived.

* The near infrared spectroscopy (NIRS) method is an indirect method and the SOC (and SOM) content of the soil is predicted based on calibration curves. To establish calibration curves classical methods for SOC analysis are necessary. Furthermore, the method was not affordable at the start of this work and therefore it fell beyond the scope of this thesis ("By what means"). 
In Chapter 2, an ignition temperature of $550^{\circ} \mathrm{C}$ was recommended because complete combustion of SOM was attained. Because decarbonatation of calcite is negligible at this temperature the use of a calcite correction factor can be omitted (Chapter 3).

Furthermore, it was demonstrated that the LOI method is able to generate results with a much larger degree of precision than the commonly used wet chemical oxidation procedure for determining SOC because of the larger sample masses used for conducting LOI (cf. Chapter 2). All other SOC analysis procedures prescribe to use soil sample masses below $3 \mathrm{~g}$, with the exception of the Walkley-Black procedure (cf. Walinga et al., 1992), which allows a maximum soil sample mass of $10 \mathrm{~g}$ (Table 1). Yet, for this analysis the amount of the SOC in the sample may not exceed $25 \mathrm{mg}$, which is equivalent to an SOC concentration of $25 \mathrm{~g} \mathrm{~kg}^{-1}$ soil in case a sample mass of $10 \mathrm{~g}$ is used for analysis. With LOI soil samples of more than $20 \mathrm{~g}$ can be used.

Table 1. Overview of analytical procedures for determining total C, SOC or SOM. The prescribed sample mass is given for each method. For some of the methods, a sample's carbon content may not exceed a certain maximum value because of incomplete oxidation (Houba et al., 1997). In that case the maximum amount of C (Equivalent $C$ content) that a soil sample can contain is given. $N A=$ not applicable.

\begin{tabular}{llll}
\hline Component & Method & Sample mass $(\mathrm{g})$ & $\begin{array}{l}\text { Equivalent C } \\
\text { content }(\mathrm{mg})\end{array}$ \\
\hline Total C & $\begin{array}{l}\text { Dry combustion (DC) } \\
\text { High-temperature induction } \\
\text { furnace method (HTIFM) }\end{array}$ & $0.5-1$ & NA \\
& Wet combustion (WC) & 0.5 & NA \\
& Walkley-Black (WB) & $0.5-3$ & 40 \\
SOC & Tube digestion method (TDM) ${ }^{1}$ & $0.1-0.5$ & $<8$ \\
& loss-on-ignition (LOI) & $<10$ & NA \\
SOM & Wet oxidation & \\
& & 20 & NA \\
\hline
\end{tabular}

${ }^{1}$ Nelson \& Sommers (1996), ${ }^{2}$ Walinga et al., (1992) ${ }^{3}$ Hoogsteen et al., (2015), ${ }^{4}$ Mikutta et al., (2005). 


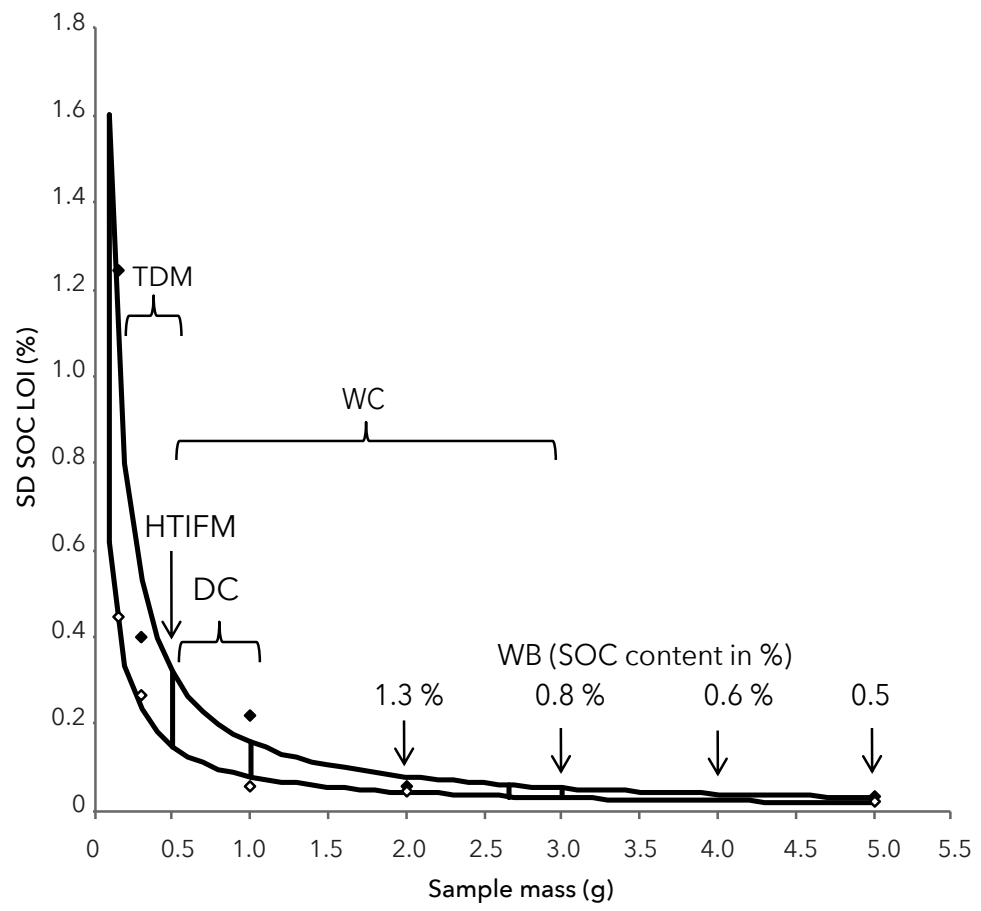

Figure 1. Relationship between standard deviation (SD) of the loss-on-ignition method (LOI) and sample mass for a sandy (solid diamonds) and loamy soil sample (open diamonds) based on the SD's found in Chapter 2, Figure 1. LOI values were converted to SOC using a factor of 0.55 (cf. Chapter 2, Figure 4a: horizontal asymptote). Soil sample masses of the analytical procedures for determining total $\mathrm{C}$ and SOM as presented in Table 1 are indicated in the figure. $\mathrm{LOI}=$ loss-on-ignition, TDM= tube digestion method, $\mathrm{WC}=$ wet combustion, HTIFM = High-temperature induction furnace method, $\mathrm{DC}=$ dry combustion, $\mathrm{WB}=$ Walkley-Black.

With average SOC contents of 20 and $44 \mathrm{~g} \mathrm{~kg}^{-1}$ for arable land and grassland of mineral soils in the Netherlands, respectively (Reijneveld et al., 2009), maximum sample masses may not exceed $1.25 \mathrm{~g}$ (arable land; 25/20) and $0.7 \mathrm{~g}$ (grassland; 25/44) when conducting the SOC analysis method that uses largest soil sample masses (i.e. Walkley-Black, see Table 1) ${ }^{\star \star}$.

In fact none of the SOC and Total C analysis procedures presented in Table 1 can be recommended for monitoring SOC contents in field experiments in the Netherlands in the short term as the variation associated with sample mass would most likely impair detecting significant differences between treatments.

** The amount of $\mathrm{SOC}$ in a soil sample may not exceed $25 \mathrm{mg}$. With an $\mathrm{SOC}$ content of $20 \mathrm{~g} \mathrm{~kg}^{-1}$ (or $20 \mathrm{mg} \mathrm{g}^{-1}$; average of arable soils in the Netherlands), the maximum sample mass that can be analysed is equal to $25 \mathrm{mg} / 20 \mathrm{mg} \mathrm{g}^{-1}=1.25 \mathrm{~g}$. 
Despite the foregoing, SOC analysis methods remain indispensable for determining the carbon content of SOM. Furthermore, the LOI method cannot be employed everywhere, because of its high energy demand (threephase electric power was needed in order to conduct the experiments presented in Chapters 2 and 3 and this is not universally available; personal communication with T. Razafimbelo, 2017).

Future research should focus on refining $\mathrm{SOC}$ analysis procedures and reducing the analytical variation through a stepwise approach as was done for the LOI method. Moreover, there is a need to further standardise SOM and SOC laboratory procedures, because sampling in the laboratory is still a largely arbitrary process that is prone to variation (Heiri et al., 2001). Extended and evidence-based universal SOC laboratory procedures should be developed specifying the conditions and procedures for each step in any soil chemical analysis procedure. This also holds for determining the OM content of root mass, compost or manure, of which a wide range in experimental conditions (such as duration and time) is reported in the scientific literature (Matthiesen et al., 2005). The results of Chapter 2 show that measured SOM concentrations increase with increasing sample mass. Because of the high OM content of for instance manure (i.e. 74\%, Chapter 5), it can be expected that the mass of manure samples for analysis influences determination of the $\mathrm{OM}$ content and thus quantification of the OM input.

Harmonization of laboratory procedures to reduce the uncertainty associated with sample analysis is of crucial importance within the context of carbon accounting. In fact later parts of the thesis show that harmonization of the whole sampling process is required. Chapters 4 and 5 have demonstrated that conclusions on carbon sequestration depend strongly on the methodological choices made. Large differences between measured SOM stock changes over time were found between fields (Chapter 4), length of the monitoring period (Chapter 5) and sampling depths (Chapters 4 and 5).

\section{3. "Where" \& "When" - Effects of sampling depth and monitoring period}

The field experiment described in Chapter 5 showed that after a period of two years SOM increases measured in the $0-10 \mathrm{~cm}$ soil layer were partly compensated by decreases in the $10-30 \mathrm{~cm}$ layer, leading to no net change or a slight increase in SOM content, when considering the $0-30 \mathrm{~cm}$ soil layer. This implies that the conversion from arable land to temporary grassland does not lead to $C$ sequestration if the grassland phase is about two years, which is the case for a large number of grasslands in the Netherlands (Hooijboer et al., 2017). Even after a five-year period no net change of SOM contents was found in the $10-30 \mathrm{~cm}$ soil layer, suggesting that a period of more than five 
years is necessary to accumulate $\mathrm{C}$ in temporary grasslands on sandy soils, when considering the $0-30 \mathrm{~cm}$ soil profile.

The decline in SOM in the $10-30 \mathrm{~cm}$ soil layer during the first two experimental years was ascribed to the fact that the annual $\mathrm{C}$ inputs in grassland did not compensate for the (lack of) input of crop residues that were added during the arable period as a result of tillage (Don et al., 2009). The higher input rates in the top soil (as compared to the arable period prior to the experiment) together with not ploughing the soil might have led also to accelerated decomposition by soil life (Lange et al., 2015; Jackson et al., 2019). After the first experimental year mounding was clearly visible next to experimental plots on the sandy soil, which indicates that the number of earthworms had increased. A decrease in SOM was also observed in the 10-30 cm soil layer of the permanent grasslands on both monitored farms (Chapter 4) where most fields had been more than 25 years under grassland (Figure 2). This cannot be ascribed to the effect of ploughing 25 years ago and I therefore hypothesize that soil biota is the main driver of SOM decreases in the 10-30 $\mathrm{cm}$ soil layer through mixing soil from deeper soil layers which have a lower SOM content.

In the 30-60 cm soil layer SOM stocks remained stable on Farm A (Chapter 4). On Farm B, a tendency towards an increase was observed. This was mainly caused by large increases of SOM in spring (see Chapter 4, Figures 10a and S4).
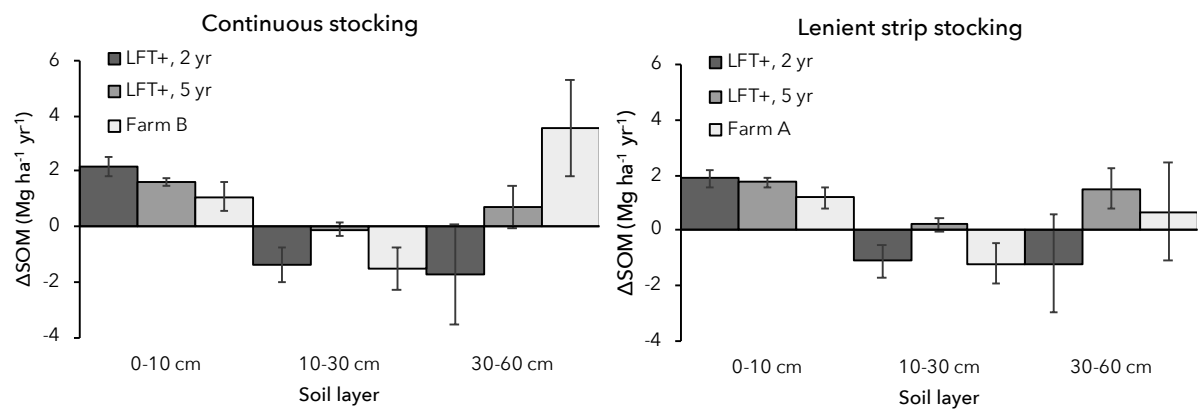

Figure 2. Average rates of change of soil organic matter (SOM) in $\mathrm{Mg} \mathrm{ha}^{-1} \mathrm{yr}^{-1}$ per soil layer under different stocking systems for experimental fields with a mixture of perennial ryegrass, tall fescue and white clover (LFT+; Chapter 5) and permanent grasslands on two farms in the 'Gelderse Vallei', the Netherlands (Chapter 4).

Based on the collected data it is not possible to uncover the mechanisms behind these differences in vertical translocation of SOM and the origin of SOM in different soil layers (e.g. the role of soil life, root exudates) could 
not be revealed (Johnson, 2006; Bluhm et al., 2019). More data is needed to elucidate the effect of the length of the grassland period on SOM dynamics in different soil layers.

It can be concluded that grasslands as such do not necessarily lead to carbon sequestration after the conversion from arable to grassland (cf. Chapter 5). Furthermore, Chapters 4 and 5 demonstrate the relevance of monitoring the subsoil for future $C$ inventories. On Farm B and under the monocultures with perennial ryegrass and tall fescue of the field experiment, the largest increases in SOM were found in the $30-60 \mathrm{~cm}$ soil layer. Following the Dutch standard sampling depth $(0-10 \mathrm{~cm})$ or IPCC guidelines (IPCC, 2006; 0-30 cm) would have led to large underestimations in SOM accumulation rates. Based on the observed differences in SOM dynamics between soil layers this thesis suggests to increase the sampling depth for grassland soils from $10 \mathrm{~cm}$ to $60 \mathrm{~cm}$. At this moment no information is available about SOM dynamics in the 30-60 cm soil layer at national scale and it requires further investigation to explore the $C$ sequestration potential of this layer in the context of the ambitions of the Dutch dairy sector specified in the recently adopted climate agreement of the Netherlands (Government of the Netherlands, 2019b-i.e. exploring the possibilities of sequestering $\mathrm{CO}_{2}$, page 131).

\section{Limitations of the study}

\section{1 "By what means"- Were inputs large enough to detect measurable differences in time of carbon storage?}

Grassland management options targeting increases in root biomass inputs could be a promising strategy to increase the SOM content of grassland soils. It was postulated in this thesis that farmers can influence root biomass and thus SOM inputs by altering stocking management and plant species composition (e.g. Deinum, 1985; Dormaar, 1992, Steinbeiss et al., 2008). However, detecting significant changes is a challenging exercise as spatial variation of SOM contents is often large. This makes long monitoring periods or a large number of replicates imperative for evaluating experimental treatment effects on C storage under field conditions (Smith, 2004; Fornara et al., 2020). Prior to this thesis work, only few publications discussed the effects of stocking systems and species compositions on total SOM and root biomass (e.g. Van Eekeren et al., 2010), and no information was available for depths deeper than $30 \mathrm{~cm}$. This inhibited calculating the minimum detectable difference (MDD; Zar, 1996) of the treatments a priori. Additionally, belowground C inputs of grass plants are highly variable (e.g. a review of Kuzyakkov \& Domanski (2000) shows that rhizodeposition varied widely across studies and ranged from $8 \%$ to $>65 \%$ of the total assimilated C). To increase the chance on detecting significant treatment effects we selected for the experiments described in Chapter 5 in this thesis homogeneous experimental fields with a relatively 
small variation and low initial SOM content as compared to Dutch permanent farm grasslands (Table 2; Chapters 4 and 5).

Table 2. Ranges in coefficients of variation (CV) of initial SOM measurements of the field experiment (Chapter 5 ; sandy soil, $\mathrm{n}=4$ per stocking system-species composition combination) and farm grasslands (Chapter $4 ; n=6$ per field). The $C V$ values of the farm grasslands originate from samples collected for determination of the soil bulk density in summer 2013 (see Chapter 4).

\begin{tabular}{rlll}
\hline Soil layer & Field experiment (sand) & Farm A & Farm B \\
\hline $0-10 \mathrm{~cm}$ & $4-7 \%$ & $14-42 \%$ & $9-19 \%$ \\
$10-30 \mathrm{~cm}$ & $4-11 \%$ & $17-82 \%$ & $15-46 \%$ \\
$0-30 \mathrm{~cm}$ & $3-10 \%$ & $8-63 \%$ & $9-25 \%$ \\
\hline
\end{tabular}

Through ad hoc power analysis it was possible to quantify, what changes in SOM contents could have been detectable based on the number of replicates given an initial level of variation. The MDD for paired observations was calculated as follows:

$\Delta \geq(s / \sqrt{n}) \cdot\left(t_{-}(\alpha, v)+t_{-}(\beta, v)\right)$

Equation 1

With:

$\Delta=$ the minimum detectable difference, $\mathrm{s}=$ the standard deviation of the paired differences in SOM stocks between the start and end of the monitoring period, $n=$ the number of replicates, $v=n-1$, the degrees of freedom for the relevant $t$-distribution, $t=$ the values of the $t$-distribution given a certain power level and $\alpha$-level, $\alpha=$ the significance level of the test, $\beta=1$ - power of the test.

To illustrate the use of the MDD-concept, MDD values for the field experiment were calculated for the plant species composition LFT+ on the sandy soil (five year period). An a-level of 0.05 was chosen and the chance to detect a significant difference was set at $80 \%$. The corresponding t-values were 1.796 and $0.876(n=12)$. In the $0-10 \mathrm{~cm}$ and $0-30 \mathrm{~cm}$ soil layers SOM dynamics were higher than the MDD values but this was not the case for the 10-30 cm, 30-60 $\mathrm{cm}$ and $0-60 \mathrm{~cm}$ soil layers (Table 3).

Finally, itshould be noted thatthe experimental design(i.e. number of replicates per treatment, sampling depth) is always confined by costs associated with field work (cf. "By what means"). For this reason, costs of demonstrating a significant treatment effect in SOM field experiments should be carefully balanced with expected outcomes. A priori insight in spatial variation together with model calculations of SOM dynamics are recommended to be used in order to maximise the chance to find significant differences in 
SOM in relatively short-term field experiments. It can be concluded from the foregoing that experiments with the aim of deriving grassland management options for increases in SOM not necessarily need research in the order of 5 to 10 years. Yet, distinguishing significant differences in SOM dynamics between treatments remains challenging in the subsoil as spatial variation is often large. On the farms (Chapter 4) large differences in trends of SOM stock changes over time were found between fields and sampling depths. For quantitative underpinning of carbon payment schemes, the whole farm should be monitored rather than a few fields as trends between fields are highly variable.

Table 3. Minimum detectable difference (MDD) for the species composition LFT+ (Chapter 5 ). $\mathrm{LFT}+=$ fertilized perennial ryegrass, tall fescue and white clover. SD = the standard deviation of the differences between the final and initial SOM stock $(n=12)$. CV is the SD divided by the square root of the number of replicates. MDD = the minimum detectable difference.

\begin{tabular}{ccccrcr}
\hline Soil layer & $\begin{array}{l}\text { Initial SOM stock } \\
\left(\mathrm{Mg} \mathrm{SOM} \mathrm{ha}^{-1}\right)\end{array}$ & $\begin{array}{l}\text { Final SOM stock } \\
\left(\mathrm{Mg} \mathrm{SOM} \mathrm{ha}^{-1}\right)\end{array}$ & $\begin{array}{l}\text { Difference } \\
\left(\mathrm{Mg} \mathrm{SOM} \mathrm{ha}^{-1}\right)\end{array}$ & SD & CV & MDD \\
\hline $0-10 \mathrm{~cm}$ & 42.6 & 48.8 & 6.2 & 2.5 & 0.7 & 2.0 \\
$10-30 \mathrm{~cm}$ & 79.5 & 77.7 & 1.8 & 2.8 & 0.8 & 2.2 \\
$30-60 \mathrm{~cm}$ & 69.0 & 75.1 & 6.1 & 15.9 & 4.6 & 12.2 \\
$0-30 \mathrm{~cm}$ & 122.1 & 126.5 & 4.4 & 4.4 & 1.3 & 3.4 \\
$0-60 \mathrm{~cm}$ & 191.1 & 201.6 & 10.5 & 17.6 & 5.1 & 13.6 \\
\hline
\end{tabular}

\section{2 "How" - Soil bulk density measurements}

There are several ways to convert SOM weight concentrations to stocks: (1) using a measured bulk density (BD) value; (2) using a pedotransfer function to convert SOM weight concentrations to SOM stocks (through a relationship between BD and SOM weight concentration; Chapters 4 and 5). In both cases the SOM weight concentration is multiplied with BD and the depth of the sampled soil layer (fixed depth method; Wendt \& Hauser, 2013). In Chapter 4 we derived different relationships between BD and SOM weight concentrations and we found that the type of BD curve hardly influences conclusions on SOM stock changes over time. When SOM stocks are to be compared across sites we argue that it is most accurate to use a BD curve based on site specific measurements rather than a (generic) curve from the literature: significant differences between SOM stocks were found based on different BD curves (Chapter 4, Figure S1).

Two years after the start of the experiment of Chapter 5 the concept of equivalent soil mass (ESM) appeared in the scientific literature as a more accurate method to convert SOM weight concentrations to stocks (cf. Wendt 
\& Hauser, 2013). The ESM procedure takes into account the actual mass of the sampled soil for determining the SOM stock based on a weight concentration as opposed to a fixed depth method (where the SOM weight concentration is multiplied with the soil bulk density and the depth of the soil layer; see above). With a fixed depth method substantial bias can be introduced caused by e.g. compaction or swelling and shrinking of clay soils. This is not taken into account with the fixed depth method and consequently differences in SOM stocks could be ascribed to treatment or management effects, while in reality these are caused by comparing unequal soil masses. While reflecting on the used approach I assume that employing the ESM concept would result in the most accurate estimates of the SOM stocks. Unfortunately, it is not possible to apply this approach now because it should have been used right from the start of the experiment or on-farm monitoring. Given that highly intensive monitoring took place for multiple years, the seasonal fluctuations in $\mathrm{BD}$ (possibly caused by compaction through trampling of animals or harvesting) are already accounted for and had little influence on trends in SOM: sampling took place four times per year on the farms and three times per year in the field experiment. In the field experiment treading of the experimental units was avoided as much as possible. Each unit consisted of a net field with a margin around it. During the harvesting of the grass, the Haldrup grass harvester did only use the margin for driving so compaction by machinery did not occur. Therefore, the ESM approach would most likely only lead to small increases in accuracy of SOM stock changes over time for a measurement frequency of four times per year (on-farm monitoring) or three times per year (field experiment).

\section{5. "Why"- The effect of grassland management options on SOM dynamics}

\subsection{Adapted stocking management}

Grassland management options targeting increased SOC supply through optimization of root growth were identified as promising strategies to increase the SOM content of grassland soils. We found that SOM dynamics were affected by both harvesting practices and plant species composition. However, no significant effect of stocking systems on root mass was observed on both the sandy and loamy soil (Figure 1 and Table 4, Chapter 5). Today the scientific literature on the effects of stocking systems on root biomass at different soil depths is still very scarce. Deinum (1985) assessed the effect of rotational (RS) and continuous stocking (CS) on root biomass in the $0-30 \mathrm{~cm}$ soil layer of fields under perennial ryegrass and found that root biomass was higher under CS than RS. By contrast, Hejduk \& Hrabě (2003) found lower root biomass values under CS than RS. Both studies only included one or two true replicates per treatment, thus significance could not be tested. 
Ennik et al. (1980) investigated the influence of mowing frequency and $\mathrm{N}$-fertilization level on root biomass of perennial ryegrass and observed an interaction between fertilization level and mowing frequency on root biomass. At an $\mathrm{N}$-application level of $200 \mathrm{~kg} \mathrm{ha}^{-1}$, root biomass increased with decreasing mowing frequency, while no effects of mowing frequency on root biomass were found at application levels of around $700 \mathrm{~kg} \mathrm{~N} \mathrm{ha}^{-1}$. Because of those contrasting responses, future studies could be conducted under controlled conditions and obviously at $\mathrm{N}$ rates which are agronomically and environmentally sound (note, currently $\mathrm{N}$ application rates for grassland soils in the Netherlands range from 250 to $385 \mathrm{~kg} \mathrm{~N} \mathrm{ha}^{-1} \mathrm{yr}^{-1}$ depending on the use (mowing / stocking) and soil type; this includes $\mathrm{N}$ from animal manure and mineral fertilizer; RVO, 2019c). Possibly, through a pot experiment more insight may have been gained in stubble and root turnover. However, the proportion of assimilates going to the roots of young grass plants is around $50 \%$ of the total while this is only $7 \%$ for established swards (Ryle, 1970). Results of pot experiments that usually contain young grass plants should therefore be interpreted with caution and cannot be compared with experiments on well-established grasslands.

During the experiment the use of tracer techniques (e.g. exposure of plants to atmospheric $\mathrm{CO}_{2}$ labelled with ${ }^{13} \mathrm{C}$ or ${ }^{14} \mathrm{C}$; e.g. according to Kuzyakov \& Domanski, 2000) combined with regular harvests of stubble and root material could have revealed the $C$ allocation in the plants, however, both stubbles and root samples can only be taken through destructive methods. This would imply sacrificing part of the experiment and consequently reducing the number of replicates. To minimize the effect of destructive sampling for root mass, measurements were only collected twice during the experimental period. This reduced the surface of the experimental plots only minimally (the net subplot size was $1.5 \times 10 \mathrm{~m}$ and the surface of the auger was $20 \mathrm{~cm}^{2}$, thus less than $0.5 \%$ of the total area was removed with all root measurements). Unless careful experimental planning is done, (i.e. splitting experimental plots for different observations where destruction of the plot/ treatment is required), monitoring root turnover and SOM dynamics cannot occur simultaneously within the same plots.

SOM accumulation tended to be higher under lenient strip stocking (LS) than rotational stocking (RS; Chapter 5, supplementary material, Table S9). After a period of grazing, the stubble height of fields under RS was $4 \mathrm{~cm}$ while the stubble height of fields under LS was $10 \mathrm{~cm}$. Consequently, a large amount of the produced herbage of LS was not harvested and was added to the SOM pool after decomposition. Because no differences in root biomass were found between stocking systems (Chapter 5, Figure 1) the larger accumulation rate of SOM is possibly a consequence of the larger input of aboveground decaying plant material coming from unharvested biomass and, additionally through trampling in case of grazing animals. This 
also could be caused by increased root exudates. Yet, the origin cannot be revealed based on the collected data. This also indicates that a trade-off exists between herbage yield and SOM accumulation (Figure 3). Yields of the LS treatment were on average $20 \%$ lower than yields under continuous stocking (CS) and even 40\% lower than the rotational stocking treatment (RS; Figure 3; note, harvested biomass of different stocking systems was compared for the fertilized treatments i.e. LP+, FA+ and LFT+ and the unfertilized treatments were excluded for this comparison). Despite the field experiment has shown that SOM accumulation can be enhanced by adopting lenient strip stocking, this is of limited practical relevance. It is improbable that farmers will invest in C sequestration while sacrificing herbage yield ${ }^{\star \star \star}$.

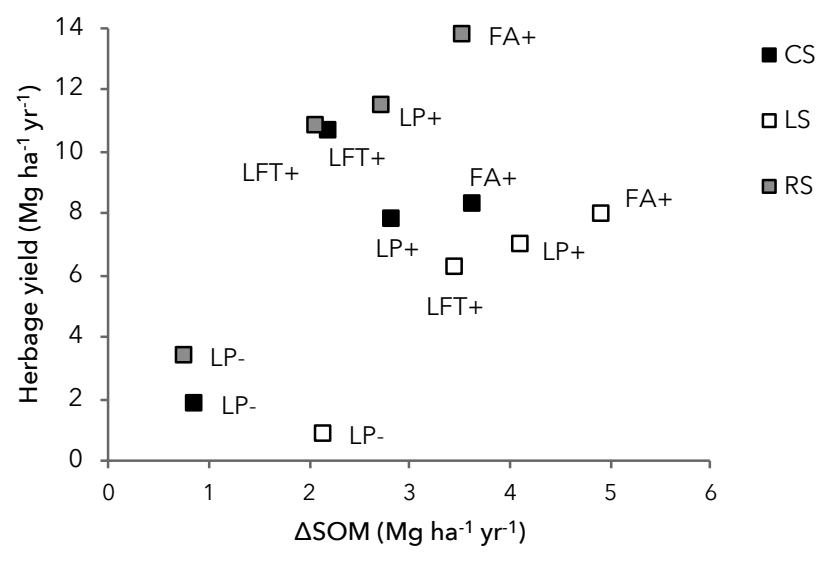

Figure 3. Relationship between herbage yield and annual changes in soil organic matter (SOM) for the $0-60 \mathrm{~cm}$ soil layer. The monitoring period was five years. See Chapter 5 for more information on the experiment. LP- $=$ unfertilized perennial ryegrass. $\mathrm{LP}+=$ fertilized perennial ryegrass. $\mathrm{FA}+=$ fertilized tall fescue. $\mathrm{LFT}+=$ fertilized perennial ryegrass, tall fescue and white clover.

\subsection{Effects of species composition}

I hypothesised that SOM increases would be higher underfields with tall fescue than perennial ryegrass monocultures because of the larger belowground biomass production (Chapter 5). Root biomass was indeed significantly higher under the tall fescue monoculture than the other treatments. The species composition with perennial ryegrass, tall fescue and white clover $(\mathrm{LFT}+)$ had the lowest root biomass. Thus, the additional root biomass of tall

*** Currently, the costs of a bale of grass silage are around $€ 25(120 \mathrm{~kg}$, DM content of $40 \% ; 120 \times 0.4=48 \mathrm{~kg} \mathrm{DM}$ bale $\left.{ }^{-1}\right)$. This is equivalent to about $€ 521$ per Mg grass on a dry matter basis). A target price of $30 €$ per $\mathrm{Mg} \mathrm{CO}_{2}$ was set in the province of Friesland (VVM, 2019), which is equivalent to about $0.5 \mathrm{Mg} \mathrm{SOM} \mathrm{ha}^{-1} \mathrm{yr}^{-1}$. 
fescue as compared to the perennial ryegrass monoculture was not able to compensate for the lower root mass of white clover. This was also reflected in the SOM accumulation rates in the sandy subsoil.

Under tall fescue SOM increased on average $4 \mathrm{Mg} \mathrm{SOM} \mathrm{ha}^{-1} \mathrm{yr}^{-1}$. Remarkably, SOM accumulation rates were about ten times as large as the estimated total root mass in the $30-60 \mathrm{~cm}$ soil layer (i.e. $0.6 \mathrm{Mg} \mathrm{DM} \mathrm{ha}^{-1} \times 0.7$ (the average ash-free dry matter (AFDM) content,$=0.4 \mathrm{Mg} \mathrm{AFDM} \mathrm{ha}^{-1}$ ). A similar observation was made for the LP+ treatment. Here, SOM accumulation rates were about 15 times larger than the root biomass values (0.1 Mg AFDM ha-1 vs. $1.5 \mathrm{Mg} \mathrm{SOM} \mathrm{ha}^{-1} \mathrm{yr}^{-1}$ ). Root turnover rates are about once or twice per year (Schneider, 2003). This divergence between root biomass and SOM dynamics was also observed by Gill et al., (1999) who attributed this to lower decomposition rates and greater root longevity in the 30-60 cm soil layer than in the top soil. Although I can only speculate about the origin of the SOM in the 30-60 cm soil layer (root biomass, rhizodeposition, etc.), considerable amounts of dissolved organic carbon (DOC) and root exudates could possibly have leached to this layer. Measurements in filtered groundwater of dairy farms in the Netherlands on sandy soils between 2010 and 2015 showed average DOC concentrations of $35 \mathrm{mg} \mathrm{l}^{-1}$ (National Minerals Policy Monitoring Program of the Netherlands; RIVM, 2019b). With a precipitation surplus of about $300 \mathrm{~mm} \mathrm{yr}^{-1}$ this is equal to an annual DOC flux of $0.1 \mathrm{Mg}$ $\mathrm{C}$ ha $^{-1}$. Because all groundwater samples are filtered $(0.45 \mu \mathrm{m})$, actual DOC fluxes will be, most likely, much larger in unfiltered samples.

Although SOM accumulation rates under the LFT+ mixture tended to be lower than under the fertilized monocultures (i.e. LP+ and FA+; see Table 3 and Tables S6 and S8 of Chapter 5), SOM accumulation rates of LP+ and $\mathrm{FA}+$ do not include 'hidden' carbon costs which are associated with the production of mineral fertilizer. In the experiment described in Chapter 5 , $200 \mathrm{~kg} \mathrm{~N} \mathrm{ha}{ }^{-1}$ was applied annually as calcium ammonium nitrate which is equivalent to a carbon footprint of $0.4 \mathrm{Mg} \mathrm{C} \mathrm{ha-1}^{-1} \mathrm{yr}^{-1}$ or $0.8 \mathrm{Mg} \mathrm{SOM} \mathrm{ha}^{-1} \mathrm{yr}^{-1}$ using a conversion factor of $8.03 \mathrm{~kg} \mathrm{CO}$, equivalent $/ \mathrm{kg} \mathrm{N}$ (Kool et al., 2012). SOM dynamics of LP+ corrected for greenhouse gas emissions associated with the production of mineral $\mathrm{N}$ fertilizers approximated SOM accumulation rates of the LFT+ treatment (Table 4). The harvested herbage of LFT+ was similar to LP+, thus including white clover and tall fescue in a mixture with perennial ryegrass seems to be a promising alternative for the extensive monocultures of perennial ryegrass in the Netherlands. In this way, the use of artificial fertilizer-N can be fully omitted while yields are maintained and GHG emissions are minimized. 
Table 4. Harvested herbage and soil organic matter (SOM) dynamics of a grassland field experiment on a sandy soil in the Netherlands for the $0-60 \mathrm{~cm}$ soil layer after a period of five years. Data was obtained from Chapter 5 of this thesis. The uncorrected values are the measured changes in SOM and the corrected values were adjusted for the $\mathrm{CO}_{2}$ emissions associated with the production of artificial $\mathrm{N}$ fertilizer (see the text for details).

\begin{tabular}{llll}
\hline $\begin{array}{l}\text { Species } \\
\text { composition }\end{array}$ & $\begin{array}{l}\text { Harvested herbage } \\
\left(\mathrm{Mg} \mathrm{DM} \mathrm{ha}^{-1}\right)\end{array}$ & $\begin{array}{l}\Delta \mathrm{SOM} \\
\left.\text { (uncorrected; } \text { Mg ha }^{-1}\right)\end{array}$ & $\begin{array}{l}\Delta \mathrm{SOM} \\
\left.\text { (corrected; } \text { Mg ha }^{-1}\right)\end{array}$ \\
\hline LP- & 2.0 & 1.3 & 1.3 \\
LP+ & 8.7 & 3.2 & 2.4 \\
FA+ & 10.0 & 4.0 & 3.2 \\
LFT+ & 9.2 & 2.8 & 2.8 \\
\hline
\end{tabular}

Both harvested herbage and corrected SOM accumulation rates of the tall fescue monoculture were higher than the other treatments (Table 4). However, a disadvantage associated with the use of tall fescue as a feeding source for ruminants is the content of cellulose and hemicellulose, which was highest for FA+ followed by LP+ and LFT+ (Qin, 2014). Methane emissions from ruminants increase with increasing contents of hemicellulose and cellulose (Moe \& Tyrrell, 1979), and therefore the FA+ treatment would result in higher methane emissions as compared to the other treatments. Amplified methane emissions (expressed in $\mathrm{CO}_{2}$ equivalents) would even further reduce the 'corrected' SOM accumulation rates of the FA+ treatment. As methane emissions are also influenced by other factors such as voluntary intake and maturity of the grass sward (Bannink \& Dijkstra, 2016), future research should include carbon accounting to obtain a complete overview of the GHG mitigation potential of adapted stocking systems and plant species composition.

As a final conclusion based on the discussion above, I conclude that based on the results described in the thesis, no unambiguous advice can be given on the effectiveness of grassland management measures that may be used to improve carbon sequestration.

\section{Conclusions}

This thesis demonstrates the relevance of accurate laboratory measurements for measuring SOM weight concentrations and standardized protocols to convert those weight concentrations into SOM stocks. Based on a large number of experiments testing a multitude of ignition conditions (i.e. furnace type, sample mass, temperature, duration) on loss-on-ignition measurements and its confounding factors (structural water loss from clay elements, 
decarbonatation) we conclude that SOM can be determined precisely in sandy and clay soils from a temperate climate. The LOI method (using the conditions recommended in this thesis) is able to generate results with a much larger degree of precision than the commonly used wet chemical oxidation procedure for determining SOC and the confounding factors such as structural water loss can be corrected for.

From intensive monitoring of SOM dynamics on managed grasslands and a field experiment testing different sward species compositions and simulated stocking systems we conclude that the standard sampling depth of grassland soils needs to be increased from $10 \mathrm{~cm}$ to $60 \mathrm{~cm}$ to assess the SOM content and account for the changes therein. SOM content increases in the $0-10 \mathrm{~cm}$ soil layer are (partly) compensated by decreases in the $10-30 \mathrm{~cm}$ soil layer leading to no net change. In the $30-60 \mathrm{~cm}$ soil layer we have found large increases of SOM contents in some fields and treatments in the monitoring periods. For quantitative underpinning of carbon payment schemes it is recommended to sample the whole farm rather than basing payments schemes on a selection of fields as trends between fields were found to be highly variable.

Even for a monitoring period of five years, the effects of adapted stocking systems and species compositions on SOM increases were limited: the SOM content increases tended to be higher under lenient strip stocking (LS) than under rotational stocking (RS) most likely due to a larger input of aboveground decaying plant material. Yet, the herbage yield of LS was much lower than under RS indicating a trade-off between SOM sequestration and herbage yield.

Measurements of SOM stocks in the context of climate policies should sample the whole farm, use a sampling depth of $60 \mathrm{~cm}$ and employ a standardized analytical procedure for measuring SOM weight concentrations. Payments for carbon sequestration on the basis of management measures can be insufficiently quantified based on the results of this thesis. 


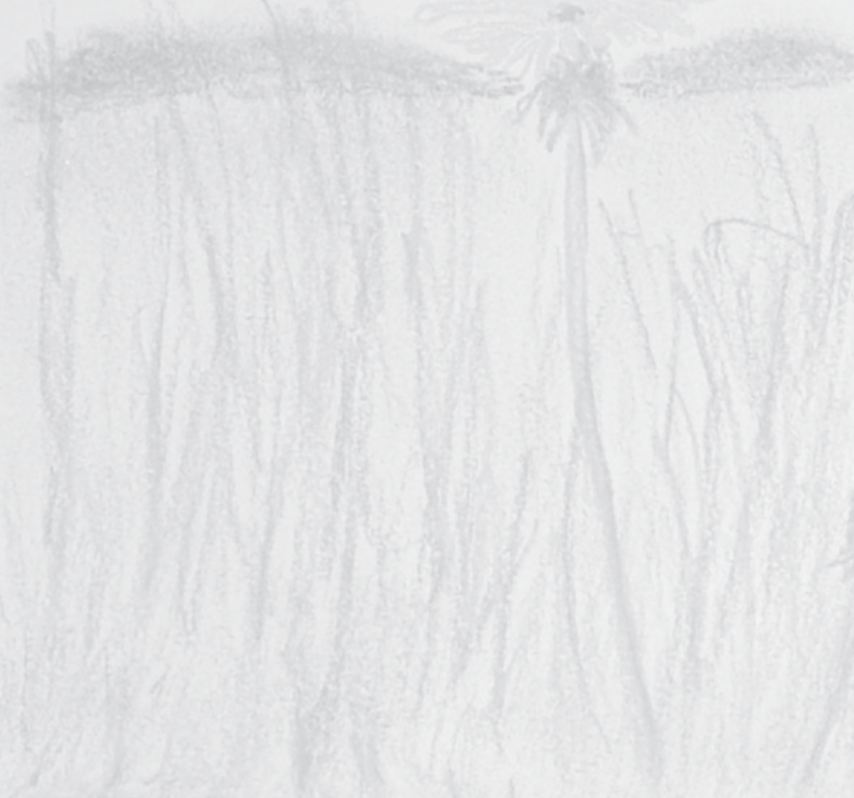

nest

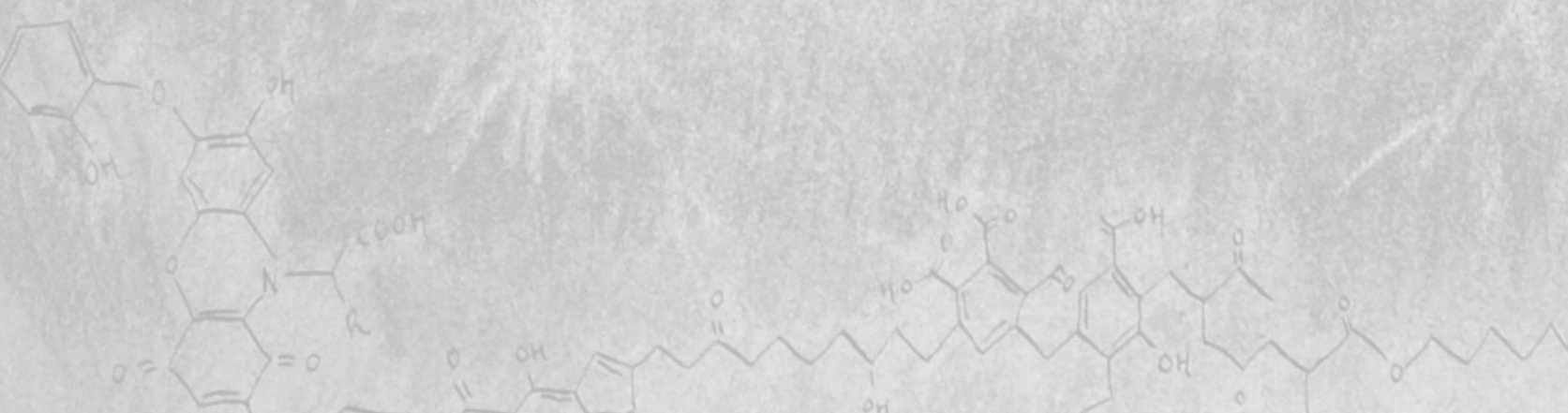


References 



\section{References}

Abdel-Latif, M. 2013. An Introduction to Ultraviolet/ Visible Absorption Spectroscopy. (At: http://goo.gl/W1 MJO. Accessed: 08/02/2013).

Abella, S.R. \& Zimmer, B.W. 2007. Estimating Organic Carbon from Loss-on-ignition in Northern Arizona Forest Soils. Soil Science Society of America Journal, 71, 545-550.

Adams, W. A. 1973. The effect of organic matter on the bulk and true densities of some uncultivated podzolic soils. Journal of Soil Science, 24 (1), 10-17.

Ahrens, B., \& Reichstein, M. 2017. Soil carbon: Depth of understanding. Nature Climate Change, 7(11), 762.

Allison, L.E. \& Moodie, C.D. 1965. Carbonate. In: Methods of soil analysis. Part 2. 2nd ed. (Eds C.A. Black, D.D. Evans, J.L. White, L.E. Ensminger, F.E. Clark and R.C. Dinauer), pp.1379-1400. American Society of Agronomy and Soil Science Society of America, Madison, USA.

Ashworth, J. 1997. Improvements to two routine methods for calcium carbonate determination in soils. Communications in Soil Science and Plant Analysis, 28, 841-848.

Automeris, 2019. WebPlotDigitizer. At: https://automeris.io/WebPlotDigitizer/ On: 18-12-2019.

Balabane, M., \& Plante, A. F. 2004. Aggregation and carbon storage in silty soil using physical fractionation techniques. European journal of soil science, 55(2), 415 427.

Balesdent, J., Basile-Doelsch, I., Chadoeuf, J. Cornu, S., Derrien, D., Fekiacova, Z. \& Hatté, C. 2018. Atmosphere-soil carbon transfer as a function of soil depth. Nature 559, 599-602 (2018) doi:10.1038/s41586-018-0328-3

Ball, D.F. 1964. Loss-on-ignition as an estimate of organic matter and organic carbon in non-calcareous soils. Journal of Soil Science, 15, 84-92.

Bannink, A., \& Dijkstra, J. 2016. Effects of roughage characteristics on enteric methane emission in dairy cows. Advances in Animal Biosciences, 7(3), 229-230.

Baert, J., Vliegherf, A. D., Hulle, S. V., Waes, C. V., Muylle, H., \& Warda, M. 2012. Biomass yield and composition from semi-extensively cultivated perennial fodder grasses. In Grassland-a European resource? Proceedings of the 24th General Meeting of the European Grassland Federation, Lublin, Poland, 3-7 June 2012. (pp. 460462). Polskie Towarzystwo Łakarskie (Polish Grassland Society).

Barillé-Boyer, A.L., Barillé, L., Massé, H., Razet, D. \& Héral, M. 2003. Correction for particulate organic matter as estimated by loss on ignition in estuarine ecosystems. Estuarine, Coastal and Shelf Science, 58,147-153.

Bellamy, P.H, Loveland, P.J., Bradley, R.I, Murray Lark, R. \& Kirk, J.D. 2005. Carbon losses from all soils across England and Wales 1978-2000. Nature, 437, 245-248.

Ben-Dor, E. \& Banin, A. 1989. Determination of organic matter content in arid-zone soils using a simple "loss-on-ignition" method. Communications in Soil Science \& Plant Analysis, 20, 1675-1695.

Berzelius, J.J., 1839. Lehrbuch der Chemie. Translated from Swedish to German by Wöhler. vol. 8, pp. 11-16 and 384-341. 
Bhatti, J. S. \& Bauer, I. E. 2002. Comparing loss-on-ignition with dry combustion as a method for determining carbon content in upland and lowland forest ecosystems. Communications in Soil Science \& Plant Analysis, 33, 3419-3430.

Bieleman, J. 2010. Five centuries of farming: a short history of Dutch agriculture 15002000. Wageningen Academic Publishers, Wageningen, The Netherlands.

Bluhm, S. L., Eitzinger, B., Ferlian, O., Bluhm, C., Schröter, K., Pena, R., Maraun, M. \& Scheu, S. 2019. Deprivation of root-derived resources affects microbial biomass but not community structure in litter and soil. PloS one, 14(3), e0214233.

Breeuwsma, A. 1987. Bodemmineralogie (Soil mineralogy). In: Bodemkunde van Nederland (eds W.P. Locher \& H. De Bakker), pp.95-99. Malmberg Den Bosch, Wageningen, the Netherlands.

Brix, H.2008.Soil Moisture and Loss-on-Ignition.(At: http://mit.biology.au.dk/ biohbn/ Protocol/Soil_Moisture_and_LOI_20081127.pdf. Accessed: 04/11/2014).

Broadbent, F. E. 1953. The soil organic fraction. In Advances in agronomy (Vol. 5, pp. 153-183). Academic Press.

Buringh, P. 1951. Over de Bodemgesteldheid Rondom Wageningen (Soil conditions in the environment of Wageningen). Doctoral dissertation, Landbouwhogeschool, Wageningen, the Netherlands.

Cabalar, A. F., \& Hasan, R. A. 2013. Compressional behaviour of various size/shape sand-clay mixtures with different pore fluids. Engineering geology, 164, 36-49.

Cade, B. S., \& Noon, B. R. 2003. A gentle introduction to quantile regression for ecologists. Frontiers in Ecology and the Environment, 1(8), 412-420.

Carroll, D. \& Starkey, H.C. 1971. Reactivity of clay minerals with acids and alkalies. Clays and Clay Minerals, 19, 321-333.

Carruthers, V. R. \& Henderson, H. V. 1994. Grazing management and pasture composition on paired farms which differed in the incidence of bloat. New Zealand Journal of Agricultural Research, 37, 535-545.

Carter, M. R. \& Gregorich, E. G. 2010. Carbon and nitrogen storage by deep-rooted tall fescue (Lolium arundinaceum) in the surface and subsurface soil of a fine sandy loam in eastern Canada. Agriculture, Ecosystems \& Environment, 136, 125-132.

Carver, R.E. 1981. Reducing sand sample volumes by spooning. Journal of Sedimentary Petrology, 51, 658.

Chemical Biological Soil Laboratory (CBLB), personal communication with A.van Leeuwen. Measurements of soil organic matter through loss-on-ignition: a comparison of different furnaces.

Chattaraj, B.D., Dutta, S.N. \& lyengar, M.S., 1973. Studies on the thermal decomposition of calcium carbonate in the presence of alkali salts $(\mathrm{Na} 2 \mathrm{CO} 3, \mathrm{~K} 2 \mathrm{CO} 3$ and $\mathrm{NaCl}$ ). Journal of Thermal Analysis, 5, 43-49.

Christensen, B. T., \& Malmros, P. A. 1982. Loss-on-ignition and carbon content in a beech forest soil profile. Holartic Ecology, 5, 376-380.

Christensen, B. T., \& Sørensen, L. H. 1986. Nitrogen in particle size fractions of soils incubated for five years with $15 \mathrm{~N}$-ammonium and 14C-hemicellulose. Journal of soil science, 37 (2), 241-247.

Ciais, P., C. Sabine, G. Bala, L. Bopp, V. Brovkin, J. Canadell, A. Chhabra, R. DeFries, J. Galloway, M. Heimann, C. Jones, C. Le Quéré, R.B. Myneni, S. Piao \& Thornton,P. 
2013: Carbon and Other Biogeochemical Cycles. In: Climate Change 2013: The Physical Science Basis. Contribution of Working Group I to the Fifth Assessment Report of the Intergovernmental Panel on Climate Change [Stocker, T.F., D. Qin, G.-K. Plattner, M. Tignor, S.K. Allen, J. Boschung, A. Nauels, Y. Xia, V. Bex and P.M. Midgley (eds.)]. Cambridge University Press, Cambridge, United Kingdom and New York, NY, USA.

Coleman, K., \& Jenkinson, D. 2014. RothC-A Model for the Turnover of Carbon in SoilModel description and users guide. Rothamsted Research, Harpenden, UK.

Conijn, J.G. \& Lesschen, J.P. 2015. Soil organic matter in the Netherlands; Quantification of stocks and flows in the top soil. Wageningen, the foundation Stichting Dienst Landbouwkundig Onderzoek. Research Institute Praktijkonderzoek Plant \& Omgeving / Plant Research International, Wageningen UR (University \& Research centre), PRI report 619 / Alterra report 2663.

Cougnon, M., Deru, J., Van Eekeren, N., Baert, J. \& Reheul, D. 2013. Root depth and biomass of tall fescue vs. perennial ryegrass. Proceedings of the 17th Symposium of the European Grassland Federation Akureyri, Iceland 23-26 June 2013. (At: http://www.europeangrassland.org/fileadmin/media/EGF2013.pdf. Accessed: 26/11/2014).

Cougnon, M., Baert, J., Van Waes, C., \& Reheul, D. 2014. Performance and quality of tall fescue (Festuca arundinacea Schreb.) and perennial ryegrass (Lolium perenne L.) and mixtures of both species grown with or without white clover (Trifolium repens L.) under cutting management. Grass and Forage Science, 69, 666-677.

Craft, C.B., Broome, S.W. \& Seneca, E.D. 1988. Nitrogen, phosphorus and organic carbon pools in natural and transplanted marsh Soils. Estuaries, 11, 272-280

Crider F.J., 1955. Root-growth stoppage resulting for defoliation of grass. USDA Tech. Bull. 1102. At: http://books.google.nl/books?hl=nl\&lr=\&id=HLIXAAAAYAA$\mathrm{J} \& \mathrm{o} i=\mathrm{fnd} \& p \mathrm{p}=\mathrm{PA} 3 \& \mathrm{dq}=$ Root-growth + stoppage + resulting + for + defolia tion+of+grass\&ots=19JNI1fx9A \&sig=0WFR11gMs5OC6_AAooxxrjPzbr8\#v=onepage \&q=Root-growth\%20stoppage\%20 resulting\%20for\%20defoliation\%20 of\%20grass\&f=false. Accessed: $27 / 11 / 2014$.

Davies, B.E. 1974. Loss-on-ignition as an estimate of soil organic matter. Soil Science Society of America Journal, 38, 150-151.

Dean, W.E. 1974. Determination of carbonate and organic matter in calcareous sediments and sedimentary rocks by Loss-on-Ignition: comparison with other methods. Journal of Sedimentary Petrology, 44, 242-248.

De Bakker, H., 1987. Het bodemprofiel (The soil profile). In: Bodemkunde van Nederland (Eds W.P. Locher and H. De Bakker), pp.33-48. Malmberg Den Bosch, Wageningen, The Netherlands.

De Boer, H.C., Bussink, D.W. \& Schils, R.L.M., 2003. Revised sampling depth under grassland http://edepot.wur.nl/34287.

De Gruijter, J., Brus, D. J., Bierkens, M. F., \& Knotters, M. (2006). Sampling for natural resource monitoring. Springer Science \& Business Media.

De Haan, J.J. \& van Geel, W.C.A., 2019. Manual on Soil and fertilization (In Dutch: HandboekBodemenBemesting).At: https://www.handboekbodemenbemesting. $\mathrm{nl} / \mathrm{nl} / \mathrm{hand}$ boekbodemenbemesting/Handeling/Organische-stofbeheer/ 
Samenstelling-en-werking-organische-meststoffen/Samenstelling-organischemeststoffen.htm. Accessed: 20/07/2019.

Deinum, B. 1985. Root mass of grass swards in different grazing systems. Netherlands Journal of Agricultural Science, 33, 377-384.

Deru, J., Van Eekeren, N.J.M, De Wit, J. \& De Boer, H. 2011. Effect of grass species and $\mathrm{N}$-fertilization level on production, rooting and mineral $\mathrm{N}$ in autumn: Field trial on sandy soil with perennial ryegrass, Tall Fescue and Cocksfoot (In Dutch: Effect van grasso ort en $\mathrm{N}$-bemestingsniveau op productie, beworteling en $\mathrm{N}$-mineraal in de herfst: Veldproef op zandgrond met Engels Raaigras, Kropaar en Rietzwenkgras) Rapport 2011-017 LbD. 29 pp, Louis Bolk Instituut, Driebergen, The Netherlands.

De Vos, B., Vandecasteele, B., Deckers, J. \& Muys, B. 2005. Capability of Loss-onIgnition as Predictor of Total Organic Carbon in Non-Calcareous Forest Soils. Communications in Soil Science \& Plant Analysis, 36, 2899 - 2921.

De Vries, D.M. 1948. Method and survey of the characterization of Dutch grasslands. Vegetatio, 1, 51-57.

De Wit, J., Van Eekeren, N.J.M., Wagenaar, J. \& Smeding, F.W. 2013. Diverse grassland mixtures for higher yields and more stable sward quality. Proceedings of the 17th Symposium of the European Grassland Federation Akureyri, Iceland 23-26 June 2013. (At: http://www.louisbolk.org/downloads/2791.pdf. Accessed: 26/11/ 2014).

Don, A., Scholten, T. \& Schulze, E. D. 2009. Conversion of cropland into grassland: Implications for soil organic-carbon stocks in two soils with different texture. Journal of Plant Nutrition and Soil Science, 172, 53-62.

Donkin, M.J. 1991. Loss-on-ignition as an estimator of soil organic carbon in A-horizons of forestry soils. Communications in Soil Science \& Plant Analysis, 22, 233-241.

Dormaar, J.F. 1992. Decomposition as a process in natural grasslands. In: R.T.Copland, Natural Grasslands Introduction and Western Hemisphere, Ecosystems of the world 8a, Elsevier, Amsterdam, pp. 121-136.

Drake, E.H.\&Motto, H.L. 1982. An analysis of the effect of clay and organic matter content on the cation exchange capacity of New Jersey soils. Soil Science, 5, 261-324.

EEA (European Environment Agency) 2019. The European environment - state and outlook 2020. Knowledge for transition to a sustainable Europe. Copenhagen, Denmark.

Ennik, G.C., Gillet, M. \& Sibma, L. 1980. Effect of high nitrogen supply on sward deterioration and root mass. In: The role of nitrogen in intensive grassland production (eds W.H. Prins \& G.H. Arnold), pp. 67-76. Institute for soil fertility, Haren, the Netherlands.

Ewing, G.W. 1969. Instrumental Methods of Chemical Analysis. McGraw-Hill, New York, USA.

Farmer's practice network "Organic: climate neutral", 2019. At: http://www.biologischklimaatneutraal.nl/uploads/images/Bestanden/PDFs/Maatregelen_PVA_ melkveebedrijven.pdf Accessed: 26/10/2019.

Feng, W., Plante, A. F., Aufdenkampe, A. K., \& Six, J. 2014. Soil organic matter stability in organo-mineral complexes as a function of increasing $C$ loading. Soil Biology and Biochemistry, 69, 398-405. 
Fisher Scientific, personal communication with M.Evers. A comparison of the carbolite CWF furnace with Isotemp furnaces.

Fornara D.A \& Tilman D 2008 Plant functional composition influences rates of soil carbon and nitrogen accumulation. Journal of Ecology, 96, 314-322.

Fornara, D., Olave, R., \& Higgins, A. 2020. Evidence of low response of soil carbon stocks to grassland intensification. Agriculture, Ecosystems \& Environment, 287, 106705.

Frangipane, G., Pistolato, M., Molinaroli, E., Guerzoni, S. \& Tagliapietra, D. 2009. Comparison of loss on ignition and thermal analysis stepwise methods for determination of sedimentary organic matter. Aquatic Conservation: Marine and Freshwater Ecosystems, 19, 24-33.

Galle, O.K \& Runnels, T.R. 1960. Determination of $\mathrm{CO}_{2}$ in carbonate rocks by controlled loss on ignition. Journal of Sedimentary Petrology, 30, 613-618.

Gill J., Burcke I.C., Milchumas, D.G. \& Laueenroth, W.K. 1999. Relationship between roots and soil organic matter pools in the shortgrass steppe of eastern Colorado. Ecosystems, 2, 226-236.

Geelhoed, B. \& Glass H.J. 2004. Comparison of theories for the variance caused by the sampling of random mixtures of non-identical particles. Geostandards \& Geoanalytical Research, 28, 263-276.

Grewal, K.S., Buchan, G.D. \& Sherlock, R.R. 1991. A comparison of three methods of organic carbon determination in some New Zealand soils. Journal of Soil Science, 42, 251-257.

Goldin, A. 1987. Reassessing the use of loss-on-ignition for estimating organic matter content in noncalcareous soils. Communications in Soil Science \& Plant Analysis, 18, 1111-1116.

Goidts, E., Van Wesemael, B., \& Crucifix, M. 2009. Magnitude and sources of uncertainties in soil organic carbon (SOC) stock assessments at various scales. European Journal of Soil Science, 60(5), 723-739.

Government of the Netherlands, 2019a. Letter to the parliament on the National Program on Agricultural Soils on 25-04-2019. At: https://www.rijksoverheid.nl/documenten/ kamerstukken/2019/04/25/kamerbrief-over-het-nationaal-programma-landbouwbodems.

Government of the Netherlands, 2019b. National Climate agreement of the Netherlands. At:https://www.klimaatakkoord.nl/documenten/publicaties/2019/06/28/ national-climate-agreement-the-netherlands. Accessed: 1/11/2019.

Grim, R. E. 1953. Clay Mineralogy. McGraw-Hill Book Company Inc., New York, USA.

Grimm, N. B., Chapin, F. S., Bierwagen, B., Gonzalez, P., Groffman, P. M., Luo, Y., Melton, F., Nadelhoffer, K., Pairis, A., Raymond, P.A., Schimel, J. \& Williamson, C.E. 2013. The impacts of climate change on ecosystem structure and function. Frontiers in Ecology and the Environment, 11(9), 474-482.

Gulde, S., Chung, H., Amelung, W., Chang, C., \& Six, J. 2008. Soil carbon saturation controls labile and stable carbon pool dynamics. Soil Science Society of America Journal, 72 (3), 605-612.

Hanegraaf M.C, Hoffland E., Kuikman P.J. \& Brussaard L., 2009. Trends in soil organic matter contents in Dutch grasslands and maize fields on sandy soils. European Journal of Soil Science, 60, 213-222. 
Heiri, O., Lotter, A.F. \& Lemcke, G. 2001. Loss on ignition as a method for estimating organic and carbonate content in sediments: reproducibility and comparability of results. Journal of Paleolimnology, 25, 101-110.

Henry, H. A. 2019. Biogeochemical cycling in grasslands under climate change. Grasslands and Climate Change, 115.

Hoogsteen, M.J.J., Lantinga, E.A., Bakker, E.J., Groot, J.C.J. \& Tittonell, P.A. 2015. Estimating soil organic carbon through loss on ignition: effects of ignition conditions and structural water loss. European Journal of Soil Science, 60, 320328.

Hoogsteen, M.J.J., Bakker, E.J., van Eekeren, N., Tittonell, P.A., Groot, J.C.J., van Ittersum, M.K. \& Lantinga, E.A. 2020. Do grazing systems and species composition affect root biomass and soil organic matter dynamics in temperate grassland swards? Sustainability, 12 (3), 1260.

Hooijboer, A.E.J., Hoogsteen M.J.J. \& Buis, E. 2017. Effects of crop rotation on water quality in the Netherlands: Combining the Minerals Policy Monitoring Program and Nationwide survey of crop data of the sandy regions of The Netherlands. Land Use and Water Quality, effect of agriculture on the environment, Den Haag, the Netherlands, 29 May - 1 June 2017.

Hopkins, D.W., Waite, I.S., Mc Nicol, J.W., Poulton, P.R., Macdonald, A.J. \& O'Donnell, A.G. 2009. Soil organic carbon contents in long-term experimental grassland plots in the UK (Palace Leas and Park Grass) have not changed consistently in recent decades. Global Change Biology, 15, 1739-1754.

Hossain, M. F., Chen, W., \& Zhang, Y. (2015). Bulk density of mineral and organic soils in the Canada's arctic and sub-arctic. Information processing in agriculture, 2(34), 183-190.

Houba, V.J.G., Chardon W.J. \& Roelse, K. 1993. Influence of grinding of soil on apparent chemical composition. Communications in Soil Science \& Plant Analysis, 24, 1591-1602.

Houba, V.J.G., van der Lee, J.J. \& Novozamsky, I. 1997. Soil analysis procedures, other procedures, syllabus soil and plant analysis. Part 5B. Department of Soil Science and Plant Nutrition, Wageningen Agricultural University, Wageningen, the Netherlands.

Howard, P.J.A. \& Howard, D.M. 1990. Use of organic carbon and loss-on-ignition to estimate soil organic matter in different soil types and horizons. Biology \& Fertility of Soils: 9, 306-310.

Ingamells, C.O. 1974. Control of geochemical error through sampling and subsampling diagrams. Geochimica et Cosmochimica Acta, 38, 1225-1237.

ISO (International Organization for Standardization). 1994. 5725-1 Accuracy (trueness and precision) of measurement methods and results - Part 1: General principles and definitions. Geneva, Switzerland.

ISO (International Organization for Standardization). 1998. 11272 Soil quality Determination of dry bulk density. Geneva, Switzerland

IPCC (Intergovernmental Panel on Climate Change). 2006. IPCC Guidelines for National Greenhouse Gas Inventories. At: http://www.ipcc-nggip.iges.or.jp/ public/2006gl/. On: 15 May 2017. 
IPCC (Intergovernmental Panel on Climate Change). 2013. Summary for Policymakers. In: Climate Change 2013: The Physical Science Basis. Contribution of Working Group I to the Fifth Assessment Report of the Intergovernmental Panel on Climate Change [Stocker, T.F., D. Qin, G.-K. Plattner, M. Tignor, S.K. Allen, J. Boschung, A. Nauels, Y. Xia, V. Bex and P.M. Midgley (eds.)]. Cambridge University Press, Cambridge, United Kingdom and New York, NY, USA.

IPCC (Intergovernmental Panel on Climate Change) 2019. Summary for Policymakers. In: IPCC Special Report on the Ocean and Cryosphere in a Changing Climate [H.O. Pörtner, D.C. Roberts, V. Masson-Delmotte, P. Zhai, M. Tignor, E. Poloczanska, K. Mintenbeck, A. Alegría, M. Nicolai, A. Okem, J. Petzold, B. Rama, N.M. Weyer (eds.)]. In press.

Isselstein, J., Jeangros, B. \& Pavlu, V. 2005. Agronomic aspects of biodiversity targeted management of temperate grasslands in Europe: A review. Agronomy Research, 3, 139-151.

Jackson, O., Quilliam, R. S., Stott, A., Grant, H., \& Subke, J. A. 2019. Rhizosphere carbon supply accelerates soil organic matter decomposition in the presence of fresh organic substrates. Plant and Soil, 1-18.

Janssen, B. H. 1984. A simple method for calculating decomposition and accumulation of 'young' soil organic matter. In Biological Processes and Soil Fertility (pp. 297. 304). Springer, Dordrecht.

Janssen, B.H. 2002. Organic matter and soil fertility. J100-225. pp.248, Wageningen Agricultural University, Wageningen, The Netherlands.

Johnston, A.E., Poulton, P.R. \& Coleman, K. 2009. Soil organic matter: its importance in sustainableagriculture and carbon dioxide fluxes. Advances in Agronomy, 101, 1-57.

Jones, M. B., \& Donnelly, A. 2004. Carbon sequestration in temperate grassland ecosystems and the influence of management, climate and elevated CO2. New Phytologist, 164(3), 423-439.

Kalra, Y.P. \& Maynard, D.G. 1991. Methods manual for forest soil and plant analysis. At: http://cfs.nrcan.gc.ca/pubwarehouse/pdfs/11845.pdf. Accessed: 04/11/2014.

Karsten, H. D., \& MacAdam, J. W. 2001. Effect of drought on growth, carbohydrates, and soil water use by perennial ryegrass, tall fescue, and white clover. Crop Science, 41, 156-166.

Kasozi, G.N., Nkedi-Kizza, P. \& Harris, W.G. 2009. Varied Carbon Content of Organic Matter in Histosols, Spodosols, and Carbonatic Soils. Soil Science Society of America Journal, 73, 1313-1318.

Kasselouri,V.,Dimopoulos, G.\&Parissakis, G., 1995. Effect of acetic and tartaric acid upon thermal decomposition of CaCO3. Cement and Concrete Research, 25, 477-484.

Klein Swormink, B., van Eekeren, N., Philipsen, B. \& van Schie, A.W.M. 2019. Graslandsignalen - praktijkgids voor optimaal graslandgebruik (In Dutch).

Kool, A., Marinussen, M., \& Blonk, H. 2012. LCl data for the calculation tool feedprint for greenhouse gas emissions of feed production and utilization. GHG Emissions of $\mathrm{N}, \mathrm{P}$ and $\mathrm{K}$ fertiliser production.

KNMI (Royal Dutch Weather Institute). 2012. Climate observations, hourly weather data of the Netherlands. At: http://www.knmi.nl/klimatologie/uurgegevens/. Accessed: 30/11/2012. 
KNMI (Royal Dutch Weather Institute). 2016. Daily data of the weather in The Netherlands. In Dutch: Daggegevens van het weer in Nederland. At: https:// www.knmi.nl/nederland-nu/klimatologie/daggegevens. Accessed: 02/01/2017.

Konare, H., Yost, R.S., Doumbia, M., McCarty, G.W., Jarju, A. \& Kablan, R. 2010. Loss on ignition: Measuring soil organic carbon in soils of the Sahel, West Africa. African Journal of Agricultural Research 22, 3088-3095.

Konen, M.E., Jacobs, P.M., Burras, C.L., Talaga, B.J. \& Mason, J.A. 2002. Equations for predicting soil organic carbon using loss-on-ignition for North Central U.S. soils. Soil Science Society of America Journal, 66, 1878-1881.

Konert, M. \& Vandenberghe, J. 1997. Comparison of laser grain size analysis with pipette and sieve analysis: a solution for the underestimation of the clay fraction. Sedimentology, 44, 523-535.

Kononova, M.M. 1966. Soil organic matter: its nature, its role in soil formation and in soil fertility. Oxford, UK.

Kortleven J, 1963. Quantitative aspects of build-up and decay of soil organic matter (In Dutch: Kwantitatieve aspecten van humusopbouw and humusafbraak). PhD Thesis, Wageningen Agricultural University, the Netherlands. Verslagen Landbouwkundige Onderzoekingen 69, 1.

Kratochvil, B. 1981. Sampling for chemical analysis. Analytical Chemistry, 53, 924-937.

Kravchenko, A. N., \& Robertson, G. P. 2011. Whole-profile soil carbon stocks: The danger of assuming too much from analyses of too little. Soil Science Society of America Journal, 75(1), 235-240.

Kuzyakov, Y., \& Domanski, G. 2000. Carbon input by plants into the soil. Review. Journal of Plant Nutrition and Soil Science, 163(4), 421-431.

Lantinga, E.A. 1985. Productivity of grasslands under continuous and rotational grazing. PhD thesis, 111 pp, Wageningen Agricultural University, Wageningen, the Netherlands.

Lange, M., Eisenhauer, N., Sierra, C. A., Bessler, H., Engels, C., Griffiths, R.I., MelladoVazquez, P.G., Malik, A.A., Roy, J. Scheu, S. \& Steinbeiss, S., Thomson, B.C., Trumbore, S.E. \& Gleixner, G. 2015. Plant diversity increases soil microbial activity and soil carbon storage. Nature communications, 6, 6707.

Lebbink, G. 1979. Soil biology. Soil pollution and soil protection. (In Dutch). Kon. PBNA 18.49-21.5:1-20.

Lee, J. R., Raymond, B., Bracegirdle, T. J., Chadès, I., Fuller, R. A., Shaw, J. D., \& Terauds, A. 2017. Climate change drives expansion of Antarctic ice-free habitat. Nature. 547(7661), 49-54.

Lenderink, G., Mok, H.Y., Lee, T.C. \& Van Oldenborgh, G.J. 2011. Scaling and trends of hourly precipitation extremes in two different climate zones - Hong Kong and the Netherlands. Hydrology and Earth System Sciences, 15, 3033-3041.

Loeppert, R.H., Hallmark, C.T. \& Koshy, M.M. 1984. Routine procedure for rapid determination of soil carbonates. Soil Science Society of America Journal, 48, 1030-1033.

Loeppert, R.H. \& Suarez, D.L. 1996. Carbonate and gypsum. In: Methods of soil analysis. Part 3 Chemical Methods (eds D.L. Sparks, A.L. Page, P.A. Helmke, R.H. Loeppert, P.N. Soltanpour, M.A. Tabatabai et al.), pp. 437-474. Soil Science 
Society of America Journal Inc., American Society of Agronomy Inc., Madison, USA.

Lorentz, C. \& Lal, R. 2005. The depth distribution of soil organic carbon in relation to land use and management and the potential of carbon sequestration in subsoil horizons. Carbon Management and Sequestration Center, Columbus, USA. At: http://tinread.usarb.md: 8888/tinread/fulltext/lal/depth.pdf. Accessed: 27/11/2014.

Lowther, J. R., Smethurst, P. J., Carlyle, J. C. \& Nambiar, E. K. S. 1990. Methods for determining organic carbon in podzolic sands. Communications in Soil Science \& Plant Analysis, 21, 45-470.

Luczak, C., Janquin, M.A. \& Kupka, A. 1997. Simple standard procedure for the routine determination of organic matter in marine sediment. Hydrobiologia, 345, 87-94.

Lüscher, A., Mueller-Harvey, I., Soussana, J. F., Rees, R. M., \& Peyraud, J. L. 2014. Potential of legume-based grassland-livestock systems in Europe: a review. Grass and Forage Science, 69, 206-228.

Macdonald, A. J., Powlson, D. S., Poulton, P. R., Watts, C. W., Clark, I. M., Storkey, J., Hawkins, N.J., Glendining, M.J., Goulding, K.W.T., \& McGrath, S. P. 2015. The Rothamsted long-term experiments. Aspects of Applied Biology, (128), 1-10.

Maillard, É. \& Angers, D.A. 2014. Animal manure application and soil organic carbon stocks: a meta-analysis. Global Change Biology, 20, 666-679.

Maillard, É., Angers, D. A., Chantigny, M., Bittman, S., Rochette, P., Lévesque, G., Hunt, D. \& Parent, L. É. 2015. Carbon accumulates in organo-mineral complexes after long-term liquid dairy manure application. Agriculture, Ecosystems \& Environment, 202, 108-119.

Manlay, R. J., Feller, C., \& Swift, M. J. 2007. Historical evolution of soil organic matter concepts and their relationships with the fertility and sustainability of cropping systems. Agriculture, Ecosystems \& Environment, 119 (3), 217-233.

Markert, B. 1996. Instrumental element and multi-element analysis of plant samples. Wiley/VCH-Publisher, Chichester.

Mestdagh, I. Sleutel, S., Lootens, P., Van Cleemput, O., Beheydt, D., Boeckx, P., De Neve, S., Hofman, G., Van Camp, N., Van De Walle, I., Samson, R., Verheyen, K., Lemeur, R. \& Carlier, L. 2009. Soil organic carbon-stock changes in Flemish grassland soils from 1990 to 2000. Journal of Plant Nutrition and Soil Science, 172, 24-31.

Mikutta R., Kleber M., Kaiser K. \& Jahn R. 2005. Review: Organic matter removal from soils using hydrogen peroxide, sodium hypochlorite, and disodium peroxodisulfate. Soil Science Society of America Journal, 69, 120-135.

Mook, D. H. \& Hoskin, C. M. 1982. Organic determinations by ignition: caution advised. Estuarine, Coastal and Shelf Science, 15, 697-699.

Municipality of Veenendaal, 2019. At: https://gemeentearchief.veenendaal.nl/ vervening-en-turfwinning/. Accessed: 28/10/2019.

Nelson, R.E. \& Sommers, L.E. 1996. Total carbon, organic carbon, and organic matter. In Sparks, D.L., et al., Eds., Methods of Soil Analysis. Part 3, SSSA Book Series, Madison, 961-1010.

Nelson, R.E. 1982. Carbonate and gypsum. In: Methods of soil analysis. Part 2Chemical and microbiological properties (eds. A.L. Page and R.C.Dinauer), pp. 
181-197. American Society of Agronomy and Soil Science Society of America, Madison, USA.

NEN-5754, 1992. Bodem: bepaling van het gehalte aan organische stof in grond volgens de gloeiverliesmethode (Soil: determination of organic matter content in soil as loss-on-ignition). Nederlands Normalisatie Instituut, Normcommissie 39009 Bodemkwaliteit, Delft, the Netherlands.

Nutting, P.G. 1943. Some standard thermal dehydration curves of minerals. U.S. Geological survey professional paper, 197E. Department of the Interior, Washington DC, USA.

Orlov, D.S. 1985. Humic acids of soils. Russian translation series no.35. Balkema, Rotterdam, the Netherlands.

Qin, Q. 2014. Agronomic evaluation of perennial ryegrass, tall fescue and white clover under three simulated stocking systems: aboveground dry matter yield and feeding value. MSc thesis, 49 p. Wageningen University \& Research centre, Wageningen, the Netherlands.

Pansu, M. \& Gautheyrou, J. 2006. Water content and loss-on-ignition. In Handbook of Soil Analysis: Mineralogical, Organic and Inorganic Methods (eds M. Pansu \& J. Gautheyrou), pp.3-13. Springer. Berlin, Germany.

PBL (Environmental Assessment Agency of the Netherlands), 2019. The development of soil organic matter. At: https://themasites.pbl.nl/evaluatie-meststoffen-wet/ jaargang-2016/achtergronden_emw2016/gevolgen-bodemvruchtbaarheidgewasopbrengsten-kosten-baten/verloop-organische-stofgehalte/verlooporganische-stofgehalte-over-de-tijd. Accessed: 26/10/2019.

Perie, C., \& Ouimet, R. 2008. Organic carbon, organic matter and bulk density relationships in boreal forest soils. Canadian journal of soil science, 88(3), 315325.

Pitard, F. F. 1993. Pierre Gy's sampling theory and sampling practice: heterogeneity, sampling correctness, and statistical process control. CRC press.

Poeplau, C., Vos. C. \& Don, A. 2017. Soil organic carbon stocks are systematically overestimated by misuse of the parameters bulk density and rock fragment content. SOIL, 3, 61-66, doi:10.5194/soil-3-61-2017.

Powlson, D. 2005. Climatology: Will soil amplify climate change? Nature, 433, 204205.

Pribyl, D. W. 2010. A critical review of the conventional SOC to SOM conversion factor. Geoderma, 156 (3), 75-83.

Province of Friesland (Humus academie, project announced during the National Soil Top Meeting of the Dutch Ministry of Agriculture, nature and food quality, on the 11 th of September, 2019).

Rabenhorst, M.C. 1988. Determination of organic and carbonate carbon in calcareous soils using dry combustion. Soil Science Society of America Journal, 52, 965-968.

Ranney, R.W. 1969. An organic carbon-organic matter conversion equation for Pennsylvania surface soils. Soil Science Society of America Journal, 33, 809-811.

Rashid, M.I. 2013. Soil biota and nitrogen cycling in production grasslands with different fertilisation histories. PhD thesis, 192p. Wageningen University \& Research centre, Wageningen, the Netherlands.

Rasse, D.P., Rumpel, C. \& Dignac, M.F. 2005. Is soil carbon mostly root carbon? 
Mechanisms for a specific stabilisation. Plant \& Soil, 269, 341-356.

Rawlins, B. G., Vane, C.H., Kim, A. W. Tye, A.M., Kemp, S.J. \& Bellamy, P.H. 2008. Methods for estimating types of soil organic carbon and their application to surveys of UK urban areas. Soil Use \& Management, 24, 47-59.

Read, J. W., \& Ridgell, R. H. 1922. On the use of the conventional carbon factor in estimating soil organic matter. Soil Science, 13, 1-6.

Reeder, J.D., Franks, C.D. \& Milchunas, D.G. 2001. Root biomass and microbial processes. In: The potential of U.S. grazing lands to sequester carbon and mitigate the greenhouse effect. (Eds. R.F. Follet, J.M. Kimble \& R. Lal.), pp. 163190. CRC Press, Boca Raton, USA.

Reijneveld, A., Van Wensum J. \& Oenema O. 2009. Trends in soil organic carbon content of agricultural land in the Netherlands between 1984 and 2004. Geoderma, 152, 231-238.

Reijneveld, J.A. 2013. Unravelling changes in soil fertility of agricultural land in the Netherlands. PhD thesis, 240pp. Wageningen University \& Research centre, Wageningen, the Netherlands.

Risnes, R., Madland, M.V. Hole, M. \& Kwabiahm, N.K. 2005. Water weakening of chalkmechanical effects of water-glycol mixtures. Journal of Petroleum Science and Engineering, 48, 21-36.

RIVM (National Institute for Public Health and the Environment, the Netherlands). 2016. Agricultural practices and water quality at grassland farms registered for derogation in 2014 (In Dutch: Landbouwpraktijk en waterkwaliteit op landbouwbedrijven aangemeld voor derogatie in 2014). Bilthoven, the Netherlands.

RIVM (National Institute for Public Health and the Environment). 2019a. Greenhouse gas emissions in the Netherlands 1990-2017 : National Inventory Report 2019. At: https://www.rivm.nl/publicaties/greenhouse-gas-emissions-in-netherlands1990-2017-national-inventory-report-2019. Accessed: 26/10/2019.

RIVM (National Institute for Public Health and the Environment) 2019b. National Minerals Policy Monitoring Program of the Netherlands. At: Imm.rivm.nl. Accessed: 15/12/2019.

Robertson, D. 1946. A Note on the Classical Origin of "Circumstances" in the Medieval Confessional. Studies in Philology, 43(1), 6-14. At: http://www.jstor.org/ stable/4172741. Accessed: 26/10/2019.

RVO (Netherlands Enterprise Agency). 2019a. Application rates of nitrogen on agricultural land. At: https://www.rvo.nl/sites/default/files/2018/03/Tabel-1Stikstofgebruiksnormen-2018.pdf. Accessed: 13/12/2019.

RVO (Netherlands Enterprise Agency). 2019b. National fixed rate values of nitrogen and phosphorus production per dairy cow (cattle slurry and solid cattle manure). At: https://www.rvo.nl/sites/default/files/2018/01/Tabel-6-Stikstof-enfosfaatproductiegetallen-per-melkkoe-2018. pdf. Accessed: 14/12/2019.

Ryle, G. J. A. 1970. Partition of assimilates in an annual and a perennial grass. Journal of Applied Ecology, 217-227.

Salehi, M. H., Hashemi Beni, O., Beigi Harchegani, H., Esfandiarpour Borujeni, I. \& Motaghian, H. R. 2011. Refining soil organic matter determination by loss-on- 
ignition. Pedosphere. 21, 473-482.

Schmidt, M.W., Torn, M.S. Abiven, S., Dittmar, T., Guggenberger, G., Janssens, I.A., Kleber, M., Kögel-Knabner, I., Lehmann, J., Manning, D.A.C., Nannipieri, P., Rasse, D.P., Weiner, S., Trumbore, S.E. 2011. Persistence of soil organic matter as an ecosystem property. Nature, 478, 49-56.

Schnitzer, M., Wright, J.R. \& Hoffman, I. 1959. Use of the thermobalance in the analysis of soils and clays. Analytical Chemistry, 31, 440-444.

Schulte, E.E. \& Hopkins, B.G. 1996. Estimation of soil organic matter by weight loss-onignition. Soil Organic Matter: Analysis and Interpretation (eds F.R. Magdoff, M.A. Tabatabai \&E.A.Hanlon), pp.21-31.Soil Science Society of America, Madison, USA.

Schulte, E. E., Kaufmann, C. \& Peter, J. B. 1991. The influence of sample size and heating time on soil weight loss-on-ignition. Communications in Soil Science \& Plant Analysis, 22, 159-168.

Schumacher, B.A., Shines, K.C., Burton, J.V. \& Papp, M.L. 1990. Comparison of Soil Sample Homogenization Techniques. Environmental Monitoring Systems Laboratory Office of Research and Development. At: http://www.epa.gov/. Accessed: 25/01/2013.

Singh, N.B. \& Singh, N.P. 2007. Formation of $\mathrm{CaO}$ from thermal decomposition of calcium carbonate in the presence of carboxylic acids. Journal of Thermal Analysis and Calorimetry, 89, 159-162.

Six, J., Conant, R. T., Paul, E. A., \& Paustian, K. 2002. Stabilization mechanisms of soil organic matter: implications for C-saturation of soils. Plant and soil, 241 (2), 155 176.

Skinner, R. H., \& Dell, C. J. 2016. Yield and Soil Carbon Sequestration in Grazed Pastures Sown with Two or Five Forage Species. Crop Science, 56, 2035-2044

Sleutel, S., De Neve, S. \& Hofman, G. 2007. Assessing causes of recent organic carbon losses from cropland soils by means of regional-scaled input balances for the case of Flanders (Belgium). Nutrient Cycling in Agroecosystems, 78, 265-278.

Sleutel, S. De Neve, S., Singier, B. \& Hofman, G. 2007. Quantification of Organic Carbon in Soils: A Comparison of Methodologies and Assessment of the Carbon Content of Organic Matter. Communications in Soil Science \& Plant Analysis, 38, 2647-2657.

Smith, P. 2004. How long before a change in soil organic carbon can be detected? Global Change Biology, 10(11), 1878-1883.

Smith, P. 2014. Do grasslands act as a perpetual sink for carbon? Global Change Biology, 20, 2708-2711.

Smith, P. 2017. Unlocking the potential of SOC for climate action, food security and sustainable development - a feasible future. Global symposium on soil organic carbon, March 21st - 23rd, FAO, Rome, Italy.

Soussana, J. F., Allard, V., Pilegaard, K., Ambus, P., Amman, C., Campbell, C., Ceschia, E., Clifton-Brown, J., Czobel, S., Domingues, R., Flechard, C., Fuhrer, J., Hensen, A., Horath, L., Jones, M., Kasper, G., Martin, C., Nagy, Z., Neftel, A., Raschi,k A., Barontin, S., Rees, R.M., Skiba, U., Stefani, P., Manca, G., Sutton, M., Tuba, Z. \& Valentini, R. 2007. Full accounting of the greenhouse gas $\left(\mathrm{CO}_{2}, \mathrm{~N}_{2} \mathrm{O}, \mathrm{CH}_{4}\right)$ budget of nine European grassland sites. Agriculture, Ecosystems \& Environment, 121, 
121-134.

Soussana, J. F., Tallec, T., \& Blanfort, V. 2010. Mitigating the greenhouse gas balance of ruminant production systems through carbon sequestration in grasslands. Animal, 4, 334-350.

Sprengel, C. 1838. Die Lehre von den Urbarmachungen and Grundverbesserungen. Immanuel Müller Publ. Co., Leipzig.

Statistics Netherlands. 2017. Larger dairy farms and more milk (In Dutch). At: https:// www.cbs.nl/nl-nl/nieuws/2017/18/grotere-melkveebedrijven-en-meer-melk. Accessed: 15/12/2019.

Statistics Netherlands. 2019a. National trends in ruminant manure. At: https:// opendata.cbs.nl/statline/\#/CBS/nl/dataset/7311slmi/table?fromstatweb. Accessed: 15/12/2019.

Statistics Netherlands.2019b. Nationaltrendsin outdoor cattle grazing.At:https://opendata.cbs.nl/statline/\#/CBS/nl/dataset/70736ned/table?ts=1573287006594. Accessed: 15/12/2019.

Statistics Netherlands. 2019c. National cattle herd (dairy cows, beef cattle and their young stock). At: https://opendata.cbs.nl/statline/\#/CBS/nl/dataset/71904ned/ table?ts=15731994454 99. Accessed: 15/12/2019.

Steinbeiss, S., Beßler, H., Engels, C., Temperton, V.M., Buchmann, N., Roscher, C., Kreutziger, Y., Baade, J., Habekost, M. \& Gleixner, G. 2008. Plant diversity positively affects short-term soil carbon storage in experimental grasslands. Global Change Biology, 14, 2937-2949.

Stevenson, F.J. 1994. Humus Chemistry: Genesis, Composition, Reactions, 2nd Edition, pp. 1-23, John Wiley \& Sons, New York, USA.

Sun H., Nelson, M., Chen, F. \& Husch, J. 2009. Soil mineral structural water loss during loss on ignition analyses. Canadian Journal of Soil Science, 89, 603-610.

Sutherland, R.A. 1998. Loss-on-ignition estimates of organic matter and relationships to organic carbon in fluvial bed sediments. Hydrobiologia, 389, 153-167.

Szava-Kovats, R. 2009. Re-analysis of the Relationship between Organic Carbon and Loss-on-Ignition in Soil. Communications in Soil Science \& Plant Analysis, 40, 2712-2724.

Taghizadeh-Toosi, A., Olesen, J. E., Kristensen, K., Elsgaard, L., Østergaard, H. S., Lægdsmand, M., Greve, M.H. \& Christensen, B. T. 2014. Changes in carbon stocks of Danish agricultural mineral soils between 1986 and 2009. European Journal of Soil Science, 65(5), 730-740.

Theng, B. K. G. 1989. Constituents of organic matter in temperate and tropical soils. In: Coleman, D.C., Oades, J.M., Uehara, G. (Eds.), Dynamics of Soil Organic Matter in Tropical Ecosystems. University of Hawaii Press, Honolulu, pp. 5-32.

Tukey, J. W. 1977. Exploratory data analysis. Addison-Wesley, Philippines.

Turner, R.C. \& Schnitzer, M. 1962. Thermogravimetry of the organic matter of a podzol. Soil Science, 93, 225-232.

UNFCCC (United Nations Framework Convention on Climate Change). 2016. Join the $4 \%$ Initiative : soils for food security and climate. At: newsroom.unfccc.int/ media/408539/4-per-1000-initiative.pdf. Accessed: 29/12/2016. 
Van Bemmelen, J.M. 1891. Über die Bestimmungen des Wassers, des Humus, des Schwefels, der in den Colloidalen Silikaten gebunden Kieselsaeuren, des mangans, u.s.w. im Ackerboden. Landwirtschaftliche Versuch Station, 37: 279290.

Vandecasteele, B. \& De Vos, B. 2001. Relationship between soil textural fractions determined by the sieve-pipette method and laser diffractometry. Research Institute for Nature \& Forest, Brussels, Belgium. At: http://www.inbo.be/files/ bibliotheek/62/166662.pdf. Accessed: 11/10/2013.

Van der Linden, A. M. A., Van Veen, J. A., \& Frissel, M. J. 1987. Modelling soil organic matter levels after long-term applications of crop residues, and farmyard and green manures. Plant and Soil, 101(1), 21-28.

Van der Marel, H. W. 1950. Het voorkomen van calciet en dolomiet in de kleifractie van de Nederlandse gronden (Calcite and dolomite in the clay fraction of Dutch soils). Landbouwkundig tijdschrift, 62, 300-306.

Van der Paauw, F. 1943. Grondonderzoek naar fosfaat- en kalitoestand op grasland. Verslagen van Landbouwkundige Onderzoeken No. 49A: 98 pp. At: https:// edepot.wur.nl/333017, On: 30/11/2019.

Van Eekeren, N., Bommelé, L., Bloem, J., Schouten, T., Rutgers, M., de Goede, R., Reheul, D., \& Brussaard, L. 2008. Soil biological quality after 36 years of leyarable cropping, permanent grassland and permanent arable cropping. applied soil ecology, 40(3), 432-446.

Van Eekeren, N.J.M., Boer, H., Bloem, J., Schouten, T., Rutgers, M., De Goede, R.G.M. \& Brussaard, L. 2009. Soil biological quality of grassland fertilized with adjusted cattle manure slurries in comparison with organic and inorganic fertilizers. Biology \& Fertility of Soils, 45, 595-608.

Van Eekeren, N.J.M., Bos, M. De Wit, J., Keidel, H. \& Bloem, J. 2010. Effect of individual grass species and grass species mixtures on soil quality as related to root biomass and grass yield. Applied Soil Ecology, 45, 275-283.

Van Eekeren, N. V., Bokhorst, J. G., \& Brussaard, L. 2010. Roots and earthworms under grass, clover and a grass-clover mixture. World Congress of Soil Science, Soil Solutions for a Changing World, Brisbane, Australia, 1-6 August 2010.

Van Eekeren, N.J.M., Hoogsteen, M.J.J., Deru, J.G.C., De Wit, J. \& Lantinga, E.A. 2015. White clover content and grassland productivity in simulated grazing systems. $p$. 484-486. In EGF 2015. Wageningen, the Netherlands. 15-17 June 2015.

Van Eekeren, N., Deru, J., Hoekstra, N. \& de Wit, J. 2018. Carbon valley - Organische stofmanagement op melkveebedrijven At: http://www.louisbolk.org/ downloads/3319.pdf. Accessed: 26/10/2019.

Vellinga, T. V., Van den Pol-van Dasselaar, A., \& Kuikman, P. J. 2004. The impact of grassland ploughing on $\mathrm{CO}_{2}$ and $\mathrm{N}_{2} \mathrm{O}$ emissions in the Netherlands. Nutrient Cycling in Agroecosystems, 70, 33-45.

Verloop, J. Hilhorst, G.J., Pronk, A.A., Šebek, L.B. Van Keulen, H., Janssen, B.H. \& Van Ittersum, M.K. 2015. Organic matter dynamics in an intensive dairy production system on a Dutch Spodosol. Geoderma, 237, 159-167.

Visscher, J., Radersma, S. \& Van Den Pol-Van Dasselaar, A. 2011. Innovations in grazing systems (In Dutch: Innovaties in beweidingssystemen). At: http://edepot.wur. 
nl/202654 Accessed: 2/10/2012.

VVM (Vereniging voor Milieuprofessionals; network for professionals working in the environmental sector). 2019. Koolstofopslag (In Dutch), At: https://www.vvm. info/nu-in-tijdschrift-milieu. Accessed: 1/11/2019.

Wadman, W.P., Sluijsmans, C.M.J. \& De La Lande Cremer, L.C.N. 1987. Value of animal manure: changes in perception. ANimal Manure on Grassland and Fodder Crops. Fertilizer of Waste? International Symposium, Martinus Nijhoff Publishers, The Netherlands. pp. 2-13.

Wahl, F.M., Grim, R.E. \& Graf, R.B. 1961. Phase transformations in silica as examined by continuous X-ray diffraction. The American Mineralogist, 46, 196-208.

Walinga, I., Kithome, M., Novozamsky, I., Houba, V.J.G. \& Van Der Lee, J.J. 1992. Spectrophotometric determination of organic carbon in soils. Communications in Soil Science \& Plant Analysis, 23, 1935-1944.

Wang Q., Li Y. \& Wang Y. 2011. Optimizing the weight loss-on-ignition methodology to quantify organic and carbonate carbon of sediments from diverse sources. Environmental Monitoring \& Assessment, 174, 241-257.

Ward, S. E., Smart, S. M., Quirk, H., Tallowin, J. R. B., Mortimer, S. R., Shiel, R. S., Wilby, A. \& Bardgett, R. D. 2016. Legacy effects of grassland management on soil carbon to depth. Global Change Biology, 22, 2929-2938.

Waugh, W.N. \& Hill, W.E. 1960. Determination of carbon dioxide and other volatiles in pyritic limestones by loss on ignition. Journal of Sedimentary Petrology, 30, 144-147.

WEcR (Wageningen Economics Research), 2019a. Nitrogen fertilization on dairy farms. At: https://agrimatie.nl/SectorResultaat.aspx?subpubID=2232\&sectorl$D=2245$ \&themal $D=2282$ \&indicator $I D=2772$. Accessed: $14 / 12 / 2019$.

WEcR (Wageningen Economics Research), 2019b. Grassland yield per hectare on derogation farms in the Netherlands. At: https://www.agrimatie.nl/ PublicatiePage.aspx?subpubID $=7352 \&$ themaID $=2754 \&$ sectorlD $=3$. Accessed: 23/10/2019.

Wendt, J. W., \& Hauser, S. 2013. An equivalent soil mass procedure for monitoring soil organic carbon in multiple soil layers. European Journal of Soil Science, 64(1), 58-65.

West, T. O., \& Six, J. 2007. Considering the influence of sequestration duration and carbon saturation on estimates of soil carbon capacity. Climatic Change, 80 (1), 25-41.

Westman, C.J., Hytönen, J. \& Wall, A. 2006. Loss-on-ignition in the determination of pools of organic carbon in soils of forests and afforested arable fields. Communications in Soil Science \& Plant Analysis, 37, 1059-1075.

Whitehead, D.C., Bristow, A.W. \& Lockyer, D.R. 1990. Organic matter and nitrogen in the unharvested fractions of grass swards in relation to the potential for nitrate leaching after ploughing. Plant \& Soil, 123, 39-49.

Wiggers, A.J. 1950. De gehalten aan organische stof in Nederlandse gronden. Maandblad van het Nederlandsch Genootschap voor Landbouwwetenschap, 62, 455-468. 
Wilkinson, M. T., Richards, P. J., \& Humphreys, G. S. 2009. Breaking ground: pedological, geological, and ecological implications of soil bioturbation. EarthScience Reviews, 97(1-4), 257-272.

Wright, A.L., Wang, Y. \& Reddy, K.R. 2008. Loss-on-ignition method to assess soil organic carbon in calcareous Everglades wetlands. Communications in Soil Science \& Plant Analysis, 39, 3074-3083.

Yoshioka, S. and Kitano, Y. 1985. Transformation of aragonite to calcite through heating. Geochemical Journal, 19, 245-249.

Zar, J.H. 1996. Biostatistical Analysis. Prentice-Hall, Englewood Cliffs, NJ.

Zhang, M. Li, Y. \& Stoffella, P.J. 2005. Comparison of Analytical Methods for Organic Matter in Composts and Organic Mulches. Communications in Soil Science \& Plant Analysis, 36, 2587-2599.

Zwart, K., Kikkert, A., Wolfs, A., Termorshuizen, A. van der Burgt, G.J. 2013. Tien vragen en antwoorden over organische stof. At: https://edepot.wur.nl/272641. Accessed: 26/10/2019. 
Summary 



\section{Summary}

Elevating soil organic matter (SOM) levels through changes in land use and management may contribute to lower greenhouse gas concentrations in the atmosphere and aid in combatting climate change. For this reason, policy makers, advisors and farmers increasingly ask for management strategies to sequester carbon and to provide indicators for soil carbon monitoring. This is challenging because of high levels of spatial heterogeneity in the soil, relatively small management induced changes in SOM as compared to the stock and a cacophony of monitoring and sampling designs and protocols, prescribing to use different analysis methods, and to sample different depths. The overall aim of this thesis was to elucidate the effects of methodological choices on quantifying management induced changes of SOM levels over time for grassland soils, and to assess the effect of different grassland management options on SOM dynamics in the Netherlands. With respect to the first part of the aim, the focus was on the effect of methodological choices in the laboratory (Chapters 2 and 3), field and farm, and on addressing sampling depth and frequency (Chapter 4). As to the second part of the aim, a field experiment was conducted to investigate the effect of grassland management options on SOM dynamics over time (Chapter 5).

The rhetorical scheme "The seven circumstances" was used to structure the methodological aspects of setting up an SOM monitoring program. Seven questions are central to the rhetorical scheme: 1.Who, 2. What, 3. Where, 4. When, 5. How, 6. Why, 7. By what means. "Who" are the information requestors, the policy makers and farmers. The answer to the "What" question is: information on the stocks of SOM and their trends. "Where" refers to effect of the sampling depth and the aggregation level of the data (experimental plots, field, farm). "When" is the effect of seasonality on the quality of the reported data. The "How" question addresses how to measure SOM weight concentrations in the laboratory and how to derive SOM stocks from SOM weight concentrations. The answer to the "Why" question is: setting up a monitoring scheme for soil carbon to further quantify the role grassland soils can play to combat climate change. And "By what means" refers to the available budget. 


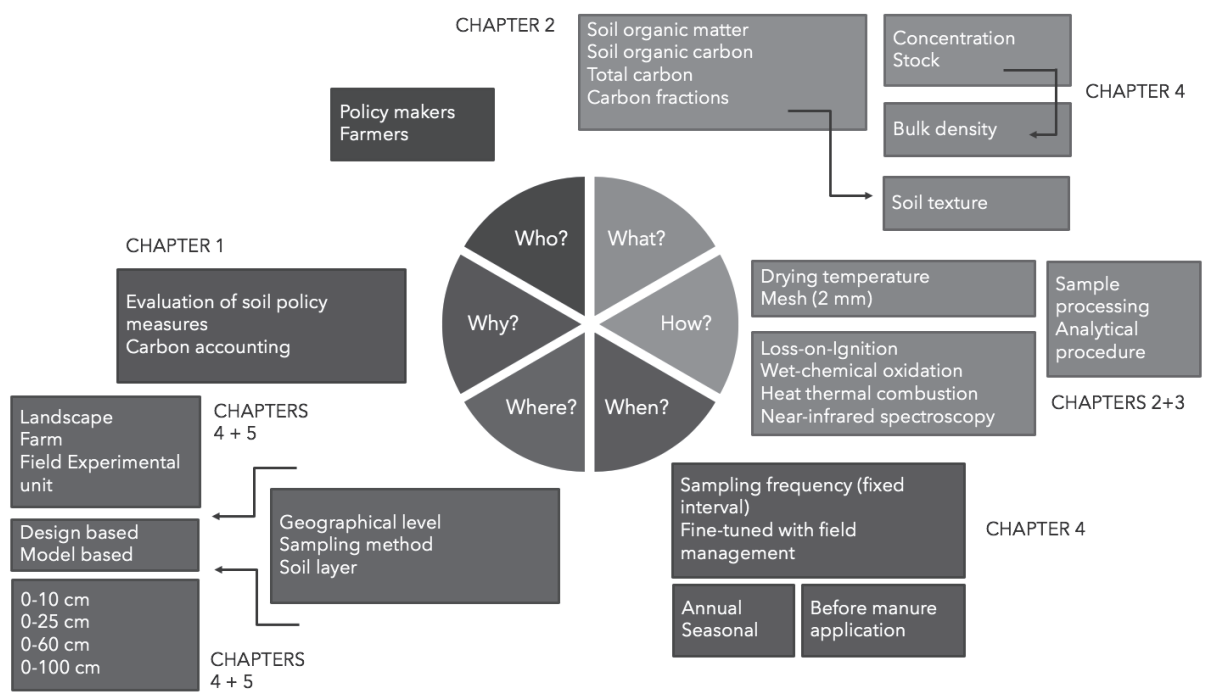

Figure 1. An overview of the questions from the rhetorical scheme "The seven circumstances" and different answers to these questions in the context of soil organic matter monitoring. The question: "By what means" in not presented.

\section{What? (Chapters 2 and 3 )}

Loss on ignition (LOI) is one of the most widely used methods for measuring organic matter content in soils but does not have a universal, standard protocol. A large number of factors may influence its accuracy, such as furnace type, sample mass, duration and temperature of ignition and clay content of samples. Furthermore, there is a risk of carbonate losses when calcareous soil samples are analysed through LOI, but this has never been investigated in detail. Moreover, a worldwide standard protocol for determining the carbonate content of soils is not available.

A series of experiments were conducted to quantify these effects, which enabled us:

(i) To derive guidelines for ignition conditions (furnace type, sample mass, duration and temperature).

(ii) To quantify temperature-specific soil organic matter (SOM) to soil organic carbon (SOC) conversion factors.

(iii) To develop clay content-dependent correction factors for structural water loss (SWL).

(iv) To evaluate two commonly employed carbonate analysis procedures using calcareous and non-calcareous soil samples: the gravimetric method with (GMF) and without (GM) the addition of the antioxidant $\mathrm{FeCl}_{2}$ and the acetic acid dissolution procedure (AAD).

(v) To evaluate the effect of ignition temperature on losses of pure calcite, calcite-quartz and calcareous soil samples. 
Bulk samples of a sandy soil ( $4 \%$ clay) and a silt loam soil ( $25 \%$ clay) were used to evaluate the effects of ignition conditions (i, ii). Samples with a range of clay contents $(0-50 \%)$ were used to quantify conversion and correction factors (iii, v), and for the evaluation of different carbonate analysis procedures (iv).

Two furnaces, one without and one with pre-heated air, did not show significant differences in terms of within-batch LOI variability. In both furnaces less combustion occurred close to the door, which necessitated tray turning at half-time as this reduced the standard deviation per batch significantly. Variation in mass loss declined exponentially with sample mass (range, 0.15 - $20 \mathrm{~g}$ ). The LOI increased with duration at lower temperatures ( $\leq 550^{\circ} \mathrm{C}$ ) for the sandy soil. At higher temperatures $\left(600\right.$ and $\left.650^{\circ} \mathrm{C}\right)$, no effect of duration was found. For the silt loam soil, LOI values increased with duration for each temperature, which was attributed to structural water loss (SWL). The SOM to $\mathrm{SOC}$ conversion factor decreased strongly with temperature at an ignition duration of 3 hours from $0.70\left(350^{\circ} \mathrm{C}\right)$ to $0.57\left(500^{\circ} \mathrm{C}\right)$ and stabilized around 0.55 between 550 and $650{ }^{\circ} \mathrm{C}$, indicating that at temperatures $\geq 550{ }^{\circ} \mathrm{C}$ all SOM had been removed. The clay correction factor for SWL increased from 0.01 to 0.09 as the temperature of ignition increased from 350 to $650{ }^{\circ} \mathrm{C}$.

It was found that the average apparent carbonate content of the noncalcareous soils was greatest for the GMF method followed by the AAD procedure. The GM method showed smallest apparent carbonate contents. For the calcite-quartz sand mixture, ignition losses started at $600{ }^{\circ} \mathrm{C}$ and increased with temperature in a sigmoidal way. LOI values stabilized at 750 ${ }^{\circ} \mathrm{C}$ when $80 \%$ of the $\mathrm{CO}_{2}$ was released.

To minimize within-batch LOI variation it is recommended to use a standard ignition duration of 3 hours, tray turning at half-time, and a sample mass $\geq 20 \mathrm{~g}$. The ignition temperature should be set at $550{ }^{\circ} \mathrm{C}$ for complete combustion of SOM and because $99.98 \%$ of the total calcite fraction remains in the soil samples at this temperature. To avoid over-estimates of SOM through structural water loss, the presented SWL correction procedure should always be applied. Furthermore, the GM procedure for carbonate analysis is recommended because the apparent carbonate contents of the non-calcareous soil samples were smallest.

\section{How, Where \& When? (Chapter 4)}

Through intensive observations during four years on two grass-based dairy farms in the Netherlands, the effects were explored of multiple methodological choices and quantitative insights were gained into the circumstances: How (conversion of SOM weight concentrations to SOM stocks), Where (soil depth), and When (seasonality) for measurements of SOM stocks and the development thereof in time. It was found that all three circumstances affect conclusions on SOM stocks or SOM dynamics. 
Considerable variation exists in pedotransfer curves relating soil bulk density and SOM weight concentration.

Therefore, preferably a site specific pedotransfer curve should be used when comparing SOM stocks based on SOM weight concentrations across sites. Large differences between SOM stock changes over time were found between fields and sampling depths (confirmed in Chapter 5). It is concluded that a sampling depth in grassland soils up to $60 \mathrm{~cm}$ may be relevant to capture the dynamics in deeper layers. Furthermore, for quantitative underpinning of carbon payment schemes, the whole farm should be monitored rather than a few fields as trends between fields are highly variable.

\section{Why? Investigating the effect of grassland management options on SOM dynamics over time (Chapters 5 and 6)}

Soil organic matter (SOM) dynamics of grassland soils may be affected by plant species composition and harvesting practices. The effects were analysed of simulated stocking systems (continuous (CS), rotational (RS) and lenient strip stocking (LS)) and species composition (monocultures of perennial ryegrass fertilized (LP+) and unfertilized (LP-)), tall fescue (fertilized, $\mathrm{FA}+$ ) and a mixture of these two species with white clover (fertilized, $\mathrm{LFT}+$ )) on root biomass and SOM dynamics in a field experiment on loamy and sandy soils in the Netherlands. Dried cattle manure was added to all fertilized treatments. It was hypothesized that SOM accumulation would be highest under CS and LS, and FA+ and LFT+ as a consequence of greater belowground biomass production. SOM was monitored for a period of two (loam and sand) and five (sand) years after conversion from arable land. It was found that conclusions on management practices to increase SOM storage are strongly influenced by sampling depth and length of the grassland period. SOM increased significantly in nearly all fertilized treatments in the 0-60 cm layer. No differences between species compositions were found. However, when only the $30-60 \mathrm{~cm}$ soil layer was considered, significantly higher SOM increases were found under FA+ which is consistent with its greater root biomass compared to the other species. SOM increases tended to be higher under LS than under RS.

The why question is further reflected upon in the general discussion of the thesis and the main findings are discussed in a climate policy context. This thesis has demonstrated that harmonizing methodologies across the whole monitoring chain from sample collection to data interpretation is crucial for specifying management effects on changes of SOM stocks in grassland over time. Measurements of SOM stocks in the context of climate policies should sample the whole farm, use a sampling depth of $60 \mathrm{~cm}$ and employ a standardized analytical procedure for measuring SOM weight concentrations. Payments for carbon sequestration on the basis of management measures can be insufficiently quantified based on the results of this thesis. 
Samenvatting 



\section{Samenvatting}

Het verhogen van het gehalte van organische stof (OS) in de bodem (bodem-OS) door veranderingen in landgebruik en management kan broeikasgasemissies en dus klimaatverandering tegengaan. In toenemende mate vragen beleidsmakers, adviseurs en boeren om managementstrategieën die vastlegging van bodem-OS bevorderen en om methoden om dit te kunnen meten en monitoren. Dit is niet eenvoudig om een aantal redenen: de ruimtelijke variatie in de gehalten van bodem-OS is groot en management-geïnduceerde veranderingen zijn klein ten opzichte van de hoeveelheid bodem-OS die reeds aanwezig is. Bovendien bestaat er een groot aantal verschillende monitoring- en bemonsteringsprotocollen met voorschriften voor het gebruik van verschillende analysemethoden en meting op verschillende bodemdieptes. Toepassing van de verschillende protocollen leidt tot slechte vergelijkbaarheid van de resultaten.

Het onderzoek beschreven in dit proefschrift beoogde om voor productiegraslanden in Nederland: (1) Het effect van methodologische keuzes om veranderingen in het gehalte van bodem-OS in beeld te brengen; (2) Het effect te kwantificeren van kansrijke graslandmengsels en -beweidingssystemen om het gehalte van bodem-OS te verhogen. Met betrekking tot heteerste doellag de nadruk op het effect van methodologische keuzes in het laboratorium (hoofdstukken 2 en 3), het schaalniveau (veld en boerderij) en de diepte en frequentie van de bemonstering (hoofdstuk 4). Voor het tweede doel werd een veldexperiment uitgevoerd om het effect van graslandbeheeropties op bodem-OS dynamiek te onderzoeken (hoofdstuk 5).

Zeven vragen werden gebruikt om de methodologische aspecten in het kader van bodem-OS monitoring te structureren: 1. Wie; 2. Wat; 3. Waar; 4. Wanneer; 5. Hoe; 6. Waarom; 7. Met welke middelen. "Wie" zijn de informatievragers zoals beleidsmakers en boeren. Het antwoord op de vraag "Wat" is: informatie over hoeveelheden bodem-OS en veranderingen daarin. "Waar" verwijst naar het effect van de bemonsteringsdiepte en het aggregatieniveau van de gegevens (experimentele plots, veld, boerderij) op de gerapporteerde hoeveelheden. "Wanneer" behelst het effect van seizoensinvloeden (wanneer moeten metingen plaatsvinden?). De "Hoe"vraag gaat over hoe bodem-OS gewichtsconcentraties (in $\mathrm{g}$ per $\mathrm{kg}$ ) in het laboratorium kunnen worden gemeten en hoe hoeveelheden van bodem-OS (in kg perha) kunnen worden afgeleid uit gewichtsconcentraties. Het antwoord op de "Waarom"-vraag is: het opzetten van een monitoringsprogramma om te kwantificeren wat het potentieel is van graslanden om bodem-OS vast te leggen om klimaatverandering tegen te gaan. "Met welke middelen" verwijst naar het beschikbare budget. 


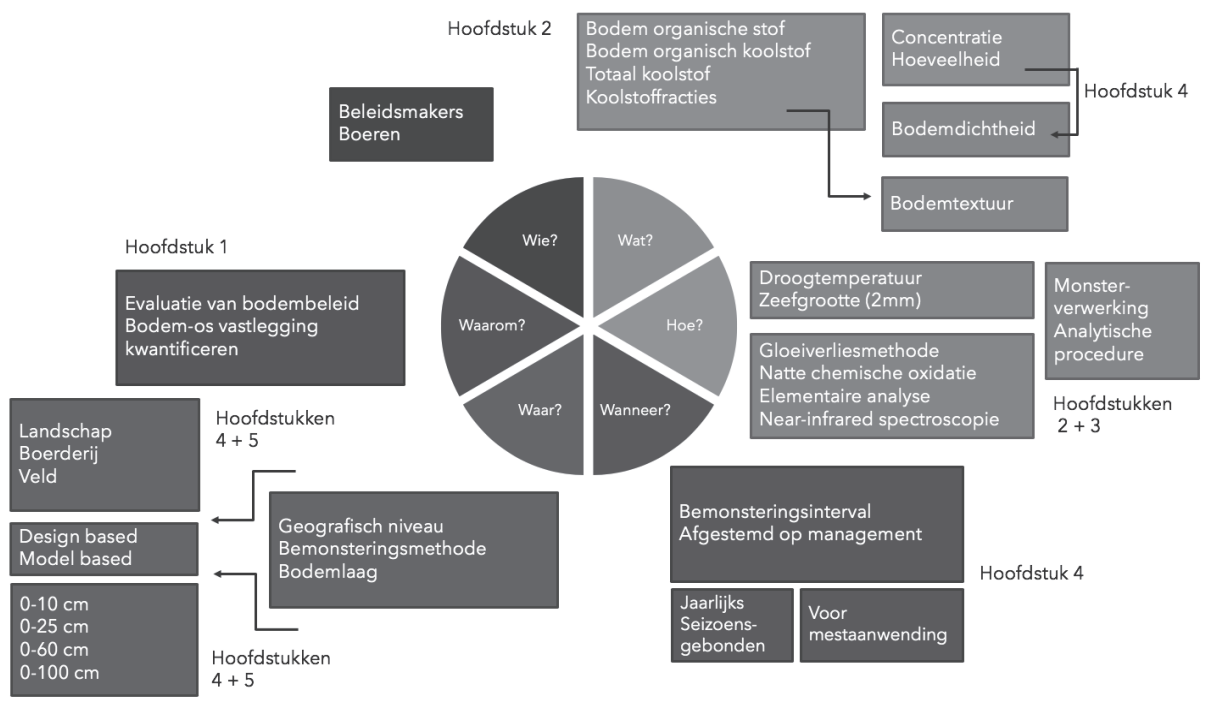

Figuur 1. Een overzicht van de vragen en verschillende keuzes in het kader van bodem-OS monitoring. De vraag: "Met welke middelen" is niet weergegeven.

\section{Wat? (Hoofdstukken 2 en 3)}

De gloeiverliesmethode is een van de meest gebruikte methoden om het gehalte van bodem-OS te meten, maar heeft geen universeel standaardprotocol. Hierbij wordt de grond na droging in het laboratorium verhit tot een hoge temperatuur, waarbij de bodem-OS volledig oxideert en vervluchtigt. De afname van het gewicht door het uitgloeien geeft het gehalte van bodem-OS. Een groot aantal factoren kan de nauwkeurigheid van metingen beïnvloeden, zoals het type oven, het monstergewicht, de duur en temperatuurvan de behandeling en het kleigehalte van de grondmonsters. In kalkhoudende grondmonsters bestaat er een risico op gewichtsverlies, door vervluchtiging van carbonaat, maar dit is nooit in detail onderzocht. Er is geen wereldwijd standaardprotocol voor het bepalen van het carbonaatgehalte van bodems. Dit bemoeilijkt het corrigeren van verliezen voor carbonaten, omdat de initiële hoeveelheid carbonaten (voordat het monster in de oven gaat) niet bekend is.

Een reeks experimenten werd uitgevoerd om deze effecten te kwantificeren met als doel:

(i) Richtlijnen af te leiden voor de gloeiverliesmethode (type oven, monstergewicht, tijdsduur en temperatuur).

(ii) Temperatuur-specifieke conversiefactoren af te leiden van bodem-OS naar bodemkoolstofgehaltes.

(iii) Correctiefactoren af te leiden voor verlies van kristalwater uit kleideeltjes.

(iv) Twee veelgebruikte carbonaatanalyseprocedures te evalueren met 
behulp van kalkhoudende en niet-kalkhoudende grondmonsters: de gravimetrische methode met en zonder de toevoeging van het antioxidant ijzerchloride $\left(\mathrm{FeCl}_{2}\right)$, (respectievelijk afgekort als GMF en GM), en de azijnzuuroplossingsmethode (AAD).

(v) Het effect van de oventemperatuur op verliezen van zuivere calciumcarbonaat, calciumcarbonaat-kwarts en kalkhoudende grondmonsters te kwantificeren.

Bulkmonsters van een zandgrond ( $4 \% \mathrm{klei}$ ) en een leemgrond ( $25 \% \mathrm{klei})$ werden gebruikt om de effecten van gloeiverliescondities te evalueren (i, ii). Monsters met een kleigehalte variërend van 0 tot $50 \%$ werden gebruikt om conversie- en correctiefactoren te kwantificeren (iii, v) en voor de evaluatie van verschillende carbonaatanalyseprocedures (iv).

Het toepassen van twee verschillende ovens, één zonder en één met voorverwarmde lucht, leverde geen significante verschillen in variatie in gloeiverlies binnen een partij van dezelfde bodemmonsters. In beide ovens trad minder verbranding op dicht bij de deur, waardoor het draaien van de monsters halverwege de tijdsduur van de analyse noodzakelijk was: de standaardafwijking verminderde hierdoor aanzienlijk. Bij een toename van het monstergewicht van 0,15 naar $20 \mathrm{~g}$ nam de variatie in het gloeiverlies exponentieel af. Voor de zandgrond namen bij lagere temperaturen ( $\leq$ $550{ }^{\circ} \mathrm{C}$ ) de gloeiverliezen toe naarmate de monsters langer in de oven stonden. Bij hogere temperaturen $\left(600\right.$ en $\left.650^{\circ} \mathrm{C}\right)$ werd geen effect van de tijdsduur gevonden (oplopend van 3 uur tot 24 uur). Voor de leemgrond namen de gloeiverlieswaarden toe met de tijdsduur voor elke temperatuur $\left(350-650{ }^{\circ} \mathrm{C}\right.$ ), wat werd toegeschreven aan verlies van kristalwater uit klei. De conversiefactor van bodem-OS naar bodem-C ( $\mathrm{kg} \mathrm{C}$ per $\mathrm{kg} O S)$ nam sterk af met de temperatuur bij een tijdsduur van 3 uur van $0,70\left(350{ }^{\circ} \mathrm{C}\right)$ tot $0,57\left(500^{\circ} \mathrm{C}\right)$ en stabiliseerde rond 0,55 tussen 550 en $650^{\circ} \mathrm{C}$, hetgeen aangeeft dat bij temperaturen $\geq 550^{\circ} \mathrm{C}$ alle bodem-OS was geoxideerd. De kleicorrectiefactor voor structureel waterverlies (kg kristalwater per kg klei) nam toe van 0,01 tot 0,09 naarmate de temperatuur toenam van 350 tot $650^{\circ} \mathrm{C}$.

De gebruikte analyseprocedures voor carbonaatbepaling (GMF, GM en $A A D$ ) schrijven voor om zoutzuur (GMF, GM) of azijnzuur (AAD) toe te voegen aan de bodemmonsters. Hierdoor worden de carbonaten opgelost. Het gewichtsverlies of een $\mathrm{pH}$-meting wordt gebruikt als proxy om het kalkgehalte te schatten. Het toevoegen van zuur kan er echter voor zorgen dat OS- en kleideeltjes oplossen en uit het monster verdwijnen. Hierdoor kunnen niet-kalkhoudende monsters toch gewicht verliezen. Deze gewichtsverliezen noemen we 'schijnbare carbonaatgehaltes'. Toevoeging van het antioxidant ijzerchloride zou dit kunnen beperken (zoals in de GMF-procedure). Geconcludeerd kon worden dat het gemiddelde schijnbare carbonaatgehalte van de niet-kalkhoudende bodems het grootst was voor de GMF-methode 
gevolgd door de AAD-procedure. Toevoeging van ijzerchloride lijkt dus te leiden tot meer in plaats van minder gewichtsverliezen. De GM-methode vertoonde het kleinst schijnbare gehalte aan carbonaat.

Voor het calciumcarbonaat-kwartszandmengsel, dat geen bodem-OS bevat, begonnen gloeiverliezen op te treden bij $600{ }^{\circ} \mathrm{C}$ en oxidatie van calciumcarbonaat nam toe met de temperatuur volgens een sigmoïdefunctie. Gloeiverlieswaarden stabiliseerden zich bij $750{ }^{\circ} \mathrm{C}$ : op dat moment was $80 \%$ van de $\mathrm{CO}_{2}$ vrijgekomen.

Deze detailexperimenten hebben geleid tot de volgende aanbevelingen voor een protocol. Om de variatie in gloeiverlieswaarden binnen een partij te minimaliseren, wordt aanbevolen om een standaard tijdsduur van 3 uur te gebruiken, de monsters halverwege de analyseduur te draaien en een monstergewicht van ten minste $20 \mathrm{~g}$ te gebruiken. De temperatuur moet worden ingesteld op $550{ }^{\circ} \mathrm{C}$, omdat bij die temperatuur volledige verbranding van bodem-OS optreedt en omdat 99,98\% van de totale calciumcarbonaatfractie bij deze temperatuur in de bodemmonsters aanwezig blijft. Om overschatting van bodem-OS door verlies van kristalwater te voorkomen, wordt geadviseerd altijd te corrigeren door gebruik te maken van de hierboven gepresenteerde factoren. Verder wordt de GM-procedure voor carbonaatanalyse aanbevolen, omdat daarmee het schijnbare carbonaatgehalte van de niet-kalkhoudende grondmonsters het kleinst was.

\section{Hoe, waar \& wanneer? (Hoofdstuk 4)}

Gedurende vier jaar zijn op twee graslandgebonden melkveebedrijven in Nederland de effecten van verschillende methodologische procedures voor monitoring op de gemeten dynamiek van de gehalten van bodemOS onderzocht. Hiermee werden antwoorden verkregen op de volgende vragen: "Hoe" (conversie van bodem-OS gewichtsconcentraties in g per kg) naar bodem-OS hoeveelheden (in kg per ha), "Waar" (bemonsteringsdiepte en schaalniveau), en "Wanneer" (seizoenseffect) voor metingen van bodemOS hoeveelheden en de ontwikkeling daarvan in de tijd. Gebleken is dat alle drie de aspecten van invloed zijn op conclusies over bodem-OS hoeveelheden en de dynamiek daarvan in de tijd. Om gewichtsconcentraties van bodem-OS uit te drukken in hoeveelheden is de bodemdichtheid nodig (kg grond per ha). Er bestaan in de literatuur verschillende formules om bodem-OS hoeveelheden te berekenen op basis van de bodemdichtheid en de bodem-OS gewichtsconcentratie. Deze formules verschillen aanzienlijk. Daarom moet bij voorkeur een locatie-specifieke formule worden gebruikt bij het vergelijken van bodem-OS hoeveelheden op basis van bodem-OS gewichtsconcentraties op verschillende locaties. 
Binnen één bedrijf werden grote verschillen gevonden in de dynamiek van de gehalten van bodem-OS tussen percelen en bemonsteringsdiepten (eveneens werd dit laatste bevestigd in hoofdstuk 5, zie hierna). De conclusie is dat een bemonsteringsdiepte in grasland tot $60 \mathrm{~cm}$ relevant kan zijn voor het kwantificeren van koolstofvastlegging: ook op grotere diepten dan de in Nederland voor metingen gebruikelijke 0-10 cm kunnen nog aanzienlijke hoeveelheden bodem-OS worden vastgelegd (en afgebroken). Dit werd echter niet op alle percelen gevonden: trends in bodem-OS tussen de percelen op hetzelfde bedrijf varieerden sterk. Daarom was een tweede conclusie, dat voor de kwantitatieve onderbouwing van eventuele betalingsregelingen in het kader van het klimaatbeleid voor de vastlegging van bodem-OS, de hele boerderij gemonitord moet worden in plaats van één of enkele percelen.

\section{Waarom? (Hoofdstukken 5 en 6)}

De dynamiek van gehalten van bodem-OS onder productiegraslanden kan worden beïnvloed door graslandmengsels en beweidingssystemen. De effecten van verschillende gesimuleerde beweidingssystemen en graslandmengsels op wortelbiomassa en bodem-OS veranderingen werden onderzocht op een zand- en een leemgrond in een veldexperiment in Nederland. De beweidingssystemen waren: 1) standweiden, 2) omweiden en 3) stripweiden. De graslandmengsels waren: 1) Engels raaigras in monocultuur, zowel bemest (LP+) als onbemest (LP-), 2) rietzwenkgras (FA+, bemest) en 3) een mengsel van deze twee soorten met witte klaver (bemest, $\mathrm{LFT}+$ )). Gedroogde rundermestkorrels werden gebruikt voor alle bemeste behandelingen om de praktijksituatie zo goed mogelijk te simuleren. LP+ en FA+ werden tevens bemest met kunstmest. De hypothese was dat de toename van bodem-OS het hoogst zou zijn onder standweiden en stripweiden, en onder FA+ en LFT+ als gevolg van een grotere ondergrondse biomassaproductie. Bodem-OS werd gemonitord gedurende een periode van twee jaar (leem en zand) en vijf jaar (zand) na conversie van bouwland. Conclusies over de effecten van graslandbeheeropties op de dynamiek van bodem-OS werden sterk beïnvloed door de bemonsteringsdiepte en de lengte van de graslandperiode. Bodem-OS nam toe in bijna alle bemeste behandelingen in de laag $0-60 \mathrm{~cm}$. Wanneer echter alleen de bodemlaag van 30-60 cm werd beschouwd, werden significant hogere bodem-OS toenames gevonden onder FA+, wat consistent is met de grotere wortelbiomassa in vergelijking met de andere plantensoorten. Toenames van bodem-OS waren meestal ook groter onder stripweiden dan onder omweiden. In hoeverre deze vastgelegde OS in de bodem blijft na omzetting van grasland naar bouwland moet verder worden onderzocht.

Verdere verdieping op de "Waarom"-vraag wordt gegeven in de algehele discussie van het proefschrift (Hoofdstuk 6). De belangrijkste bevindingen worden besproken in de context van het Nederlandse klimaatbeleid. Dit 
proefschrift heeft aangetoond dat harmonisatie van methoden in de hele monitoringsketen, van monsterverzameling tot gegevensinterpretatie, cruciaal is voor het specificeren van managementeffecten op veranderingen van bodem-OS in graslanden. Monitoring van bodem-OS in het kader van het klimaatbeleid dient over het gehele bedrijf plaats te vinden op een bemonsteringsdiepte van $60 \mathrm{~cm}$ en daarbij een gestandaardiseerde analytische procedure te gebruiken. De hoogte van mogelijke financiële vergoedingen voor koolstofvastlegging in grasland op basis van de onderzochte beheersmaatregelen was geen onderzoeksvraag voor dit proefschrift. 
About the author Acknowledgements List of publications PE\&RC certificate Financial support 



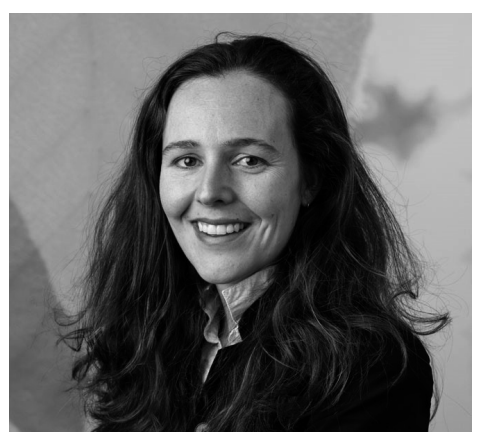

\section{About the author}

Martine Hoogsteen was born on the $5^{\text {th }}$ of March 1986 in Dordrecht, the Netherlands. She grew up in the south of NoordBrabant and after obtaining her secondary education degree at the van Maerlant lyceum in Eindhoven in 2004 she travelled to China and studied Chinese for about a year. In 2005 she enrolled in the BSc/ MSc program Plant sciences at Wageningen

University. During her studies her main interest was within the field of tropical agriculture which made her travel to different parts of the world. She went abroad for several courses, obtained a minor in environmental studies at Kenyatta University (Kenya) and conducted her academic consultancy training in Kumasi (Ghana). After her travels she started to develop an interest in soil chemistry, and particularly laboratory procedures to analyse carbon in soils. Her MSc thesis focused on refining laboratory procedures for measuring soil organic matter and soil carbon. In 2010 she obtained her MSc degree Plant sciences (cum laude) with a specialisation in crop sciences. After graduation she was offered a lecturing position at the Farming Systems Ecology group. Until the summer of 2012 she coordinated the courses "Organic agriculture and society" and "Organic Plant Production". She also set up the field experiment in this period of time (Chapter 5 of this thesis). In July 2012 she started her PhD project on soil organic matter dynamics in temperate production grasslands at the Farming Systems Ecology Group. Since July 2015, Martine has been employed at the National Institute for Public Health and the Environment (RIVM), Bilthoven, the Netherlands. She is involved in developing the strategy of the institute on sustainable and healthy agriculture through her activities within the context of the National Minerals Policy Monitoring Program of the Netherlands and the Plant Protection Product Program of the Netherlands. Martine shares her life with Jimi Lovon and their children Jane, James \& Myles. 



\section{Dankwoord}

Op een van de laatste zaterdagen op het RIVM besef ik me dat het tijd is om mijn dankwoord te schrijven. Ik ren naar beneden om een grote beker thee te vullen. Voor het memoreren van een periode van precies 10 jaar moet ik even goed gaan zitten. In februari 2010 bezocht ik de boerderij van Floor en Lodewijk voor het eerst, samen met Egbert. Na een korte fietstocht vanaf de WUR (Egbert fietste zo hard naar de boerderij dat ik hem nauwelijks bij kon houden) spraken we met Lodewijk over het (voor) onderzoek dat op zijn boerderij plaats zou gaan vinden. Frans Bakker (Unifarm) zou de grondmonsters binnenkort komen steken. Een promotor was op dat moment nog niet in beeld en budget was er ook nog niet. Na een toekenning van financiering kon het veldwerk van dit proefschrift opgestart worden. In de zomer van 2012 startte ik officieel als promovenda.

Pablo en Jeroen, jullie wil ik graag bedanken voor de begeleiding gedurende het eerste deel van het traject.

Martin, Egbert, Ton Breure en Ton van der Linden, jullie ben ik ontzettend dankbaar voor het succesvol afronden van de thesis. Martin en Ton Breure, jullie geduld en opbouwende kritische vragen waren van grote waarde. Bedankt voor jullie adviezen en de 'scientific guidance' zoals dat in mooi Engels heet. Egbert, bedankt voor het delen van waardevolle lessen over het publiceren van wetenschappelijke papers ('je moet je eigen appeltjes meer oppoetsen') en de kritische wetenschappelijke blik. Hier heb ik veel van geleerd en dit pas ik nog regelmatig toe in mijn dagelijks werk.

De laatste jaren werden ook gekenmerkt door verdriet vanwege het verlies van een van mijn beste collega's, Ton van der Linden. Ton was betrokken bij dit proefschrift vanaf 2016 tot zijn plotseling overlijden in januari 2018. Sindsdien is hij een bron van motivatie geweest: in veel van onze gesprekken moedigde hij me aan het proefschrift af te maken en de gedachten aan deze gesprekken gaven me de energie om daadwerkelijk tot een afronding te komen. Ton, ik ben je ontzettend dankbaar. Dit proefschrift draag ik op aan jou.

Naast verdriet speelde vriendschap ook een centrale rol bij de totstandkoming van dit proefschrift. Frans, de vele gesprekken in het veld zijn erg belangrijk voor me geweest en hebben mijn kijk op het leven wezenlijk veranderd. Bedankt voor het delen van je levenservaring, en ook de meer praktische adviezen (variërend van hypotheken tot restaurants en kippen slachten). Ik hoop dat we elkaar nog vaak blijven spreken.

Ook wil ik graag Floor, Lodewijk en Jan-Dirk bedanken. Voor de mogelijkheid tot het doen van onderzoek op jullie bedrijven, maar ook voor de inspirerende 
gesprekken. Hier denk ik met veel plezier aan terug. Floor, bedankt dat je mijn paranimf wil zijn in deze drukke periode. Erg bijzonder!

Evert-Jan of senior (statistician) zoals ik je ben gaan noemen na onze brief aan een wetenschappelijk tijdschrift. Bedankt voor je tijd en voor de mooie gesprekken. Ik waardeer het enorm dat je uitgebreid de tijd hebt genomen om alle statistische analyses uit te leggen. Hier heb ik veel van geleerd. Bedankt voor het geduld en het delen van je kennis.

Hennie, ook jou wil ik graag bedanken. Wat hebben we veel gelachen in het lab. Het uitvoeren van analyses was altijd een feest. De grappen over vakantiefoto's zal ik nooit vergeten.

Mijn RIVM collega's ben ik ook erg dankbaar: Kees, voor het betrekken van Ton Breure bij het onderzoek; Emile, Joyce en Job: voor jullie mentale ondersteuning op momenten dat het even lastig was. Op belangrijke momenten waren jullie een luisterend oor of kon ik mijn blijdschap met jullie delen. Bedankt!

Tot slot wil ik graag mijn familie bedanken. Mijn moeder voor het luisteren naar mijn ups en downs en het geven van advies, en mijn vader voor de wetenschappelijke en praktische aspecten van het doen van promotieonderzoek naast een druk gezinsleven.

Jimi, I am greatly indebted to you for all the support throughout the journey. Without you this wouldn't have been possible. Although you haven't written a single word of this thesis, we could say that the degree should be awarded to both of us. Thank you so much.

Janie, jij hebt dit onderzoek vanaf je geboorte meegemaakt. Jij groeide op tussen het gras, maakte met Frans ritjes op de maaimachine en ging af en toe mee naar de boerderij. Soms gingen we samen naar het lab. Jij las kinderboekjes aan de weegtafel terwijl ik bezig was met de oven. Na moeilijke dagen op het werk was jij degene die me liet denken dat het allemaal wel mee viel.

James en Myles: de gedachten aan jullie toverde een lach op mijn gezicht tijdens het schrijven en zorgde voor focus. Als ik sneller mijn geplande werk af had, kon ik weer lekker naar huis om bij jullie te zijn. Lieve Janie, James en Myles. Bedankt voor jullie positieve energie. Weet dat je al je dromen waar kunt maken, als je hard werkt en er in gelooft. Ik zal er voor jullie zijn. 


\section{List of publications}

\section{Refereed scientific papers}

Hoogsteen, M.J.J., Lantinga, E.A., Bakker, E.J., Groot, J.C.J. \& Tittonell, P.A. 2015. Estimating soil organic carbon through loss on ignition: effects of ignition conditions and structural water loss. European Journal of Soil Science, 60, 320-328.

Hoogsteen, M.J.J., Lantinga, E.A., Bakker, E.J., \& Tittonell, P.A. 2018. An Evaluation of the Loss-on-Ignition Method for Determining the Soil Organic Matter Content of Calcareous Soils. Communications in Soil Science and Plant Analysis, 49 (13), 1541-1552.

Hoogsteen, M.J.J., Bakker, E.J., van Eekeren, N., Tittonell, P.A., Groot, J.C.J., van Ittersum, M.K. \& Lantinga, E.A. 2020. Do grazing systems and species composition affect root biomass and soil organic matter dynamics in temperate grassland swards? Sustainability, 12 (3), 1260.

Hoogsteen, M.J.J., Zwartkruis, J.V. \& Spijker, J. Under review. Quantifying healthy and sustainable diets in an agro-food policy context.

\section{Conference proceedings}

Buis, E. , Fraters, B. Boumans, L.J.M. Hooijboer, A.E.J., Klein, J. Rozemeijer, J. \& Hoogsteen, M.J.J. 2016. Strength and weaknesses of early warning monitoring systems for water quality protection. In: Proceedings of the 19th Nitrogen workshop, Skara, Sweden, 27 - 29 June 2016.

Hoogsteen, M.J.J., Spijker, J., \& Breure, A.M. 2019. Can we derive a proxy for the carbon stabilization potential of soils? International Symposium on Soil and Plant Analysis, Wageningen, the Netherlands, 17-20 June 2019.

Hoogsteen, M.J.J., Baumann, B., van Pul, A., Spijker, J., Hooijboer, A.E.J. \& Hoogeveen, M.W. 2017. The environmental benefits of plant-based diets contested: the nitrate footprint of agricultural commodities compared. Sustainable N conference, 26 - 28 June 2017, Aarhüs, Denmark.

Hoogsteen, M.J.J., Boumans, L.J.M., Daatselaar, C.H.G., Ge, L., Prins, H., van den Berg, W., \& van Geel, W.C.A. 2017. Contrasting outcomes of statistical methods to assess if animal manure and mineral fertilizer have different effects on nitrate leaching, Land Use and Water Quality, effect of agriculture on the environment, Den Haag, the Netherlands, 29 May - 1 June 2017. 
Hoogsteen, M.J.J., Buis, E. \& Fraters, B. 2017. Water quality of springs in Southern Limburg, the Netherlands: does sampling time matter? Land Use and Water Quality, effect of agriculture on the environment, Den Haag, the Netherlands, 29 May - 1 June 2017.

Hoogsteen, M.J.J., Hooijboer, A.E.J. \& Buis, E., Cropping sequence affects nitrate leaching on sandy soils in the Netherlands. In: Proceedings of the 19th Nitrogen workshop, Skara, Sweden, 27 - 29 June 2016.

Hoogsteen M.J.J., Lantinga E.A. \& van Dijk T.J., 2012. Refining the Loss-onIgnition method: The effect of sample weight. In: Proceedings of EUROSOIL 2012, 4th international congress, Bari, Italy, 2 - 6 July 2012.

Hooijboer, A.E.J., Hoogsteen, M.J.J. \& Buis, E. 2017. Effects of crop rotation on water quality in the Netherlands: Combining the Minerals Policy Monitoring Program and Nationwide survey of crop data of the sandy regions of The Netherlands. Land Use and Water Quality, effect of agriculture on the environment, Den Haag, the Netherlands, 29 May - 1 June 2017.

Lantinga E.A. \& Hoogsteen, M.J.J. 2012. The influence of precipitation and temperature on soil organic matter dynamics in a Dutch mixed farm system. In: Proceedings of EUROSOIL 2012, 4th international congress, Bari, Italy, 2 - 6 July 2012.

Spijker, J. \& Hoogsteen, M.J.J. 2019. Towards an integrated agroenvironmental policy with Big Data International Symposium on Soil and Plant Analysis, Wageningen, the Netherlands, 17 - 20 June 2019.

Spijker, J., Hoogsteen, M.J.J., \& Buis, E. 2018. Disentangling the causes of variability in carbon leaching: effects of soil type and land use. Sustainable Development Goals conference, "Towards zero hunger, Partnership for impact", 30 - 31 August 2018.

Van Eekeren, N.J.M., Hoogsteen, M.J.J., Deru, J.G.C., de Wit, J. \& Lantinga, E.A. 2015. White clover content and grassland productivity in simulated grazing systems. p. 484-486. In EGF 2015. Wageningen, The Netherlands. 15 - 17 June 2015.

Wipfler, E.L, Boesten, J.J.T.I., Hoogsteen, M.J.J., van der Linden, A., van Os, E.A., \& van der Staaij, M. 2017. Testing of the Greenhouse Emission Model for a Dutch soilless system. Pesticide Behaviour in Soils, Water and Air 2017 University of York, York, United Kingdom. 


\section{Other publications}

Coenen, P.W.H.G., van der Maas, C.W.M., Zijlema, P.J., Arets, E.J.M.M., Baas, K., van den Berghe, A. C. W. M., van Huis, E.P., Geilenkirchen, G., Hoogsteen, M., Spijker, J. te Molder, R., Dröge, J.A., Montfoort, C.J., Peek, C.J., Vonk, J. Oude Voshaar, S., Dellaert, S., 2017. Greenhouse gas emissions in the Netherlands 1990-2015: National Inventory Report 2017. National Institute for Public Health and the Environment.

Coenen, P. W. H. G., van Zanten, M. C., Zijlema, P. J., Arets, E. J. M. M., Baas, K., van den Berghe, A. C. W. M., van Huis, E.P., Geilenkirchen, G., 't Hoen, M., Hoogsteen, M., te Molder, R., Dröge, R., Montfoort, J.A., Peek, C.J., Vonk, J., Dellaert, S. \& Koch, W.W.R. 2018. Greenhouse gas emissions in the Netherlands 1990-2016. RIVM report: 2018-0006. National Institute for Public Health and the Environment (RIVM), Bilthoven, the Netherlands.

FAO. 2019. Measuring and modelling soil carbon stocks and stock changes in livestock production systems - Guidelines for assessment, Rome, Italy. 152 pp.

Van der Linden, A.M.A., Hoogsteen, M.J.J., Boesten J.J.T.I., Van Os E.A. \& Wipfler, E.L. 2017. Fate of plant protection products in soilless cultivations after drip irrigation: measured vs. modelled concentrations : Interpretation of the 2014 experiment with the Substance Emission Model. RIVM report 2016-0063. National Institute for Public Health and the Environment (RIVM), Bilthoven, the Netherlands.

Verschoor, A., Zwartkruis, J., Hoogsteen, M., Scheepmaker, J., de Jong, F., van der Knaap, Y., Leendertse, P., Boeke, S., Vijftigschild, R., Kruijne, R. \& Tamis, W. 2019. Midterm evaluation of the Dutch plant protection policy: subproject environment (In Dutch: Tussenevaluatie van de nota 'Gezonde Groei, Duurzame Oogst' Deelproject milieu). RIVM report 2019-0044. National Institute for Public Health and the Environment (RIVM), Bilthoven, the Netherlands. 



\section{PE\&RC Training and education statement}

With the training and education activities listed below the PhDcandidate has complied with the requirements set by the C.T. de Wit Graduate School for Production Ecology and Resource Conservation (PE\&RC) which comprises of a minimum total of 32 ECTS (= 22 weeks of activities)

Review of literature (4.5 ECTS)

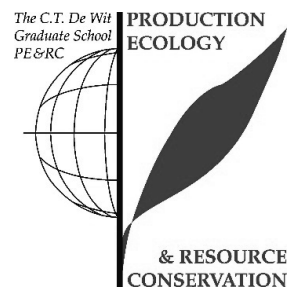

A comparison of procedures for measuring soil organic matter (2013)

Writing of project proposal (4.5 ECTS)

Soil organic matter dynamics in Dutch production grasslands: measurement and management

\section{Post-graduate courses (5.4 ECTS)}

- $\quad$ Sampling in space and time; PE\&RC (2013)

- Linear models; PE\&RC (2013)

- Introduction to R for statistical analyses; PE\&RC (2013)

- Geostatistics; PE\&RC (2013)

- $\quad$ Spatial sampling for mapping; PE\&RC (2015)

Invited review of (unpublished) journal manuscript (2 ECTS)

- $\quad$ AMBIO: crop distribution in Nigeria (2013)

- Agricultural Systems: sustainability of smallholder systems in Rwanda (2013)

Competence strengthening / skills courses (5.55 ECTS)

- Supervising thesis students; Educational Staff Development, WUR (2012)

- Lecturing; Educational Staff Development, WUR (2012)

- General didactics; Educational Staff Development, WUR (2012)

- Imaging science; PE\&RC (2012)

PE\&RC Annual meetings, seminars and the PE\&RC weekend (3.85 ECTS)

- PE\&RC Introduction weekend (2012)

- PhD Workshop carousel (2014)

Discussion groups / local seminars / other scientific meetings (4.5 ECTS)

- WaCaSa (2012-2013)

- $\quad$ Sustainable Intensification of Agricultural Systems (2013-2014)

International symposia, workshops and conferences (5.4 ECTS)

- $\quad$ EUROSOIL; poster and oral presentation, Bari, Italy (2012)

- European Grassland Federation, high output production systems; poster presentation; Wageningen, the Netherlands (2015) 


\section{Financial support}

This research was funded by the Dutch Dairy Board (Productschap Zuivel). The field experiment (Chapter 5) was funded by Barenbrug Holland B.V and the Louis Bolk Institute.

Cover design by Martine Hoogsteen \& Rebekka Roozendaal Layout by Loes van de Kraats - Kema Printed by GVO printers \& designers 

